Florida International University FIU Digital Commons

\title{
Advanced Characterization of Hydraulic Structures for Flow Regime Control: Experimental Developement
}

Amirmasoud Hamedi

PhD. Candidate, ahame006@fiu.edu

DOI: $10.25148 /$ etd.FIDC001966

Follow this and additional works at: https://digitalcommons.fiu.edu/etd

Part of the Hydraulic Engineering Commons

\section{Recommended Citation}

Hamedi, Amirmasoud, "Advanced Characterization of Hydraulic Structures for Flow Regime Control: Experimental Developement" (2017). FIU Electronic Theses and Dissertations. 3369.

https://digitalcommons.fiu.edu/etd/3369 


\title{
FLORIDA INTERNATIONAL UNIVERSITY
}

Miami, Florida

\section{ADVANCED CHARACTERIZATION OF HYDRAULIC STRUCTURES FOR FLOW REGIME CONTROL: EXPERIMENTAL DEVELOPMENT}

\author{
A dissertation submitted in partial fulfillment of the \\ requirements for the degree of \\ DOCTOR OF PHILOSOPHY \\ in
}

CIVIL ENGINEERING

by

Amirmasoud Hamedi

2017 


\section{To: Interim Dean Ranu Jung}

College of Engineering and Computing

This dissertation, written by Amirmasoud Hamedi, and entitled Advanced Characterization of Hydraulic Structures for Flow Regime Control: Experimental Development, having been approved in respect to style and intellectual content, has been referred to you for judgment.

We have read this dissertation and recommend that it be approved.

Assefa Melesse

Florence George

Seung Jae Lee

Ioannis Zisis

Hector R. Fuentes, Major Professor

Date of Defense: May 26, 2017

The dissertation of Amirmasoud Hamedi is approved.

Interim Dean Ranu Jung

College of Engineering and Computing

Andres G. Gil

Vice President for Research and Economic Development and Dean of the University Graduate School

Florida International University, 2017 
(C) Copyright 2017 by Amirmasoud Hamedi

All rights reserved. 


\section{DEDICATION}

This dissertation is dedicated to all the members of my family. Without their patience,

understanding, support, and most importantly of all love, completing this work would not have been possible. Thank you a million times over! 


\section{ACKNOWLEDGMENTS}

I would like to acknowledge my major advisor, Dr. Hector R. Fuentes, for his mentorship and support during my Ph.D. program. He always encouraged me to seek new knowledge in hydraulic engineering while striving to solve problems using advanced and creative techniques. I also appreciate that he gave me the opportunity to work in the fluid mechanics laboratory, providing the resources needed to complete this research. Moreover, I would like to thank Dr. Seung Jae Lee, Dr. Ioannis Zisis, Dr. Assefa Melesse, and Dr. Florence George, my dissertation committee members, for their valuable advice and their timely involvement during my research development and completion. Special thanks to Dr. Ben R. Hodges for providing me with the opportunity to work at the Center for Research in Water Resources at the UT-Austin, as well as to his Ph.D. student Muhammad for his support before, during, and after my work there. I would also like to extend my thanks to the Water Research Institute, Hydraulic Laboratory in Tehran, Iran, for providing pictures of a physical model of a stepped spillway, which were used in some parts of this study. Special thanks to the FIU University Graduate School for the Doctoral Evidence Acquisition and the Dissertation Year Fellowships, which I was awarded to conduct experiments, completing my research and dissertation. In addition, I extend my gratitude to the FIU Department of Civil and Environmental Engineering for their financial support through Graduate Assistantships during my doctoral degree program. 


\title{
ABSTRACT OF THE DISSERTATION \\ ADVANCED CHARACTERIZATION OF HYDRAULIC STRUCTURES FOR FLOW \\ REGIME CONTROL: EXPERIMENTAL DEVELOPMENT
}

\author{
by \\ Amirmasoud Hamedi \\ Florida International University, 2017 \\ Miami, Florida \\ Professor Hector R. Fuentes, Major Professor
}

A good understanding of flow in a number of hydraulic structures, such as energy dissipators, among others, is needed to effectively control upstream and downstream flow conditions, for instance, high water depth and velocity to ensure, scouring, flow stability and control scouring, which is thus crucial to ensuring safe acceptable operation. Although some previous research exists on minimizing scouring and flow fluctuations after hydraulic structures, none of this research can fully resolve all issues of concern. In this research, three types of structures were studied, as follows: a) a vertical gate; b) a vertical gate with an expansion; and c) a vertical gate with a contraction. A Stability Concept was introduced and defined to characterize the conditions downstream of gated structures. When established criteria for stability are met, erosion is prevented. This research then investigated and evaluated two methods to classify the flow downstream of a gated structure to easily determine stability. The two classification methods are: the Flow Stability Factor and the Flow Stability Number. The Flow Stability Factor, which is developed based on the Fuzzy Concept, is defined in the range of 0 to 1 ; the maximum value is one and indicates that the flow is completely stable; and the minimum value is zero 
and indicates that the flow is completely unstable. The Flow Stability Number is defined as the ratio of total energy at two channel sections with a maximum value of one, and it allows flow conditions to be classified for various hydraulic structures; the number is dimensionless and quantitatively defines the flow stability downstream of a hydraulic structure under critical and subcritical flow conditions herein studied, also allowing for an estimate of the downstream stable condition for operation of a hydraulic structure. This research also implemented an Artificial Neural Network to determine the optimal gate opening that ensures a downstream stable condition. A post-processing method (regression-based) was also introduced to reduce the differences in the amount of the gate openings between experimental results and artificial intelligence estimates. The results indicate that the differences were reduced approximately $2 \%$ when the post-processing method was implemented on the Artificial Neural Network estimates. This method provides reasonable results when few data values are available and the Artificial Neural Network cannot be well trained. 


\section{TABLE OF CONTENTS}

CHAPTER

PAGE

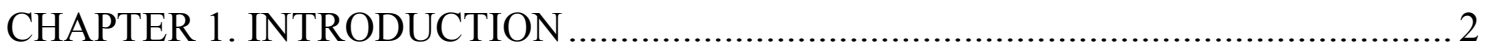

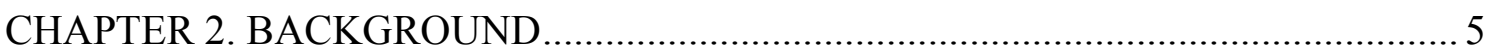

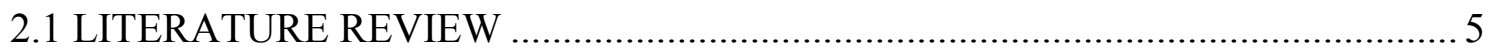

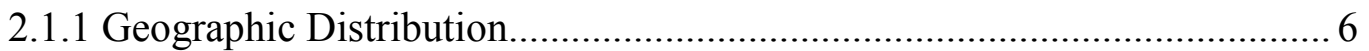

2.1.2 Timeline Distribution....................................................................... 9

2.1.3 Popular Subjects.................................................................................. 11

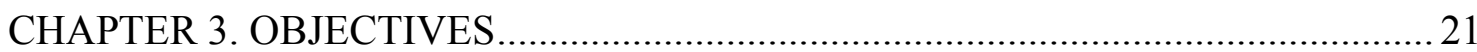

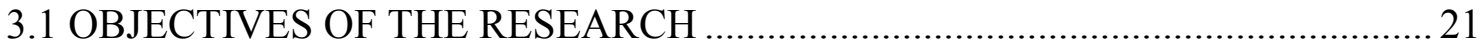

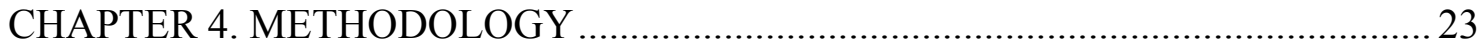

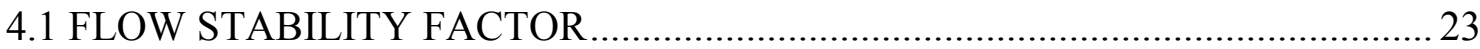

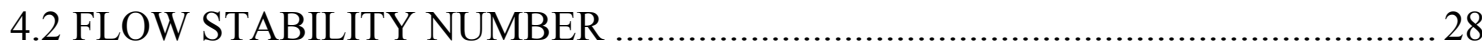

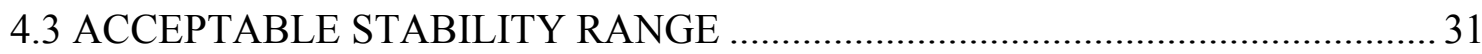

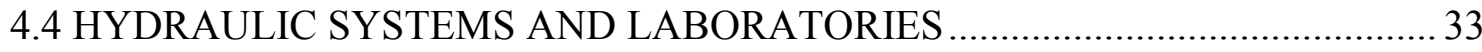

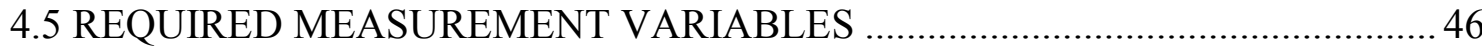

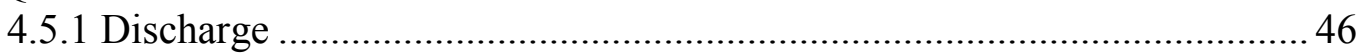

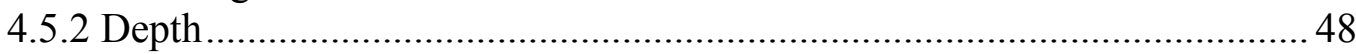

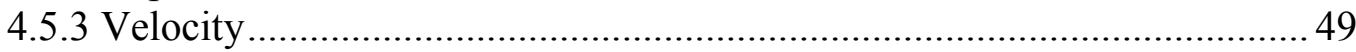

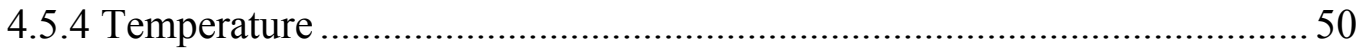

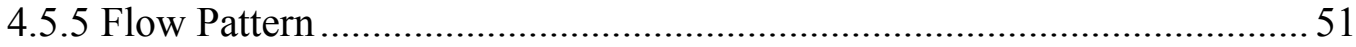

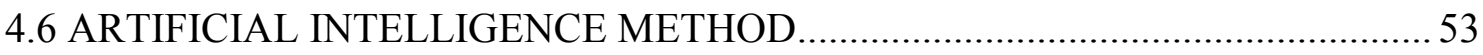

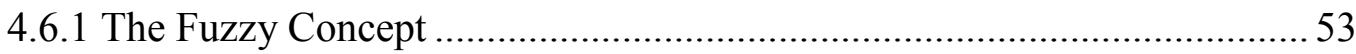

4.6.2 Artificial Neural Network (ANN) ..........................................................5 54

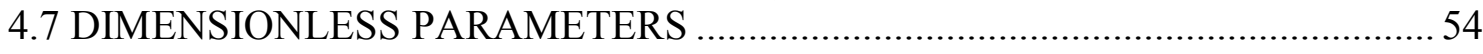

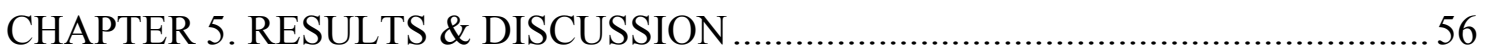

SECTION 1. OPTIMIZING GATE OPENINGS FOR FLOW REGIME CONTROL: EXPERIMENTAL AND ARTIFICIAL NEURAL NETWORK

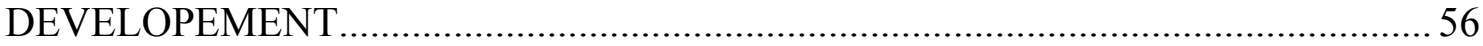

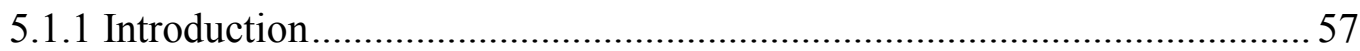

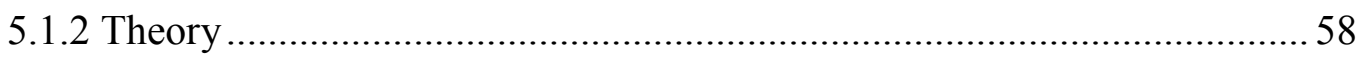

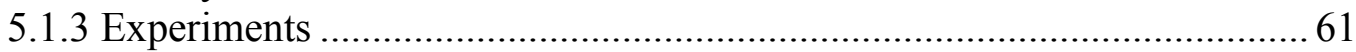

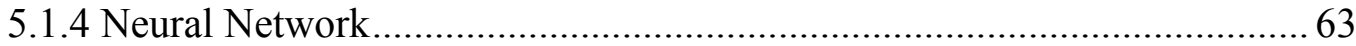

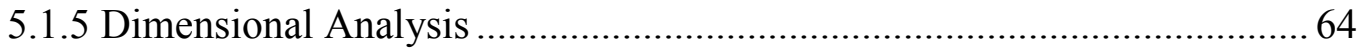




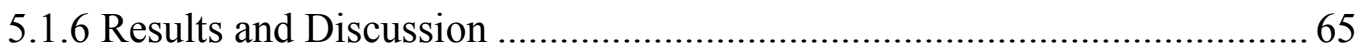

SECTION 2. FLOW STABILITY NUMBER IN VERTICAL SLUICE GATES..........75

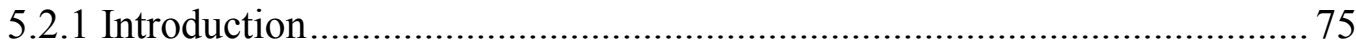

5.2.2 Experiments (Set One) ............................................................................. 75

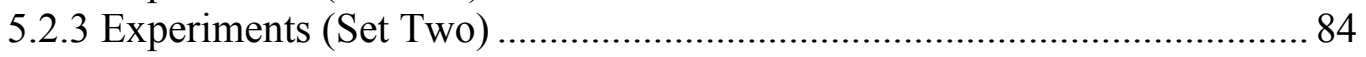

SECTION 3. THE FLOW STABILITY NUMBER IN A GATE WITH

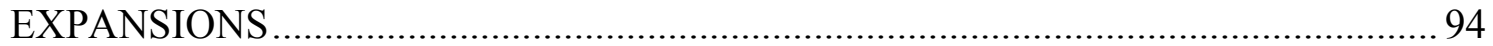

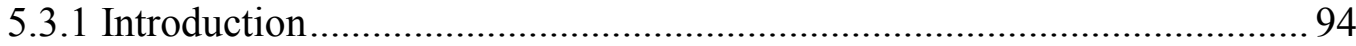

5.3.2 Experiments (Set One) …………………………………………........ 94

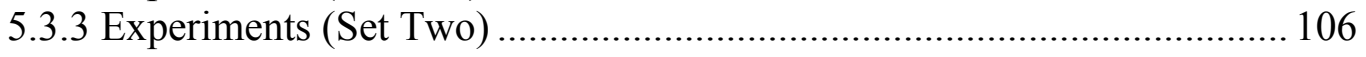

SECTION 4. THE FLOW STABILITY NUMBER IN A GATE WITH

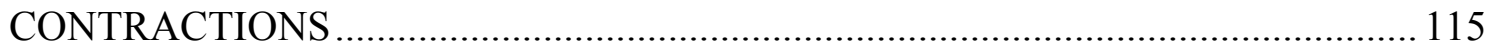

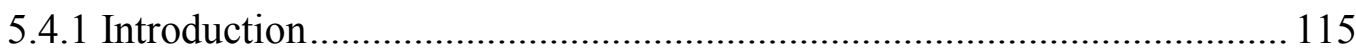

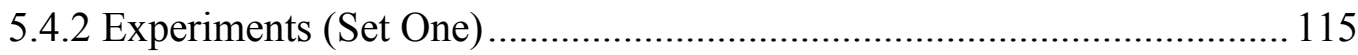

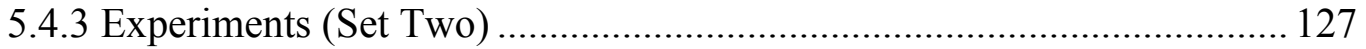

SECTION 5. COMPARISON OF THE RESULTS OF A GATE, A GATE WITH

EXPANSION, AND A GATE WITH CONTRACTION ………………………....... 136

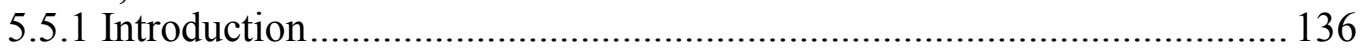

5.5.2 Comparison of Stabilities....................................................................... 137

5.5.3 Comparison of a Gate, a Gate with Expansion, and a Gate with

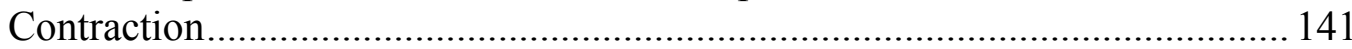

5.5.4 Choose an Appropriate Hydraulic Structure ........................................... 149

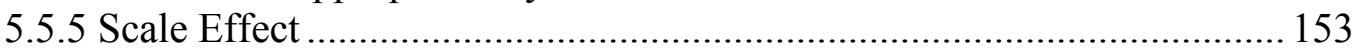

SECTION 6. AN IMAGE PROCESSING TECHNIQUE TO DETERMINE THE EFFICIENCY OF ENERGY DISSIPATION IN HYDRAULIC STRUCTURES157

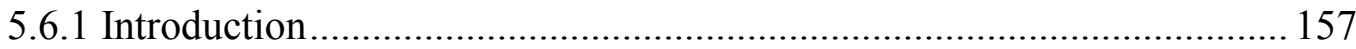

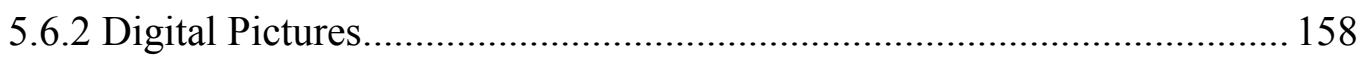

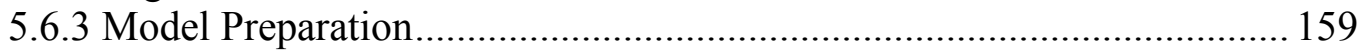

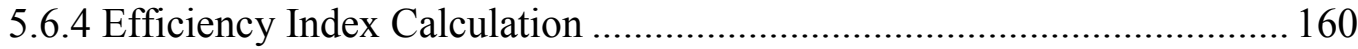

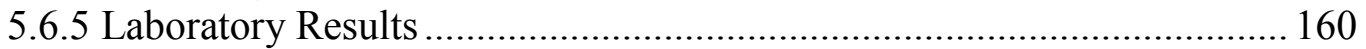

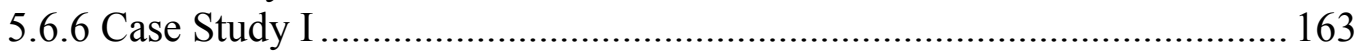

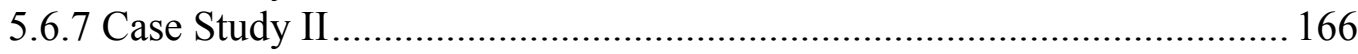

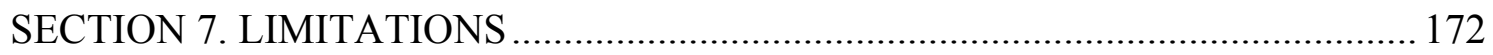

CHAPTER 6. CONCLUSIONS AND RECOMMENDATION ……………….......... 174

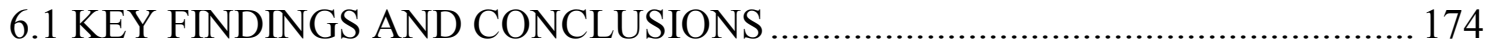

6.2 RECOMMENDATIONS FOR FUTURE WORK ............................................... 179

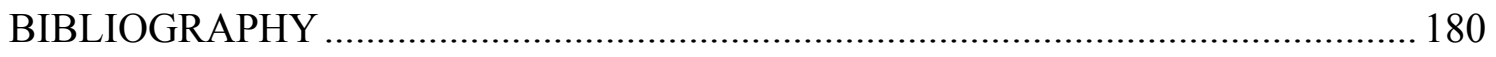

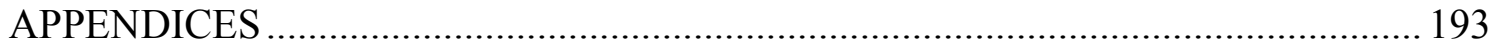

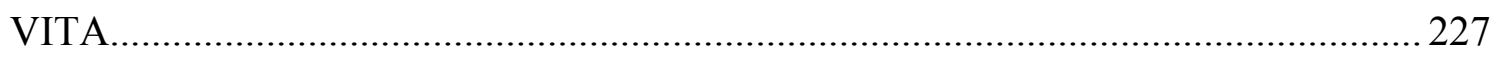




\section{LIST OF TABLES}

TABLE

PAGE

2.1 Number of Publications and Researchers ......................................................... 7

2.2 Contributing Countries, Number of Publications and Researchers in Asia............... 7

2.3 Number of Publications and Researchers in North America .................................... 9

2.4 Contributing Countries, Number of Publications and Researchers in Europe............ 9

2.5 Countries' Contribution from Each Decade .................................................. 10

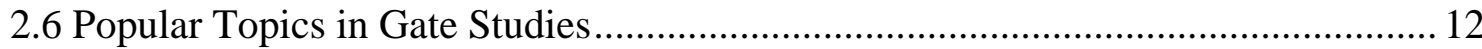

2.7 Summary of Selected Gate Studies .............................................................. 17

4.1 Flow Stability Factor.................................................................................. 24

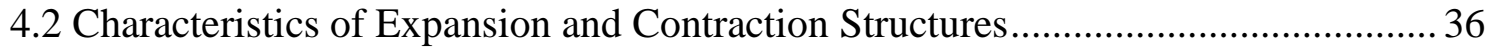

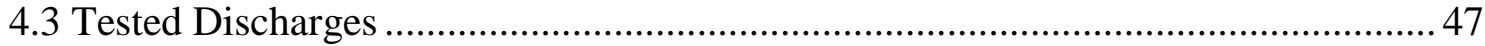

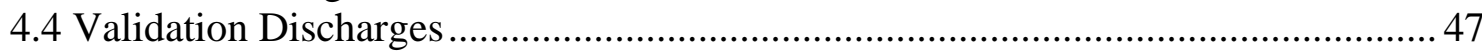

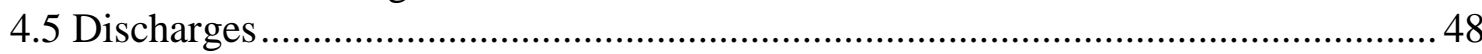

4.6 Structures and Measurement Sections ........................................................... 49

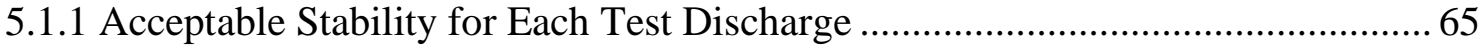

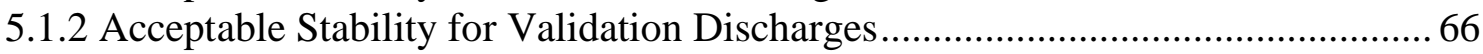

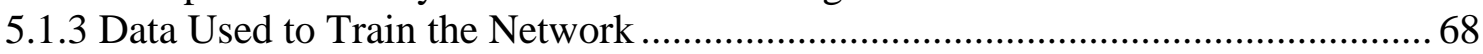

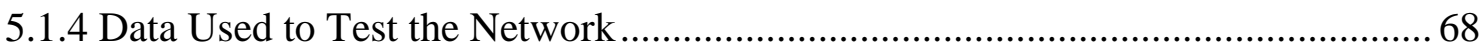

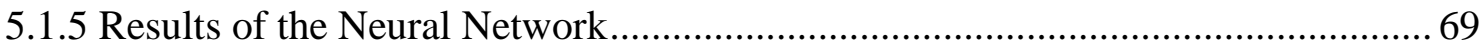

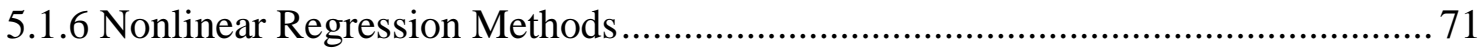

5.1.7 Results of Post-Processing on the Neural Network ........................................ 72

5.1.8 Nash-Sutcliffe Coefficient Results Using Post-Processing Neural Network ........ 73

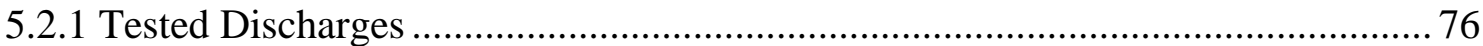

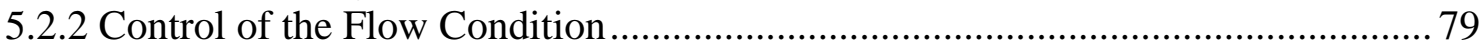

5.2.3 Control of the Permissible Velocity............................................................... 79

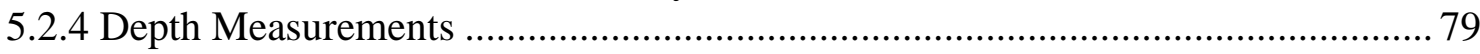

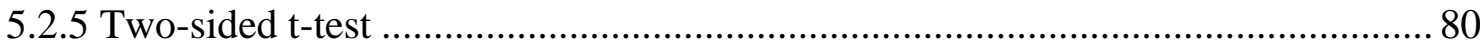

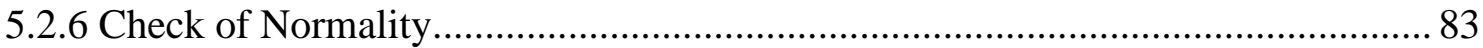

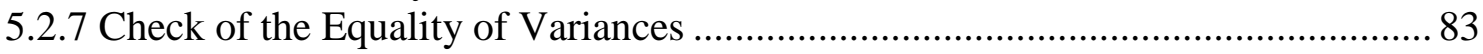

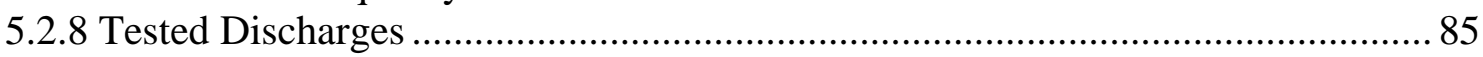

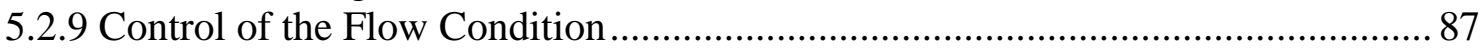

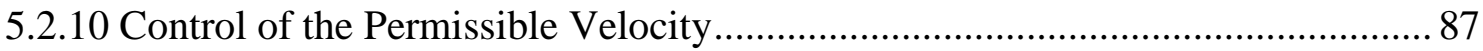

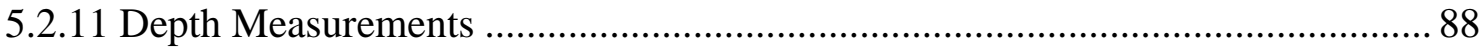

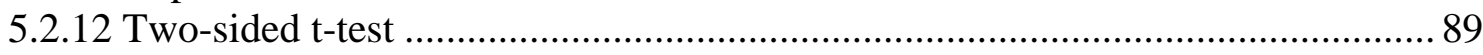

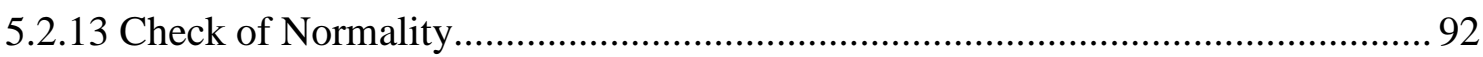

5.2.14 Check of the Equality of Variances ....................................................... 92

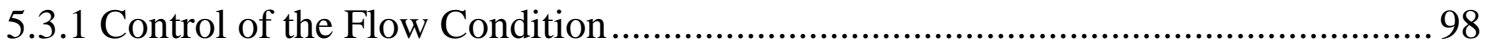




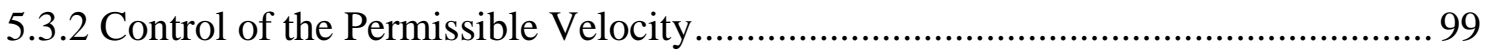

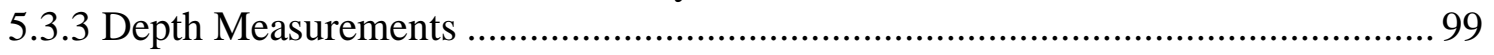

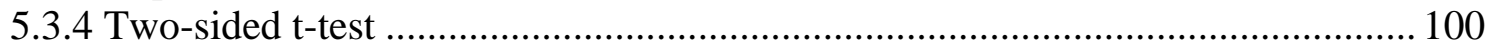

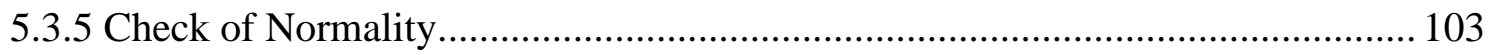

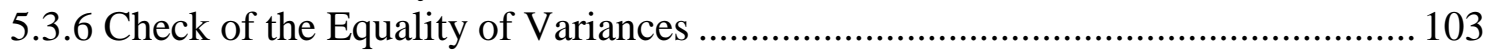

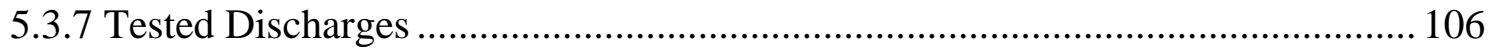

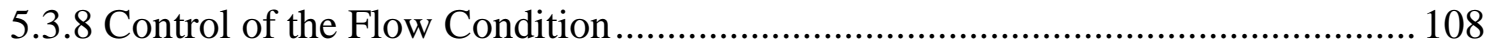

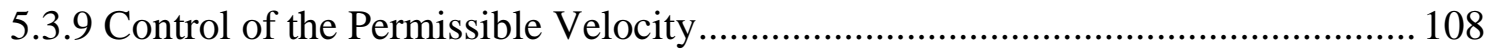

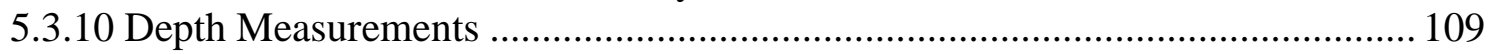

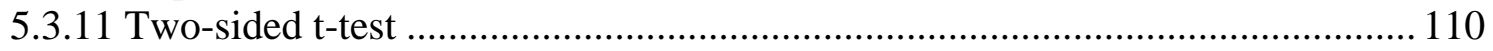

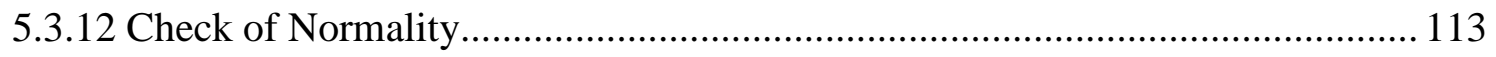

5.3.13 Check of the Equality of Variances ................................................................. 113

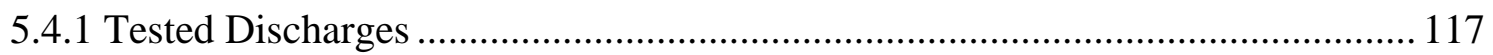

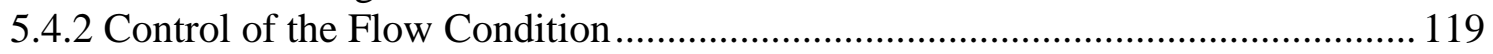

5.4.3 Control of the Permissible Velocity .................................................................. 120

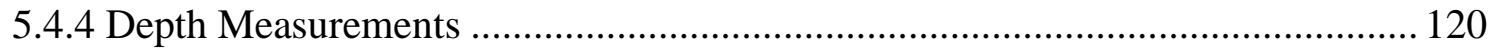

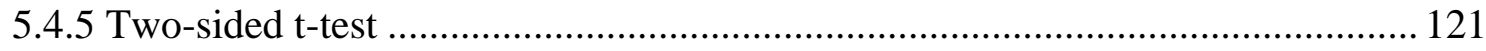

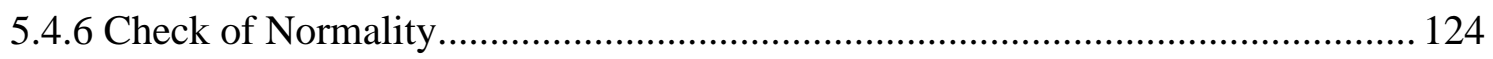

5.4.7 Check of the Equality of Variances ................................................................. 124

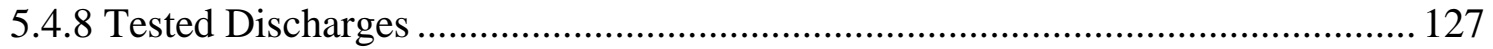

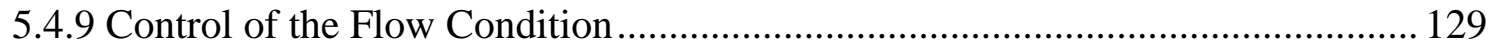

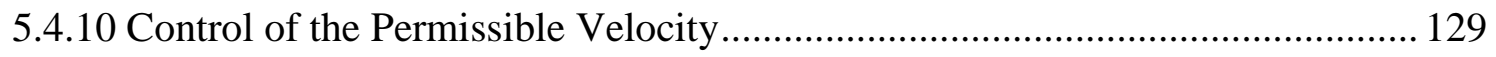

5.4.11 Depth Measurements ................................................................................. 130

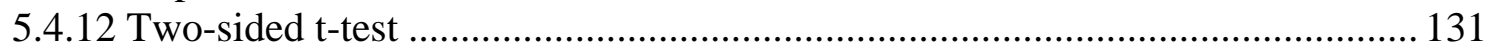

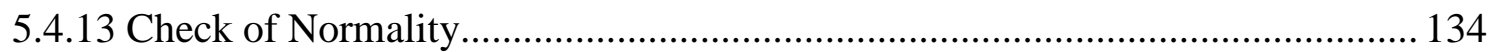

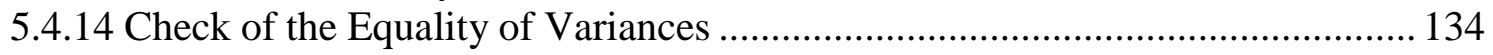

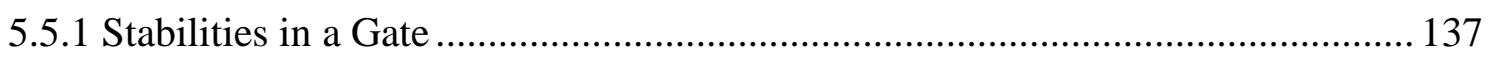

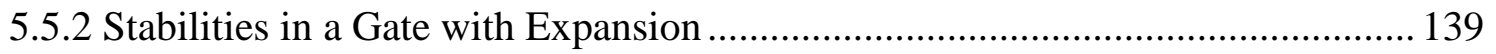

5.5.3 Stabilities in a Gate with Contraction ............................................................ 140

5.5.4 Results for All Three Hydraulic Structures .......................................................... 144

5.5.5 Results for All Three Hydraulic Structures (The Second Laboratory) ................. 148

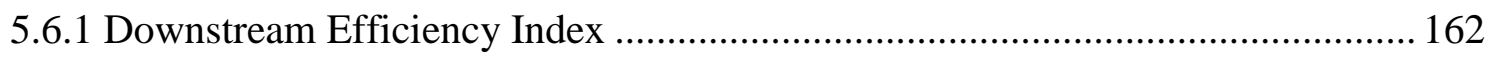

A.1 Permissible Velocities in Unlined, Earthen Channels ............................................. 194

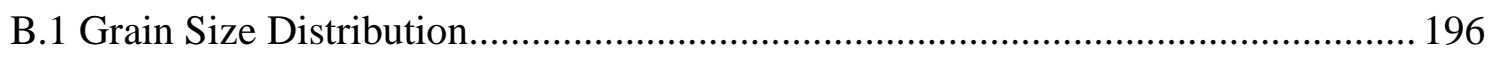

C.1 Experimental Measurements (Main Data) ........................................................... 199

C.2 Experimental Measurements (Validation Data) .................................................... 201

D.1 Measurements in the First Laboratory .................................................................. 203 
D.2 Measurements in the Second Laboratory ............................................................2. 205

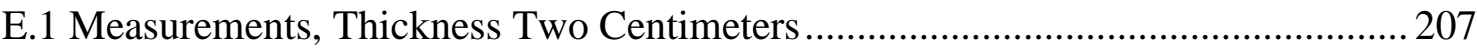

E.2 Measurements, Thickness 1.2 Centimeters .......................................................... 209

E.3 Measurements, Thickness 0.7 Centimeters …………....................................... 211

E.4 Measurements in the Second Laboratory ..........................................................213

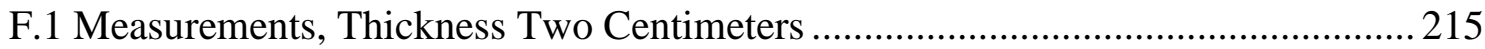

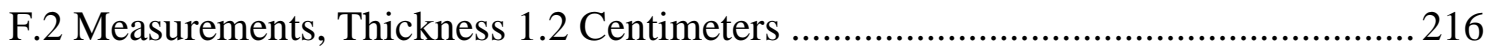

F.3 Measurements, Thickness 0.7 Centimeters …………….....................................217

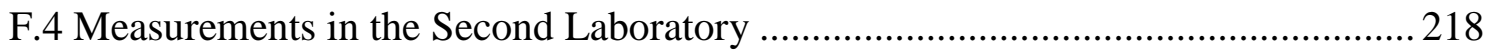

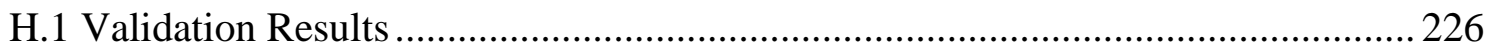




\section{LIST OF FIGURES}

4.1. (a) Hydraulic jump at the end of the flume and far from the gate $(\mathrm{St}=0)$.............25

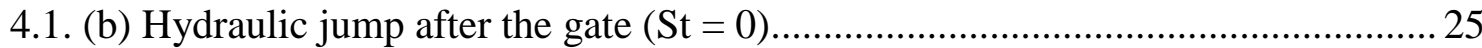

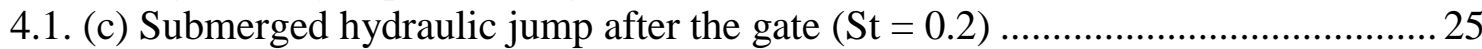

4.1. (d) Weak submerged hydraulic jump after the gate $(\mathrm{St}=0.4) \ldots \ldots \ldots \ldots \ldots \ldots \ldots \ldots \ldots \ldots \ldots . . .26$

4.1. (e) Very weak submerged hydraulic jump after the gate $(\mathrm{St}=0.5) \ldots \ldots \ldots \ldots \ldots \ldots \ldots \ldots . . .26$

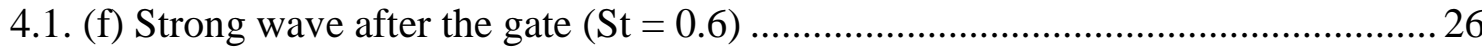

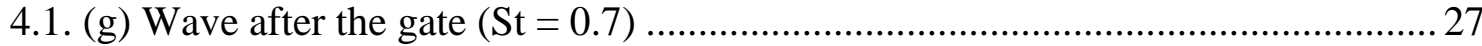

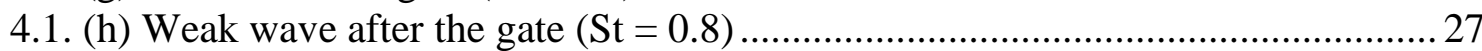

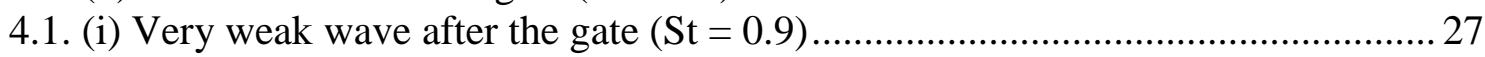

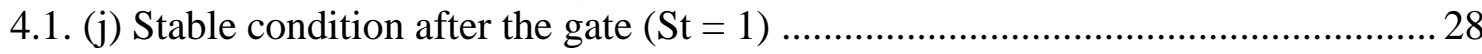

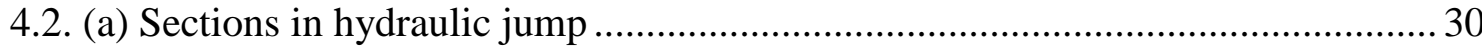

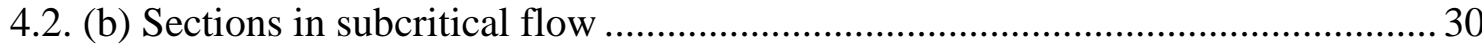

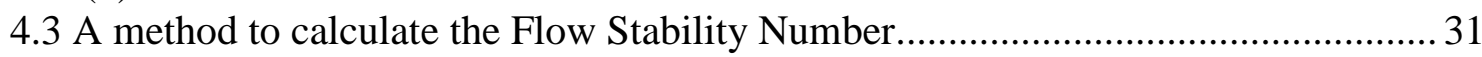

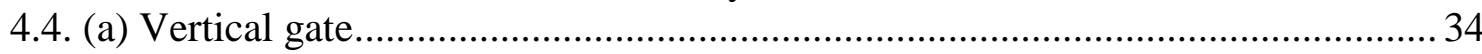

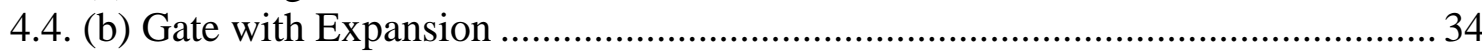

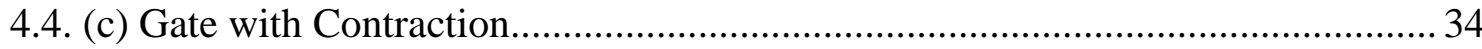

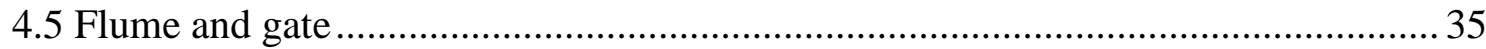

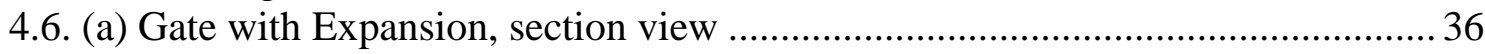

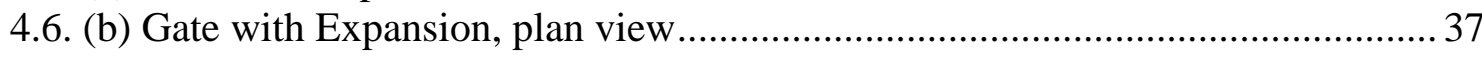

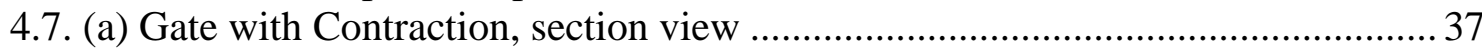

4.7. (b) Gate with Contraction, plan view.................................................................... 38

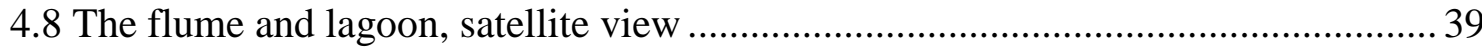

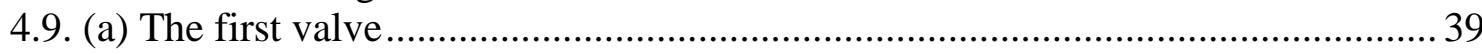

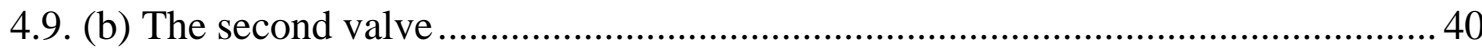

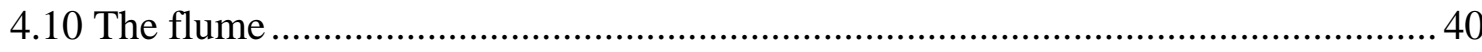

4.11 The mixture which covers the flume bed............................................................ 41

4.12. (a) An overview of the gate ............................................................................ 42

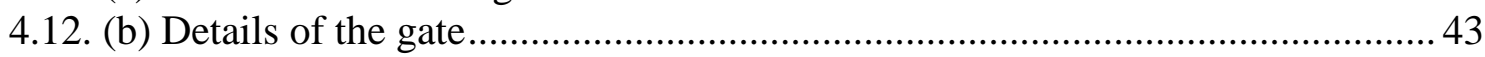

4.13. (a) Gate with Expansion, section view …………................................................ 44

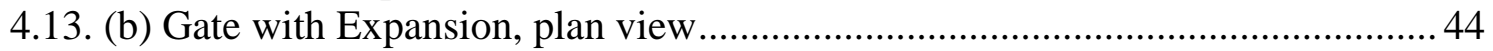

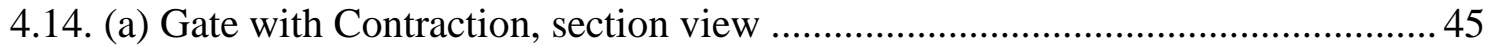

4.14. (b) Gate with Contraction, plan view................................................................. 45

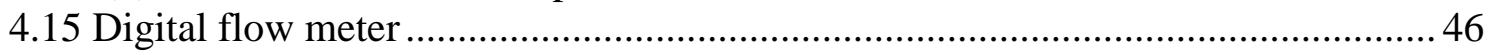

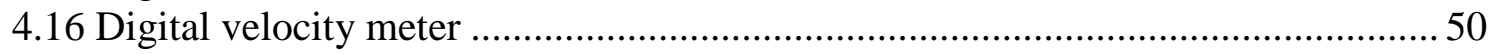

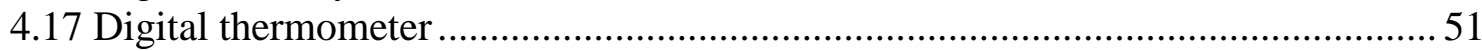

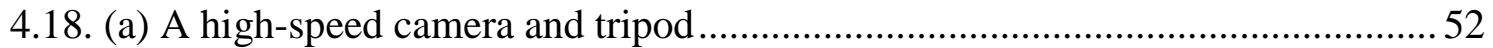

4.18. (b) 1000 lumen LED portable work light ......................................................... 53

5.1.1 Free flow under the vertical sluice gate ……….............................................5

5.1.2 Submerged flow under the vertical sluice gate .................................................... 59 


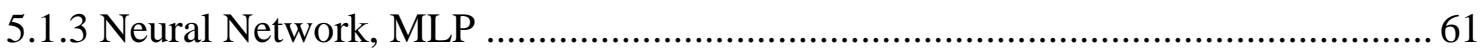

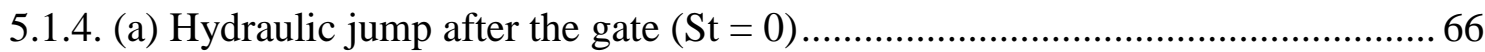

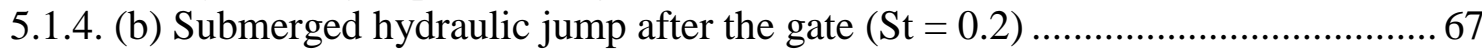

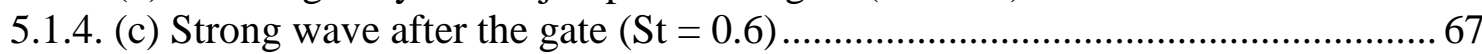

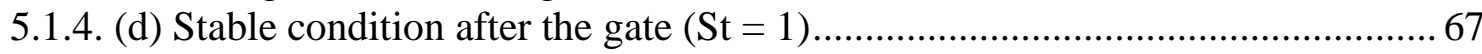

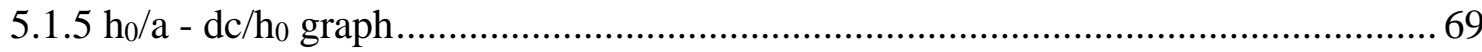

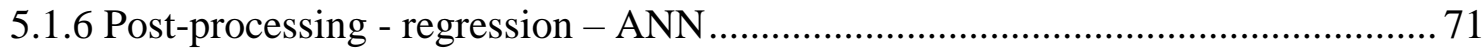

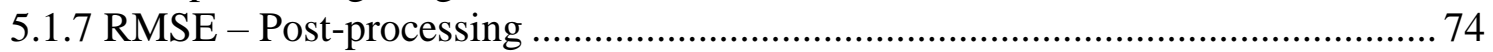

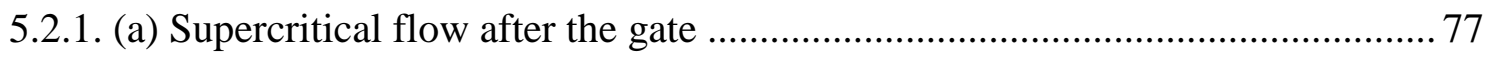

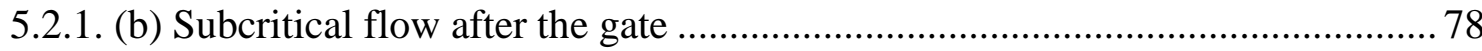

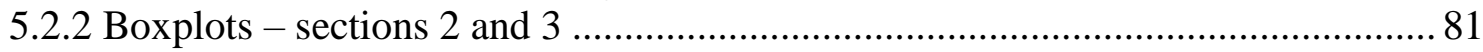

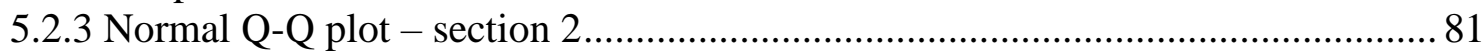

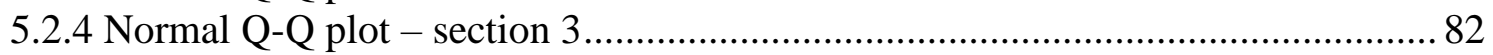

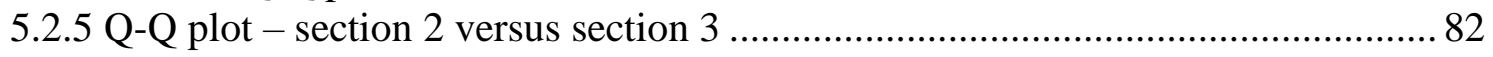

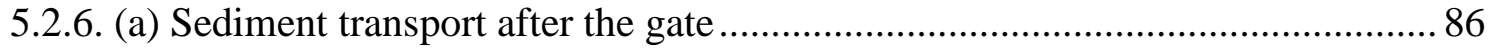

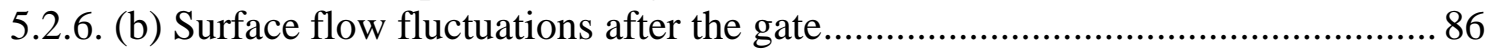

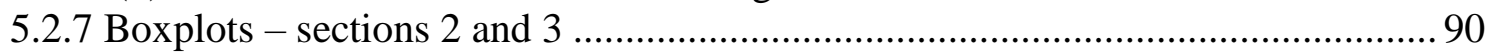

5.2.8 Normal Q-Q plot - section 2................................................................... 90

5.2.9 Normal Q-Q plot - section 3 ...................................................................... 91

5.2.10 Q-Q plot - section 2 versus section 3 ......................................................... 91

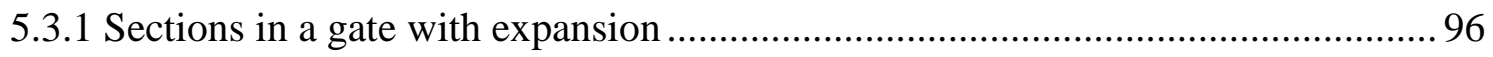

5.3.2. (a) Flow fluctuations after a gate with expansion................................................. 97

5.3.2. (b) Stable flow after a gate with expansion ....................................................... 97

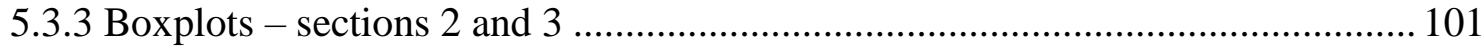

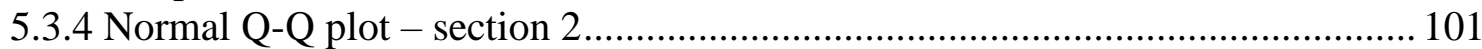

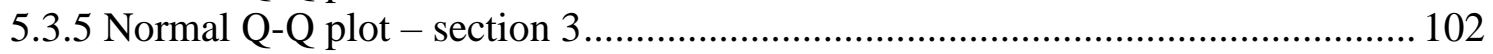

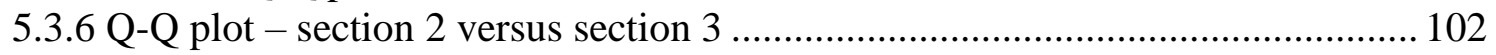

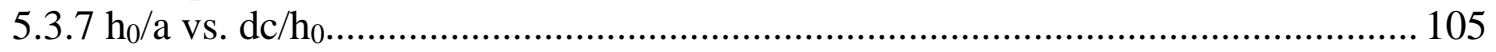

5.3.8. (a) Sediment transport in the presence of a gate with expansion......................... 107

5.3.8. (b) Flow pattern in the presence of a gate with expansion................................... 107

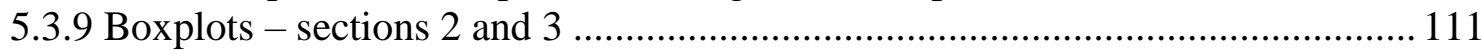

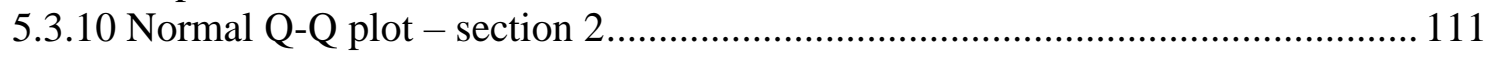

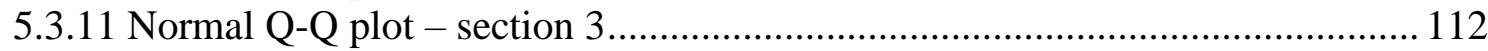

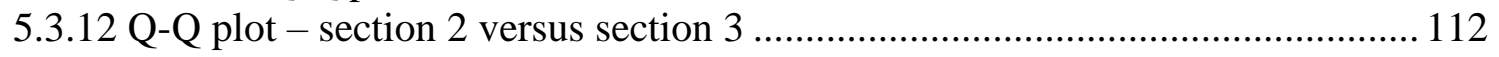

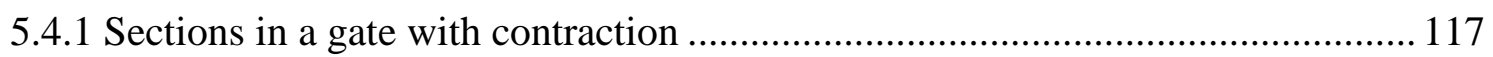

5.4.2. (a) Flow fluctuations in the presence of a gate with contractions........................ 118

5.4.2. (b) Stable flow in the presence of a gate with contractions ................................ 118

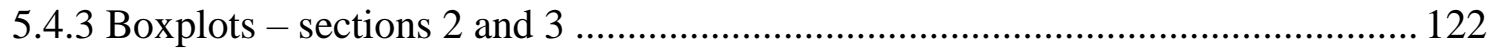

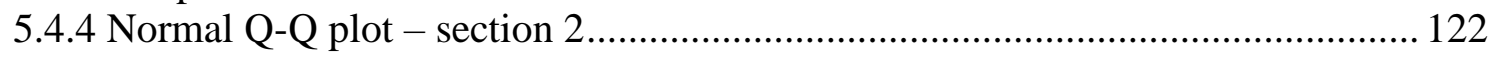

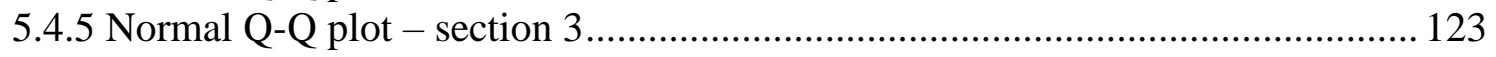

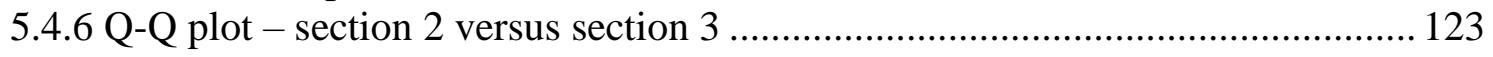

$5.4 .7 \mathrm{~h} / \mathrm{a}$ vs. de/ho 
5.4.8. (a) Sediment transport in the presence of a gate with contractions .................... 128

5.4.8. (b) Flow pattern in the presence of a gate with contractions ............................. 128

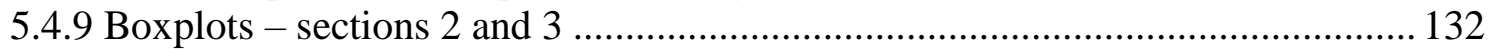

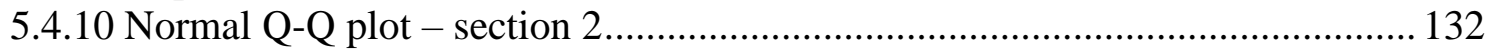

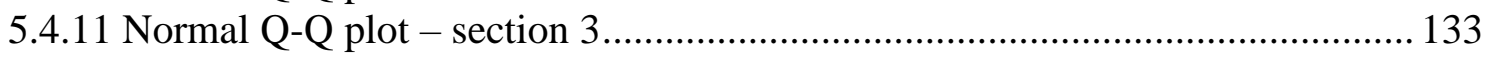

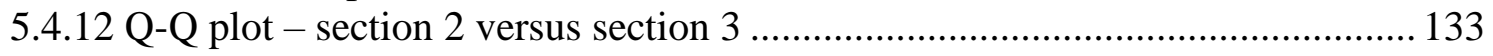

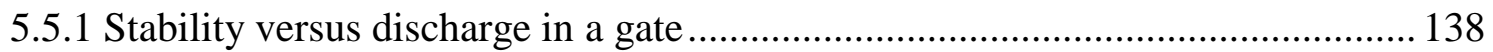

5.5.2 Stability versus discharge in a gate with expansion.......................................... 139

5.5.3 Stability versus discharge in a gate with contraction........................................... 140

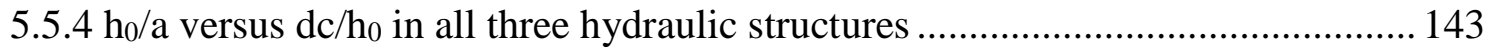

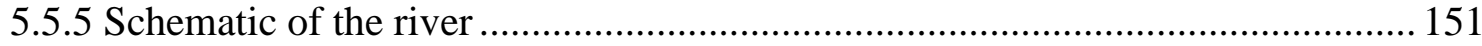

5.5.6 Benefits to each agency in different situations ................................................. 152

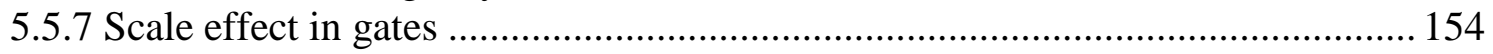

5.5.8 Scale effect in a gate with expansion............................................................ 155

5.5.9 Scale effect in a gate with contraction ............................................................. 155

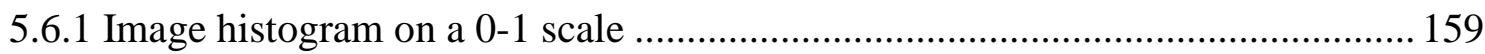

5.6.2. (a) Stepped spillway physical model, the Water Research Institute ..................... 161

5.6.2. (b) Top view, stepped spillway, the Water Research Institute ............................. 161

5.6.3. (a) Top view, Spillway Park - Lake Worth, FL, [Google Earth] ......................... 163

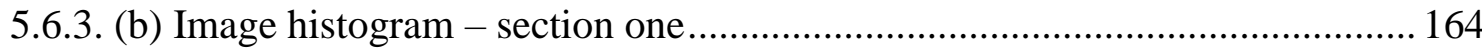

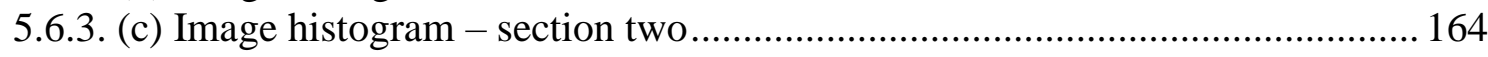

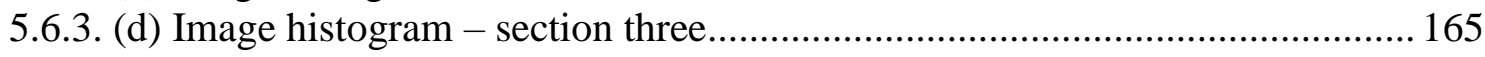

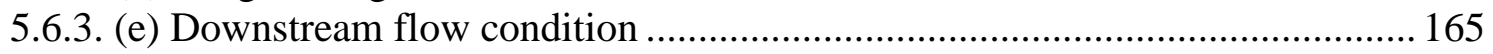

5.6.4. (a) Top view, Oroville Dam - CA, [Google Earth] ........................................... 167

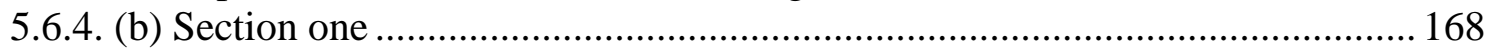

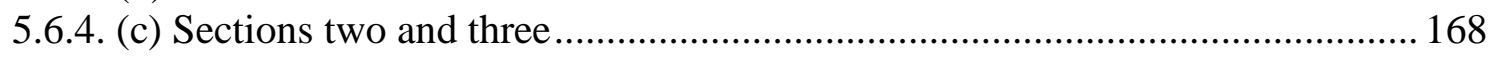

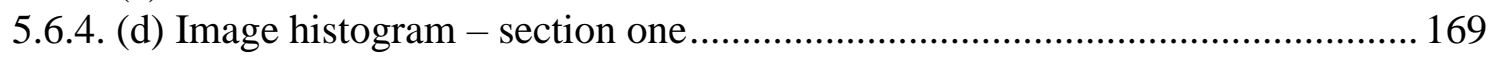

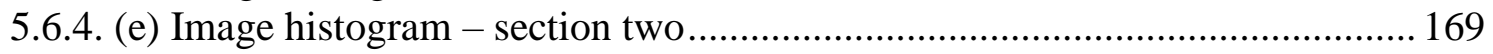

5.6.4. (f) Image histogram - section three …………............................................... 170

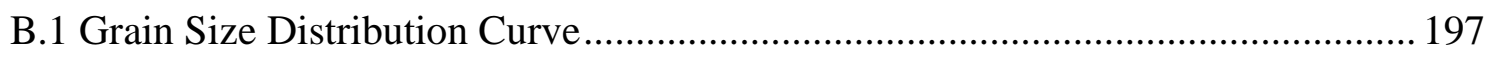

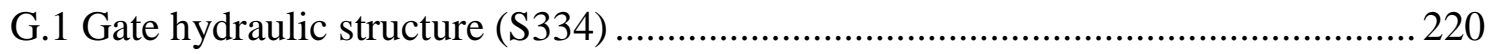

G.2 Downstream of the hydraulic structure (S334) .................................................220

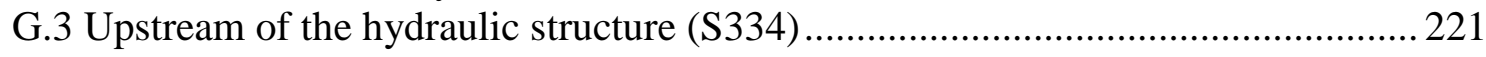

G.4 Flow condition immediately after a gate (S334).................................................. 221

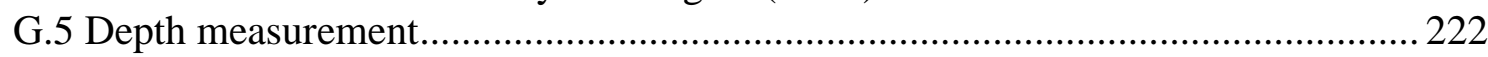

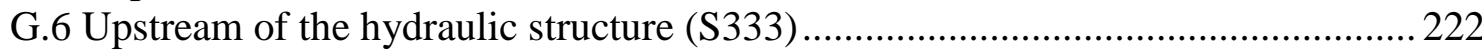

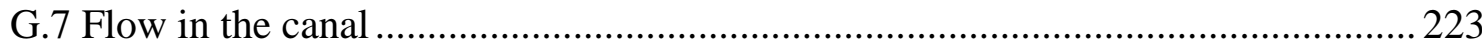

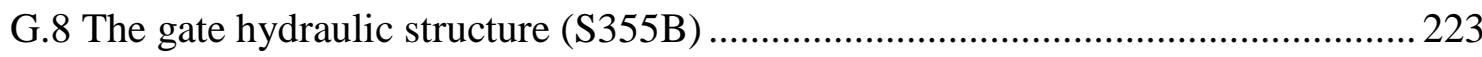

G.9 Details of the gate hydraulic structure (S355B) ...................................................224

G.10 Upstream of the gate hydraulic structure (S355B) .............................................224 


\section{SYMBOLS}

\begin{tabular}{|c|c|}
\hline $\bar{X}_{o b s}$ & Average of observation data \\
\hline$h_{0}$ & Upstream depth \\
\hline$h_{1}$ & Depth before the hydraulic jump \\
\hline$h_{2}$ & Depth after the hydraulic jump \\
\hline$R^{2}$ & Coefficient of determination \\
\hline$X_{\text {mod }}$ & Data obtained from the model \\
\hline$X_{o b s}$ & Observation data \\
\hline$C_{d}$ & Discharge coefficient \\
\hline$(a, b, c)_{1,2,3}$ & Power in dimensional analysis \\
\hline $\mathrm{a}$ & Gate opening \\
\hline $\mathrm{b}$ & Length of the gate (in width) \\
\hline $\mathrm{dc}$ & Critical depth \\
\hline $\mathrm{g}$ & Gravitational acceleration \\
\hline q & Unit discharge \\
\hline Q & Flow discharge \\
\hline $\mathrm{w}$ & Gate opening \\
\hline
\end{tabular}


$y_{1} \quad$ Upstream flow depth

$y_{3} \quad$ Downstream water depth

$y_{3 t} \quad$ Transitional value of tail water depth

$\alpha, \beta, \eta \quad$ Parameters in the DRF formula

$\rho$

Density of water 


\section{ABBREVIATIONS AND ACRONYMS}

\begin{tabular}{|c|c|}
\hline ANN & Artificial Neural Network \\
\hline DRF & Discharge Reduction Factor \\
\hline $\mathrm{E}$ & Nash-Sutcliffe Coefficient \\
\hline GPM & Gallons per minute \\
\hline $\mathrm{L}$ & Length in dimension analysis \\
\hline M & Mass in dimension analysis \\
\hline MLP & Multi-Layer Perceptron \\
\hline $\mathrm{n}$ & Number of observed data points used to calculate RMSE \\
\hline NLPCA & Nonlinear principal component analysis \\
\hline PCA & Principal component analysis \\
\hline $\mathrm{r}$ & Basic (main) parameters in the dimension analysis \\
\hline RMSE & Root mean square error \\
\hline St & Flow Stability Factor \\
\hline $\mathrm{T}$ & Time in dimension analysis \\
\hline$k$ & All parameters in dimension analysis \\
\hline$\pi$ & Buckingham Method \\
\hline
\end{tabular}




\section{DISCLAIMER}

The author, Professor Hector R. Fuentes, Florida International University, the Civil and Environmental Engineering Graduate Program, and all other technical sources referred to in this report:

1. Do not make any warranty or representation, expressed or implied, with respect to the accuracy and completeness of the information contained in this report.

2. Do not warrant that the use of any information, method, or process described in this report may not infringe on privately owned rights; and

3. Do not assume any liability with respect to the use of or for damages resulting from the use of any information, method, or process described in this report.

This dissertation does not reflect the official views or policies of any sponsoring or participating organizations and individuals. 


\section{CHAPTER 1}

\section{INTRODUCTION}

Streams, rivers, and canals are able to transfer flow from one point to another. Along their pathways, they can be used for different purposes, such as water supply, recreation, fisheries, and agricultural irrigation, etc. Hydraulic structures are usually built along streams, rivers, and canals to manage and control the flow, including, for instance, maintaining the upstream level to ensure that irrigation needs are met.

Despite the advantages of hydraulic structures, they also have disadvantages that may be reduced by a better understanding of flow conditions and their control. A vertical gate is one type of hydraulic structure. When the gate opening is small, downstream the flow has a high velocity and flow fluctuation, which causes erosion downstream of the gate.

If the main causes of erosion (and the resulting sediment transport) downstream of gates need to be controlled, a flow classification method is helpful in minimizing erosion. Although a few flow classification methods have been developed via past research, none has fully aided in minimizing erosion after gates. Consequently, there is a need to develop a new flow classification method that can aid in identifying desired flow conditions. This is stable flow.

Two flow classification methods have been introduced in this research. The first one classifies flow based on the Flow Stability Factor and the second one classifies flow based on the Flow Stability Number (which is dimensionless). The gated structures 
should be managed in a way that the downstream condition is very close to the stable condition, thus minimizing undesirable flow conditions.

This research focuses on three gated structures including a gate, a gate with expansion, and a gate with contraction. These structures were investigated in two laboratories, and at different scales, to address a possible scale effect on the methodologies herein developed. These structures were investigated over a range of discharges and thicknesses (for both gates with expansion and contraction). Consequently, they can be compared under flow to select the best structure type to ensure a stable flow.

Six chapters of this dissertation present and analyze numerous research questions. The first chapter is an introduction and describes the needs, problems, and probable solutions; it also outlines the overall structure of the dissertation. The second chapter documents the literature review and defines gaps in the existing knowledge. Objectives are defined in the third chapter. The methods that are used in the research, laboratories, variables, instruments, and the accuracy of results are detailed in chapter four.

The fifth chapter includes results and a discussion, covering seven sections. The Flow Stability Factor is defined in the first section and its application in vertical gates is also demonstrated in that section. The second, third, and fourth sections show the applications of the Flow Stability Number in a gate, a gate with expansion, and a gate with contraction, respectively. The accuracy of the Flow Stability Factor was compared with the Flow Stability Number in section five; the three studied structures were also compared in this section. A method that uses Game Theory and the Nash Equilibrium was implemented to select the best structure for specific flow conditions. A scale effect and the probable causes of a scale effect in this research were also discussed in the last 
part of section five. Section six introduces the Efficiency Index as an innovative index which is practical, low-cost, and quick to apply. This index can be determined using an image processing technique and is able to estimate the overall efficiency of hydraulic structures. Two case studies were presented in this section to show the application of this method. Section seven, which is the last section of chapter five, documented the limitations of the methods used in these investigations.

Chapter six, the last chapter, includes both conclusions and recommendations for future research. In addition, supporting data and information regarding permissible velocity, bed materials, and flow stability, as well as pictures of real scale structures, are provided in the Appendices. 


\section{CHAPTER 2}

\section{BACKGROUND}

\subsection{LITERATURE REVIEW}

Sluice gates are primarily used to control the upstream depth to provide required water for irrigation and to manage passing discharge below gates in channels [1 - 14]. A wide range of sluice gate characteristics has been considered by researchers in different parts of the world during past decades. The geographic distribution, as well as the timeline of these studies, are reported in the first and second parts of the literature review in this chapter (2.1.1 and 2.1.2). The geographical distribution includes a statistical analysis to show the contributing percentage of sluice gates studies from each country. The timeline distribution reports relevant research work on the sluice gate from the $19^{\text {th }}$ century to the present day differentiated by continent and country. Gate studies can be categorized as either old or new studies. Old studies are those published before 1900 and from 1900 to 1949 . New studies are divided into three time periods: 1950 to 1979 , 1980 to 1999 , and finally 2000 to 2017 . The results indicate that most studies belong to the two most recent time periods (new studies). There are some old studies which were published prior to 1900 [15 - 18]. The oldest study was published in 1848 by Boileau [15]. Also, some other studies were published in the first half of the $20^{\text {th }}$ century [19 - 29]. New studies started with Henry [30] in 1950 and were followed by other research from 1959 [31 - 36] and 1960 to 1969 [37 - 44]. The final part of this chapter illustrates the most popular subjects in sluice gate studies and briefly explains other researchers' work. It should be noted that all data has been collected from research 
scholars, including conference and journal papers, books, journal discussions, and closures to journal discussions and handbooks.

In the initial stage, more than 150 pieces of research were collected and briefly considered to prepare the sluice gate research database; this was then narrowed down to 71 works for further consideration based on their relevance to this topic of study.

\subsubsection{Geographic Distribution}

Research has been conducted to show the geographical distribution of studies related to sluice gates. Each continent was considered separately and then a statistical analysis was conducted for each country based on the number of publications and the number of researchers.

Based on the database which has been used in this research, in total 21 countries (the UK is counted as a single country) have contributed to sluice gate research studies. These countries are from all the continents. This means that the topic is important

globally and that researchers are paying attention to gate issues. It should be noted that some gate research may have been conducted in other countries. However, these works are not found in research journals. The author did try to include all important and relevant work in the database. The criteria for considering the research in the statistical results are the first author and the institute/school of the first author when he/she published the work. Therefore, the nationality of the first author was not considered in the statistical analysis. 
In total, 125 research works were selected to include in the statistical analysis. These works have been conducted by 94 researchers from around the world. Table 2.1 listed the number of publications and the number of researchers from each continent.

Table 2.1 Number of Publications and Researchers

\begin{tabular}{ccc}
\hline Continent & \# Publications & \# Researchers \\
\hline Asia & 23 & 18 \\
\hline Africa & 14 & 6 \\
\hline Australia/ Oceania & 4 & 4 \\
\hline South America & 1 & 28 \\
\hline North America & 37 & 37 \\
\hline Europe & 46 & \\
\hline
\end{tabular}

In Asia, six countries contributed to sluice gate research. India and Iran with seven publications were considered the most active countries in Asia. Based on the number of researchers, again, these two countries placed first and second in Asia with six and four researchers, respectively. Table 2.2 reported the contribution of countries in Asia.

Table 2.2 Contributing Countries, Number of Publications and Researchers in Asia

\begin{tabular}{cccc}
\hline Number & Continent & \# Publications & \# Researchers \\
\hline 1 & India [8,10, 45-49] & 7 & 6 \\
\hline 2 & Iran [5,12, 50-54] & 7 & 4 \\
\hline 3 & Taiwan [13, 55, 56] & 3 & 3 \\
\hline 4 & South Korea [9, 57, 58] & 3 & 2 \\
\hline 5 & Japan [59, 60] & 2 & 2 \\
\hline 6 & Saudi Arabia [61] & 1 & 1 \\
\hline
\end{tabular}


In Africa, the only country that contributed to sluice gate research was Egypt with 14 published works [38, $62-74]$ and six researchers. Moreover, the same situation happened in South America. In this continent, the only country which contributed to research about sluice gates was Uruguay with just one publication [75] and one researcher. On the other hand, in Australia/ Oceania, three countries contributed to sluice gate research. Australia had two publications $[76,77]$ and two researchers; Tasmania had one publication [78] and one researcher, and finally New Zealand had one publication [79] and one researcher who contributed to research. It should be mentioned that Tasmania is not considered its own country by the United Nations, but for the purposes of this research it is considered to be a separate country.

Among all continents, Europe and North America have the greatest number of publications and researchers working on the sluice gate topic. In North America, two countries, the United States and Canada, contributed to the research with 21 and 16 publications, respectively. Publications by American authors can be categorized into three levels based on the time at which they were published. First, studies before 1950 [24, 28], those completed from 1950 to 1999 [6, 36, 42, 44, 80 - 86], and those done after 2000 [14, 87 - 93]. The same categories can be used for publications from Canada. It should be noted that no research was published by Canadian authors prior to 1950 . However, there are some publications from 1950 to 1999 [39, 40, 94 - 101], and after $2000[2,7,102-105]$. Table 2.3 listed the number of publications and the number of researchers in North America. 
Table 2.3 Number of Publications and Researchers in North America

\begin{tabular}{cccc}
\hline Number & Continent & \# Publications & \# Researchers \\
\hline 1 & USA & 21 & 19 \\
\hline 2 & Canada & 16 & 9 \\
\hline
\end{tabular}

In Europe, eight countries contributed to sluice gate research which was the maximum number of contributions among the continents based on the number of participating countries. In total, 44 published works were reported on sluice gate research. Also, 36 researchers contributed to research from this continent. Table 2.4 illustrates the European countries that contributed to the research with the number of publications and the number of researchers from each country.

Table 2.4 Contributing Countries, Number of Publications and Researchers in Europe

\begin{tabular}{cccc}
\hline Number & Continent & \# Publications & \# Researchers \\
\hline 1 & France [11,15,26,29,106-110] & 9 & 7 \\
\hline 2 & Germany [16,17,19,22,23,34,111] & 7 & 5 \\
\hline 3 & UK [31,33,41,43,112,113] & 6 & 6 \\
\hline 4 & Italy [32, 114-118] & 6 & 4 \\
\hline 5 & Spain [121-124,143] & 5 & 4 \\
\hline 6 & Switzerland [1,25,119,120] & 4 & 4 \\
\hline 7 & Turkey [3,4,125,126] & 4 & 3 \\
\hline 8 & Netherland [127-129] & 3 & 3 \\
\hline
\end{tabular}

\subsubsection{Timeline Distribution}

In the previous section, the geographical distribution of sluice gate studies was considered. This section includes statistical analysis results to show the timeline distribution of sluice gate studies. The distribution of research is presented for each 
country by decade. In total, 144 research works have been included in this statistical analysis. Table 2.5 shows the contribution of each country in different decades.

Table 2.5 Countries' Contribution from Each Decade

\begin{tabular}{|c|c|c|c|c|c|c|c|c|c|c|}
\hline \multirow{2}{*}{ Country } & 2010- & 2000- & 1990- & 1980- & 1970- & 1960- & 1950- & 1940- & 1930- & Before \\
\hline & 2017 & 2009 & 1999 & 1989 & 1979 & 1969 & 1959 & 1949 & 1939 & 1930 \\
\hline USA & 1 & 7 & 2 & 3 & 2 & 3 & 1 & 1 & 1 & - \\
\hline Canada & 2 & 4 & 2 & 4 & 2 & 2 & - & - & - & - \\
\hline Uruguay & 1 & - & - & - & - & - & - & - & - & - \\
\hline Egypt & - & 1 & 11 & 1 & - & 1 & - & - & - & - \\
\hline Australia & - & - & 1 & - & 1 & - & - & - & - & - \\
\hline Tasmania & - & - & - & - & 1 & - & - & - & - & - \\
\hline New & - & - & 1 & - & - & - & - & - & - & - \\
\hline India & - & 1 & 4 & 2 & - & - & - & - & - & - \\
\hline Taiwan & - & 2 & - & - & 1 & - & - & - & - & - \\
\hline South & 2 & 1 & - & - & - & - & - & - & - & - \\
\hline Japan & - & - & 1 & - & 1 & - & - & - & - & - \\
\hline Iran & 4 & 2 & 1 & - & - & - & - & - & - & - \\
\hline Saudi & - & - & 1 & - & - & - & - & - & - & - \\
\hline France & 2 & 4 & - & - & - & - & - & 1 & 1 & 1 \\
\hline Germany & - & - & - & - & 1 & - & 1 & - & 2 & 3 \\
\hline UK & - & - & 1 & - & 1 & 2 & 2 & - & - & - \\
\hline Italy & - & 3 & 1 & - & 1 & - & 1 & - & - & - \\
\hline Switzerland & 1 & - & 2 & - & - & - & - & - & 1 & - \\
\hline Spain & 4 & 1 & - & - & - & - & - & - & - & - \\
\hline Netherland & - & 1 & 2 & - & - & - & - & - & - & - \\
\hline Turkey & 1 & 2 & - & 1 & - & - & - & - & - & - \\
\hline
\end{tabular}

From Table 2.5, it can be inferred that Iran and Spain have the most contributions in the 2010-2017 period with four publications. The United States had the maximum number of contributions in the 2000-2009 period with seven publications, and Egypt had the greatest number of publications (11) during the 1990-1999 period. France and Germany had the most contributions in the initial stage of the studies (1930-1939 and 
before 1930). Disregarding studies before 1930, the United States is the only country in the world that contributed to sluice gate research in all considered decades.

\subsubsection{Popular Subjects}

Among the 142 studies focused on gates, fourteen topics were the most popular subjects for gate research. Some of these topics have sub-topics. The most frequently used gate types are vertical [130] and radial gates, respectively; furthermore, some researchers used H-weir in their research $[61,74]$.

There are two distinguished flow types downstream from the gates. Free flow [131, 132] and submerged flow [133, 134]. Both of these have been considered a lot by research scholars experimentally [135 - 139], numerically [140, 141, 142], and theoretically $[138,141]$. In free flow, the tailwater depth is less than the gate opening. However, in submerged flow, the tailwater depth is more than the gate opening. Some researchers developed equations to determine the free and submerged flow condition $[5,103]$ based on dimensional analysis $[117,118,144]$. Ferro applied dimensional analysis [145] and self-similarity [146] in gate studies. 
Table 2.6 Popular Topics in Gate Studies

\begin{tabular}{|c|c|c|c|}
\hline Number & Topic & Sub-topic & $\begin{array}{c}\text { Number of } \\
\text { Studies }\end{array}$ \\
\hline \multirow{3}{*}{1} & \multirow{3}{*}{ Gate Type } & Vertical & 66 \\
\hline & & Radial & 19 \\
\hline & & Other Types & 2 \\
\hline & & Free & 56 \\
\hline 2 & Flow Type & Submerged & 62 \\
\hline 3 & Distinguishing Condition & - & 62 \\
\hline \multirow{4}{*}{4} & \multirow{4}{*}{ Flow Classification } & Froude Number & 1 \\
\hline & & Fuzzy Concept & 1 \\
\hline & & Sub-free flow & 1 \\
\hline & & Partially Submerged Flow & 1 \\
\hline 5 & Dimensionless Numbers & - & 69 \\
\hline \multirow[t]{2}{*}{6} & Sediment Transport & - & 17 \\
\hline & \multirow{3}{*}{ Depths and Gate Opening } & Upstream Depth & 73 \\
\hline \multirow[t]{2}{*}{7} & & Downstream Depth & 72 \\
\hline & & Gate Opening & 74 \\
\hline 8 & Depth Profile & - & 10 \\
\hline 9 & Stage-Discharge & - & 5 \\
\hline 10 & Energy Downstream & - & 4 \\
\hline \multirow[t]{2}{*}{11} & Velocity and Velocity & - & 29 \\
\hline & Profile & & \\
\hline 12 & Discharge Coefficient & - & 33 \\
\hline \multirow[t]{2}{*}{13} & Contraction Coefficient & - & 34 \\
\hline & & Experimental & 67 \\
\hline \multirow[t]{2}{*}{14} & Research Type & Numerical & 23 \\
\hline & & Theoretical & 49 \\
\hline
\end{tabular}


Upstream depth, tailwater, and gate opening are the most common variables which have been used in the dimensional analysis of gate studies [2, 5, 10, 14, 55]. Yen et al. [13] studied maximum gate openings in vertical gates in rectangular canals. They noted that supercritical flow occurs exactly after the gate in the downstream section when the gate opening is smaller than the critical depth. Furthermore, the Froude number has been considered by some researchers in dimensional analysis $[9,59,62,115]$.

Some researchers have tried to classify the flow regime downstream of the gate. Hamedi and Fuentes used the Fuzzy Concept to classify the flow [14]. In their research, the number zero was assigned to a hydraulic jump. It means that the flow was completely unstable, and the number one was assigned to a stable condition. Belaud et al. [106] plotted the submergence ratio versus the relative gate opening and defined three flow types downstream of the gate. These three flow types are free flow, partially submerged flow, and submerged flow. The partially submerged flow can be seen between the other two flow types. Defina and Susin [115] related flow and gate opening under the vertical gates to the Froude number. With a Froude number greater than 0.8, the flow behavior is like a hysteresis, due to the contraction effect under the gate. Bhowmik [81], also, classified different types of a hydraulic jump based on the Froude number. Moreover, Vanden-Broeck [80] assumed an incompressible fluid. He mentioned that when the Froude number is large downstream, negligible waves occur, and the flow is mostly smooth upstream. However, when the Froude number is small downstream, large waves occur. 
Sediment transport downstream of the gate is another topic which has been considered by some researchers. A moderate number of publications have paid attention to this topic. Bove et al. [75] used PIV (Particle Image Velocimetry) to consider sediment transport in non-cohesive particle sediment beds after the gate. They observed two holes downstream of the gate and reported that the first hole is made because of the shear stress of the jet flow, whereas the second hole is made because of turbulent fluctuations which happened due to jet flow destabilization. Therefore, the production mechanism of these holes is completely different. Furthermore, Kells et al. [102] considered the effect of grain size downstream of the gate on the dynamics of the local scour process in the submerged flow. They noted that the area and depth of the scours are dependent on grain size. Smaller grain size produces larger scours. They, also, reported that the smaller scour had been seen when a mixed bed was used (compared with a uniform grain). Moreover, in the presence of higher discharges and tailwater, the maximum scour depth is increasing.

Another popular topic among researchers is determining stage-discharge relationships in gates. Shahrokhnia and Javan used dimensional analysis and presented some relationships for determining the stage-discharge relationship in radial gates for both free and submerged flow conditions. They pointed out that the Reynolds number has a negligible effect on average discharge. Therefore, it can be disregarded. They also claimed that their method was better than conventional ones for determining the stagedischarge relationship in radial gates [12]. Bijankhan et al. determined that the methods to obtain the stage-discharge relationships under gates are suitable for free flow, but need to be reconsidered for a low submerged condition [5]. They presented a method 
using the Buckingham Theorem and presented the Discharge Reduction Factor, DRF, which is defined as follows:

$$
D R F=\left(\frac{\left(y_{1}-y_{3}\right) / w}{\alpha\left[\left(y_{3}-y_{3 t} / w\right]^{\beta}+\left(y_{1}-y_{3}\right) / w\right.}\right)^{\eta}
$$

Where, $\mathrm{y}_{1}$ is upstream flow depth, $\mathrm{y}_{3}$ is downstream water depth, $\mathrm{y}_{3 t}$ is the transitional value of the tail water depth and $\alpha, \beta, \eta$ are parameters that should be determined experimentally. Moreover, to determine the discharge under the gates, Altan-Sakarya and Kökpınar presented two experimental relationships to estimate discharge under the gate in free flow situations. The relationships, based on the gate opening and the vertical difference between the weir bottom and the top of the gate, is quite accurate [4].

Little research has focused on the flow energy downstream of gates. Kim et al. [9] installed a sill after the gate in their experimental research and considered the effect of this hydraulic structure on the amount of energy downstream of the gate. They reported that a height equal to $10 \%$ of the tailwater is the most effective sill height to reduce the hydraulic jump and protect the river bed downstream of the sluice gates. Their results indicate that the presence of a sill raises the amount of energy lost about $50 \%$ compared to a gate without a sill when the sill height is approximately $10 \%$ of tailwater.

A number of investigations have been conducted to determine the discharge coefficient. Swamee [10] stated that in the case of free flow, the discharge coefficient of a sluice gate depends on the upstream depth and the amount of the gate opening, 
whereas in a submerged flow, the discharge coefficient depends on the tailwater depth, as well as the factors mentioned for free flow. This researcher proposed a new method to attain the discharge coefficient as a function of the gate opening. He also believed that previous graphical methods that determined the discharge coefficient using the upstream depth to gate opening ratio graphs under free flow conditions were not strong enough to use in numerical and analytical methods. Habibzadeh et al. utilized formulas to determine the discharge coefficient under gates under both free and submerged flow conditions. They accounted for the energy lost between the upstream section and the venna section (immediately after the gate) in the discharge coefficient. They also acknowledged that energy loss is a function of gate geometry, and can thus change the discharge coefficient. Their formula can be used to determine the discharge coefficient in gates with different shapes [103].

The contraction coefficient is one of the important parameters in sluice gate studies. Belaud et al. considered the contraction coefficient under gates in both free and submerged flow conditions. They determined that when the gate opening is small the contraction coefficient is approximately the same for free and submerged flow conditions. However, the gate opening is larger [106].

There are lots of studies on each topic. Therefore, a summary of important studies is listed in Table 2.7. This table illustrates the authors, the year, and the contribution of each selected publication to different popular topics of sluice gate studies. 
Table 2.7 Summary of Selected Gate Studies

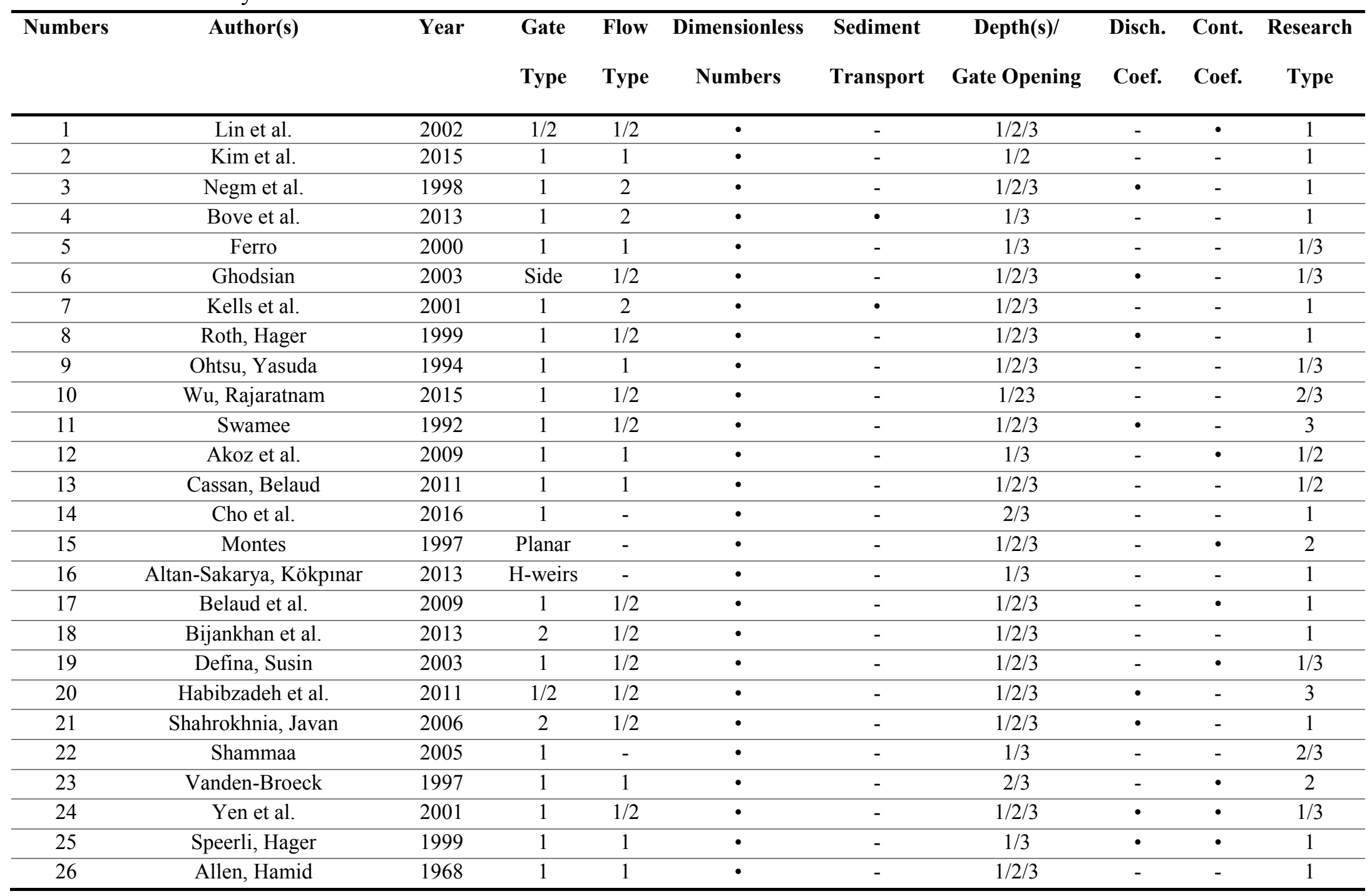


Table 2.7 Summary of Selected Gate Studies (Continued)

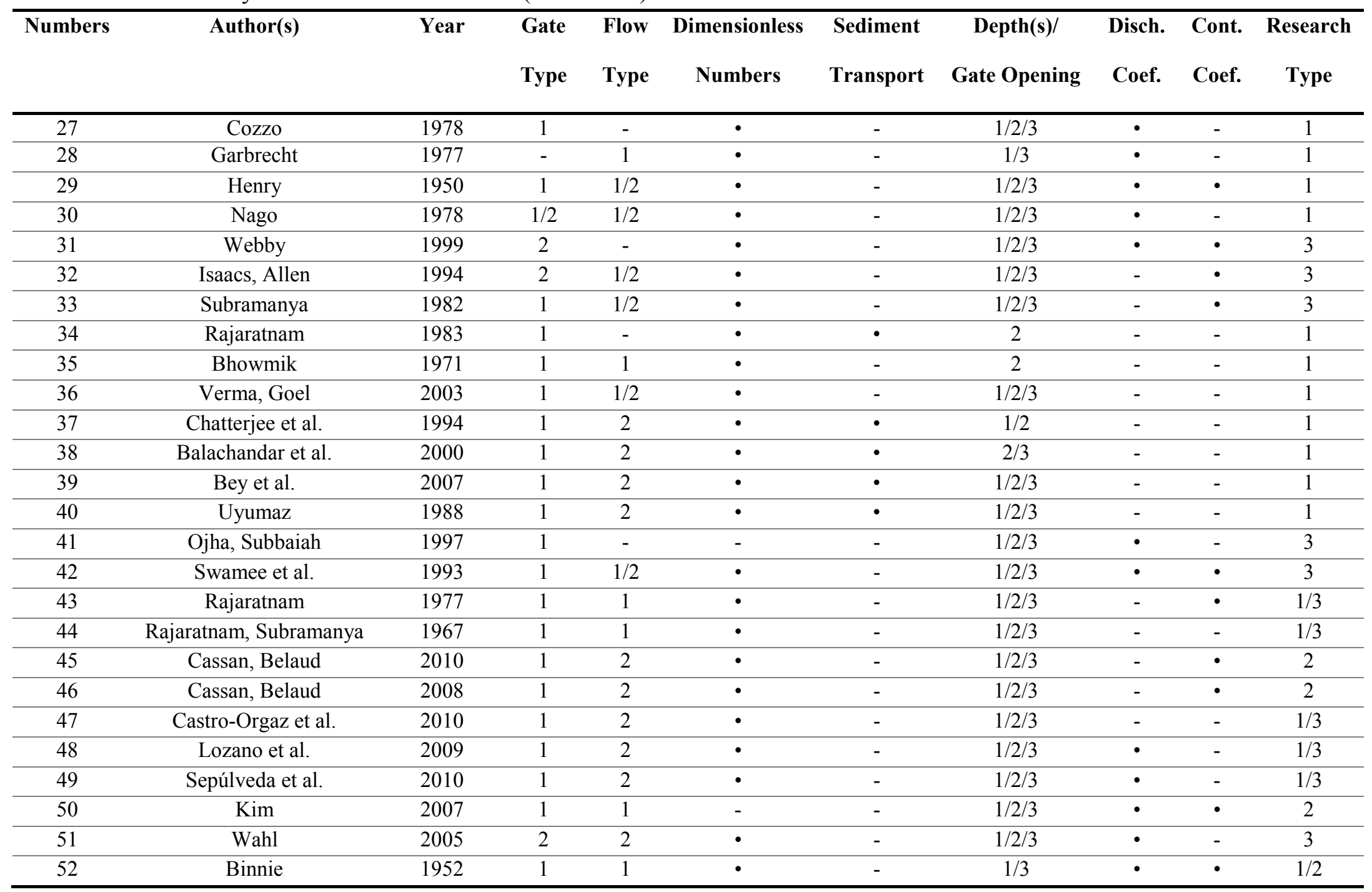


Table 2.7 Summary of Selected Gate Studies (Continued)

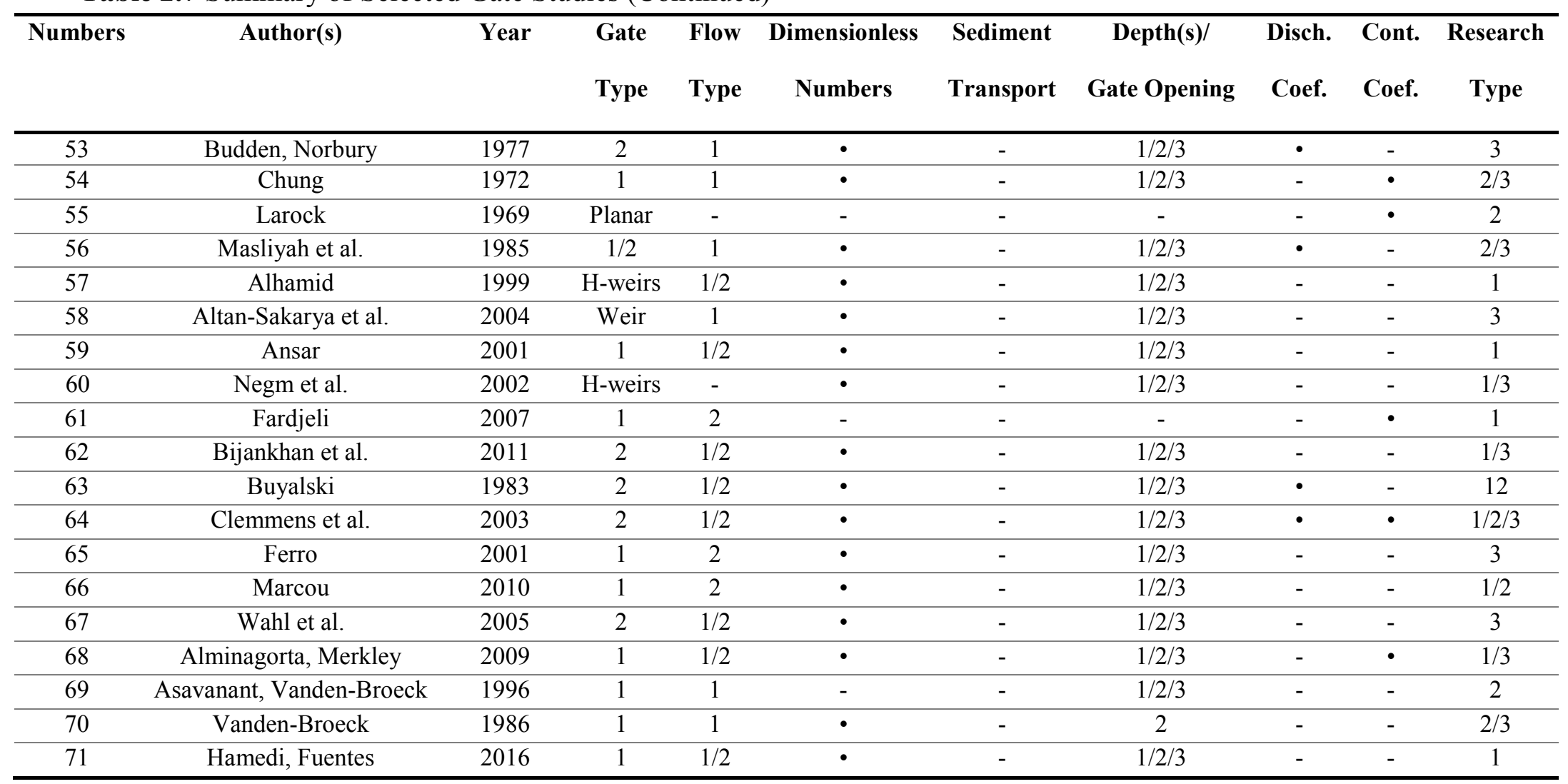

Table Guide: Gate Type: 1 = Vertical gate, $2=$ Radial gate; Flow Type: $1=$ Free flow, $2=$ Submerged flow; Depth(s): $1=$ Upstream Depth, $2=$ Tailwater, 3 = Gate Opening; Disch. Coef: Discharge Coefficient; Cont. Coef: Contraction Coefficient; Dimensionless Numbers, Sediment Transport, Disch. Coef,

Cont Coef: $\bullet=$ Applied, $-=$ Not applied; Research Type: $1=$ Experimental, $2=$ Numerical, $3=$ Theoretical. 
Dimensionless numbers and dimensional analysis have been used in studies, as reported in Table 2.6. Those studies highlight the importance of using dimensional analysis and dimensionless numbers in future studies. Furthermore, numerous studies, which have focused on upstream depth, downstream depth, and gate opening indicate the importance of these variables in gate studies. In addition, these studies also indicate that the discharge coefficient and contraction coefficient are also important factors in gate studies.

On the other hand, based on the results in Table 2.6, flow classification, energy downstream, depth profile, and stage-discharge relationships have not been widely considered in the literature, and there is a resulting knowledge gap in these areas. Therefore, it is recommended that these topics receive greater focus in future studies. In addition, sediment transport should also be more strongly considered in future work. This research focuses on flow classification, developing the Flow Stability Factor and the Flow Stability Number. The Flow Stability Number is able to define the stability of the flow based on the ratio of total energy between two sections downstream of the structures; total energy includes bottom elevation (Z), flow depth (y), and velocity heads $\left(\mathrm{v}^{2} / 2 \mathrm{~g}\right)$. This dimensionless number adds to knowledge in gate studies, addressing sediment transport in the condition of stability in flow. 


\section{CHAPTER 3}

\section{OBJECTIVES}

\subsection{OBJECTIVES OF THE RESEARCH}

The main goal of this research is the development of an improved understanding of the hydraulic characteristics of flow and the energy downstream of hydraulic structures, since this currently represents an information gap in knowledge about the hydraulics of gate studies. The flow was classified using the Fuzzy Concept and the Flow Stability Number as a dimensionless number; this number is obtained by dividing energy into the two sections downstream. Sediment transport also has been considered to determine the acceptable range of the Flow Stability number. Therefore, this research is filling in parts of the knowledge gap in gate studies.

The specific research objectives are listed next:

- Introduce the Fuzzy-based Flow Stability Factor as an innovative factor to classify the flow downstream of hydraulic structures; also, the application of the Flow Stability Factor to determine flow stable conditions has been presented.

- Show the application of the Artificial Neural Network (ANN) to determine the amount of the gate openings and introduce the post-processing technique to reduce the differences between the results of the ANN network and the experiment.

- Introduce the dimensionless Flow Stability Number which can be used to classify the flow downstream of hydraulic structures; also, the application of the Flow Stability Number to determine flow stable conditions in gates, gates with expansions, and gates with contractions has been presented. 
- Compare hydraulic performance of gates, gates with expansions, and gates with contractions.

- Show the application of Game Theory and the Nash Equilibrium to determine the best hydraulic structure under different conditions.

- Introduce an Efficiency Index as a Fuzzy-based index to determine the efficiency of hydraulic structures using image processing technique; moreover, the application of the Efficiency Index in a laboratory model, as well as two case studies from Florida and California have been presented.

In addition to these topics, upstream depth, downstream depth, and gate opening have also been measured in this research, and the application and usefulness of these measures have been illustrated using dimensional analysis. 


\section{CHAPTER 4}

\section{METHODOLOGY}

Hydraulic, human-made structures are used to manage and control the flow in channels. For example, a vertical gate is used to control the upstream water level [1]. The flow condition may change after hydraulic structures. Therefore, it is necessary to classify the flow after these structures, then manage the structure to ensure safe and stable downstream flow conditions. Investigations on flow characteristics are one of the most interesting parts of hydraulic engineering. There are some methods that classify flow conditions. Some of these methods classify flow conditions based on dimensionless numbers. The Froude number and the Reynolds number are two examples of this kind, which are widely used in hydraulic engineering [36]. As mentioned in chapter 3 , one of the objectives of this research is to find flow stability conditions downstream in hydraulic structures. Two methods have been presented in this research to estimate flow stability after hydraulic structures. The first method uses the Fuzzy Concept to categorize different flow conditions downstream based on engineering judgments and the second method utilizes a dimensionless value to determine flow stability. The stability definition in the second method is again based on the Fuzzy Concept.

\subsection{FLOW STABILITY FACTOR}

In this method, flow conditions downstream of the hydraulic structure are categorized based on the Fuzzy Concept. The optimum hydraulic structure is obtained when the 
flow condition is stable in the downstream section. Consequently, it is necessary to define a stable condition in the downstream section. Depending on the type of hydraulic structure, different conditions can occur downstream, such as a hydraulic jump, a submerged hydraulic jump, a wave, or a stable condition.

The Flow Stability Factor for the flow pattern is defined based on the Fuzzy Concept within a range between 0 and 1 (Table 4.1). This arbitrary range has been chosen because it is simple and easy to understand. As an example, a stability parameter of 0.2 means that the submerged hydraulic jump is just 0.2 or $20 \%$ close to the stable condition. Different hydraulic conditions, like a hydraulic jump and a submerged hydraulic jump, etc., should be determined based on engineering judgment. This is a weakness of this method, because a hydraulic expert is needed to determine the flow condition after hydraulic structures. Figures 4.1 (a to j) show the different flow conditions after the hydraulic structures, which are determined based on engineering judgment.

Table 4.1 Flow Stability Factor

\begin{tabular}{ccc}
\hline Numbers & Downstream condition & Flow Stability Factor \\
\hline 1 & Hydraulic Jump & 0 \\
\hline 2 & Submerged Hydraulic Jump & 0.2 \\
\hline 3 & Weak submerged H.J & 0.4 \\
\hline 4 & Very weak submerged H.J & 0.5 \\
\hline 5 & Strong wave & 0.6 \\
\hline 6 & Wave & 0.7 \\
\hline 7 & Weak wave & 0.8 \\
\hline 8 & Very weak wave & 0.9 \\
\hline 9 & Stable & 1 \\
\hline
\end{tabular}




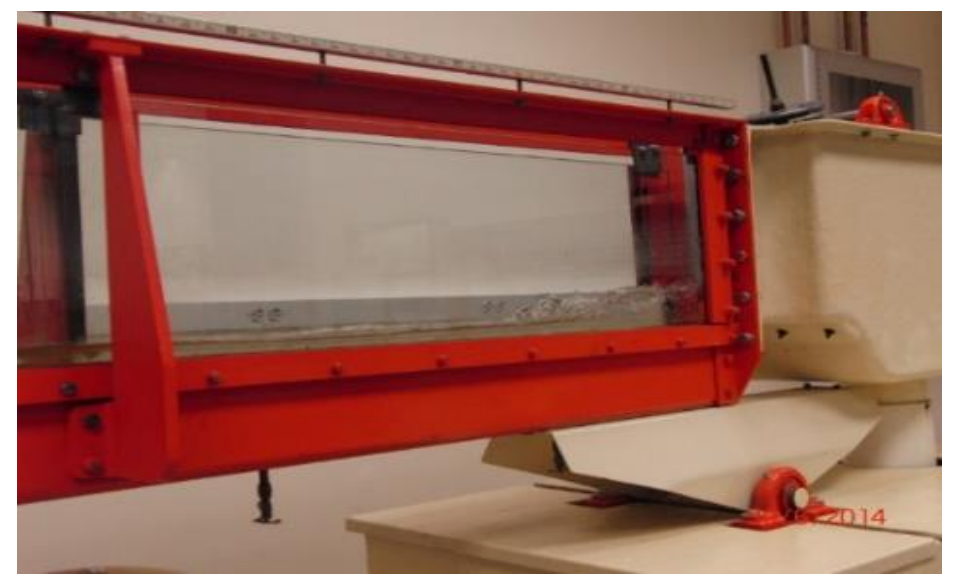

Figure 4.1. (a): Hydraulic jump at the end of the flume and far from the gate $(\mathrm{St}=0)$

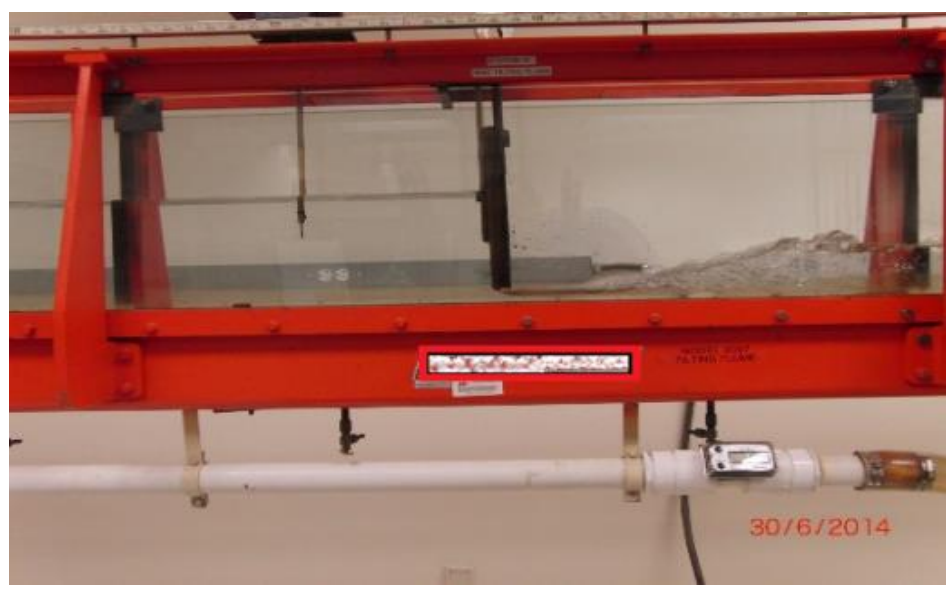

Figure 4.1. (b): Hydraulic jump after the gate $(\mathrm{St}=0)$

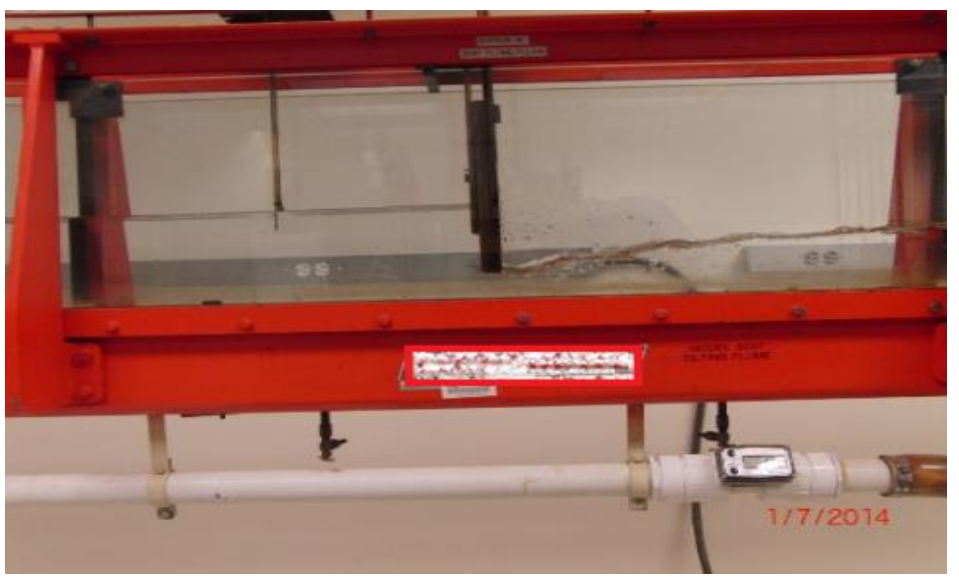

Figure 4.1. (c): Submerged hydraulic jump after the gate $(\mathrm{St}=0.2)$ 


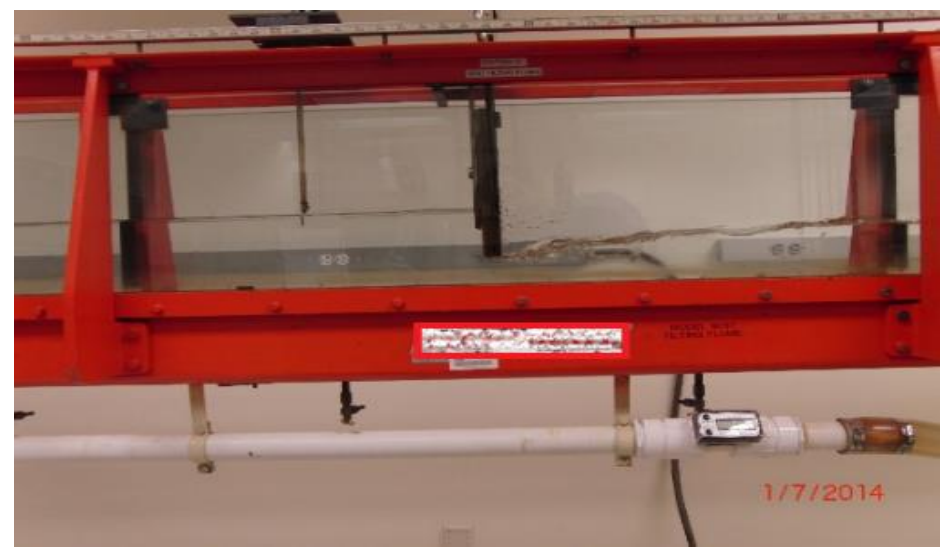

Figure 4.1. (d): Weak submerged hydraulic jump after the gate $(\mathrm{St}=0.4)$

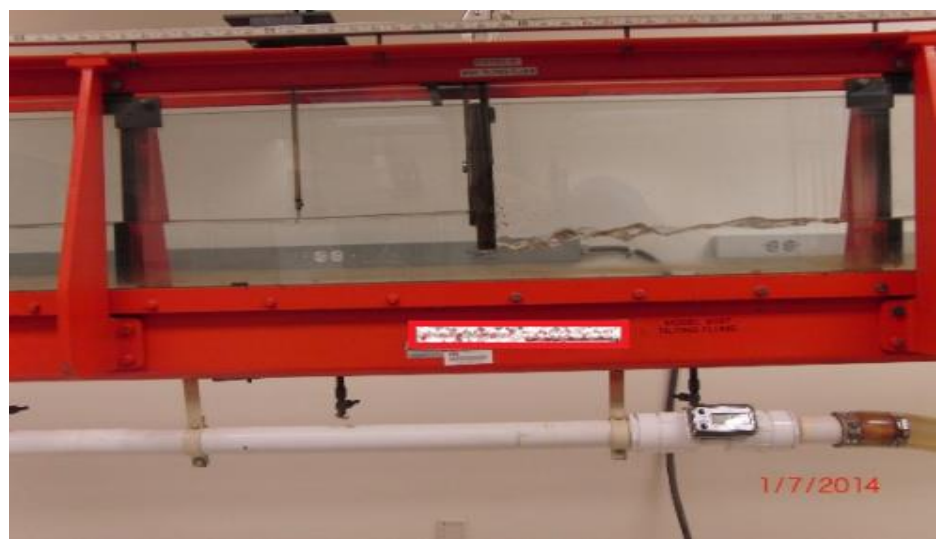

Figure 4.1. (e): Very weak submerged hydraulic jump after the gate $(\mathrm{St}=0.5)$

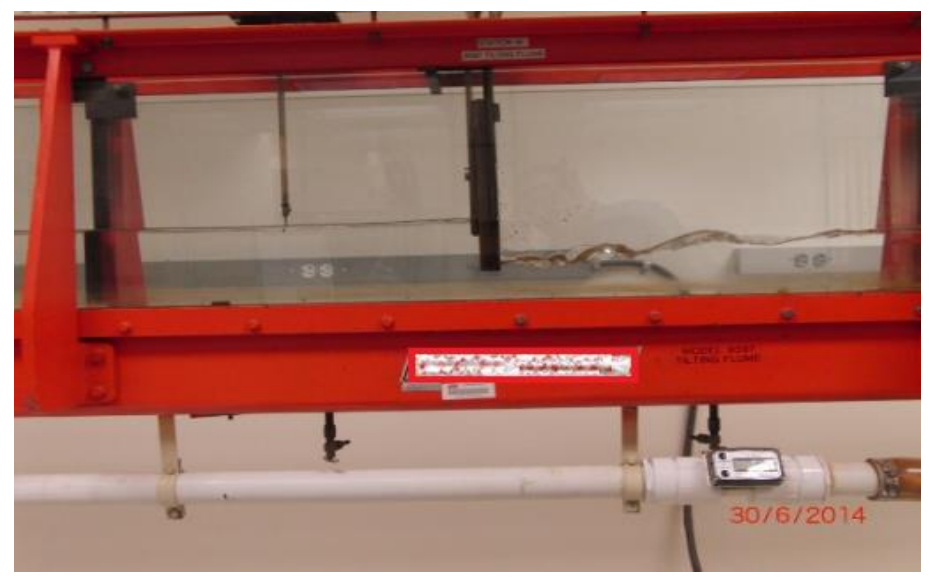

Figure 4.1. (f): Strong wave after the gate $(\mathrm{St}=0.6)$ 


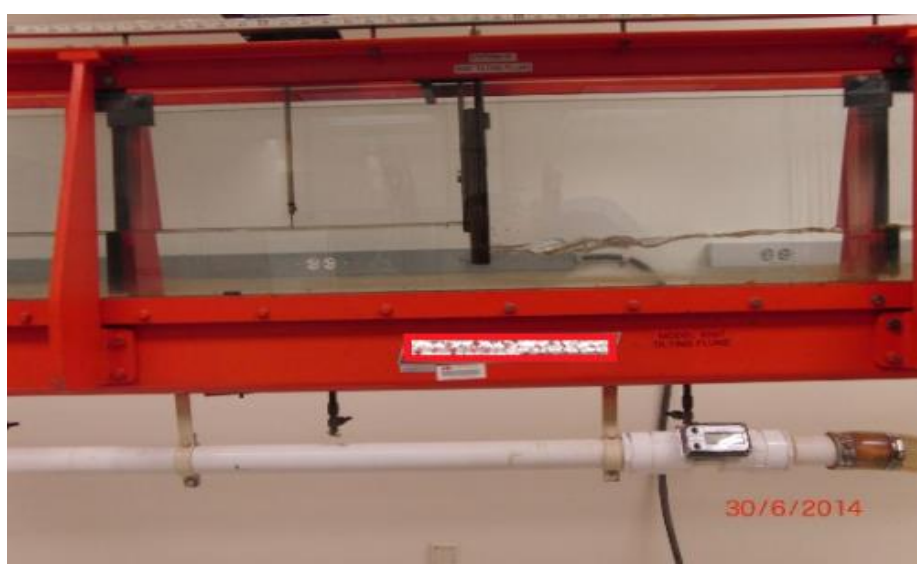

Figure 4.1. (g): Wave after the gate $(\mathrm{St}=0.7)$

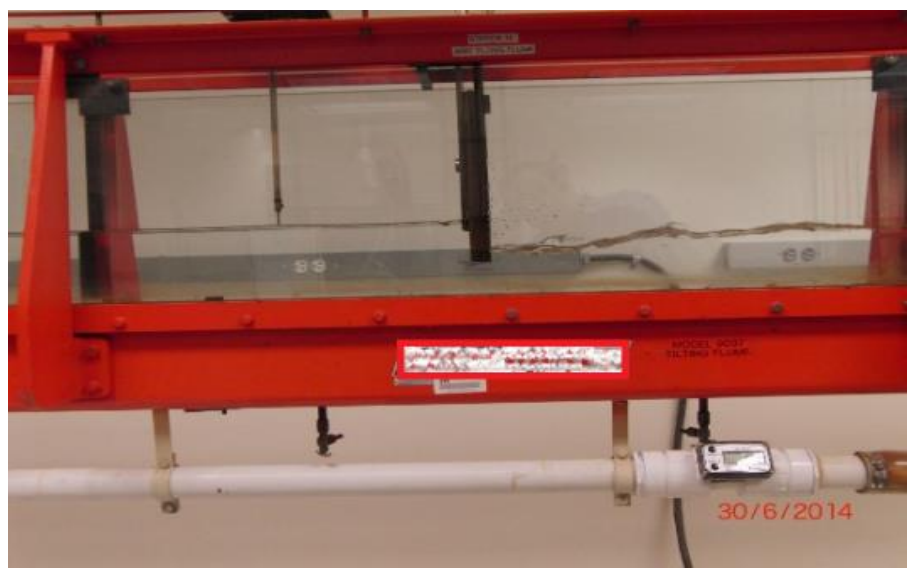

Figure 4.1. (h): Weak wave after the gate $(\mathrm{St}=0.8)$

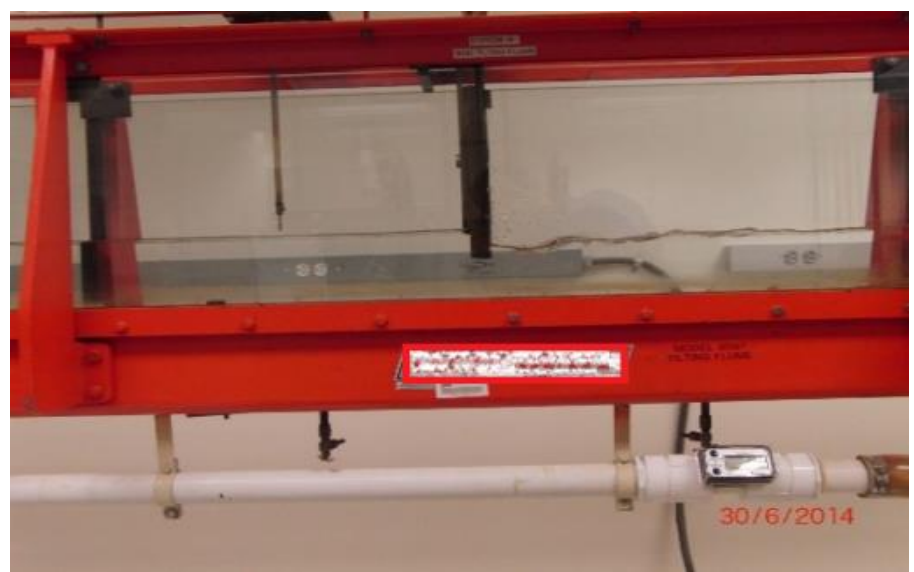

Figure 4.1. (i): Very weak wave after the gate $(\mathrm{St}=0.9)$ 


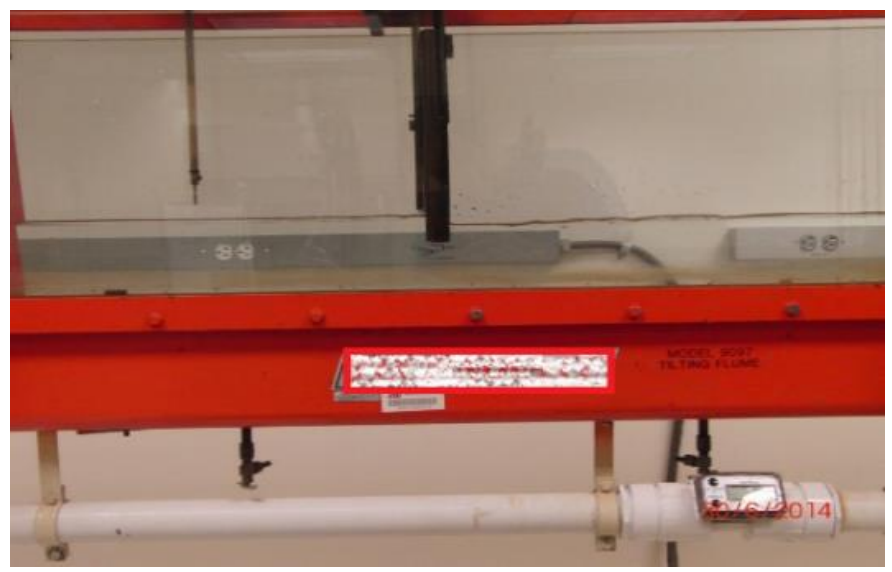

Figure 4.1. (j): Stable condition after the gate $(\mathrm{St}=1)$

\subsection{FLOW STABILITY NUMBER}

Unstable flow condition happens under some conditions. First, it occurs when the velocity is high after the gated structures, resulting in erosion and sediment transport. Second, it also happens when the depth of the flow is less than the critical depth and the flow is supercritical. Third, it may occur when the flow is wavy. The change in the energy of the flow along a structure can be used to investigate flow stability. The total energy of the flow at a section includes bottom elevation, water depth, and the velocity head in its definition; therefore, the total energy content and its change along a structure is a good indicator of flow stability because it accounts for all the terms that relate to flow instability. Flow instability primarily happens due to energy changes between two sections along a stream, river, or channel. When the flow is "stable" in the first section, then the flow will be "stable" again in the second section, if energy loss is negligible. Regarding hydraulic behavior, a "stable" condition happens when the flow is subcritical in channels. Moreover, other factors, like surface flow fluctuations and bed and wall velocities, are important to determine the acceptable flow stability range. Hamedi 
and Fuentes [14] classified downstream flow conditions based on engineering judgment to determine different flow conditions, like hydraulic jump, submerged hydraulic jump, and wave, etc. This study introduces the Flow Stability Number and the procedure to calculate this number. The study also considered other quantities (e.g. hydraulic gradient, change in specific energy, and velocity head) as possible indicators of flow stability; however, the change in total energy was selected given its full accounting of the total energy at the sections of concern within the structure; in fact, the change in total energy between sections within a structure is widely used in the common design and operation of energy dissipation via hydraulic jumps, among other structures

Two sections should be selected in the same flow direction; then, the energy of each section is calculated and the two values are divided, that is the energy of the second section is divided by the energy of the first section, thus determining the value of the Flow Stability Number as a dimensionless number. The maximum value of the Flow Stability Number is one. The Flow Stability Number is based on the Fuzzy Concept and indicates the stability percentage of the flow in subcritical flows. For example, when the Flow Stability Number is 0.67 , it means that the flow is $67 \%$ stable. It should be noted that both channel sections should be located after the hydraulic structure(s). The first section should be selected immediately after the hydraulic structure(s) (in gates after the vena-contracta) and the second section can be selected downstream of the first section where the flow is uniform. Figure 4.2 shows the selected sections to calculate energies after the vertical gate. In Figure 4.2 a, the jump is not submerged and the vena- 
contracta happens after the gate. To select the depth, which is not impacted by venacontracta, the first section should be selected so that it is far enough away from the gate.
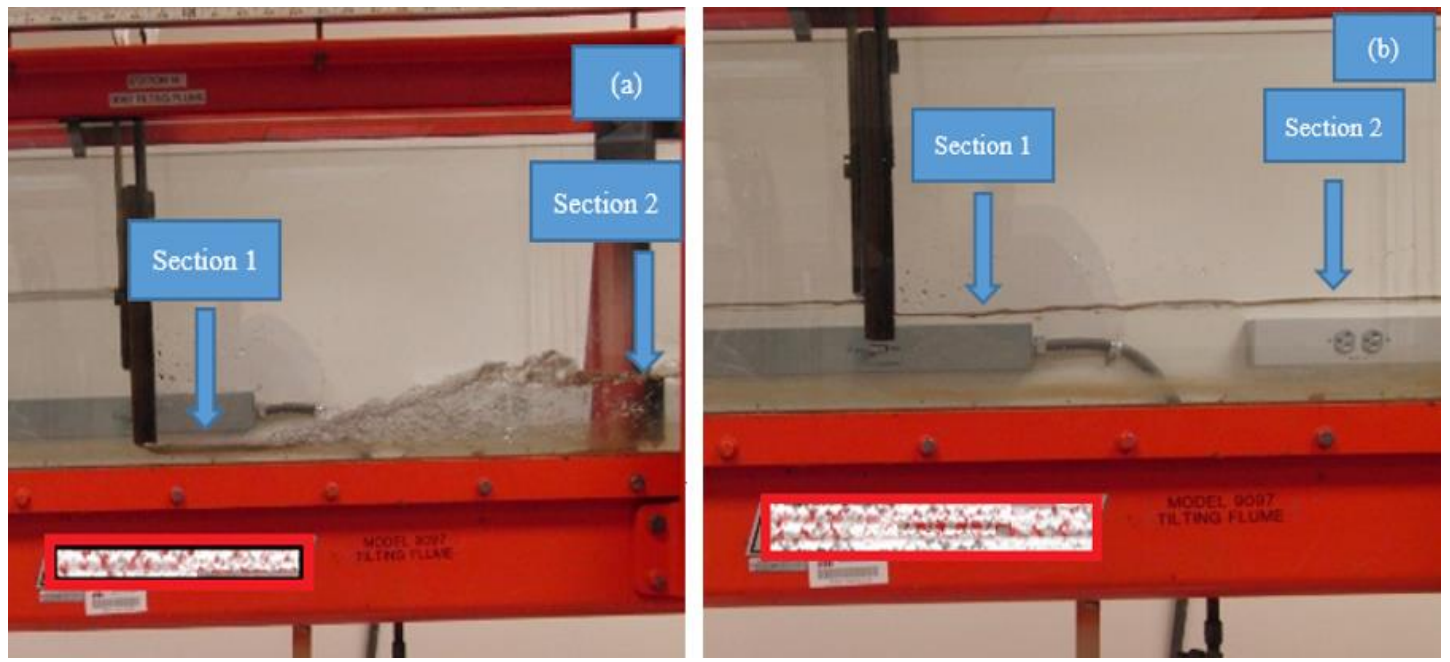

Figure 4.2. (a): Sections in hydraulic jump (b): sections in subcritical flow

Equation 4.1 presents the general concept of the Flow Stability Number. Equations 4.1 can be used when the flow depth in both selected sections is not less than the critical depth. When the depth in at least one section is less than the critical depth, the Flow Stability Number is not defined.

$$
\text { Flow Stability Number }=\frac{H_{j}}{H_{i}}=\frac{Z_{j}+y_{j}+\frac{V_{j}^{2}}{2 g}}{Z_{i}+y_{i}+\frac{V_{i}^{2}}{2 g}}
$$

Where $\mathrm{H}$ is the total head, $\mathrm{y}$ is the depth, $\mathrm{v}$ is the velocity, and $\mathrm{z}$ is the distance from the datum to the bottom in sections $\mathrm{i}$ and $\mathrm{j}$. There are two scenarios which happen in channels with equal Z, and which need more attention. The first scenario happens when the flow is supercritical in both sections. It means that the depth in both sections is less 
than the critical depth. In this scenario, the Flow Stability Number is not defined, because flow is supercritical. The second scenario happens when the flow in the first section is supercritical, and the flow is subcritical in the second section (a hydraulic jump). In this scenario, again, the Flow Stability Number is not defined, because the flow is supercritical. Figure 4.3 shows the method to calculate the Flow Stability Number.

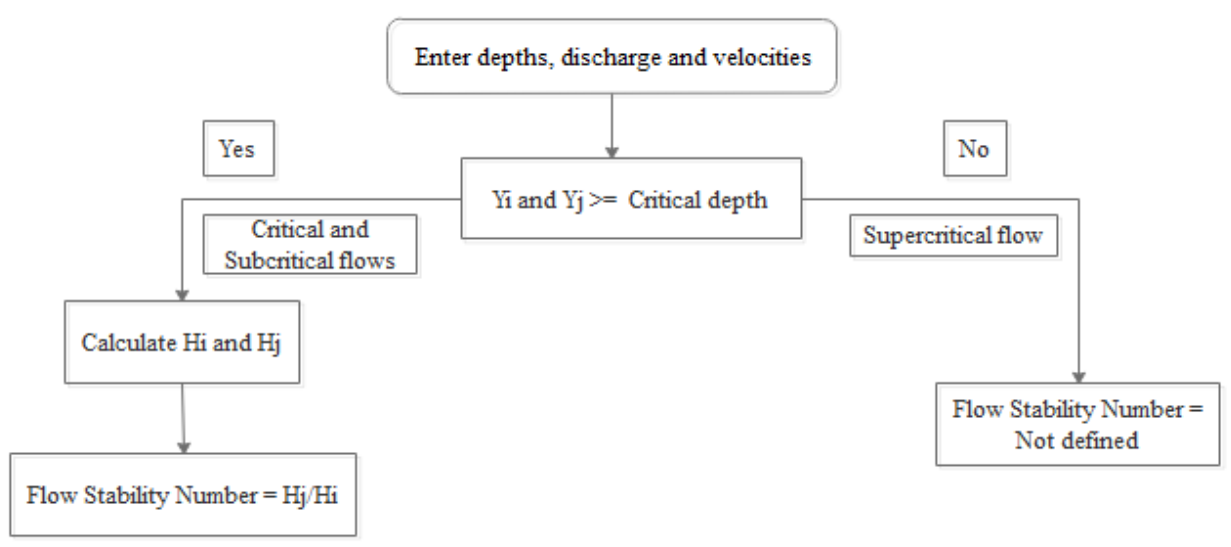

Figure 4.3: A method to calculate the Flow Stability Number

\subsection{ACCEPTABLE STABILITY RANGE}

Three criteria should be met in flow to have a stable condition downstream of the hydraulic structures. Erosion, fluctuations, and depths should be controlled in channels to make the flow stable. These criteria are described below:

1) The velocity, which is used in the energy equation, should be less than the maximum permissible velocity $\left(\mathrm{V}_{\max }\right)$. If the velocity is greater than $\mathrm{V}_{\max }$, sediment transport will be seen in the channel. Table A.1 in Appendix A presents the maximum permissible velocity values in different non-vegetated linings [147]. 
2) After the hydraulic structures, the flow regime in both sections should be critical or sub-critical. It means that the Froude number should be equal or less than one.

$$
\text { Froude number }=\frac{V}{\sqrt{\mathrm{gD}}}
$$

Where $\mathrm{V}$ is the flow velocity, $\mathrm{g}$ is gravitational acceleration, and $\mathrm{D}$ is hydraulic depth [36].

3) The flow has minimum fluctuations. In both sections after hydraulic structures, average depths should be measured by at least ten measurements. Then, a t-test [148] should be used to compare the average depth values in both sections after the hydraulic structures with the assumption of the equality of means and a confidence interval of $95 \%$. The flow is completely stable when the assumption is not rejected. Based on the experimental results of this research, the Flow Stability Number could be considered as acceptable stability when the assumption is not rejected with a confidence interval of $80 \%$. It means that there is not a meaningful difference between average depths and flow fluctuations. This limitation is proposed based on results from this study and the engineering judgment of the author, and it may change at different scales of application (e.g., laboratory, prototypes) or under different channel conditions.

It should be noted that after using the t-test, the box plots [148] for each group should be plotted. Then, a normality test [149], like the Shapiro Test [150] or Q-Q plot [151], as well as an equality of variances test, like the F-test [152], should be done. If there is no outlier and data follows a normal distribution and variances are equal in all groups, 
then a t-test can be applied. When outliers are seen or data doesn't follow a normal distribution, then non-parametric tests should be applied.

Based on the criteria for flow stability, stable flow should have the minimum level of erosion and sediment transport and surface flow fluctuations in the channels. This flow condition reduces aeration and helps operators to manage the hydraulic structures in a better way.

\subsection{HYDRAULIC STRUCTURES AND LABORATORIES}

A Gate, a gate with an expansion, and a gate with a contraction, are the three hydraulic structures that have been used in this research to investigate the downstream flow stability condition. These structures have been chosen due to the ease of manufacturing and installation and the lower construction cost compared with other hydraulic structures. The schematics of these hydraulic structures are depicted in Figures 4.4 (a, $\mathrm{b}$, and c). In Figure $4.4 \mathrm{a}, \mathrm{h}_{0}$ is upstream flow depth, and $\mathrm{h}_{1}$ is the flow depth after the gate, $\mathrm{h}_{2}$ is downstream flow depth, and a is the gate opening. The vertical gate is presented in a section view, but the gate with expansion, as well as the gate with contraction, are presented in plan views. In Figures 4.4 (b and c), the hashed rectangle is the gate. Furthermore, the flow direction is illustrated. 


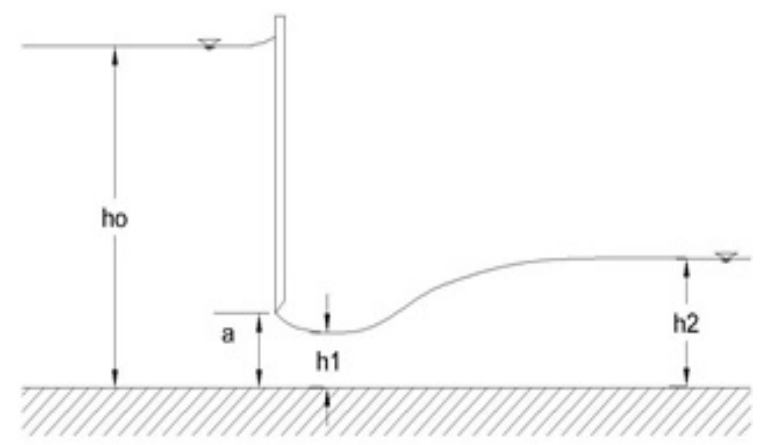

Figure 4.4. (a): Vertical gate

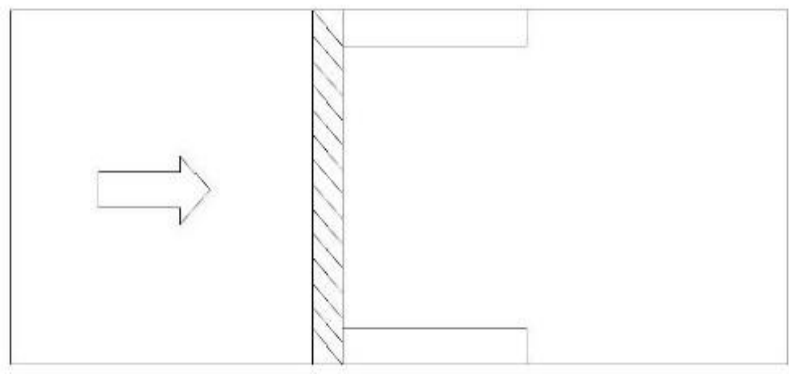

Figure 4.4. (b): Gate with expansion

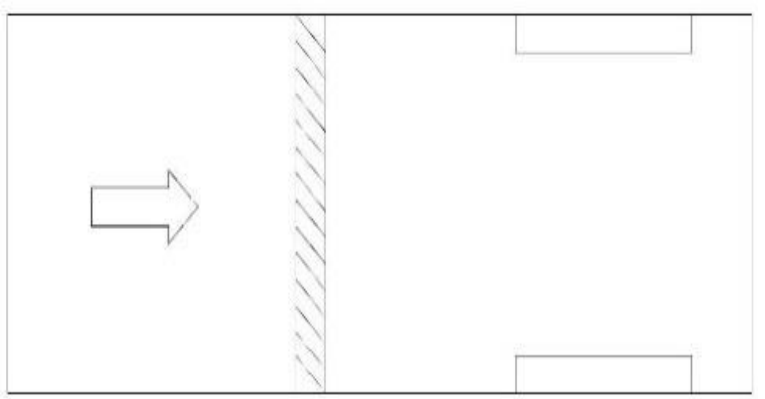

Figure 4.4. (c): Gate with contraction

Experiments have been conducted in two laboratories. The first series of experiments were conducted in a narrow flume located at the Fluid Mechanics Laboratory of the Civil and Environmental Engineering Department of Florida International University. The width of the flume is eleven centimeters; the length and height of the flume are 
long and high enough for this research. The flume is made up of a steel frame with a glass wall. The flume was equipped with a pump which conducted the flow from the reservoir to the flume and circulated the flow into the flume and reservoir. A vertical steel gate, which is completely sealed with rubber on both the right and left sides, was installed in the middle of this flume. Investigating the developed flow was the reason this location was chosen for the gate. A developed flow means a location which is not affected by flow circulation in the flume. Figure 4.5 shows the flume and the gate.

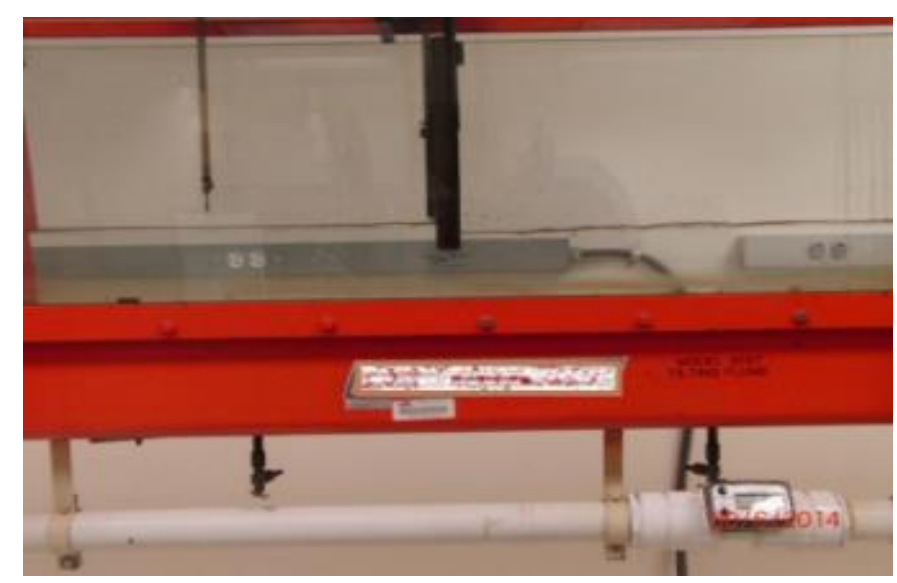

Figure 4.5: Flume and gate

The same structures, made from wood, have been used for expansion and contraction in this lab. For each of them, three thicknesses with the same length and the same height have been used to show the effect of the thickness on flow stability after hydraulic structures. These structures have been attached to the flume and completely sealed. Table 4.2 shows the characteristics of expansion and contraction structures. 
Table 4.2 Characteristics of Expansion and Contraction Structures

\begin{tabular}{ccccc}
\hline Numbers & Material & Length (cm) & Height (cm) & Thickness (cm) \\
\hline 1 & Wood & 28.5 & 9.2 & 2.0 \\
\hline 2 & wood & 28.5 & 9.2 & 1.2 \\
\hline 3 & wood & 28.5 & 9.2 & 0.7 \\
\hline
\end{tabular}

The expansion structures were installed in the flume exactly after the gate and the contraction structures were installed in the flume 25 centimeters downstream of the gate. Figures 4.6 (a) and (b) show the gate with an expansion structure in section and plan views, respectively. Moreover, Figures 4.7 (a) and (b) present the gate with a contraction structure in section and plan views, respectively.

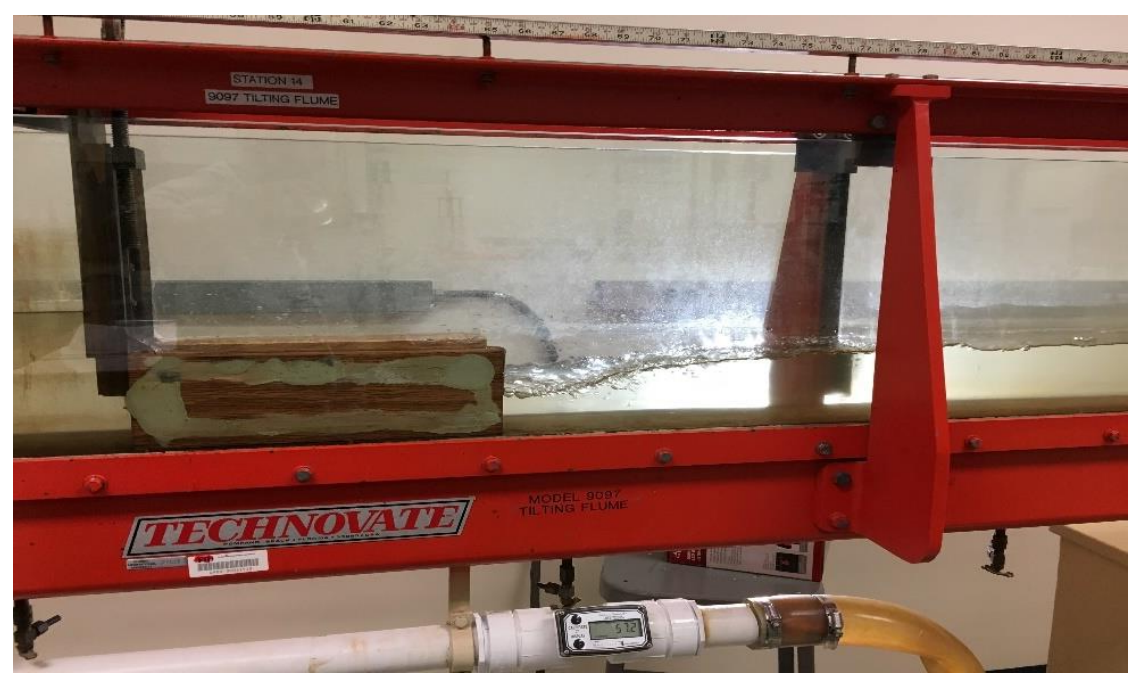

Figure 4.6. (a): Gate with expansion, section view 


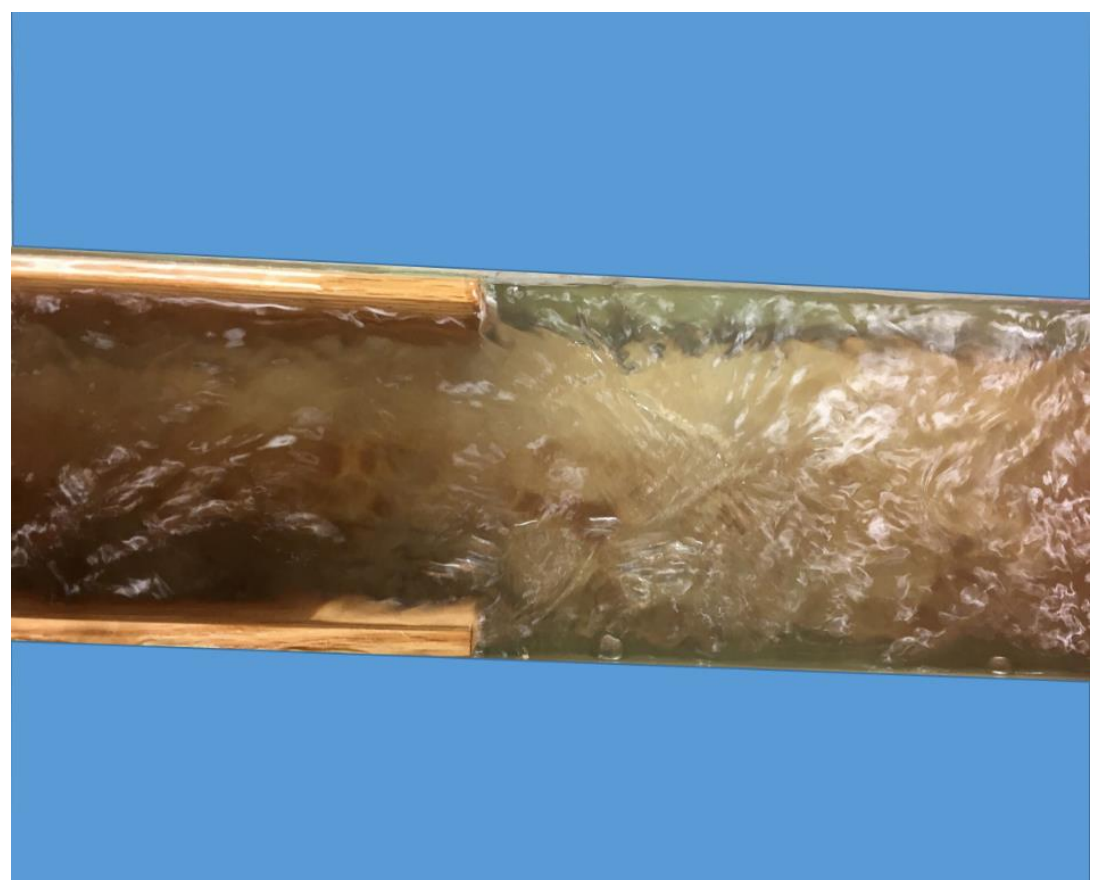

Figure 4.6. (b): Gate with expansion, plan view

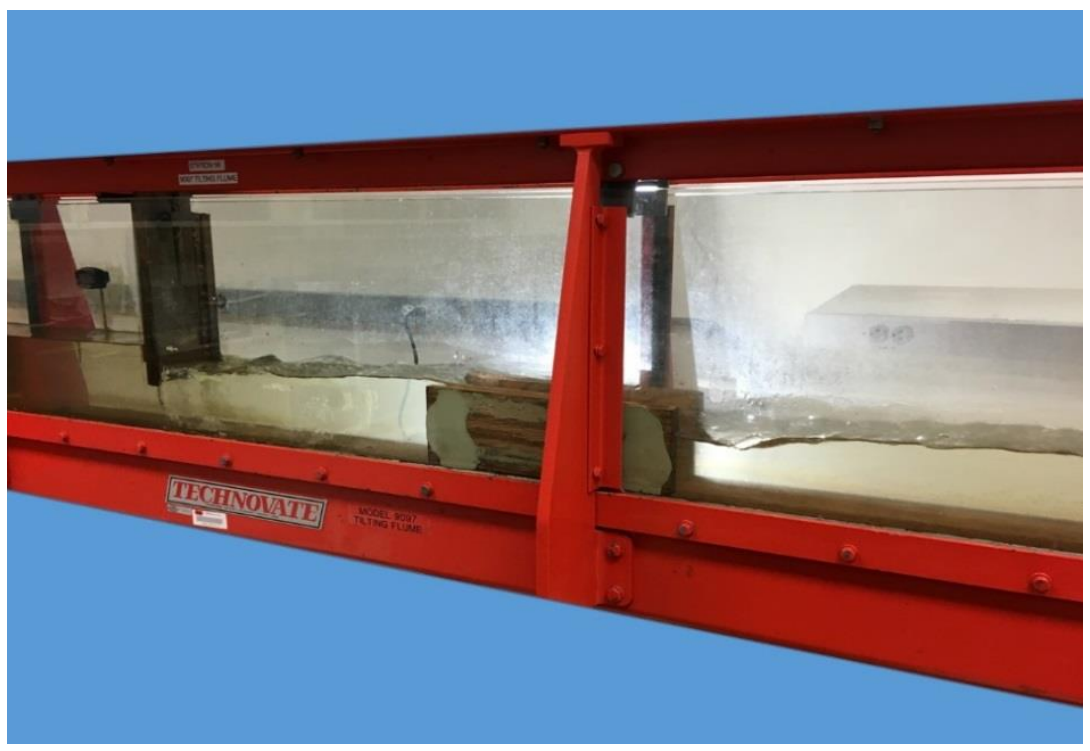

Figure 4.7. (a): Gate with contraction, section view 


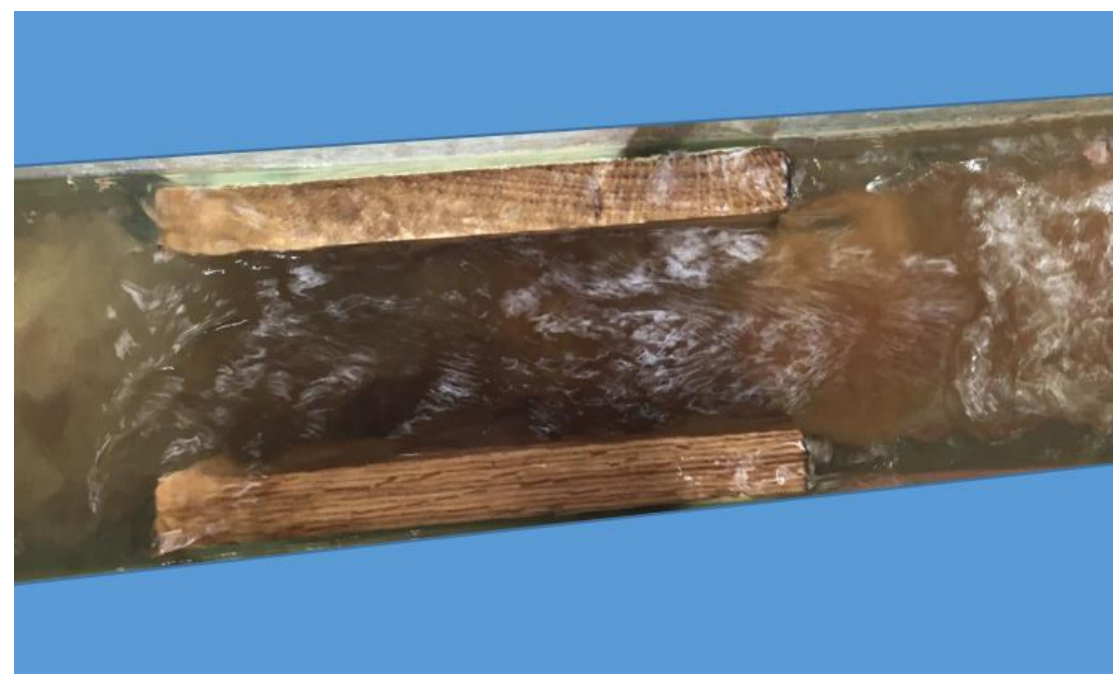

Figure 4.7. (b): Gate with contraction, plan view

Some parts of the experiments were conducted at the Center for Research in Water Resources (CRWR) at the University of Texas at Austin, which is in the J.J. Pickle Research Campus, to consider the scale effect on this research. Flow is pumped from a big lagoon to the flume and then back to the lagoon. Two valves were used to manage the discharge into the flume. The first valve is close to the lagoon and lets the flow go back to the lagoon before entering the pipes. The second valve was installed after the pipe which connects the lagoon to the flume entrance and is located very close to the flume entrance. The flume is long enough for this research. It is also approximately 63.5 centimeters high and 55 centimeters wide. One side of the flume is made of wood, and the other side is made of concrete. The flume bed is covered with a mixture of sand and gravel which includes brown pea gravel circled, white limestone (the coarsest), and dark basalt gravel (intermediate size). The Grain Size Distribution (GSD) of the mixture is presented in Appendix B, Table B.1. Figure 4.8 shows a satellite view of the lagoon and the flume also presents flow direction in the flume. Figures 4.9 (a) and 
(b) indicate the first and the second valve, respectively. Figure 4.10 presents the flume and Figure 4.11 shows the mixture which covers the flume bed.

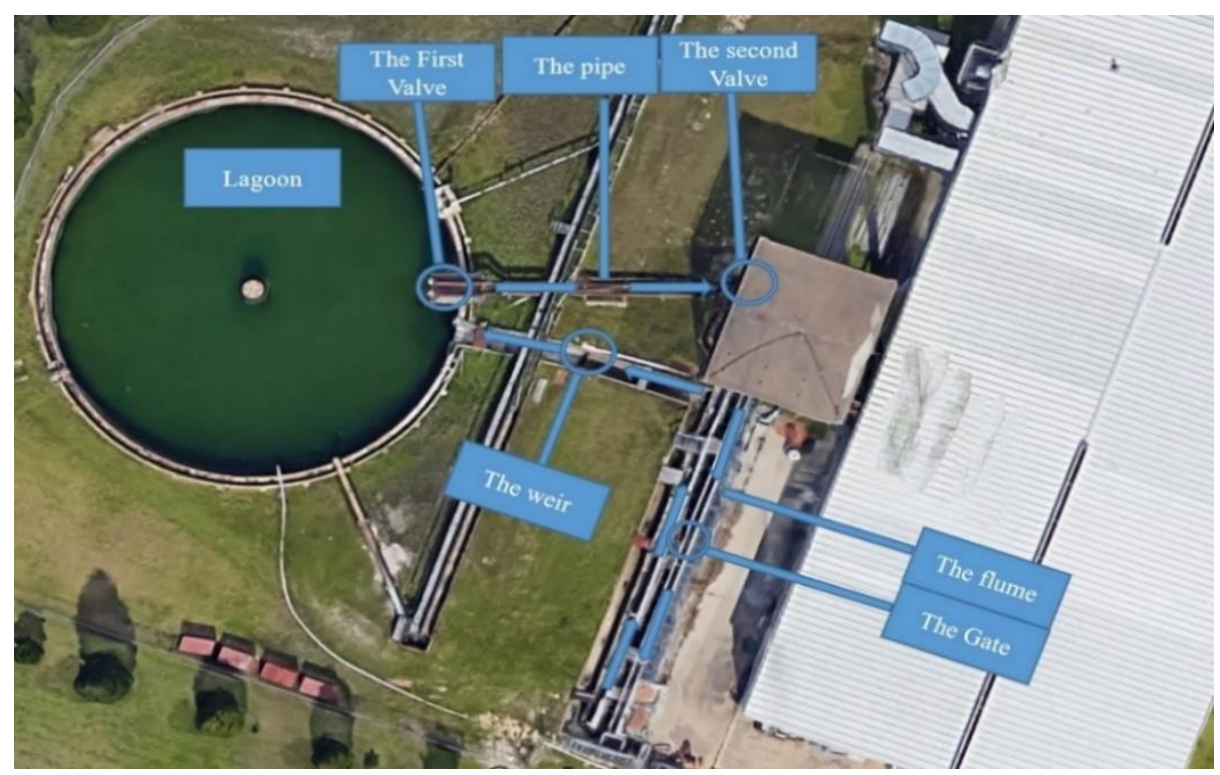

Figure 4.8: The flume and lagoon, satellite view

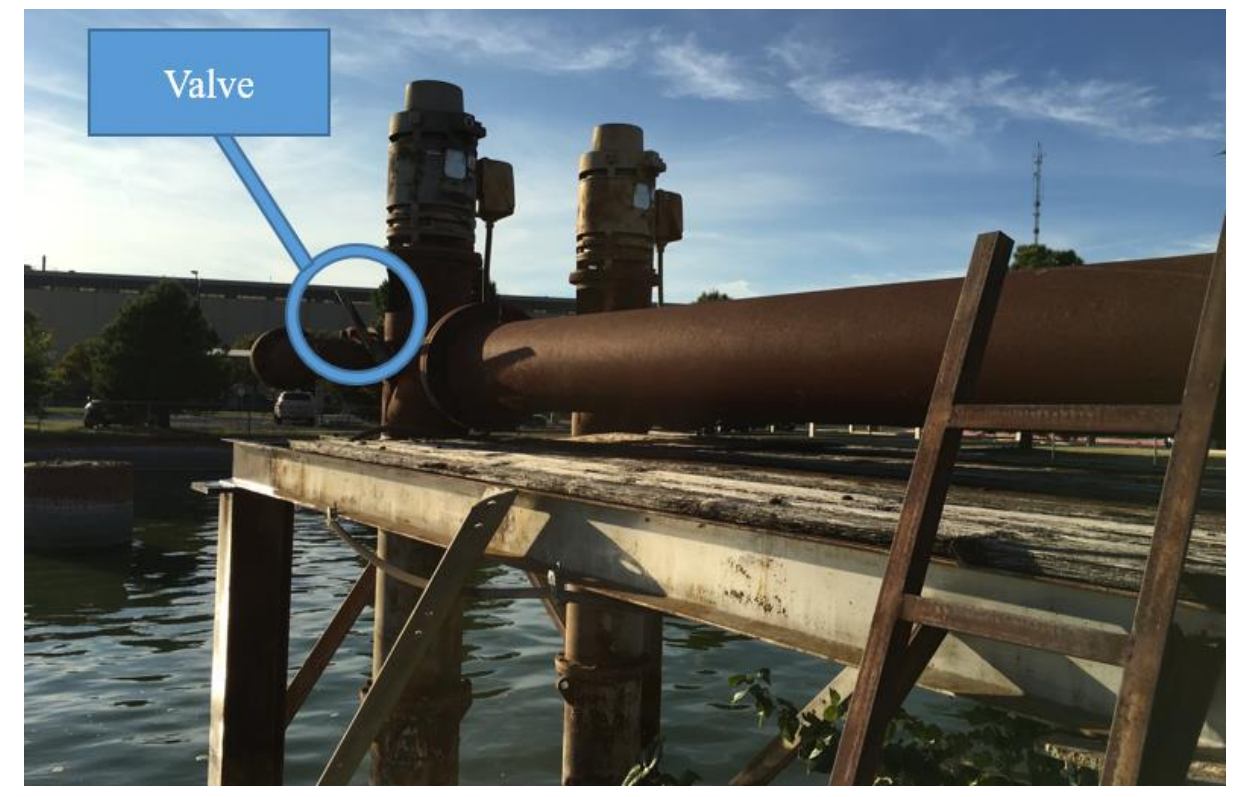

Figure 4.9. (a): The first valve 


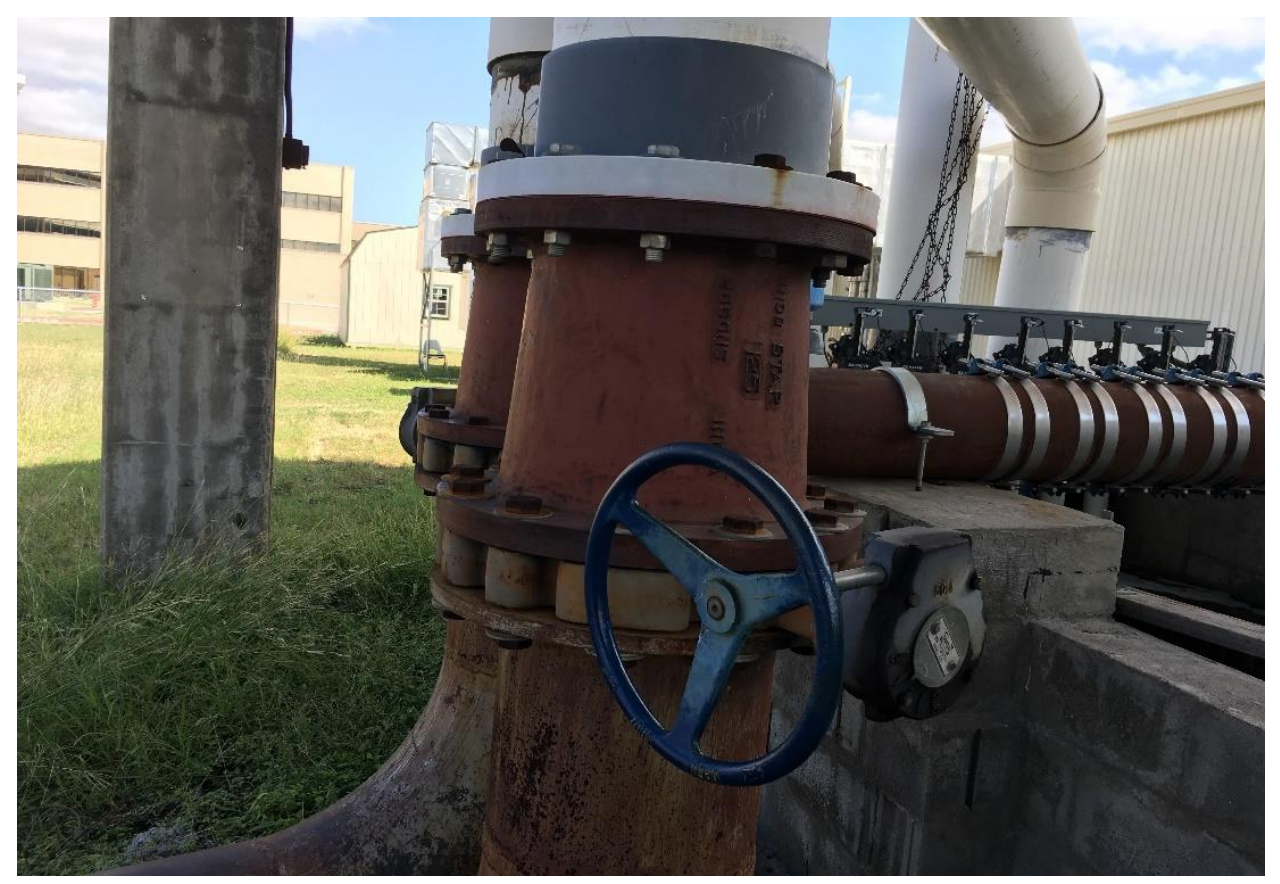

Figure 4.9. (b): The second valve

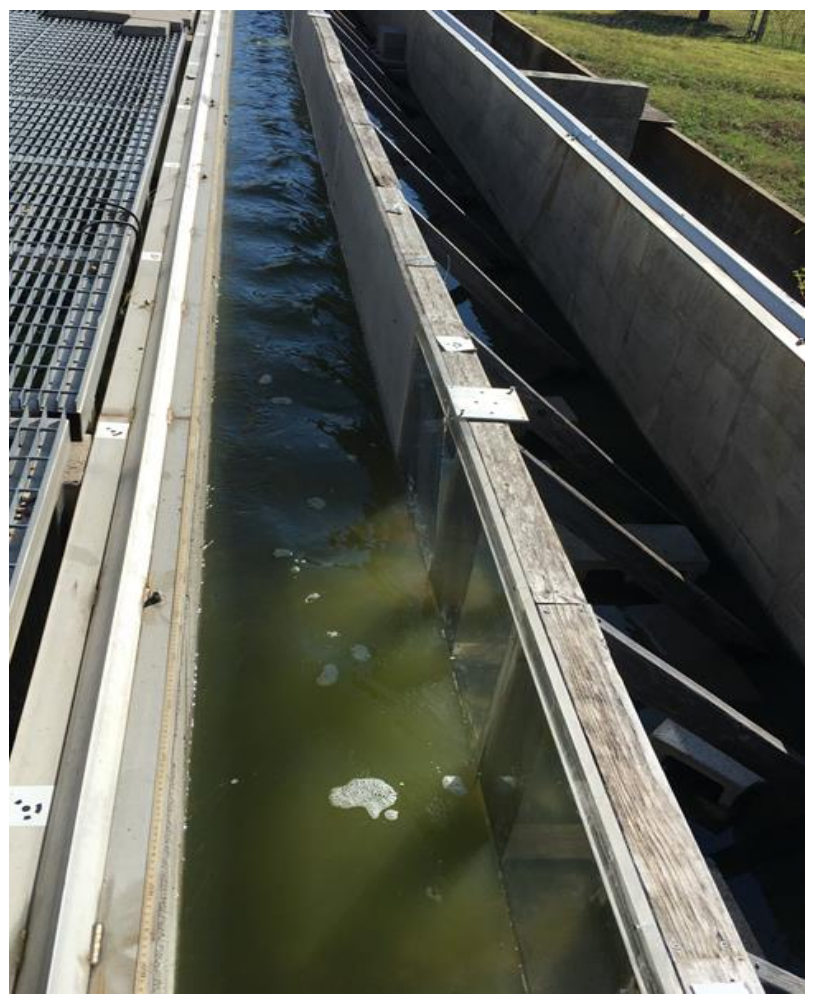

Figure 4.10: The flume 


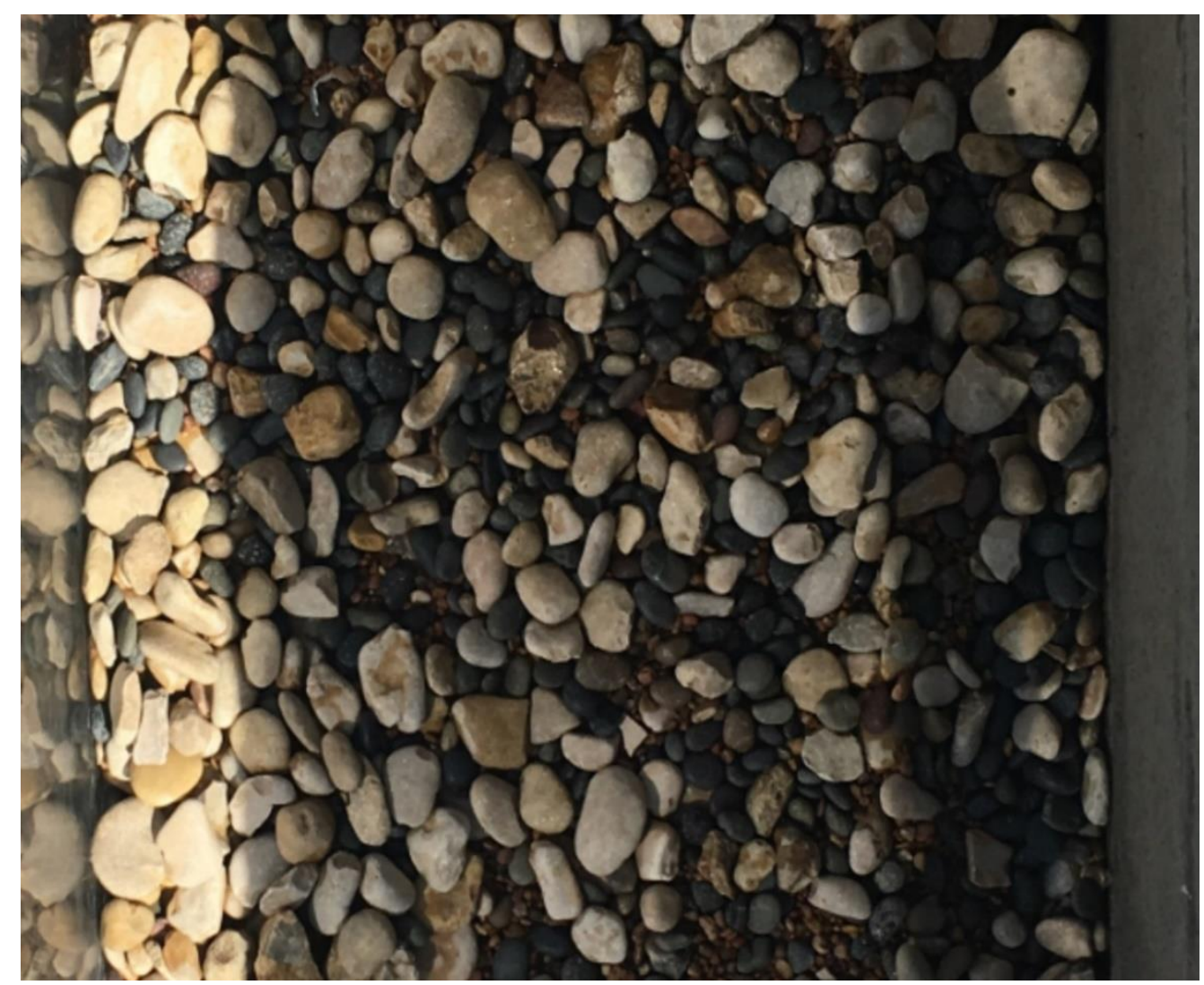

Figure 4.11: The mixture which covers the flume bed

The gate is made of wood with a steel frame. Two wooden parts were used in the gate; the fixed part and the sliding part. The fixed part is 51 centimeters high and is thicker than the sliding part to tolerate flow pressure and maintain the gate in a stable condition. This part can be seen from downstream of the gate and is fixed with bar \#10 at an elevation of 78 centimeters from the bottom of the flume. The sliding part is 51 centimeters high and is less thick than the fixed portion. Because of its thickness, it easily slides in the frame. This part can be seen from the upstream part of the gate. The frame is fixed to both sides of the flume, and the gate slides up and down in the frame. Therefore, the gate opening is easily managed. The sliding part of the gate is completely 
sealed with rubber inside the frame, and the frame is carefully sealed with caulking cord. This gate was installed in the flume in less than one hour simply for this research, and it is considered to be a trustworthy, easy to use, low-cost, and somewhat portable gate. This gate can be easily uninstalled from the flume and promptly installed again at some point in the future. The gate is installed approximately in the middle of the flume where the flow is developed, and it is not affected by flume entrance fluctuations. After the gate, the wooden side of the flume is replaced by Plexiglas for some meters (Figure 4.10). Therefore, the flow can be easily monitored for this section. In the current research, this section was used to monitor flow conditions and sediment transport after the gate and other hydraulic structures. Furthermore, some parts of pictures have been taken, and slow-motion movies have been recorded in this section. Figures 4.12 (a) and (b) show an overview of the gate and the gate and sealing details, respectively.

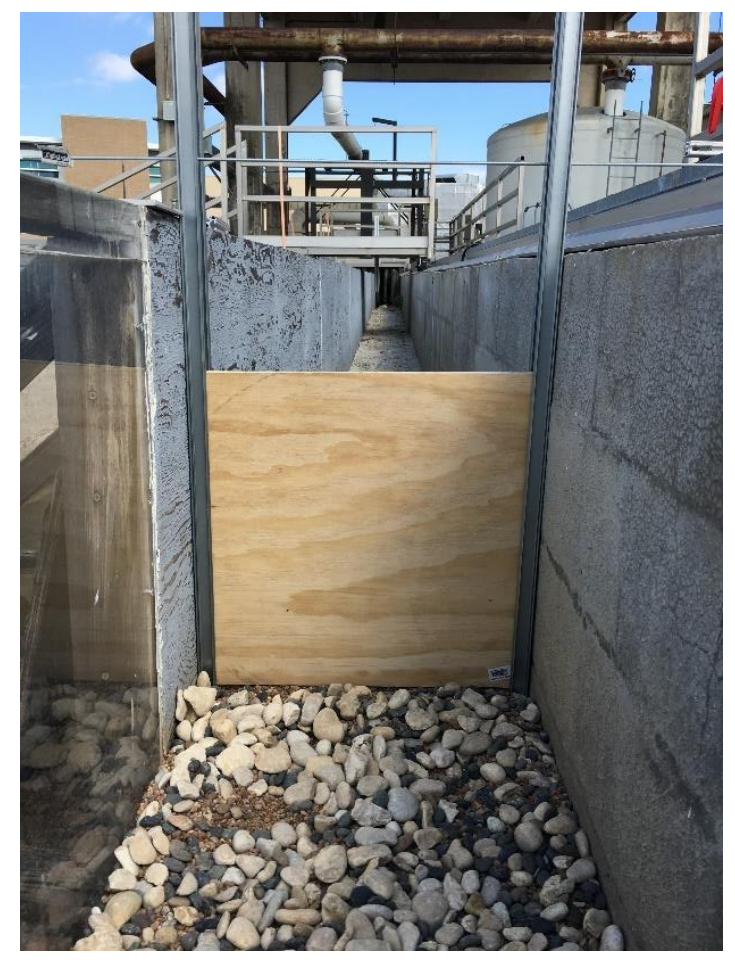

Figure 4.12. (a): An overview of the gate 


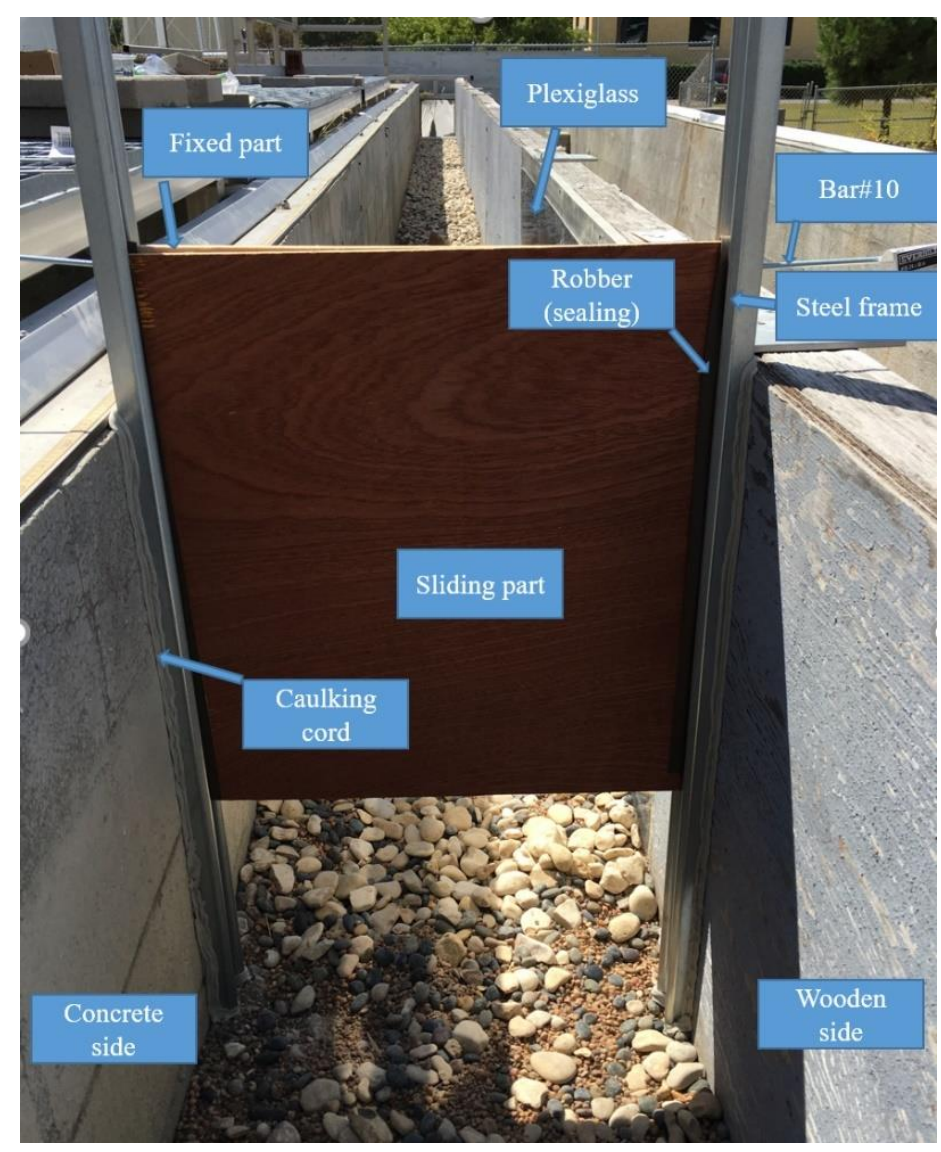

Figure 4.12. (b): Details of the gate

Structures (blocks) which are of the same size and made of cement have been used for expansion and contraction in this lab. The length of the blocks is 40 centimeters, and the height and thickness of the blocks are 22.2 centimeters and 4 centimeters, respectively. The expansion structures were installed in the flume exactly after the gate and the contraction structures were installed in the flume downstream of the gate. Figures 4.13 (a) and (b) indicate the gate with expansion structure in section and plan views, respectively. Furthermore, Figures 4.14 (a) and (b) show the gate with the contraction structure in section and plan views, respectively. 


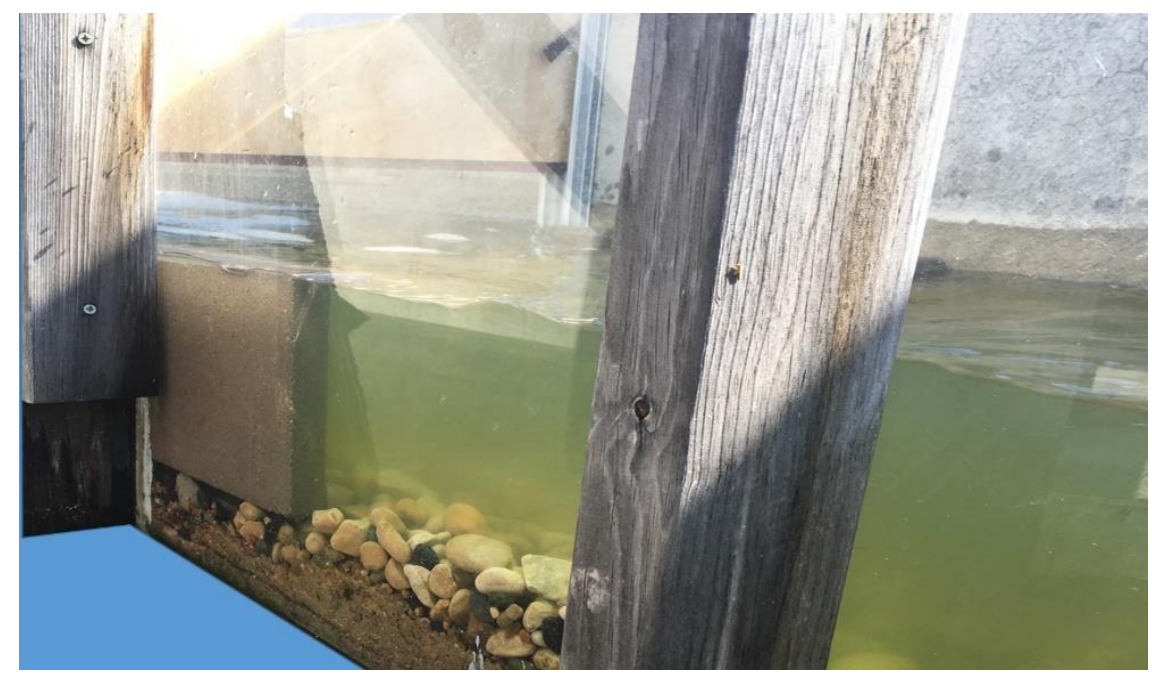

Figure 4.13. (a): Gate with expansion, section view

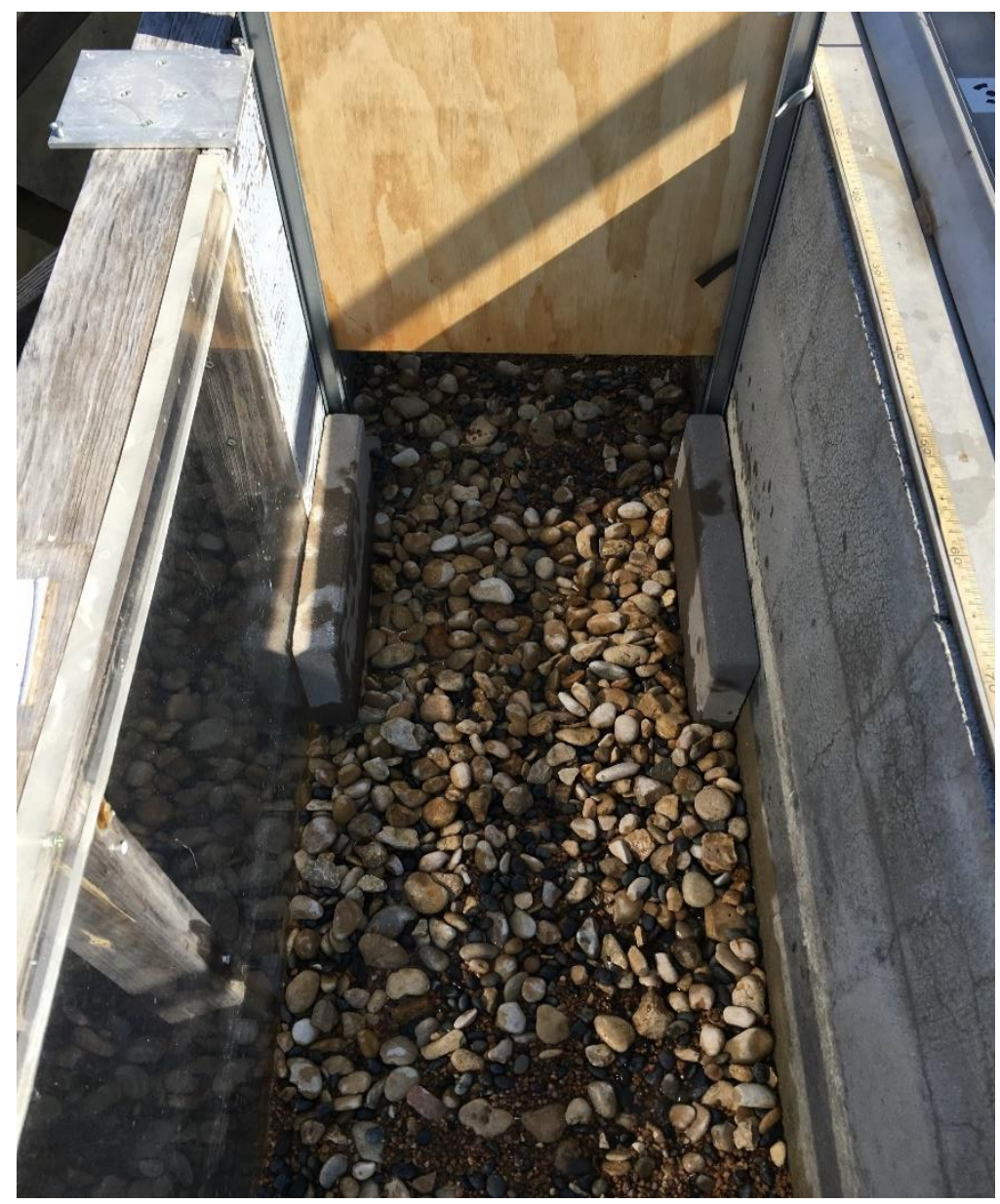

Figure 4.13. (b): Gate with expansion, plan view 


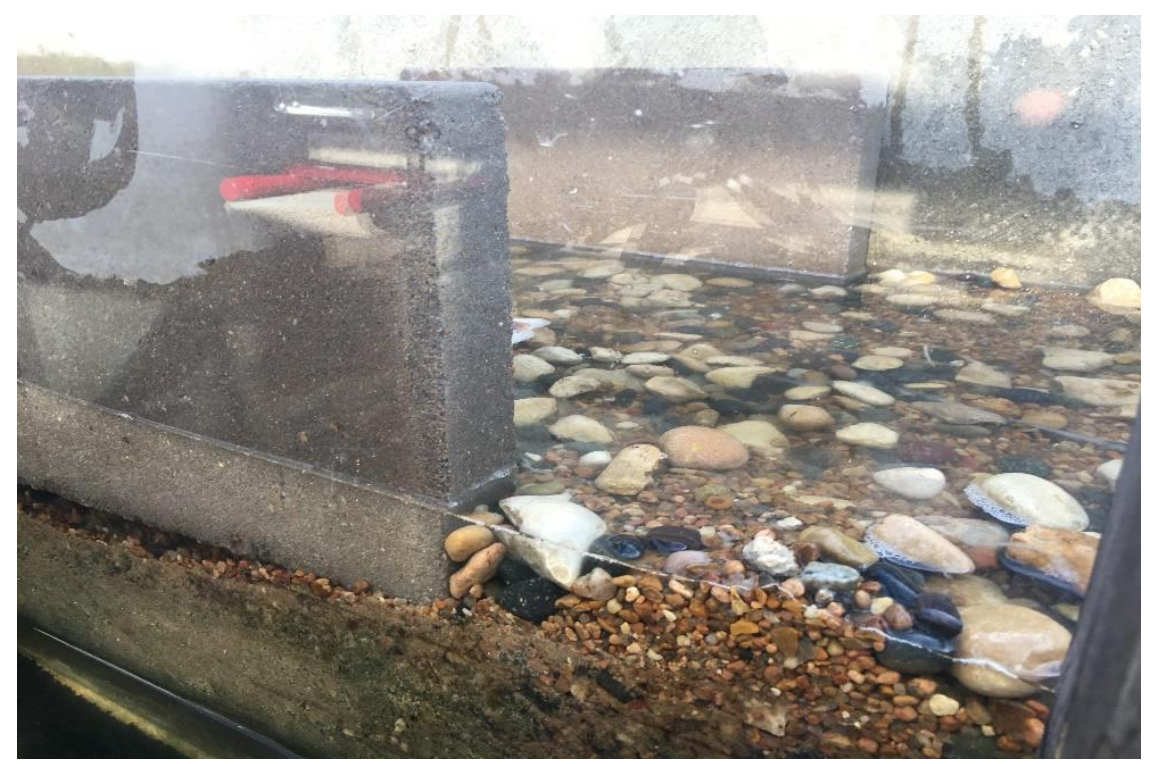

Figure 4.14. (a): Gate with contraction, section view

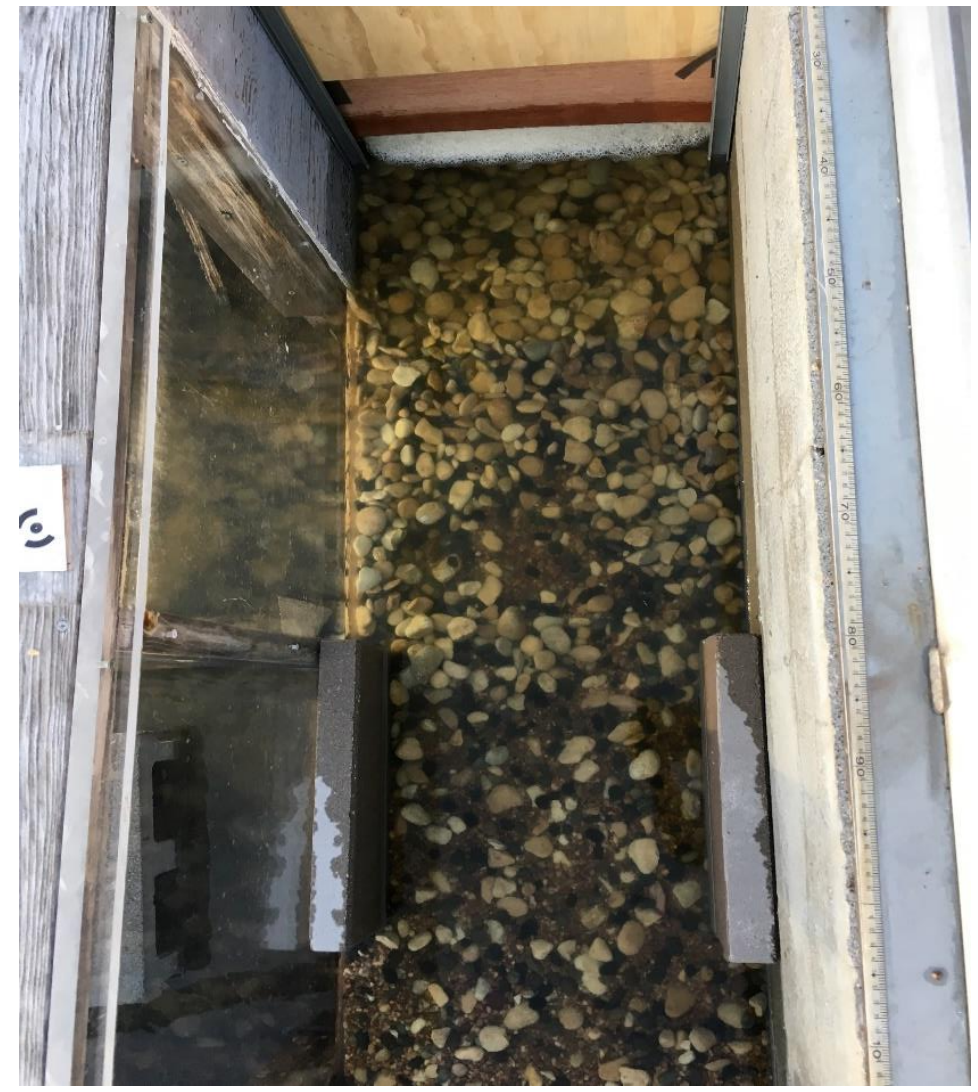

Figure 4.14. (b): Gate with contraction, plan view 


\subsection{REQUIRED MEASUREMENT VARIABLES}

Five variables including the discharge, velocity, depth, temperature, and gate opening have been measured in this research. Velocity and depth were used to calculate flow stability after hydraulic structures. This section introduces the devices which were used to measure these variables and also describes measurement sections.

\subsubsection{Discharge}

A digital flow meter with one digit accuracy (Figure 4.15) was used to calculate the discharge in gallons per minute, which was then converted to cubic meters per second and liters per second in the Fluid Mechanics Laboratory at Florida International University.

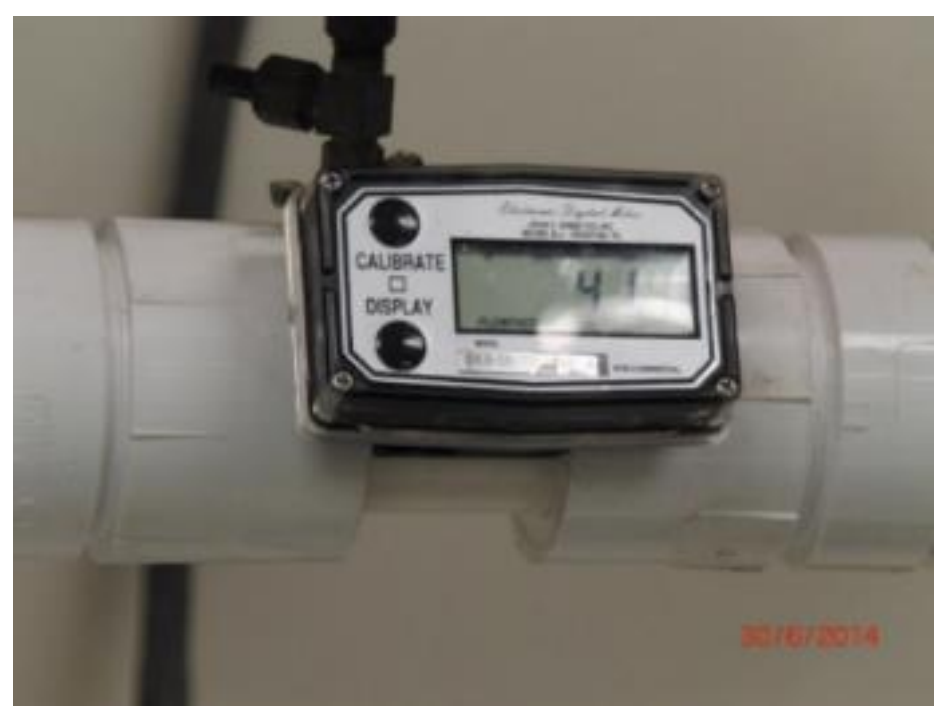

Figure 4.15: Digital flow meter

Ten discharges were used in this research, ranging from low to high levels. The range of discharges has been applied to various hydraulic structures, allowing for their 
hydraulic comparison, performance, and most optimal application. Table 4.3 presents selected discharges for this research.

Table 4.3 Tested Discharges

\begin{tabular}{cccc}
\hline Numbers & $\mathbf{( G P M )}$ & $\left.\mathbf{m}^{\mathbf{3}} / \mathbf{s} \mathbf{( x 1 \mathbf { x } ^ { 3 }}\right)$ & $\mathbf{( \mathbf { m } ^ { 2 } / \mathbf { s } )}$ \\
\hline 1 & 10.0 & 0.63 & 0.0057 \\
\hline 2 & 15.0 & 0.95 & 0.0086 \\
\hline 3 & 27.7 & 1.75 & 0.0159 \\
\hline 4 & 34.6 & 2.18 & 0.0198 \\
\hline 5 & 41.4 & 2.61 & 0.0237 \\
\hline 6 & 47.5 & 3.00 & 0.0270 \\
\hline 7 & 53.2 & 3.36 & 0.0305 \\
\hline 8 & 61.2 & 3.86 & 0.0350 \\
\hline 9 & 70.2 & 4.43 & 0.0400 \\
\hline 10 & 74.5 & 4.70 & 0.0427 \\
\hline
\end{tabular}

These discharges have been used to train the ANN between discharge, upstream depth, gate opening, and stability. Four other discharges have then been used to validate the Neural Network (Table 4.4). Six discharges have been used in the second laboratory (i.e. CRWR, the University of Texas at Austin). Table 4.5 shows these discharges in detail.

Table 4.4 Validation Discharges

\begin{tabular}{cccc}
\hline Numbers & $\mathbf{( G P M )}$ & $\mathbf{m}^{\mathbf{3}} / \mathbf{s} \mathbf{( x 1 0 ^ { \mathbf { 3 } } )}$ & $\left.\mathbf{( m}^{\mathbf{2}} / \mathbf{s}\right)$ \\
\hline 1 & 29.9 & 1.89 & 0.0171 \\
\hline 2 & 38.8 & 2.45 & 0.0222 \\
\hline 3 & 56.8 & 3.58 & 0.0325 \\
\hline 4 & 72.3 & 4.56 & 0.0414 \\
\hline
\end{tabular}


Table 4.5 Discharges

\begin{tabular}{ccc}
\hline Numbers & $\mathbf{m}^{\mathbf{3}} / \mathbf{s}\left(\mathbf{x} \mathbf{1 0} \mathbf{3}^{\mathbf{3}}\right)$ & \multicolumn{1}{c}{ Structures } \\
\hline 1 & 18.94 & Gate, Gate with expansion, Gate with contraction \\
\hline 2 & 25.66 & Gate, Gate with expansion, Gate with contraction \\
\hline 3 & 32.20 & Gate, Gate with expansion, Gate with contraction \\
\hline 4 & 52.39 & Gate \\
\hline 5 & 69.57 & Gate \\
\hline 6 & 89.66 & Gate \\
\hline
\end{tabular}

\subsubsection{Depth}

Depth is needed to describe the water surface and also to define the total energy or specific energy. A point gauge of \pm 1 millimeters reading accuracy was used as common depth measurement equipment in the laboratory, and to measure the water depth upstream and downstream (Figure 4.5) in the Fluid Mechanics Laboratory at Florida International University. Each depth was measured three times (in centimeters) to enhance statistical reliability, and the average value of these three measurements was used as the depth in calculations (in meters). A photo was taken for each test to enhance the accuracy of the work; then, if there were doubts about the depth, the picture was inserted into the ArcGIS and the required depths were determined with a high degree of precision. The point gauge was located at three sections in the gate structure and four sections in the gate with expansion and the gate with contraction structures. The first section was located 40 centimeters upstream of the gate for all measurements. The location of the other sections was related to the type of the hydraulic structure. In a gate with an expansion and a gate with a contraction hydraulic structure, the second section was in the structure, and the third and the fourth sections were located after the hydraulic structures. In the "gate" hydraulic structure, the second section was located after the gate (i.e. after the hydraulic structure), also the third section was located 
downstream of the second section. The same procedure was used to measure depth in the second laboratory. The depth measurement sections are presented in Table 4.6.

Table 4.6 Structures and Measurement Sections

\begin{tabular}{ccccc}
\hline Structure type & Section 1 & Section 2 & Section 3 & Section 4 \\
\hline Vertical gate & $\begin{array}{c}\text { Before } \\
\text { the gate }\end{array}$ & $\begin{array}{c}\text { Middle of the } \\
\text { jump }\end{array}$ & - & Downstream \\
\hline Contraction with vertical gate & $\begin{array}{c}\text { Before } \\
\text { the gate }\end{array}$ & $\begin{array}{c}\text { Middle of the } \\
\text { contraction }\end{array}$ & $\begin{array}{c}\text { After } \\
\text { the } \\
\text { contraction }\end{array}$ & Downstream \\
\hline Expansion with vertical gate & $\begin{array}{c}\text { Before } \\
\text { the gate }\end{array}$ & $\begin{array}{c}\text { Middle of the } \\
\text { expansion }\end{array}$ & $\begin{array}{c}\text { After } \\
\text { the } \\
\text { expansion }\end{array}$ & Downstream \\
\hline
\end{tabular}

Furthermore, the amount of the gate opening was measured in all experiments. Estimating the optimum gate opening is the purpose of this research. The optimum gate opening happens when the flow downstream of the hydraulic structure is stable and is in a safe condition. This factor has been measured in the same way as the depth (in centimeters) and with a reading accuracy of \pm 1 millimeters by a point gauge in both laboratories. The value of the gate opening indicates the distance between the bottom of the channel and the bottom part of the vertical gate.

\subsubsection{Velocity}

Velocity was measured in all experiments to find the total energy. Moreover, this variable was considered carefully and was compared with allowable velocity in channels to avoid sediment transport. A digital velocity meter with one digit accuracy 
was used in this research to determine the velocity in meters per second (both laboratories). Figure 4.16 shows the digital velocity meter.

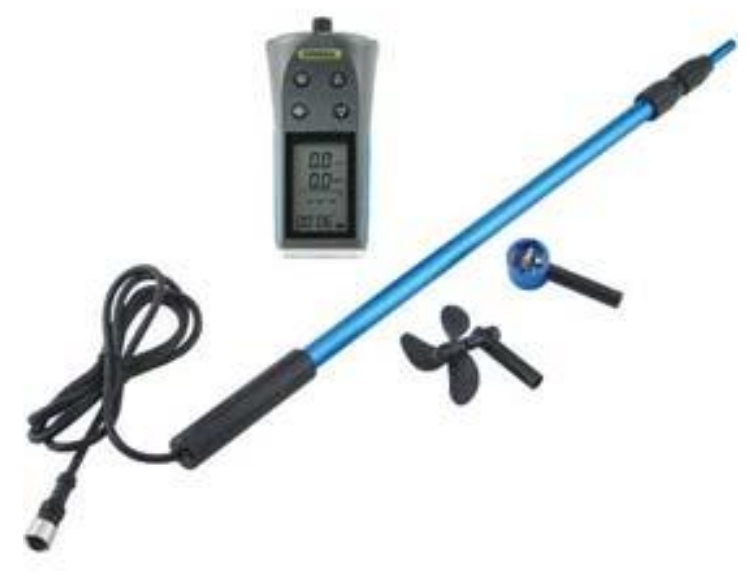

Figure 4.16: Digital velocity meter (globalindustrial.com)

The sections which were used to measure depth were also used to determine velocity (Table 4.6). Velocity was measured using two methods. When the depth was deep (high discharge), the velocity was measured at 0.2 and 0.8 depth from the surface and the average of these two values was used as velocity. On the other hand, when the depth was not deep enough, the velocity was only measured at 0.6 depth from the surface. All measurements were repeated three times to reduce the error and the average of these three measurements were used as velocity in the calculations.

\subsubsection{Temperature}

The Reynolds number is affected by temperature; therefore, this variable was measured in all the experiments. A digital thermometer with one digit accuracy was used in the 
first laboratory (FIU) to measure the temperature in Celsius $\left({ }^{\mathrm{OC}}\right)$. The thermometer is presented in Figure 4.17. In the second laboratory (CRWR - UT Austin), the velocity meter (Figure 2.16) was used to measure the temperature with one digit accuracy, again in Celsius $\left({ }^{\mathrm{OC}}\right)$. This device can measure temperature as well as velocity. The sections which were used to measure depth were also used to determine the temperature in both laboratories (Table 4.6).

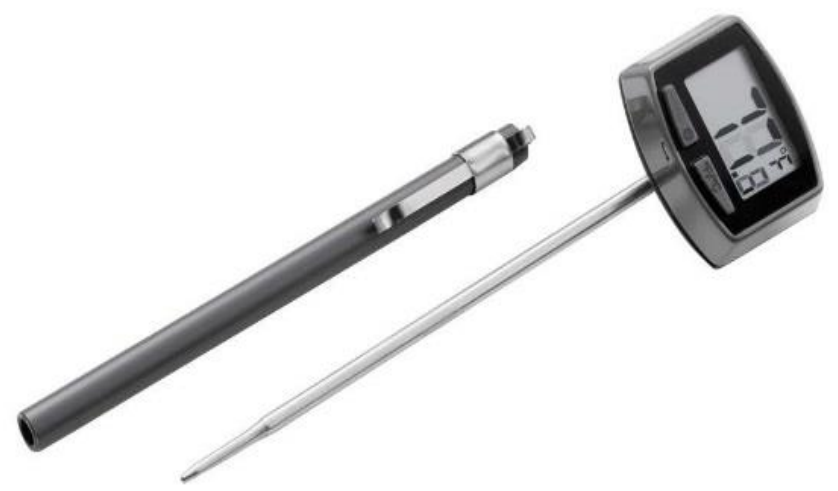

Figure 4.17: Digital thermometer (homedepot.com)

\subsubsection{Flow Pattern}

The flow pattern is one of the most important factors in determining the downstream flow stability of the hydraulic structures based on both definitions previously presented in this chapter. Pictures and movies were captured and recorded by a high-speed camera 
which can take pictures at 40 frames per second and record a movie at up to 1000 frames per second to allow careful consideration of the flow pattern. Moreover, two kinds of tripods, long and short, with the flexibility to set in different angles, as well as a 1000 lumen LED portable work light, have been used in this study to enhance the quality of the pictures and movies. Figures $4.18 \mathrm{a}$ and $\mathrm{b}$ illustrate the high-speed camera with the tripod and the portable work light, respectively.

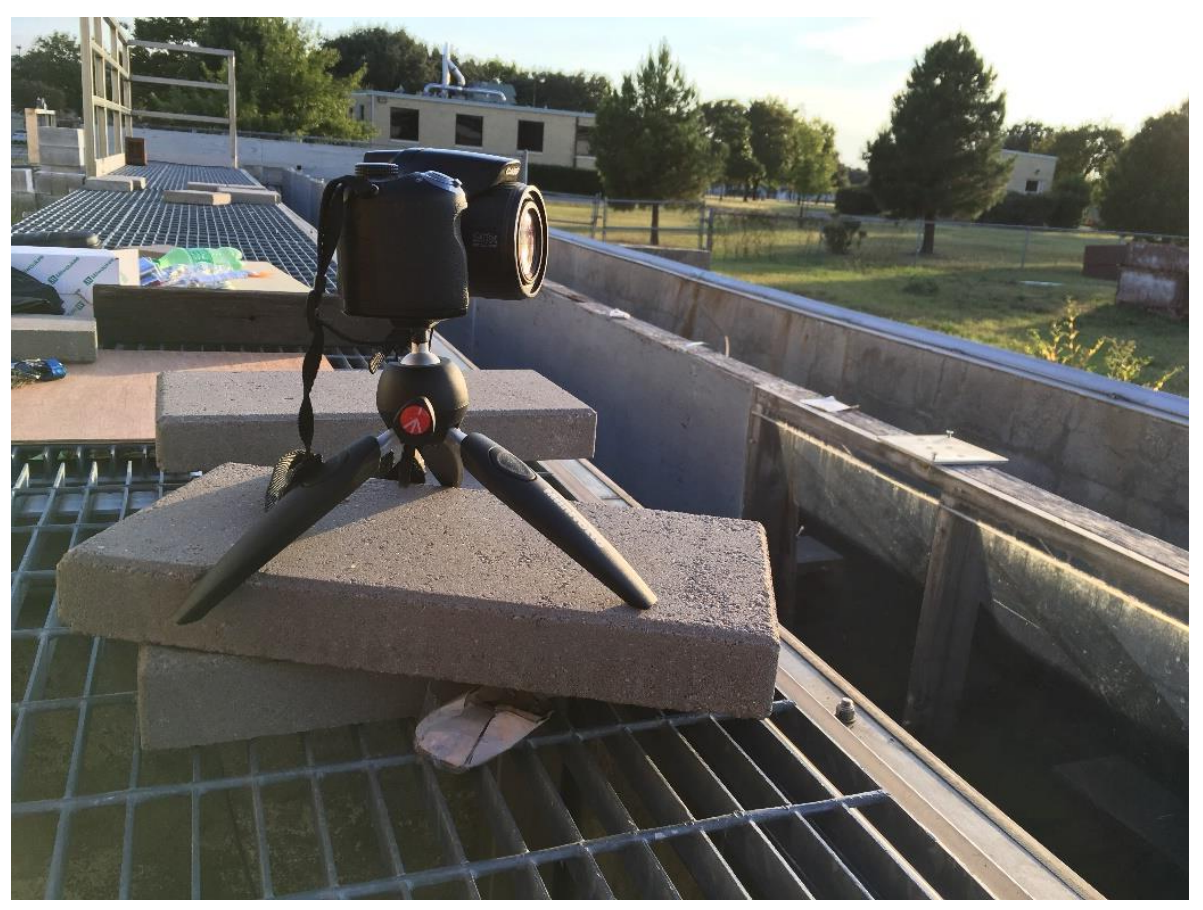

Figure 4.18. (a): A high-speed camera and tripod 


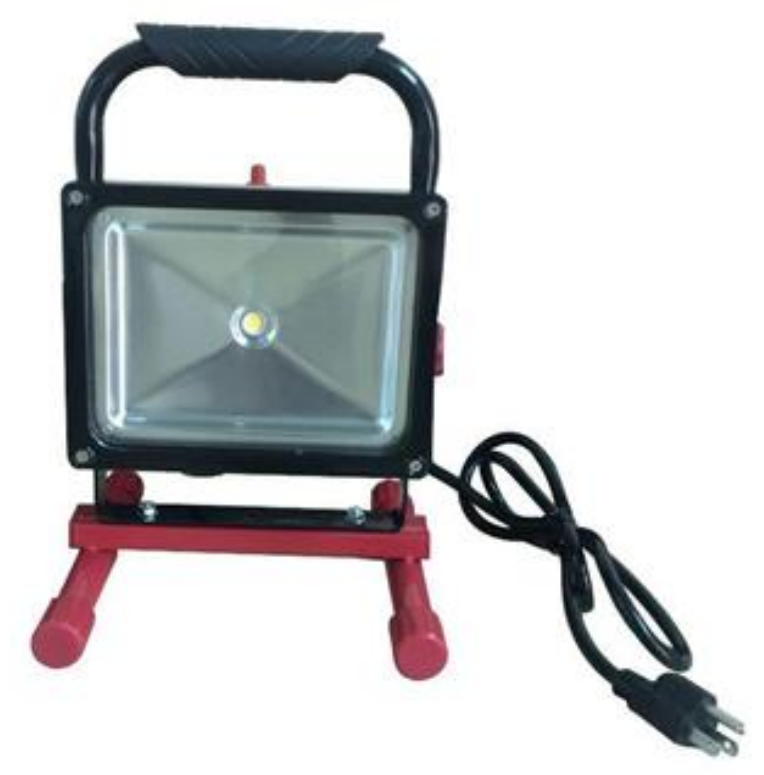

Figure 4.18. (b): 1000 lumen LED portable work light (homedepot.com)

\subsection{ARTIFICIAL INTELLIGENCE METHODS}

Two artificial intelligence methods, the Fuzzy Concept and the Artificial Neural Network (ANN), have been used in this study to define the stability concept and predict the amount of the gate opening.

\subsubsection{The Fuzzy Concept}

The Fuzzy Concept has been used to define flow stability types (flow categories) downstream of the vertical gates in sections 4.1 and 4.2. When the flow experienced a hydraulic jump that means that the flow is completely unstable and the stability number is not defined in supercritical flow. On the other hand, when the flow is sub- critical and the velocity is low, the flow is completely stable $(100 \%)$ and the assigned stability 
number for this type of flow is "1." Between these two flow types, there are some other types of flow with an assigned stability number of more than zero and less than one. This concept is borrowed from the Fuzzy Concept, which was introduced by Zadeh [153].

\subsubsection{Artificial Neural Network (ANN)}

In this research, the Artificial Neural Network toolbox in MATLAB was used to predict the amount of the gate opening. The stability parameter and the unit discharge are imported as inputs and the upstream depth over the gate opening is calculated as output using Multi-Layer Perceptron (MLP) in ANN. Two layers with ten neurons in each layer were used to create the network. This method, however, does not result in very accurate results when there is not a lot of data, and it needs some corrections to reduce error. Therefore, a regression-based post-processing method has been introduced and applied in this study to reduce error. The results indicate that the post-processing method effectively works when fewer data points are available. Various statistical methods (e.g., RMSE and Nash-Sutcliff) have been used to determine model accuracy. The details of the ANN network and the post-possessing method which were used are presented in the results and discussion chapter.

\subsection{DIMENSIONLESS PARAMETERS}

The first step in calculating the optimum hydraulic structure is determining all relevant dimensionless parameters. The Buckingham Pi Theorem has been used to find effective dimensionless parameters. Some parameters like density, gravitational acceleration, 
upstream depth, critical depth, gate opening, viscosity, downstream depth, and slope are important to develop the most effective dimensionless parameters. For each hydraulic structure, the set of dimensionless parameters has been determined and used in graphs, calculations, and relationships. These sets of dimensionless parameters are introduced and described in their specific sections in the results and discussion chapter. Moreover, two dimensionless numbers are important in this research. The Froude number and the Reynolds number. The Froude number is a ratio of inertia force to gravity force and the Reynolds number is a ratio of inertia force to viscosity force.

$$
\begin{aligned}
& F r^{2}=\frac{\text { Inertia force }}{\text { Geravity force }}=\frac{\text { mass } \times \text { acceleration }}{\text { mass } \times \text { gravity acceleration }} \\
& =\frac{\frac{\text { velocity }}{\text { time }}}{\text { gravity acceleration }} \\
& \frac{\left(\frac{V}{t}\right)}{g}=\frac{V}{t g}=\frac{V}{\frac{D}{V} \times g}=\frac{V^{2}}{D g} \rightarrow F r=\frac{V}{\sqrt{g D}} \\
& R e=\frac{\text { Inertia force }}{\text { Viscosity force }}=\frac{\text { mass } \times \text { acceleration }}{\text { shear stress } \times \text { area }} \\
& =\frac{\text { volume } \times \text { density } \times \frac{\text { velocity }}{\text { time }}}{\text { shear stress } \times \text { area }} \\
& \frac{\frac{\text { volume }}{\text { time }} \times \text { density } \times \text { velocity }}{\text { shear stress } \times \text { area }}=\frac{\text { area } \times \text { velocity } \times \text { density } \times \text { velocity }}{\text { shear stress } \times \text { area }} \\
& \frac{\text { velocity } \times \text { density } \times \text { velocity }}{\text { shear stress }}=\frac{V \rho V}{\mu\left(\frac{d V}{d y}\right)}=\frac{V \rho V}{\mu \frac{V}{L}}=\frac{V \rho}{\frac{\mu}{L}}=\frac{V L}{\frac{\mu}{\rho}}
\end{aligned}
$$




\section{CHAPTER 5}

\section{RESULTS \& DISCUSSION}

\section{SECTION 1}

\section{OPTIMIZING GATE OPENINGS FOR FLOW REGIME CONTROL: EXPERIMENTAL AND ARTIFICIAL NEURAL NETWORK DEVELOPEMENT}

Vertical gates are important structures that control flow characteristics in both downstream and upstream flows in streams and canals. In this investigation, laboratory tests were conducted to find the optimum vertical gate opening as a function of the upstream water level to yield a stable downstream condition. Physical simulations were conducted within a range of discharges for the experimental flume. Fuzzy Concepts were also used to define the Flow Stability Factor. Experimental results were then analyzed via an artificial neural network (ANN) to estimate the optimum gate opening. The ANN results were post-processed via regression analysis to minimize estimation errors. This investigation highlights the potential for optimizing hydraulic performance based on regression-based post-processing ANN to define optimal design, analysis, and operating conditions for hydraulic structures (e.g., gates) in controlling stream flow conditions. 


\subsubsection{Introduction}

Numerous hydraulic structures can be used in rivers and canals to control flow and keep downstream water in a stable and safe flow condition. A common structure is a gate. There are various types of gates, such as vertical gates and radial gates, etc. Vertical gates are easier to design, deploy, and operate. Optimal gate performance will be achieved when the gate opening is set at an optimal value that avoids a hydraulic jump. In fact, small openings can cause a hydraulic jump (or a submerged hydraulic jump). A hydraulic jump is associated with unstable downstream flow conditions and can lead to downstream erosion. To ensure a stable downstream condition, various types of hydraulic jumps and wave flow conditions should be avoided. The best way to avoid this is by setting an optimum gate opening. A comprehensive literature review for sluice gates is presented in chapter two.

Artificial intelligence has also been used in gate operations. Guven and Gunal [154] used genetic programming to predict the scour downstream of gates. They derived equations from linear and non-linear regression, using an analysis of dimensionless parameters. They compared their predictions with experimental results and concluded that the precision of their method is higher than for others. Guven et al. [155] used an artificial neural network method to predict pressure fluctuations during a hydraulic jump at the bottom of a sloped stilling basin. They used a feed forward model with a back propagation algorithm. This model was compared with models based on linear and non-linear regression that had been developed from testing physical models. The results show that the neural network outputs perform better than regression estimates, showing less error. Najafzadeh and Lim [156] used neuro-fuzzy GMDH (Group 
Method of Data Handling) to estimate gates' downstream scour. They used six dimensionless parameters and did sensitivity analysis, defining the effect of each factor on the amount of scour. They also compared the results of the model with regression equations, concluding that their model had less error than other methods.

\subsubsection{Theory}

The vertical gate is a hydraulic structure for conducting and controlling the flow of canals and rivers. Figure 5.1.1 shows a schematic vertical gate.

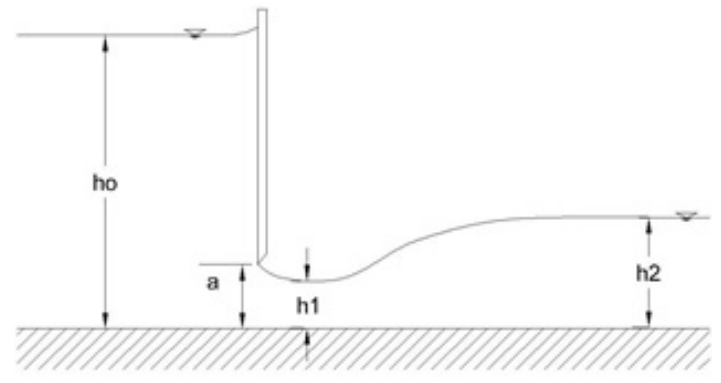

Figure 5.1.1: Free flow under the vertical sluice gate

Discharge can be obtained by the following formula:

$$
Q=C_{d} a b \sqrt{2 g h_{0}}
$$

In this formula, "Q" is the discharge under the gate, "a" is the gate opening, " $b$ " is the length of the gate, "ho" is the upstream depth, "g" is the gravitational acceleration, and " $\mathrm{C} d$ " is the discharge coefficient. Submerged flow is presented in Figure 5.1.2. 


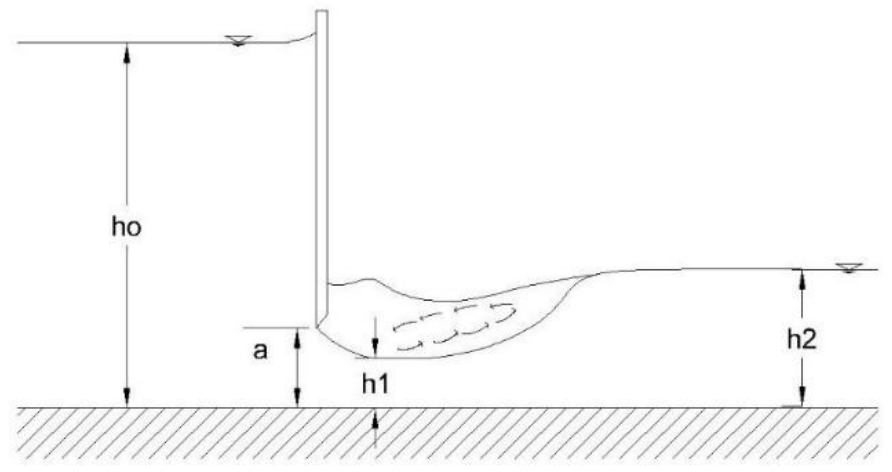

Figure 5.1.2: Submerged flow under the vertical sluice gate

For the submerged flow regime, Henry [30] presented a graph to calculate the discharge coefficient at gates. This researcher also suggested using equation (5.1.1) in submerged flow; $\mathrm{C}_{\mathrm{d}}$ needs to be experimentally determined.

An artificial neural network is a simulation of the human brain. It can be implemented by both electric and computer software. It learns new knowledge, stores this information in connection weights, and uses it to solve problems. Modern artificial neural network research (i.e., ANN) began about 60 years ago [157]. An artificial neural network typically consists of a large number of simple processing units (i.e., neurons) that are mutually interconnected. It learns to solve problems by adequately adjusting the strength of the interconnections according to input data. Moreover, the neural network adapts easily to new environments by learning. It can deal with information that is noisy, inconsistent, vague, or probabilistic [158].

The first ANN model was developed by McCulloch and Pitts [159]. They proposed a neuron model that performs a weighted sum of inputs to the element, followed by a 
threshold logical operation. Hebb [160] proposed a learning scheme for adjusting a connection weight based on pre- and post-synaptic variable values. Minsky [161] developed a learning machine in which the connection strength could be automatically adapted. Rosenblatt [162] proposed that a perception model that has adjustable weights be the perception learning law. Minsky and Papert [163] produced a multilayer perceptron (MLP) to solve difficult problems. Hopfield [164] developed an energy analysis for feedback neural networks.

The MLP is made up of elements or perceptrons that are based on the McCulloch and Pitts [159] model of a simple human neural. The perceptron units are made up of multiple inputs linked via weighted connections (synapses or weights) to summing and nonlinear squashing functions. When perceptrons are connected in a network with more than one layer, the subsequent structure is called an MLP (Figure 5.1.3). MLPs, with the correct weight configurations, can be used to solve many problems in pattern recognition, system identification, and time series prediction. The strength of the MLP is that the underlying rules of the function do not need to be known prior to network training (i.e., finding the relationship between inputs and outputs in a black box). During the training process, assuming there is a representative training data set, the network extracts the mapping function in its internal representation, thus obtaining a solution. The simplicity of this solution adds to its usefulness. It is important to note, however, that in some applications it is necessary to know how the task has been solved. The black-box nature of the MLP can be a drawback rather than a strength [165]. 


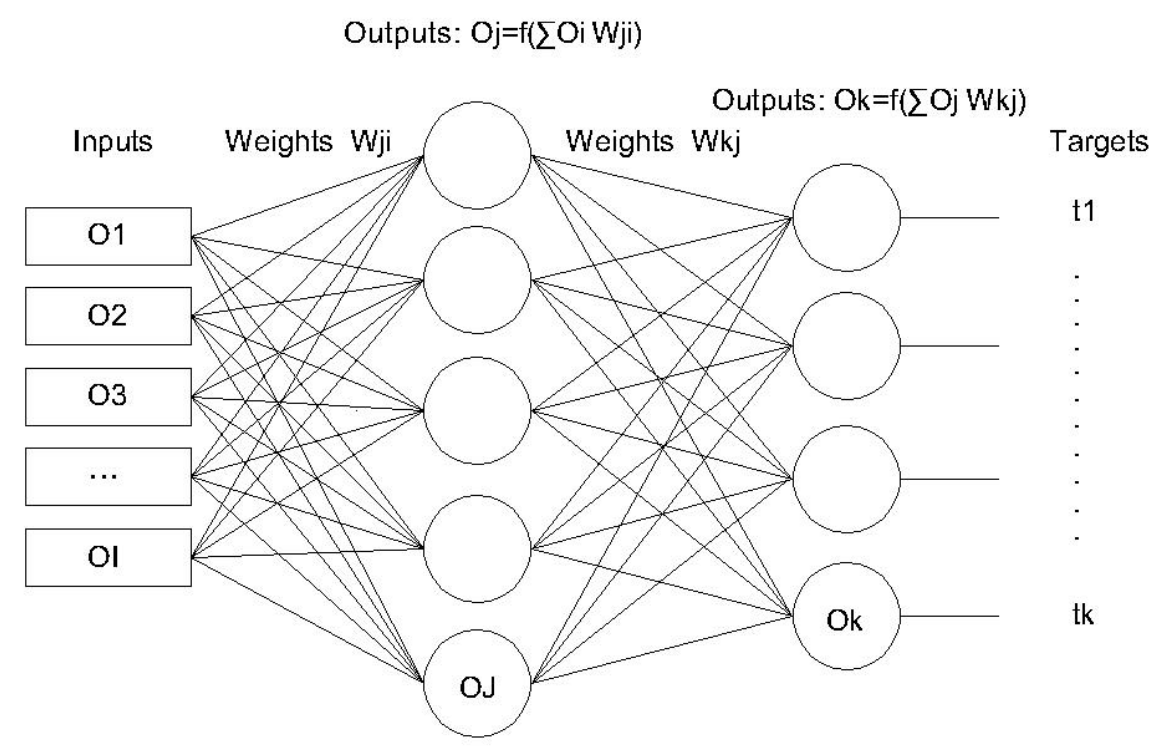

Figure 5.1.3: Neural Network, MLP

\subsubsection{Experiments}

A total of 73 experiments (14 discharges) were conducted in this research to find the optimum gate opening for each discharge, which leads to a stable downstream flow condition. These experiments were performed in a narrow flume, located at the Fluid Mechanics Laboratory of the Civil and Environmental Engineering Department of Florida International University. The details of the flume and measurement devices are presented in chapter 4.

Ten discharges were tested in this research and are presented in Table 4.3, ranging from low to high levels. For each discharge, various gate openings (i.e., 59 tests) were looked at to determine the acceptable gate opening range. These discharges were used to train the Artificial Neural Network between discharge, upstream depth, and gate opening; 
then, four other discharges (i.e., 14 tests) were used to validate the Neural Network (Table 4.4).

Finding the optimum gate opening for each upstream depth and discharge is the purpose of this research. The optimum gate opening is obtained when the flow condition is stable in the downstream section, and consequently, it is necessary to define a stable condition in the downstream section. Depending on the gate opening, different conditions can occur downstream, such as a hydraulic jump, a submerged hydraulic jump, a wave, or a stable condition.

The Flow Stability Factor is defined in chapter 4, based on the Fuzzy Concept, to classify the downstream flow condition and consequently determine the optimum gate opening (Table 4.1).

For each discharge, various gate openings were examined. For each gate opening, the downstream flow condition was recorded. The first step in calculating the optimum gate opening is to determine all relevant dimensionless parameters.

Unit discharges and dimensionless parameters were applied in this study; therefore, the results can be used in real streams and rivers. However, a scale effect should be taken into account to validate the results or to find a correction factor for the outcomes due to the small dimensions used in this research. Roth and Hager [1] noted that due to fluid viscosity, channel width has an effect on the minimum gate opening. They stated that for any channel width and with inviscid flow, for the Froude similarity to apply, a gate opening of at least approximately 50 millimeters is required. Also, they reported that narrower channels need a higher minimum gate opening. The flume which was used in this research was narrow (11 centimeters), and some gate openings were less than the 
minimum gate opening reported by Roth and Hager [1]. It should be noted that Roth and Hager's claim is based on fluid viscosity which can vary with temperature and water quality. The flow classification which is used in this research can be applied in larger scale models.

\subsubsection{Neural Network}

The neural network toolbox (i.e., nntool) in Matlab was used to create a network for predicting the optimum gate opening. The critical depth and upstream depth are network inputs, and "a" is the network output. First, stable conditions were separated from all the tests. A network was then generated for eight critical depths, and four other critical depths were used to validate the network. The characteristics of the neural network are as follows:

Multi-layer perceptron (MLP);

Inputs: unit discharge and Flow Stability Factor;

Target: $\mathrm{h}_{0} / \mathrm{a}$;

Network type: Feed-forward backprop;

Training function: TRAINLM;

Adaption learning function: LEARNGDM;

Performance function: MSE;

Number of layers: 2;

Property for the first layer: 10 Neurons;

Property for the second layer: 10 Neurons; and

Transfer function: PURELIN. 
An artificial intelligence network was created to predict the optimum gate opening for each condition. Matlab software was used to create an artificial intelligence network.

\subsubsection{Dimensional Analysis}

The Buckingham Pi Theorem was used to find effective dimensionless parameters.

Some parameters like density, gravitational acceleration, upstream depth, critical depth, gate opening, viscosity, downstream depth, and slope are important in developing the most effective dimensionless parameters.

After proper consideration, the effect of viscosity is determined to be negligible. In addition, only one slope (the horizontal slope) was used as a parameter in this analysis; therefore, it can be disregarded. To determine the gate opening (a), density, gravitational acceleration, upstream depth, critical depth, and downstream depth are all important variables.

The MLT (mass-length-time) system of fundamental variables was used here to develop a fundamental relationship among dimensionless parameters that should best represent the flow behavior of interest:

$$
\begin{gathered}
k=6 \rightarrow\left(\rho, g, h_{0}, d c, h_{2}, a\right) \\
r=3 \rightarrow\left(\rho, g, h_{0}\right) \\
\pi=k-r=3 \\
\pi_{1}=\frac{d c}{h_{0}} \\
\pi_{2}=\frac{h_{2}}{h_{0}}
\end{gathered}
$$




$$
\begin{gathered}
\pi_{3}=\frac{h_{0}}{a} \\
\left(\frac{d c}{h_{0}}, \frac{h_{2}}{h_{0}}, \frac{h_{0}}{a}\right)
\end{gathered}
$$

Dimensionless parameters, $\mathrm{dc} / \mathrm{h}_{0}$, and $\mathrm{h}_{0} / \mathrm{a}$, were used to calculate "a."

\subsubsection{Results and Discussion}

Fifty-nine (59) tests were conducted in the laboratory, and an additional 14 tests were carried out for validation. The outcomes of all experiments are reported in Tables C.1 and C. 2 in Appendix C. After measuring the upstream depth $\left(\mathrm{h}_{0}\right)$ and the gate opening (a) for each discharge, the $\mathrm{h}_{0} / \mathrm{a}$ can then be determined. Tables 5.1.1 and 5.1.2 contain both the acceptable stability and the $\mathrm{h}_{0} / \mathrm{a}$ ratio for each discharge.

Table 5.1.1 Acceptable Stability for Each Test Discharge

\begin{tabular}{cccc}
\hline Unit Discharge & Discharge $\left(\mathbf{m}^{\mathbf{3}} / \mathbf{s}\left(\mathbf{x 1 0 ^ { 3 }}\right)\right)$ & Flow Stability Factor & ho/a \\
\hline 0.0057 & 0.63 & & \\
\hline 0.0086 & 0.93 & 0.8 & 4.16 \\
\hline 0.0159 & 1.75 & 0.8 & 1.96 \\
\hline 0.0198 & 2.18 & 0.8 & 1.60 \\
\hline 0.0237 & 2.61 & 0.8 & 1.57 \\
\hline 0.0270 & 3.00 & 0.9 & 1.55 \\
\hline 0.0305 & 3.36 & 0.9 & 1.45 \\
\hline 0.0350 & 3.86 & 0.9 & 1.37 \\
\hline 0.0400 & 4.43 & 0.9 & 1.31 \\
\hline 0.0427 & 4.70 & &
\end{tabular}


Table 5.1.2 Acceptable Stability for Validation Discharges

\begin{tabular}{cccc}
\hline Unit Discharge & Discharge $\left(\mathbf{m}^{\mathbf{3}} / \mathbf{s}\left(\mathbf{x 1 0} \mathbf{3}^{\mathbf{3}}\right)\right.$ & Flow Stability Factor & $\mathbf{h} \mathbf{0} / \mathbf{a}$ \\
\hline 0.0171 & & & 3.33 \\
\hline 0.0222 & 1.89 & 0.8 & 1.96 \\
\hline 0.0326 & 2.45 & 0.8 & 1.46 \\
\hline 0.0415 & 3.58 & 0.9 & 1.28 \\
\hline
\end{tabular}

As can be seen in Table 5.1.1, the first and second discharge stability cells are blank, because these discharges are too low, and for every gate opening (even those that are smaller than 1 centimeter), the downstream condition is stable. Figures 5.1.4 (a to d) illustrate some representative downstream conditions after the gate.

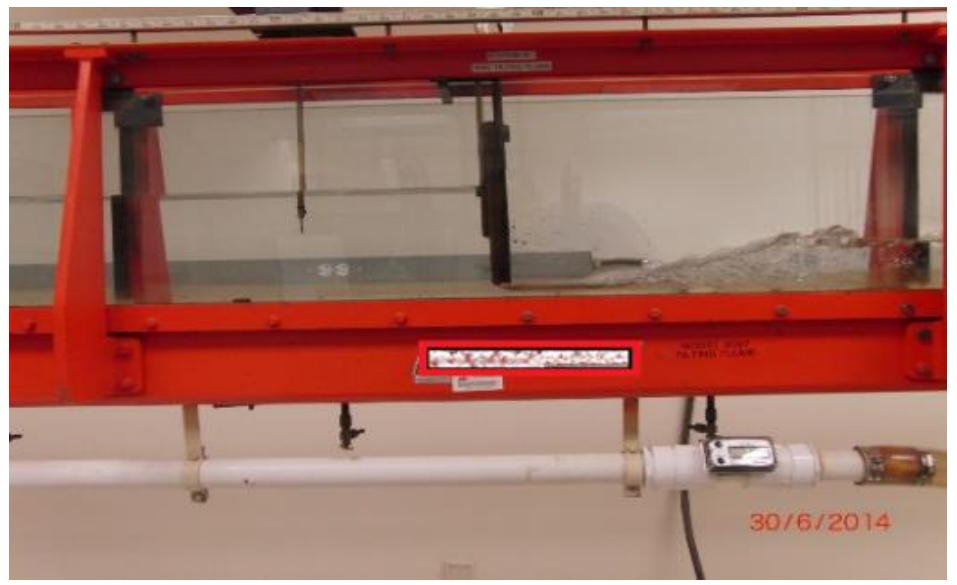

Figure 5.1.4. (a): Hydraulic jump after the gate $(\mathrm{St}=0)$ 


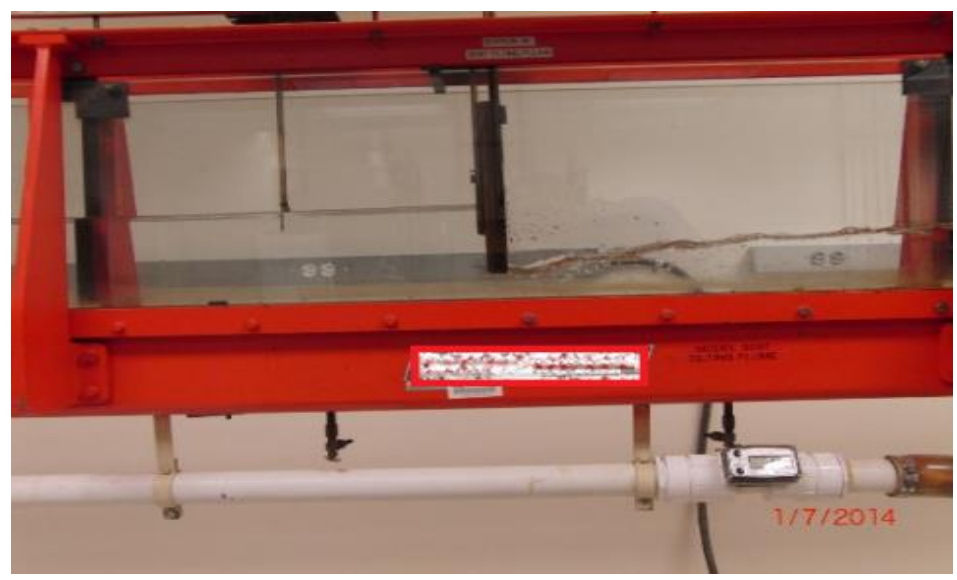

Figure 5.1.4. (b): Submerged hydraulic hump after the gate $(\mathrm{St}=0.2)$

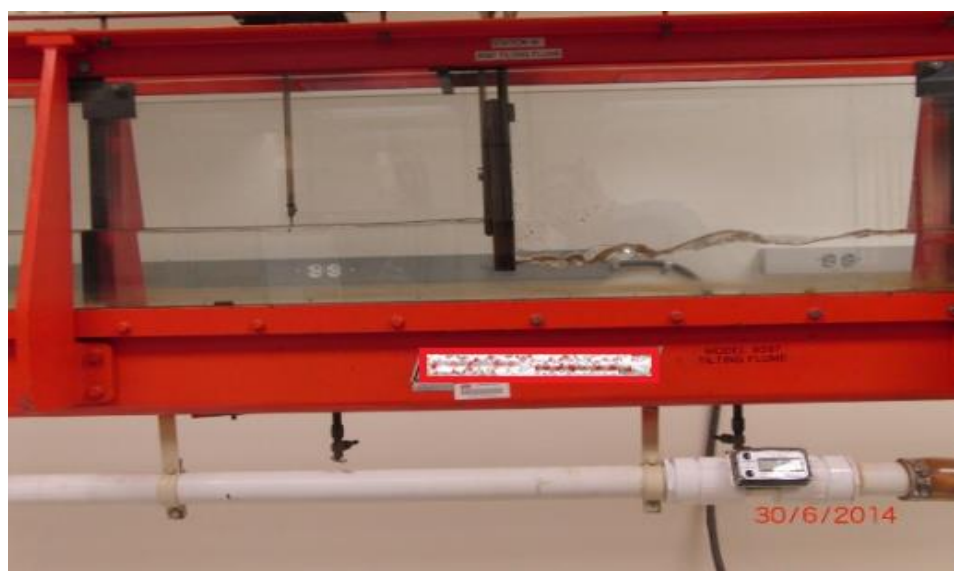

Figure 5.1.4. (c): Strong wave after the gate $(\mathrm{St}=0.6)$

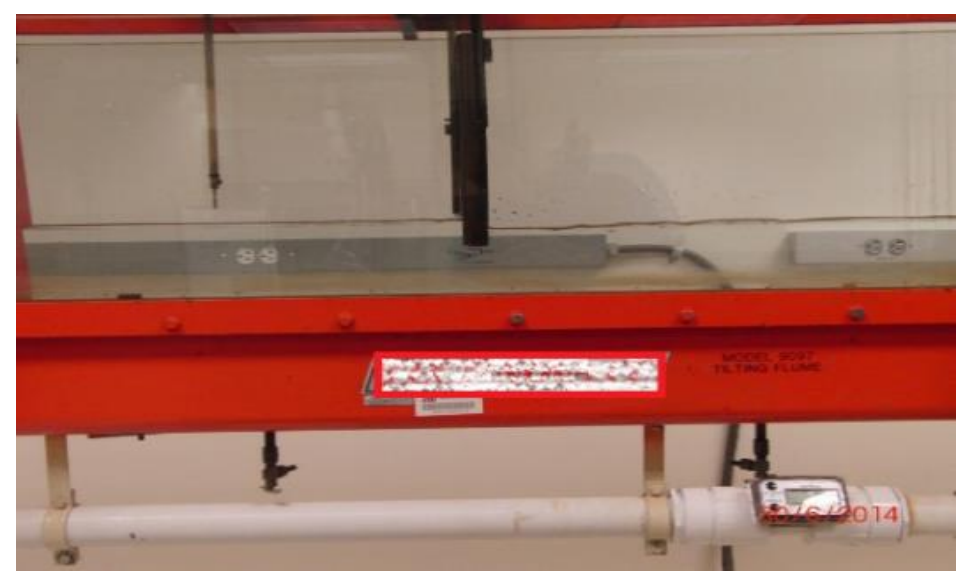

Figure 5.1.4. (d): Stable condition after the gate $(\mathrm{St}=1)$ 
Among the tests, eight tests were selected because they yielded a stable condition boundary for each discharge. They were used to create a neural network. Training data is highlighted in Table 5.1.3. Four discharges were used to test the network; specific data is provided in Table 5.1.4. A graph of $h_{0} /$ a versus $d c / h_{0}$ is drawn (Figure 5.1.5). The dimensionless parameter $\mathrm{dc} / \mathrm{h}_{0}$ determines discharge and upstream depth and provides an $h_{0} / a$ value; from $h_{0} / a$, the size of the gate opening can then be obtained.

Table 5.1.3 Data Used to Train the Network

\begin{tabular}{ccccc}
\hline Number & $\begin{array}{c}\mathbf{q} \\
\left(\mathbf{m}^{2} / \mathbf{s}\right)\end{array}$ & $\begin{array}{c}\mathbf{h}_{\mathbf{0}}(\mathbf{c m}) \\
\text { Input }\end{array}$ & $\begin{array}{c}\text { dc (cm) } \\
\text { Input }\end{array}$ & $\begin{array}{c}\text { a (cm) } \\
\text { Target }\end{array}$ \\
\hline 1 & 0.0159 & 10.4 & 3.0 & 2.5 \\
\hline 2 & 0.0198 & 8.8 & 3.4 & 4.5 \\
\hline 3 & 0.0237 & 8.8 & 3.9 & 5.5 \\
\hline 4 & 0.0272 & 9.4 & 4.2 & 6.0 \\
\hline 5 & 0.0305 & 9.3 & 4.6 & 6.0 \\
\hline 6 & 0.0351 & 9.4 & 5.0 & 6.5 \\
\hline 7 & 0.0403 & 9.6 & 5.5 & 7.0 \\
\hline 8 & 0.0427 & 9.8 & 5.7 & 7.5 \\
\hline
\end{tabular}

Table 5.1.4 Data Used to Test the Network

\begin{tabular}{ccccc}
\hline Number & $\begin{array}{c}\mathbf{q} \\
\left(\mathbf{m}^{2} / \mathbf{s}\right)\end{array}$ & $\begin{array}{c}\mathbf{h}_{\mathbf{0}}(\mathbf{c m}) \\
\text { Input }\end{array}$ & $\begin{array}{c}\text { dc (cm) } \\
\text { Input }\end{array}$ & $\begin{array}{c}\text { a (cm) } \\
\text { Target }\end{array}$ \\
\hline 1 & 0.0171 & 10.0 & 3.1 & 3.0 \\
\hline 2 & 0.0222 & 8.8 & 3.7 & 4.5 \\
\hline 3 & 0.0321 & 9.5 & 4.8 & 6.5 \\
\hline 4 & 0.0415 & 9.6 & 5.6 & 7.5 \\
\hline
\end{tabular}




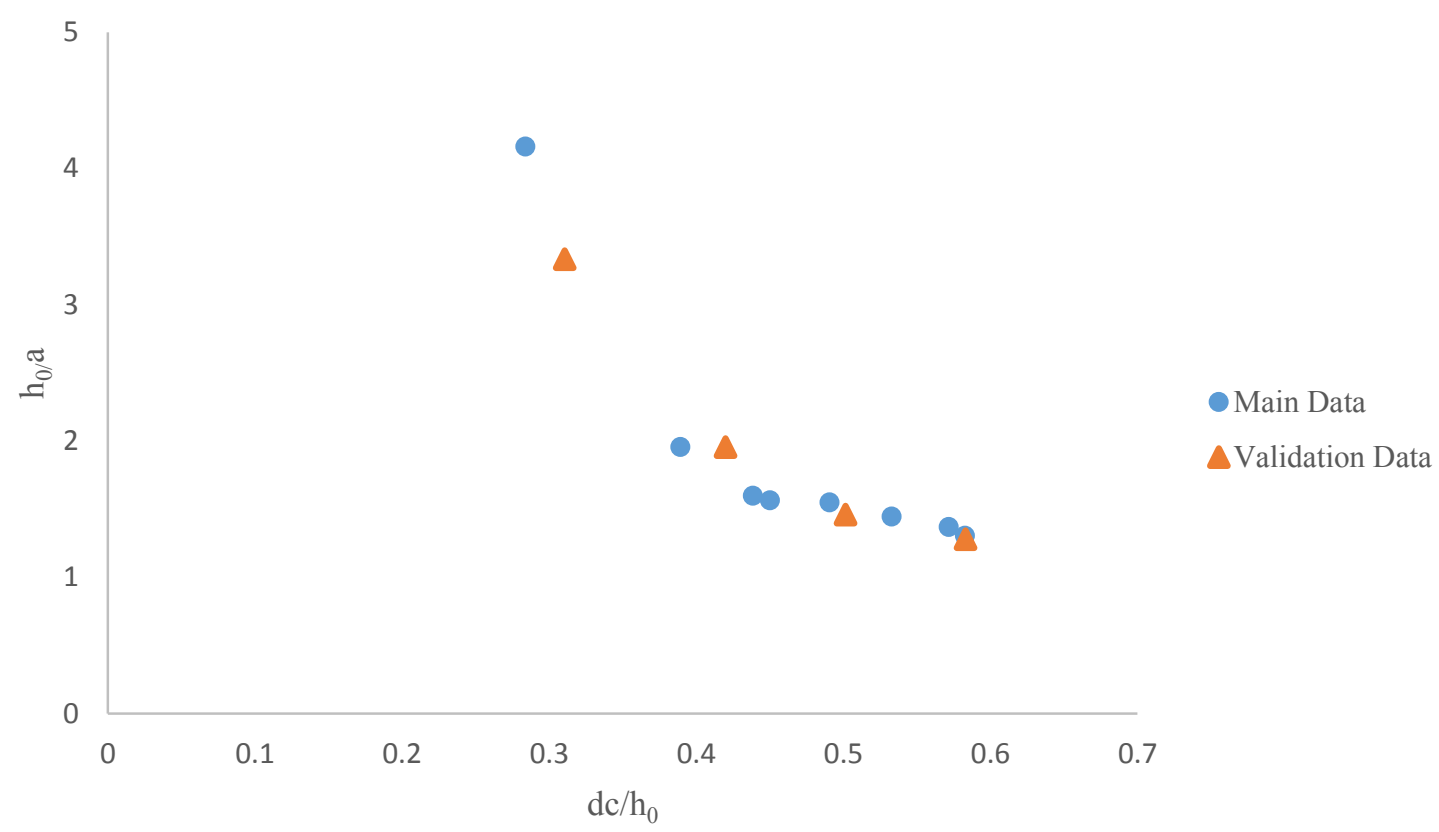

Figure 5.1.5: $\mathrm{h}_{0} / \mathrm{a}-\mathrm{dc} / \mathrm{h}_{0}$ graph

An Artificial Neural Network has been used in this research to show that this powerful technique can be used in hydraulic engineering and predicting gate openings. Data in Tables 5.1.3 and 5.1.4 were respectively used to both train the neural network and to test the created network. The average difference for the four discharges is $4.87 \%$. The maximum difference is $12.00 \%$, and the minimum difference is $0.00 \%$ (Table 5.1.5).

Table 5.1.5 Results of the Neural Network

\begin{tabular}{|c|c|c|c|c|}
\hline Number & $\underset{\left(\mathbf{m}^{2} / \mathbf{s}\right)}{\mathbf{q}}$ & Real a & a (A.N.N) & $\begin{array}{c}\text { Difference } \\
\%\end{array}$ \\
\hline 1 & 0.0171 & 3.0 & 3.00 & 0.00 \\
\hline 2 & 0.0222 & 4.5 & 5.04 & 12.00 \\
\hline 3 & 0.0326 & 6.5 & 6.16 & 5.23 \\
\hline 4 & 0.0415 & 7.5 & 7.33 & 2.27 \\
\hline
\end{tabular}


Some researchers have used pre-processing methods, like principal component analysis (PCA) for linear data and nonlinear principal component analysis (NLPCA) for linear or nonlinear data $[166,167,168,169]$ to reduce the number of components, upgrade the quality of learning for the network, and improve the network's speed of learning. Postprocessing in the artificial neural network (ANN) was herein done by polynomial regression to reduce the difference percentage. The latter means that data obtained from experimental tests enter into the ANN and instead of pre-processing with PCA or NLPCA to obtain a better network or to reduce error, a regression-based post-processing method was used. Different types of regressions were applied to the results (outputs) of ANN. However, polynomial regression was ultimately selected because it shows the best fit and gives the minimum error. Although ANN sometimes has good predictive power with a small amount of data, the result of the prediction is much more accurate with more data because of better network learning [158]; as a result, ANN is not very accurate with a small amount of data. Applying the regression-based post-processing method to ANN results gives an accurate enough prediction with the available data. The $\mathrm{h}_{0} / \mathrm{a}-\mathrm{dc} / \mathrm{h}_{0}$ graph was drawn from the results of the neural network, and nonlinear regressions were then applied to the graph (Figure 5.1.6). Some nonlinear regression methods have been used to find the curve fit with a high coefficient of determination. Table 5.1.6 listed the regression methods which have been used in post-processing and reported the coefficient of determination for each of them. Based on the results of Table 5.1.6, Michaelis-Menten (Rectangular Hyperbola) with a coefficient of determination of 0.9978 was selected to use in postprocessing. 
Table 5.1.6 Nonlinear Regression Methods

\begin{tabular}{ccccc}
\hline Number & Method* & Type & Formula & $\mathbf{R}^{\mathbf{2}}$ \\
\hline 1 & Four Parameter Logistic Curve & Symmetrical Sigmoidal & $y=d+\frac{a-d}{1+\left(\frac{x}{c}\right)^{b}}$ & 0.9973 \\
\hline 2 & Michaelis Menten & Rectangular Hyperbola & $y=\frac{V_{\max } x}{k_{m}+x}$ & 0.9978 \\
\hline 3 & Exponential & Basic & $y=a+b e^{-c x}$ & 0.9965 \\
\hline 4 & Exponential & Half-life & $y=a+\frac{b}{2^{\frac{x}{c}}}$ & 0.9965 \\
\hline 5 & Exponential & Proportional Rate Growth & $y=y_{0}-\frac{v_{0}}{k}\left(1-e^{-k x}\right)$ & 0.9965 \\
\hline 6 & Power & Decrease & & \\
\hline 7 & Gaussian & Power Curve & $y=a x^{b}$ & 0.9656 \\
\hline & & Bell Curve & $y=a e^{\left(-\frac{(x-b)^{2}}{2 c^{2}}\right)}$ & 0.9297
\end{tabular}

*mycurvefit.com

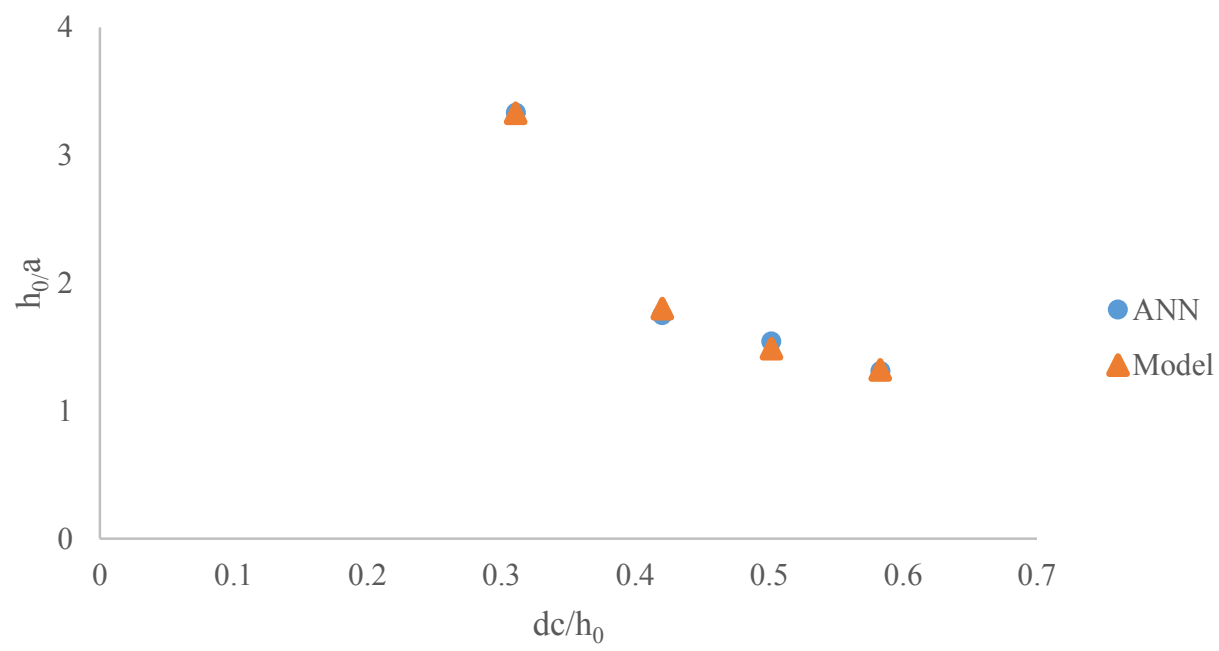

Figure 5.1.6: Post-processing - regression - ANN 
The ANN outcomes for the gate opening have been used in nonlinear regressions to determine the post-processed value for the gate opening in each discharge. Figure 5.1.5 illustrates the ANN and the post-processed model in the dimensionless graph. Furthermore, Table 5.1.7 reported the amount of the gate opening after post-processing. The last column in this table shows the comparison of the real gate opening (column 3) and the gate opening which is obtained from post-processing (column 6) in percentage terms.

Table 5.1.7 Results of Post-Processing on the Neural Network

\begin{tabular}{ccccccc}
\hline Number & dc/ $\mathbf{h}$ & Real a & ho/a & Reg. (ho/a) & Reg.(a) & Difference\% \\
\hline 1 & 0.31 & 3.0 & 3.33 & 3.33 & 3.01 & 0.23 \\
\hline 2 & 0.42 & 4.5 & 1.96 & 1.80 & 4.89 & 8.74 \\
\hline 3 & 0.50 & 6.5 & 1.46 & 1.48 & 6.40 & 1.49 \\
\hline 4 & 0.58 & 7.5 & 1.28 & 1.32 & 7.28 & 2.88 \\
\hline
\end{tabular}

The average difference for the four discharges is $3.33 \%$. The maximum difference is $8.74 \%$, and the minimum difference is $0.23 \%$. Table 5.1 .7 indicates that post-processing decreases the average difference percentage by approximately $1.54 \%$ compared with ANN outcomes. This method also decreases the maximum difference percentage.

To determine the model that is more "effective" across all predictions, the Nash-Sutcliffe Coefficient was calculated for each model application. This coefficient varies from $-\infty$ to 1. Effectiveness, E, which equals 1, defines a perfect similarity between predictions and observations $[14,170]$. Effectiveness, E, which equals 0, defines a situation in which the predictions equal the mean of the observations (equation 5.1.9). Effectiveness within the range $-\infty<\mathrm{E}<0$ happens when the mean of the observations is a better estimator than model predictions. In general, the closer the effectiveness of model predictions to 1 , the 
more accurate the model is [171]. The Nash-Sutcliffe Coefficient in the post-process neural network model is also slightly improved compared with ANN results. (Table 5.1.8).

$$
E=1-\frac{\sum_{i=1}^{n}\left(X_{o b s, i}-X_{\text {model }}\right)^{2}}{\sum_{i=1}^{n}\left(X_{o b s, i}-\overline{X_{o b s}}\right)^{2}}
$$

Table 5.1.8 Nash-Sutcliffe Coefficient Results Using Post-Processing Neural Network Indicator

ANN

0.964

Post-processing

Nash-Sutcliffe Coefficient

0.964 0.983

The Root Mean Square Error (RMSE) (also called the root mean square deviation, RMSD) is a frequently used measure of the difference between the values predicted by the model and the values observed from the environment that is being modelled by equation 5.1.10 [172]. To determine if the post-processed neural network model is good enough to simulate the gate opening or not, RMSE was used. The RMSE for the regression model is 0.026 which shows slightly more correlation between ANN results and experimental results with RMSE equal to 0.054 . This shows an acceptable agreement between data from the test results and the post-processed model. All points are around the 45-degree straight line. Figure 5.1.6 (a) show the test data and validation data used to obtain RMSE. The gate openings from experiments and the post-process gate openings are used to draw the RMSE graph (Figure 5.1.7). Although it is desirable to have many more points, the available number of points have been used to show the accuracy of the model. 


$$
R M S E=\sqrt{\frac{\sum_{i=1}^{n}\left(X_{o b s, i}-X_{\text {model }, i}\right)^{2}}{n}}
$$

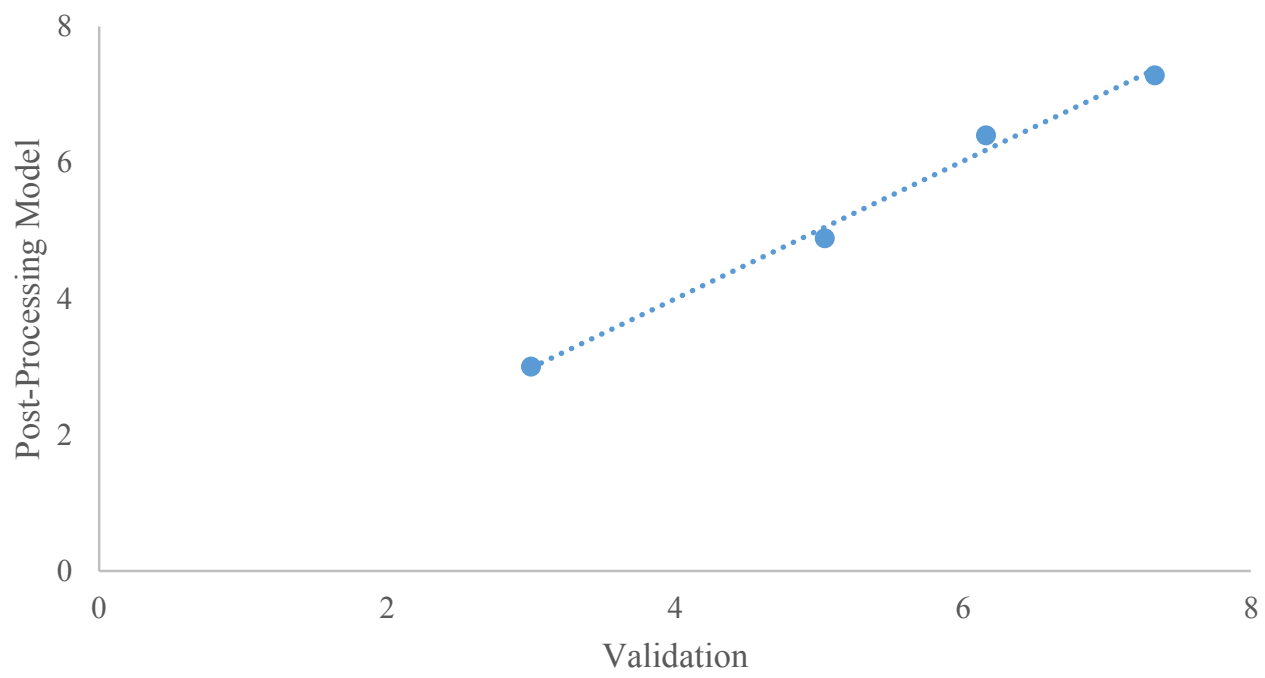

Figure 5.1.7: RMSE - Post-processing 


\section{CHAPTER 5}

\section{RESULTS \& DISCUSSION}

\section{SECTION 2}

\section{FLOW STABILITY NUMBER IN VERTICAL SLUICE GATES}

\subsubsection{Introduction}

The Flow Stability Number was defined in chapter four as a dimensionless number to show the flow characteristics after hydraulic structures. The maximum value for this number is one. When the value is equal to one or very close to one, the flow may be stable. There are three conditions for the flow to be stable. These three conditions were presented in chapter four. When the flow is stable, it means that the channel is safe from surface flow fluctuations and also erosion. The experiments were conducted in two laboratories; the Fluid Mechanics Laboratory at Florida International University and the Center for Research in Water Resources at the University of Texas at Austin. Two laboratories were selected for this research to see the scale effect. Moreover, sediment transport was considered in the second laboratory to find an acceptable range for the Flow Stability Number.

\subsubsection{Experiments (Set One)}

A total of 10 experiments (10 discharges) were selected from the gate results to find the Flow Stability Number. These experiments were performed in a narrow flume, located at the Fluid Mechanics Laboratory of the Civil and Environmental Engineering 
Department of Florida International University. Flume details and measurement devices are presented in chapter 4.

Ten discharges were tested in this research and presented in Table 5.2.1, ranging from low to high levels. For each discharge, numerous gate openings were considered to determine the Flow Stability. Finding an optimum gate opening for each discharge is the purpose of this research. The optimum gate opening is obtained when the flow condition is stable downstream. Therefore, it is necessary to define a stable condition in the downstream section.

Table 5.2.1 Tested Discharges

\begin{tabular}{cccc}
\hline & \multicolumn{3}{c}{ Discharges } \\
\cline { 2 - 4 } Numbers & Gallons Per Minute & $\mathrm{m}^{3} / \mathrm{s}\left(\mathrm{x} 10^{3}\right)$ & $\mathrm{q}\left(\mathrm{m}^{2} / \mathrm{s}\right)$ \\
\hline 1 & 34.6 & 2.18 & 0.0198 \\
\hline 2 & 38.8 & 2.45 & 0.0223 \\
\hline 3 & 41.4 & 2.61 & 0.0237 \\
\hline 4 & 47.5 & 3.00 & 0.0272 \\
\hline 5 & 53.2 & 3.36 & 0.0305 \\
\hline 6 & 56.8 & 3.58 & 0.0326 \\
\hline 7 & 61.2 & 3.86 & 0.0351 \\
\hline 8 & 70.2 & 4.43 & 0.0403 \\
\hline 9 & 72.3 & 4.56 & 0.0415 \\
\hline 10 & 74.5 & 4.70 & 0.0427 \\
\hline
\end{tabular}

The Flow Stability Number is defined in chapter 4, based on the Fuzzy Concept, to classify the downstream flow condition in sub-critical flow. This number is defined based on total energy; therefore, total energy should be calculated in the downstream section. Velocity and depth were measured to calculate energy. In each test, the 
downstream flow condition was recorded in two sections. The dimensionless numbers for gate studies are defined in chapter five-section one.

Table D.1 in Appendix D reports the discharge, gate opening, critical depth, upstream depth, downstream depth in two sections, velocity upstream and downstream (for two sections), and downstream energy (for two sections) as well as the Flow Stability Number. Section one is located upstream; section two is located immediately after the venna-section after the gate; and finally, section three is also located downstream after section two at the beginning of the uniform flow (Figure 4.2 (a)). Depths are reported as the average of all measurements. This can be seen in Table D.1. Appendix D, the Flow Stability Number is not defined in supercritical flows, whereas it is equal to the ratio of total energies (sections two and three) in critical and subcritical flows. Figures 5.2.1 (a) and (b) show the supercritical and sub-critical flows after the vertical sluice gates.

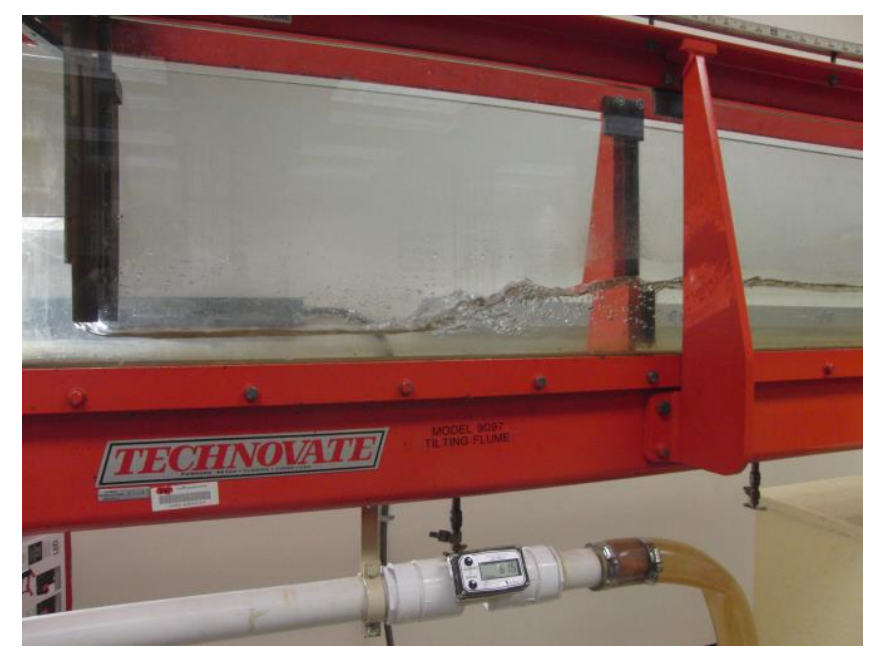

Figure 5.2.1. (a): Supercritical flow after the gate 


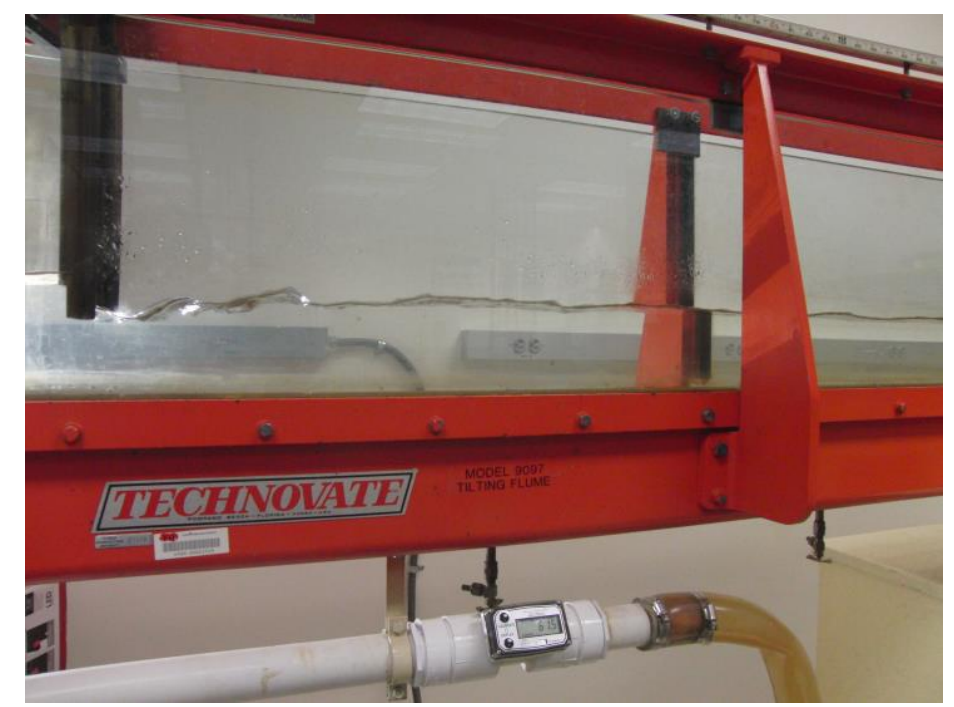

Figure 5.2.1. (b): Subcritical flow after the gate

Test numbers 5 and 10 have been selected, from Table D.1 Appendix D, as an example to show the details of the calculation. It is not possible to see sediment transport in the flume which is in the FIU lab. Therefore, the bed is assumed to be alluvial silts, colloidal to find the permissible velocity (imaginary situation). Considering Table A.1, Appendix A for stable, unlined, earthen channels, the maximum permissible velocity for fine sand, non-colloidal in clear water is $0.457 \mathrm{~m} / \mathrm{s}$. Tables 5.2 .2 to 5.2 .5 reported the details of the calculation to determine the acceptability of the stability. Table 5.2.3 shows that in test 10 the velocity in the first section is more than the permissible velocity; therefore, this test cannot satisfy the stable condition. Consequently, the only test which remains to check the third assumption (surface flow fluctuations) is test number 5. Table 5.2.4 shows the depth measurements in sections two and three (test 
number 5) downstream. These values should then be used in statistical analysis to determine if the flow is stable or not.

Table 5.2.2 Control of the Flow Condition

\begin{tabular}{ccccc}
\hline Test Number & $\begin{array}{c}\mathbf{a} \\
(\mathbf{c m})\end{array}$ & $\begin{array}{c}\mathbf{d c} \\
(\mathbf{c m})\end{array}$ & $\begin{array}{c}\mathbf{h}_{\mathbf{1}}(\mathbf{c m}) \\
\text { Section 2 }\end{array}$ & $\begin{array}{c}\mathbf{h}_{2}(\mathbf{c m}) \\
\text { Section 3 }\end{array}$ \\
\hline 5 & 6.0 & 4.56 & 8.71 & 8.70 \\
\hline 10 & 7.5 & 5.71 & 8.93 & 9.00 \\
\hline
\end{tabular}

Table 5.2.3 Control of the Permissible Velocity

\begin{tabular}{ccccc}
\hline Test Number & Bed Material & $\begin{array}{c}\text { Permissible } \\
\text { Velocity }(\mathbf{m} / \mathbf{s})\end{array}$ & $\begin{array}{c}\mathbf{V}_{\mathbf{1}}(\mathbf{m} / \mathbf{s}) \\
\text { Section 2 }\end{array}$ & $\begin{array}{c}\mathbf{V}_{\mathbf{2}}(\mathbf{m} / \mathbf{s}) \\
\text { Section 3 }\end{array}$ \\
\hline 5 & $\begin{array}{c}\text { Fine sand, } \\
\text { non-colloidal }\end{array}$ & 0.457 & 0.3 & 0.3 \\
\hline 10 & $\begin{array}{c}\text { Fine sand, } \\
\text { non-colloidal }\end{array}$ & 0.457 & 0.5 & 0.4 \\
\hline
\end{tabular}

Table 5.2.4 Depth Measurements

\begin{tabular}{ccc}
\hline Number & $\begin{array}{c}\mathbf{h}_{\mathbf{1}}(\mathbf{c m}) \\
\text { Section 2 }\end{array}$ & $\begin{array}{c}\mathbf{h}_{\mathbf{2}}(\mathbf{c m}) \\
\text { Section 3 }\end{array}$ \\
\hline 1 & 8.70 & 8.70 \\
\hline 2 & 8.71 & 8.69 \\
\hline 3 & 8.70 & 8.72 \\
\hline 4 & 8.72 & 8.70 \\
\hline 5 & 8.70 & 8.69 \\
\hline 6 & 8.69 & 8.71 \\
\hline 7 & 8.68 & 8.68 \\
\hline 8 & 8.71 & 8.71 \\
\hline 9 & 8.70 & 8.72 \\
\hline 10 & 8.69 & 8.70 \\
\hline & & \\
\hline & & \\
\hline & & \\
\hline
\end{tabular}


Table 5.2.5 Two-sided t-test

\begin{tabular}{|c|c|c|c|c|c|}
\hline \multirow[b]{2}{*}{ Value } & \multicolumn{5}{|c|}{ t-test } \\
\hline & $\mathbf{H}_{\mathbf{0}}$ & $\mathbf{H}_{\mathbf{a}}$ & P-Value & Result & Explanation \\
\hline \multirow[t]{2}{*}{$\begin{array}{l}\text { Section } 2 \text { versus } \\
\text { section } 3\end{array}$} & $\begin{array}{l}\text { *The average of } \\
\text { section } 2 \text { is equal to } \\
\text { the average of } \\
\text { section } 3\end{array}$ & $\begin{array}{c}\mathrm{H}_{0} \\
\text { is false }\end{array}$ & 0.7223 & $\begin{array}{l}\text { Do not } \\
\text { reject } H_{0}\end{array}$ & $\begin{array}{l}\text { There is no evidence to conclude that } \\
\text { the average of section } 2 \text { is different } \\
\text { from the average of section } 3 \text {. So, it is } \\
\text { reasonable to assume that the two } \\
\text { averages are equal. }\end{array}$ \\
\hline & $\bullet$ Assume $\alpha=0.005$ & & $\begin{array}{l}\text { Degree of } \\
\text { freedom: } \\
n-2=18\end{array}$ & $\begin{array}{l}\text {-t value : } \\
-0.36116\end{array}$ & $\begin{array}{l}-95 \% \text { confidence interval } \\
-0.013648584 \quad 0.009648584\end{array}$ \\
\hline
\end{tabular}

*the mean of section 2 is 8.700 and the mean of section 3 is 8.702 


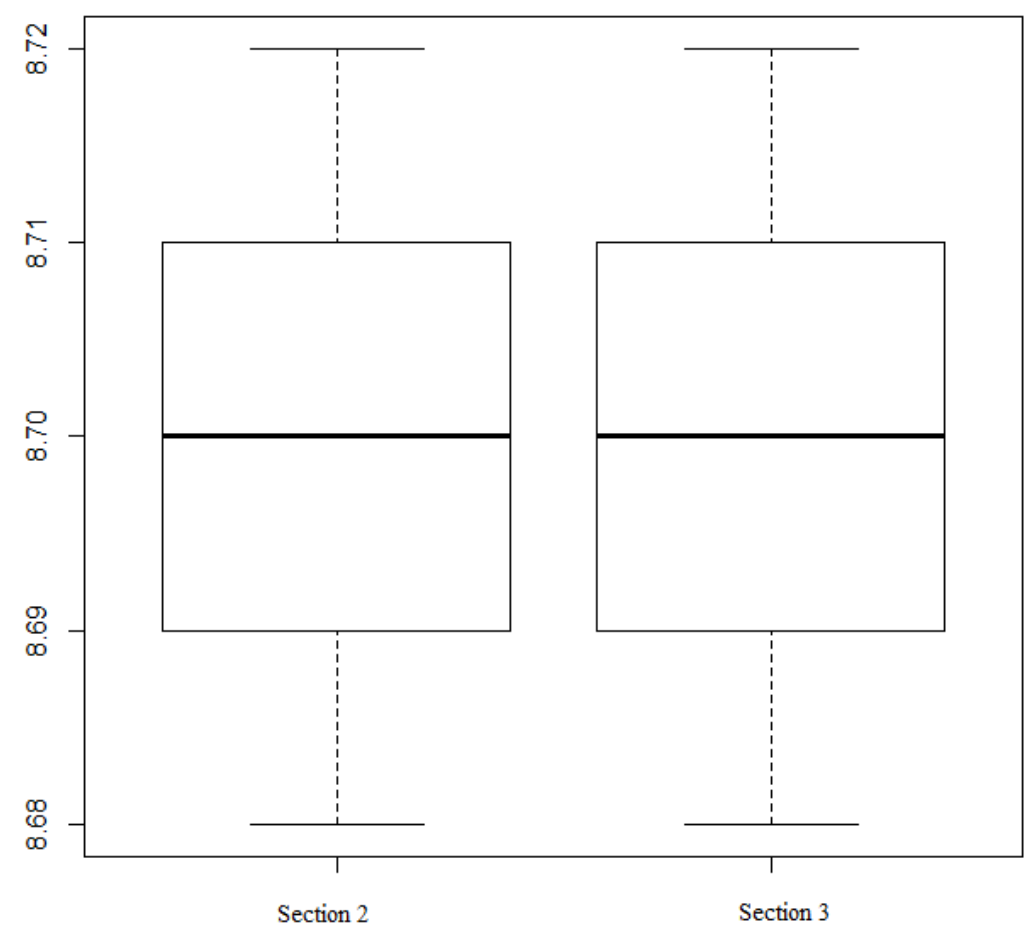

Figure 5.2.2: Boxplots - sections 2 and 3

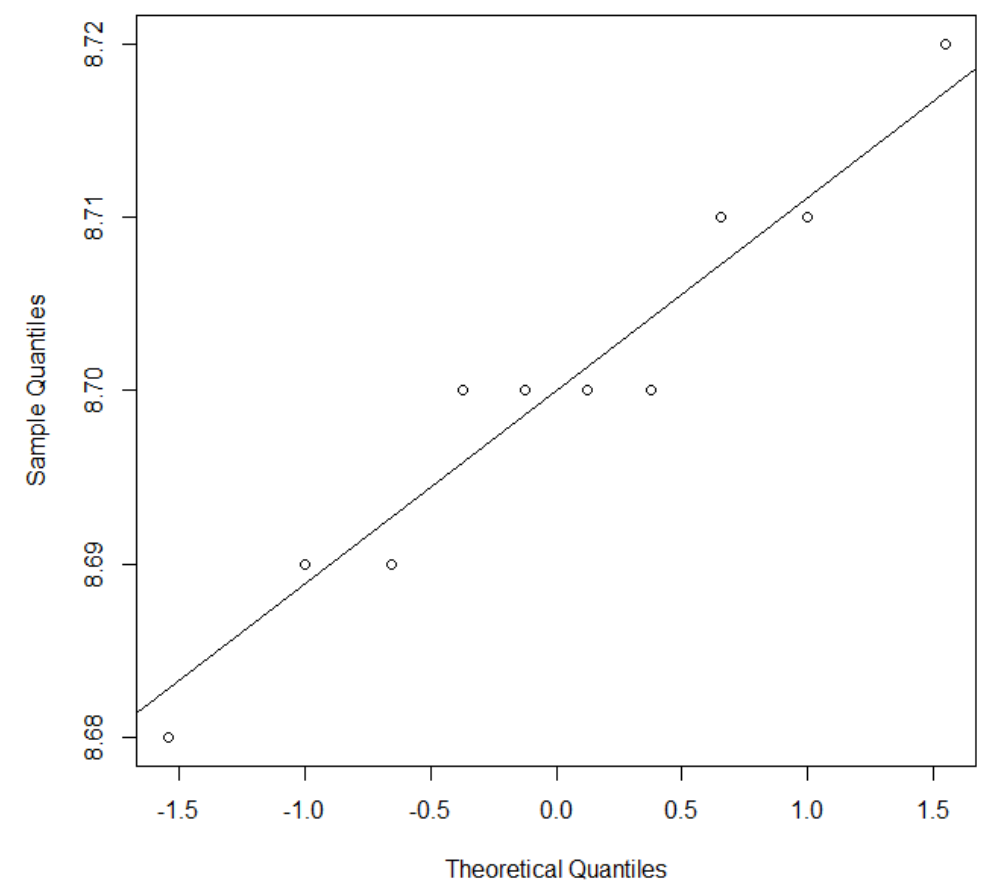

Figure 5.2.3: Normal Q-Q plot - section 2 


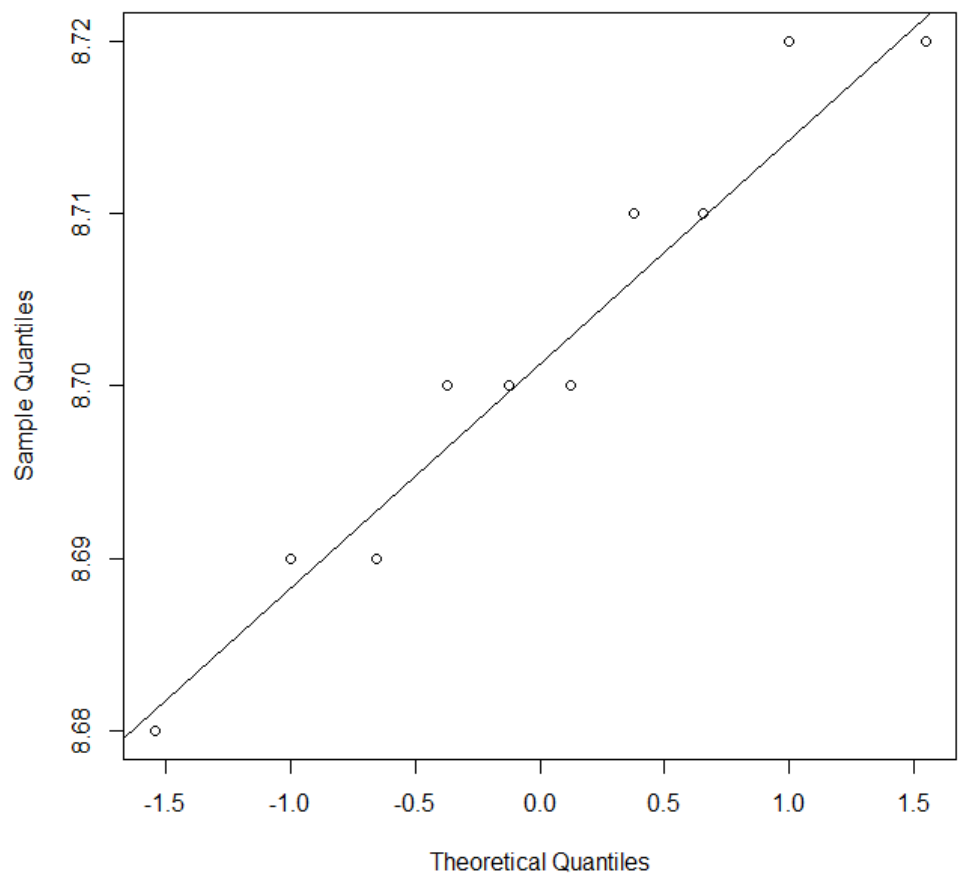

Figure 5.2.4: Normal Q-Q plot - section 3

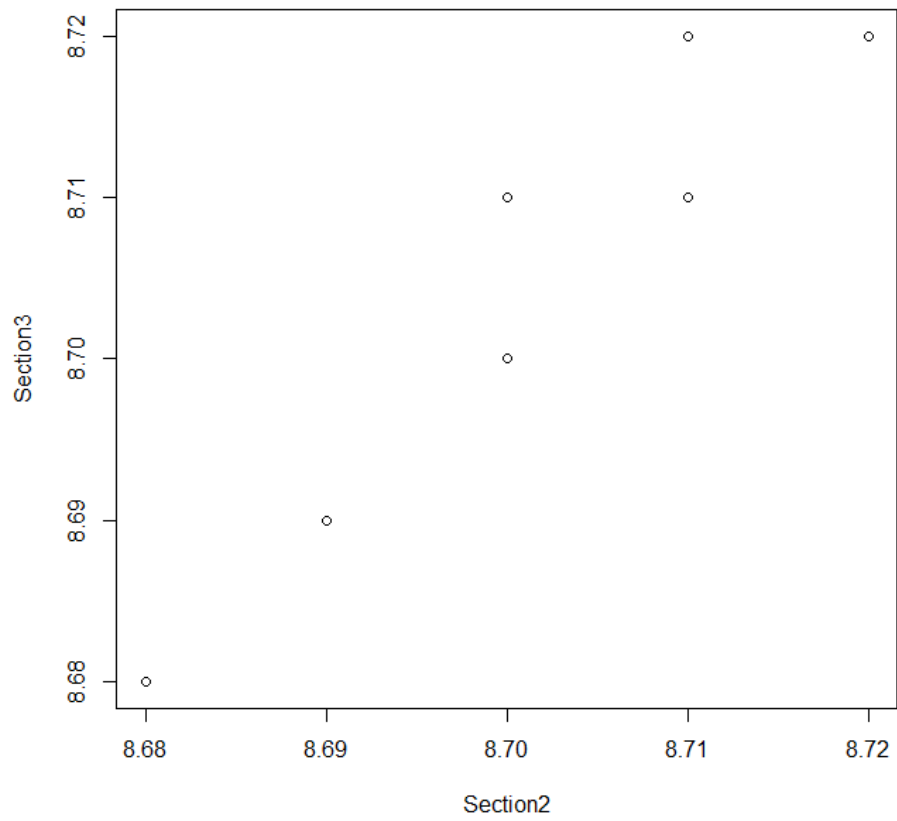

Figure 5.2.5: Q-Q plot - section 2 versus section 3 
Table 5.2.6 Check of Normality

\begin{tabular}{|c|c|c|c|c|c|}
\hline \multirow[b]{2}{*}{ Value } & \multicolumn{4}{|c|}{ Shapiro-Wilk Test } & \multirow[b]{2}{*}{ Explanation } \\
\hline & $\mathbf{H}_{\mathbf{0}}$ & $\mathbf{H}_{\mathbf{a}}$ & P-Value & Result & \\
\hline $\begin{array}{r}\mathrm{h}_{1}(\mathrm{~cm}) \\
\text { Section } 2\end{array}$ & $\begin{array}{l}\text { Data follows a } \\
\text { normal distribution }\end{array}$ & $\begin{array}{l}\mathrm{H}_{0} \\
\text { is false }\end{array}$ & 0.7026 & $\begin{array}{l}\text { Do not } \\
\text { reject } H_{0}\end{array}$ & $\begin{array}{l}\text { Fail to reject the null hypothesis. So, it } \\
\text { is reasonable to assume normality. }\end{array}$ \\
\hline $\begin{array}{r}\mathrm{h}_{2}(\mathrm{~cm}) \\
\text { Section } 3\end{array}$ & $\begin{array}{l}\text { Data follows a } \\
\text { normal distribution }\end{array}$ & $\begin{array}{c}\mathrm{H}_{0} \\
\text { is false }\end{array}$ & 0.5745 & $\begin{array}{l}\text { Do not } \\
\text { reject } H_{0}\end{array}$ & $\begin{array}{l}\text { Fail to reject the null hypothesis. So, it } \\
\text { is reasonable to assume normality. }\end{array}$ \\
\hline
\end{tabular}

Table 5.2.7 Check of the Equality of Variances

\begin{tabular}{|c|c|c|c|c|c|}
\hline \multirow[b]{2}{*}{ Value } & \multicolumn{5}{|c|}{ F Test } \\
\hline & $\mathbf{H}_{0}$ & $\mathrm{Ha}_{\mathbf{a}}$ & P-Value & Result & Explanation \\
\hline \multirow[t]{2}{*}{$\begin{array}{l}\text { Section } 2 \text { versus } \\
\text { Section } 3\end{array}$} & $\begin{array}{l}\text { The variance of } \\
\text { section } 2 \text { is equal to } \\
\text { the variance of }\end{array}$ & $\begin{array}{c}\mathrm{H}_{0} \\
\text { is false }\end{array}$ & 0.7023 & $\begin{array}{l}\text { Do not } \\
\text { reject } H_{0}\end{array}$ & $\begin{array}{l}\text { Fail to reject the null hypothesis. So, it } \\
\text { is reasonable to assume the equality of } \\
\text { variances. }\end{array}$ \\
\hline & -Assume $\alpha=0.005$ & & $\begin{array}{l}\text {-Degree of } \\
\text { freedom } \\
n-1=9\end{array}$ & & $\begin{array}{l}\bullet 95 \% \text { confidence interval } \\
0.1910663 .096919\end{array}$ \\
\hline
\end{tabular}


The t-test has been selected for the statistical analysis because there are just two data sets (section 2 and section 3). Table 5.2.5 shows the results of the t-test for these two sections. As can be seen from the results, the flow is completely stable.

There are two assumptions for the t-test to be applied. The first assumption is normality; it means that the data (in both data sets) should follow a normal distribution. The second assumption is the equality of variances in both data sets. Boxplots of both sections have been drawn in Figure 5.2.2. Moreover, QQ-Plots (quantile-quantile plot) are presented (Figures 5.2.3 to 5.2.5). Furthermore, normality was checked via the Shapiro-Wilk test (Table 5.2.6). In addition, the equality of variances has been checked by an F-test (Table 5.2.7).

All in all, two tests have been selected to show the details of the calculations. In the first step, the velocity was more than the allowable velocity in test number 10; therefore, this test did not meet the criteria of a stable condition. Test number 5 was the only test which was left for the second step of the analysis (surface flow fluctuations). Based on the results of the statistical analysis, the flow is completely stable in test number 5 which is compatible with the Flow Stability Number calculation; the dimensionless number is equal to one for this test number.

\subsubsection{Experiments (Set Two)}

A total of six experiments (6 discharges) were selected to find the Flow Stability Number (Table 5.2.8). These experiments were performed in a flume, which is located at the Center for Research in Water Resources (CRWR) at the University of Texas at Austin. Flume details and measurements devices were presented in chapter 4. 
Table 5.2.8 Tested Discharges

\begin{tabular}{cccc}
\hline & \multicolumn{3}{c}{ Discharges } \\
\cline { 2 - 4 } Numbers & Gallons Per Minute & $\mathrm{m}^{3} / \mathrm{s}\left(\mathrm{x} 10^{3}\right)$ & $\mathrm{q}\left(\mathrm{m}^{2} / \mathrm{s}\right)$ \\
\hline 1 & 300.20 & 18.94 & 0.0344 \\
\hline 2 & 406.72 & 25.66 & 0.0466 \\
\hline 3 & 510.38 & 32.20 & 0.0585 \\
\hline 4 & 830.40 & 52.39 & 0.0952 \\
\hline 5 & 1102.71 & 69.57 & 0.1265 \\
\hline 6 & 1421.14 & 89.66 & 0.1630 \\
\hline
\end{tabular}

Table D.2 Appendix D reported the discharge, gate opening, critical depth, upstream depth, downstream depth in two sections, upstream and downstream velocity (in two sections), and downstream energy (in two sections), as well as the Flow Stability Number. Section one is located 0.4 meters upstream; section two is located 0.45 meters downstream of the gate; and finally, section three is also located one meter downstream from the gate. Depths are reported as the average of all measurements. In addition, Figures 5.2.6 (a) and (b) show the sediment transport and surface flow fluctuations after the vertical sluice gates. 


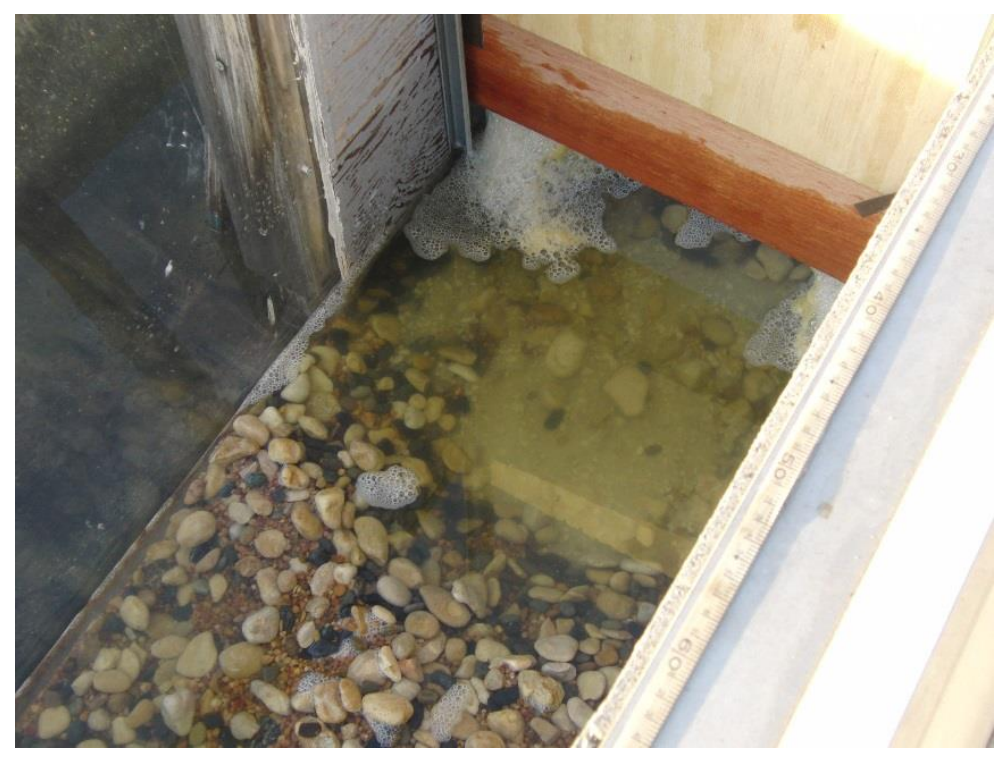

Figure 5.2.6 (a): Sediment transport after the gate

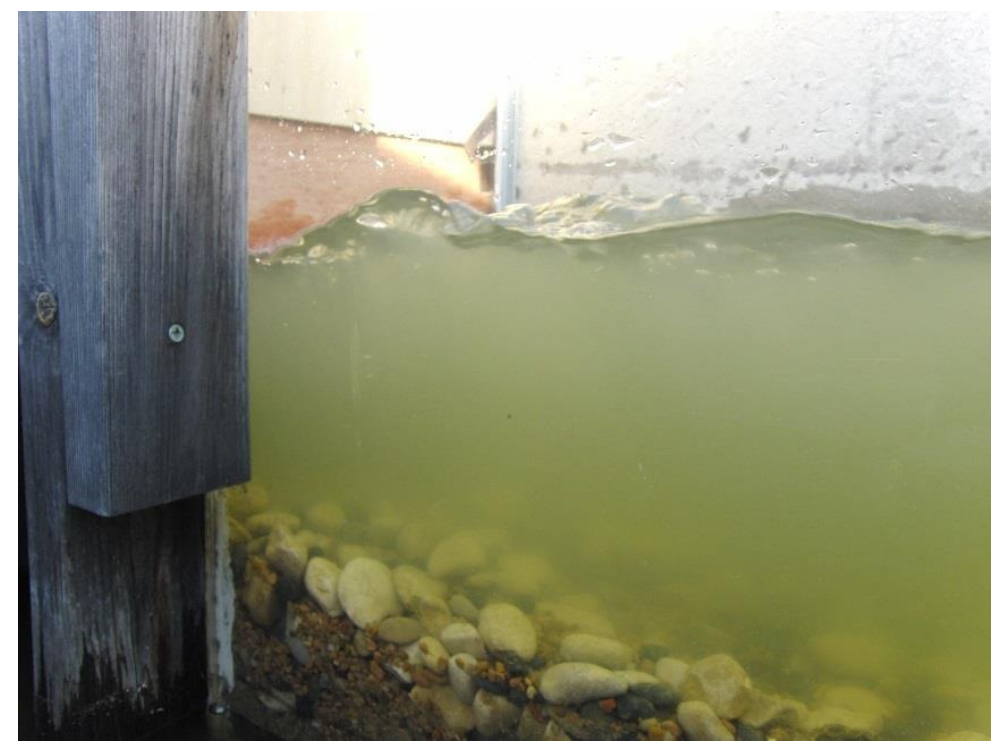

Figure 5.2.6 (b): Surface flow fluctuations after the gate 
Test number 6 was selected as an example to show the details of the calculation. The bed is a mixture of limestone pebbles, basalt pebbles, and brown pea gravel. Considering Table A.1. Appendix A, for stable, unlined, earthen channels, the maximum permissible velocity for coarse gravel, non-colloidal, and fine gravel in clear water are 1.220 and $0.762 \mathrm{~m} / \mathrm{s}$, respectively. The minimum value is taken in this study as a safety factor. Tables 5.2.9 to 5.2.12 reported the details of the calculation to determine the acceptability of the stability. As can be seen from Table 5.2.9, the depths in both the second and the third section are more than the critical depth; therefore, the first assumption is satisfied. Table 5.2.10 shows that the velocities in both sections are less than the permissible velocity; consequently, the test is eligible for checking the third assumption (surface flow fluctuations). Table 5.2.11 shows the depth measurements in sections two and three (test number 6) downstream. These values should then be used in the statistical analysis to determine if the flow is stable or not.

Table 5.2.9 Control of the Flow Condition

\begin{tabular}{ccccc}
\hline Test Number & $\begin{array}{c}\mathbf{a} \\
(\mathbf{c m})\end{array}$ & $\begin{array}{c}\mathbf{d c} \\
(\mathbf{c m})\end{array}$ & $\begin{array}{c}\mathbf{h}_{\mathbf{1}}(\mathbf{c m}) \\
\text { Section } \mathbf{2}\end{array}$ & $\begin{array}{c}\mathbf{h}_{\mathbf{2}}(\mathbf{c m}) \\
\text { Section 3 }\end{array}$ \\
\hline 6 & 23.0 & 13.94 & 21.91 & 21.91 \\
\hline
\end{tabular}

Table 5.2.10 Control of the Permissible Velocity

\begin{tabular}{ccccc}
\hline Test Number & Bed Material & $\begin{array}{c}\text { Permissible } \\
\text { Velocity (m/s) }\end{array}$ & $\begin{array}{c}\mathbf{V}_{\mathbf{1}}(\mathbf{m} / \mathbf{s}) \\
\text { Section 2 }\end{array}$ & $\begin{array}{c}\mathbf{V}_{\mathbf{2}}(\mathbf{m} / \mathbf{s}) \\
\text { Section 3 }\end{array}$ \\
\hline 6 & Fine gravel & 0.762 & 0.74 & 0.74 \\
\hline
\end{tabular}


Table 5.2.11 Depth Measurements

\begin{tabular}{ccc}
\hline Number & $\begin{array}{c}\text { h1 (cm) } \\
\text { Section 2 }\end{array}$ & $\begin{array}{c}\text { h2 (cm) } \\
\text { Section 3 }\end{array}$ \\
\hline 1 & 21.91 & 21.89 \\
\hline 2 & 21.90 & 21.88 \\
\hline 3 & 21.89 & 21.89 \\
\hline 4 & 21.92 & 21.95 \\
\hline 5 & 21.94 & 21.89 \\
\hline 6 & 21.93 & 21.90 \\
\hline 7 & 21.89 & 21.91 \\
\hline 8 & 21.90 & 21.93 \\
\hline 9 & 21.94 & 21.89 \\
\hline 10 & 21.91 & \\
\hline & & \\
\hline & & \\
\hline & & \\
\hline & & \\
\hline & & \\
\hline & & \\
\hline & & \\
\hline & & \\
\hline
\end{tabular}


Table 5.2.12 Two-sided t-test

\begin{tabular}{|c|c|c|c|c|c|}
\hline \multirow[b]{2}{*}{ Value } & \multicolumn{5}{|c|}{ t-test } \\
\hline & $\mathbf{H}_{\mathbf{0}}$ & $\mathbf{H}_{\mathbf{a}}$ & P-Value & Result & Explanation \\
\hline \multirow[t]{2}{*}{$\begin{array}{c}\text { Section } 2 \text { versus } \\
\text { section } 3\end{array}$} & $\begin{array}{l}\text { *The average of } \\
\text { section } 2 \text { is equal to } \\
\text { the average of } \\
\text { section } 3\end{array}$ & $\begin{array}{c}\quad \mathrm{H}_{0} \\
\text { is false }\end{array}$ & 0.1402 & $\begin{array}{l}\text { Do not } \\
\text { reject } H_{0}\end{array}$ & $\begin{array}{l}\text { There is not enough evidence to } \\
\text { conclude that the average of section } 2 \text { is } \\
\text { different from the average of section } 3 \text {. } \\
\text { So, it is reasonable to assume that the } \\
\text { two averages are equal. }\end{array}$ \\
\hline & $\bullet$ Assume $\alpha=0.005$ & & $\begin{array}{l}\text { Degree of } \\
\text { freedom: } \\
n-2=18\end{array}$ & $\begin{array}{l}\text {-t value : } \\
1.543\end{array}$ & $\begin{array}{l}-95 \% \text { confidence interval } \\
-0.003615531 \quad 0.023615531\end{array}$ \\
\hline
\end{tabular}

*the mean of section 2 is 21.909 and the mean of section 3 is 21.899 


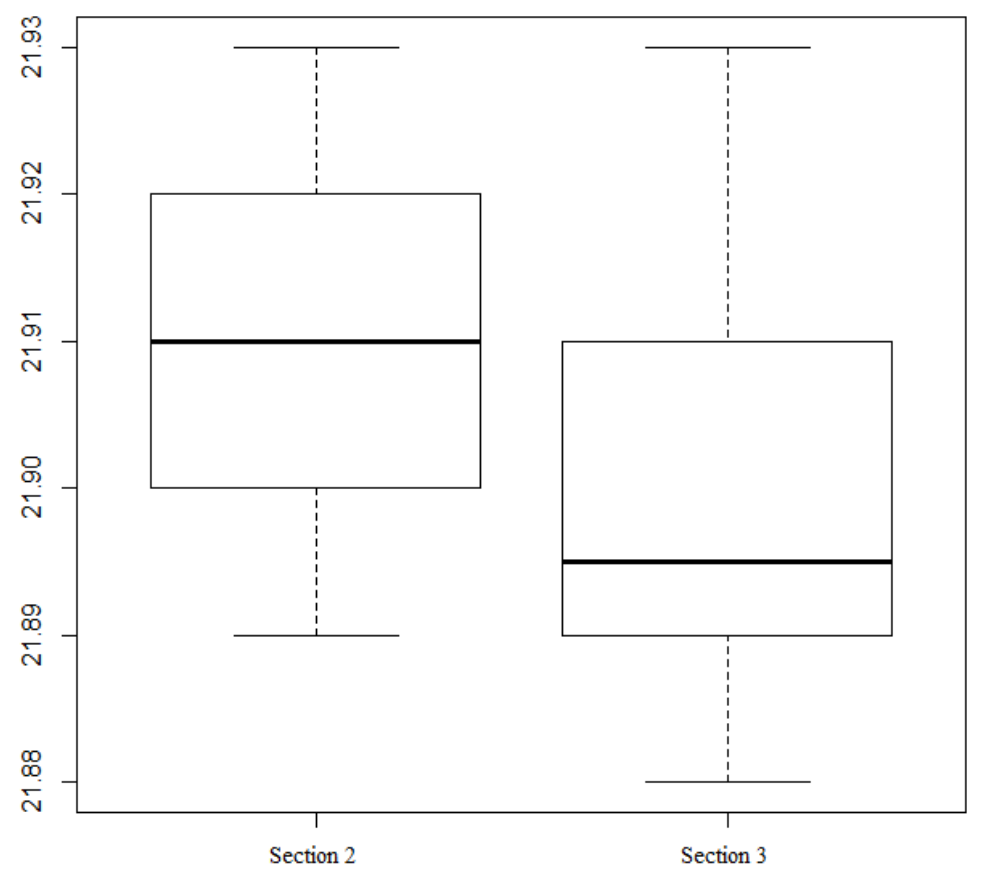

Figure 5.2.7: Boxplots - sections 2 and 3

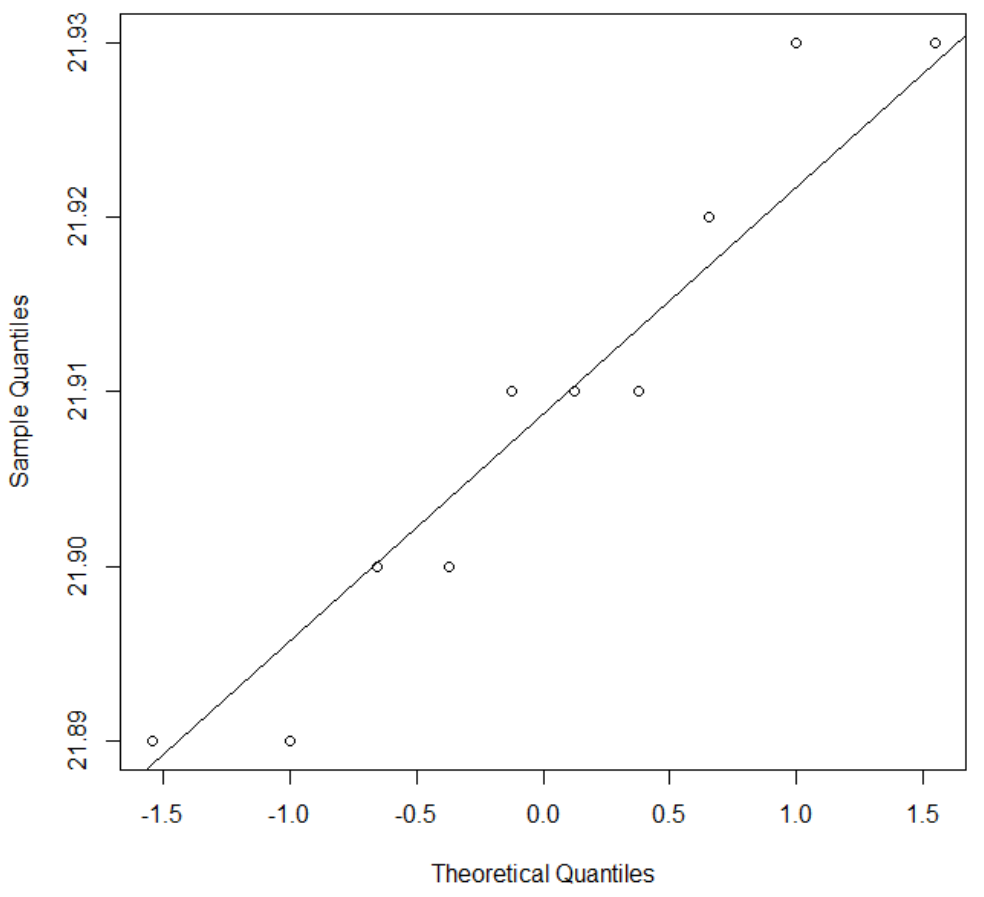

Figure 5.2.8: Normal Q-Q plot - section 2 


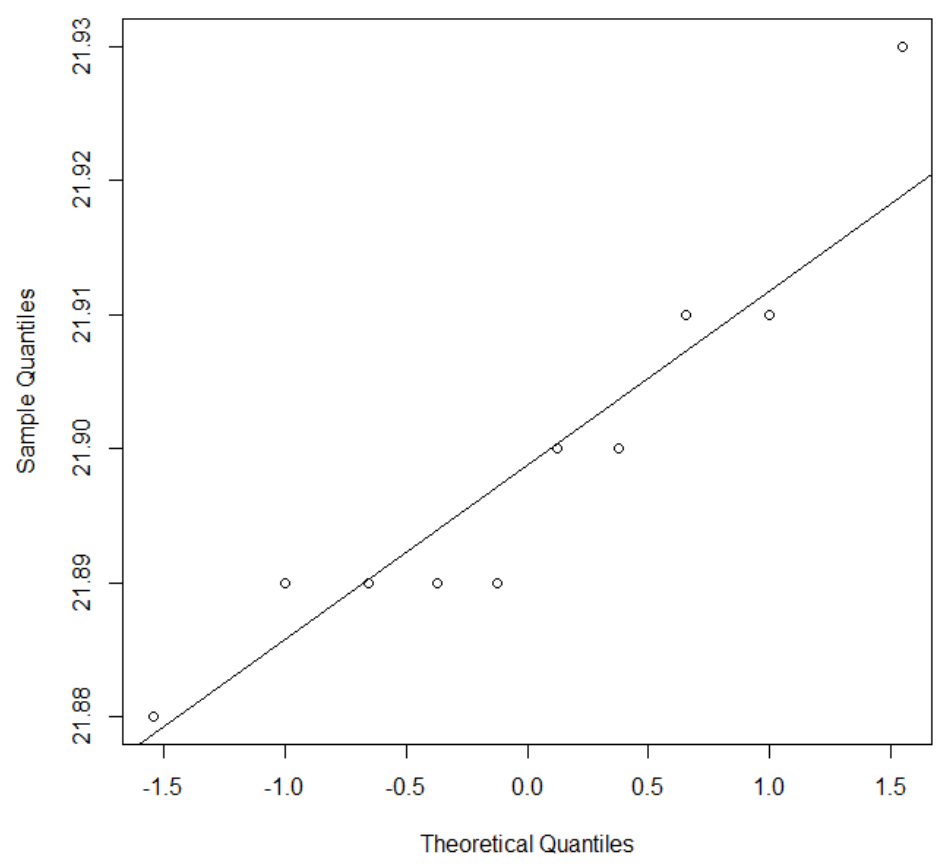

Figure 5.2.9: Normal Q-Q plot - section 3

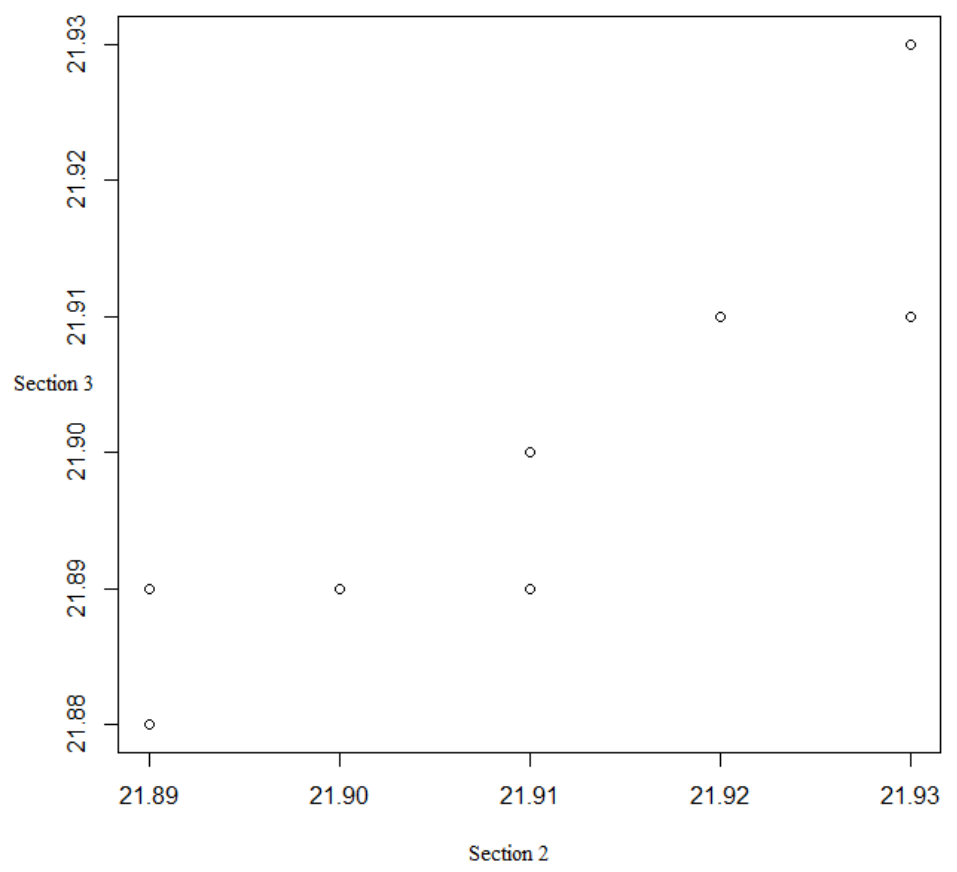

Figure 5.2.10: Q-Q plot - section 2 versus section 3 
Table 5.2.13 Check of Normality

\begin{tabular}{|c|c|c|c|c|c|}
\hline \multirow[b]{2}{*}{ Value } & \multicolumn{4}{|c|}{ Shapiro-Wilk Test } & \multirow[b]{2}{*}{ Explanation } \\
\hline & $\mathbf{H}_{\mathbf{0}}$ & $\mathbf{H}_{\mathbf{a}}$ & P-Value & Result & \\
\hline $\begin{array}{r}\mathrm{h}_{1}(\mathrm{~cm}) \\
\text { Section } 2\end{array}$ & $\begin{array}{l}\text { Data follows a } \\
\text { normal distribution }\end{array}$ & $\begin{array}{c}\mathrm{H}_{0} \\
\text { is false }\end{array}$ & 0.3296 & $\begin{array}{l}\text { Do not } \\
\text { reject } H_{0}\end{array}$ & $\begin{array}{l}\text { Fail to reject the null hypothesis. So, it } \\
\text { is reasonable to assume normality. }\end{array}$ \\
\hline $\begin{array}{r}\mathrm{h}_{2}(\mathrm{~cm}) \\
\text { Section } 3\end{array}$ & $\begin{array}{l}\text { Data follows a } \\
\text { normal distribution }\end{array}$ & $\begin{array}{c}\mathrm{H}_{0} \\
\text { is false }\end{array}$ & 0.2045 & $\begin{array}{l}\text { Do not } \\
\text { reject } H_{0}\end{array}$ & $\begin{array}{l}\text { Fail to reject the null hypothesis. So, it } \\
\text { is reasonable to assume normality. }\end{array}$ \\
\hline
\end{tabular}

Table 5.2.14 Check of the Equality of Variances

\begin{tabular}{|c|c|c|c|c|c|}
\hline \multirow[b]{2}{*}{ Value } & \multicolumn{5}{|c|}{ F Test } \\
\hline & $\mathbf{H}_{\mathbf{0}}$ & $\mathbf{H}_{\mathbf{a}}$ & P-Value & Result & Explanation \\
\hline \multirow[t]{2}{*}{$\begin{array}{l}\text { Section } 2 \text { versus } \\
\text { section } 3\end{array}$} & $\begin{array}{l}\text { The variance of } \\
\text { section } 2 \text { is equal to } \\
\text { the variance of }\end{array}$ & $\begin{array}{c}\mathrm{H}_{0} \\
\text { is false }\end{array}$ & 1 & $\begin{array}{l}\text { Do not } \\
\text { reject } H_{0}\end{array}$ & $\begin{array}{l}\text { Fail to reject the null hypothesis. So, it } \\
\text { is reasonable to assume the equality of } \\
\text { variances. }\end{array}$ \\
\hline & $\bullet$ Assume $\alpha=0.005$ & & $\begin{array}{c}\text {-Degree of } \\
\text { freedom } \\
n-1=9\end{array}$ & & $\begin{array}{l}\bullet 95 \% \text { confidence interval } \\
0.2483859 \quad 4.0259942\end{array}$ \\
\hline
\end{tabular}


The t-test has been selected for the statistical analysis because there are just two data sets (section 2 and section 3). Table 5.2.12 shows the results of the t-test for these two sections. As can be seen from the results, the flow is completely stable.

There are two assumptions for the t-test to be applied. The first assumption is normality; it means that the data (in both data sets) should follow a normal distribution. The second assumption is the equality of variances in both data sets. Boxplots of both sections have been drawn as Figure 5.2.7. Moreover, QQ-Plots (quantile-quantile plot) are presented in both sections (Figures 5.2.8 to 5.2.10). Furthermore, normality was checked by the Shapiro-Wilk test (Table 5.2.13). In addition, the equality of variances was checked by an F-test (Table 5.2.14).

Based on the results of the statistical analysis, the flow is completely stable in test number 6 which is compatible with the Flow Stability Number calculation; the dimensionless number is equal to one for this test number. 


\section{CHAPTER 5}

\section{RESULTS \& DISCUSSION}

\section{SECTION 3}

\section{THE FLOW STABILITY NUMBER IN A GATE WITH EXPANSIONS}

\subsubsection{Introduction}

The Flow Stability Number was calculated for vertical sluice gates in section 2. In this section, a combination of a gate with an expansion is considered as another type of hydraulic structure. The experiments were conducted in two laboratories; the Fluid Mechanics Laboratory at Florida International University and the Center for Research in Water Resources at the University of Texas at Austin. Two laboratories were selected for this research to see the scale effect. Moreover, sediment transport was considered in the second laboratory to find an acceptable range for the Flow Stability Number.

Three thicknesses were considered in the first laboratory; 2 centimeters, 1.2 centimeters, and 0.7 centimeters to determine the effect of thickness on the Flow Stability Number.

\subsubsection{Experiments (Set One)}

A total of 30 experiments, including ten discharges and three thicknesses, were selected from the gate with expansion results to find the Flow Stability Number for the first laboratory. The experiments were conducted in a narrow flume, located at the Fluid 
Mechanics Laboratory at the Civil and Environmental Engineering Department of Florida International University. Flume details and measurements devices were presented in chapter 4.

Ten discharges were tested in this research and presented in Table 5.2.1, ranging from low to high levels. Determining the optimum gate opening, as well as finding the effect of thickness on the Flow Stability Number for each discharge, are the purposes of this study. The optimum gate opening happens when the flow condition is stable downstream of the hydraulic structure.

The Flow Stability Number is defined in chapter4, based on the Fuzzy Concept in subcritical flow, to classify the downstream flow condition. This dimensionless number is defined based on total energy. Velocity and depth were measured to calculate energy. In each test, measurements were performed in four sections; one section upstream of the hydraulic structure, one in the middle of the structure, and two downstream of the structure.

Tables E.1 to E.3 Appendix E reported the discharge, gate opening, critical depth, upstream depth, downstream depth in two sections, upstream and downstream velocity (two sections), and downstream energy (two sections), as well as the Flow Stability Number for a gate with an expansion with different thicknesses. The results of the section in the middle of the hydraulic structure were not reported in these; therefore, section one is located upstream, section two is located immediately after the hydraulic structure, and finally, section three is also located downstream after section two at the 
beginning of the uniform flow (Figures5.3.1). Depths are reported as the average of all measurements.

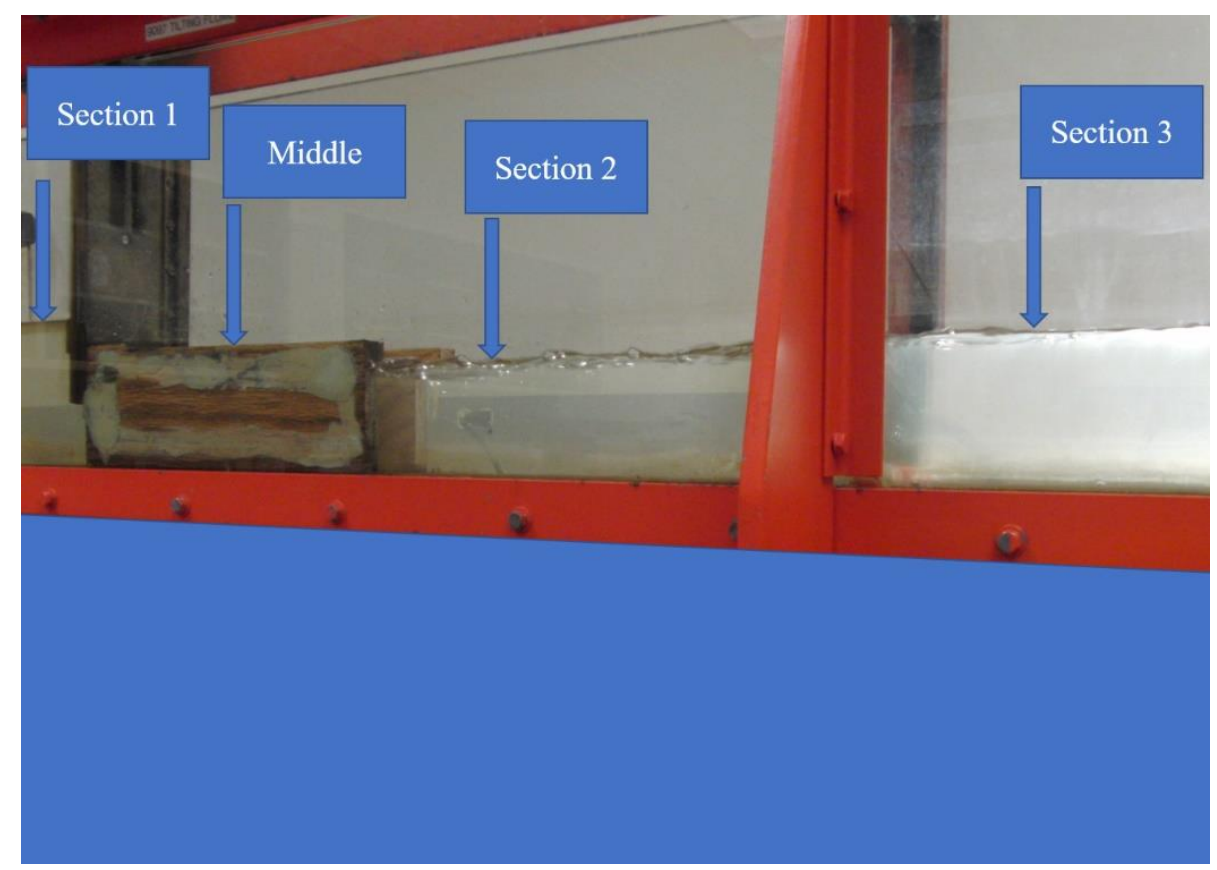

Figure 5.3.1: Sections in a gate with expansion

The Flow Stability Number is not defined in super-critical flows, whereas it is equal to the ratio of total energy (sections two and three) in critical and sub-critical flows. Figures 5.3.2 (a) and (b) show the flow fluctuations and the stable flow after the gate with expansion. 


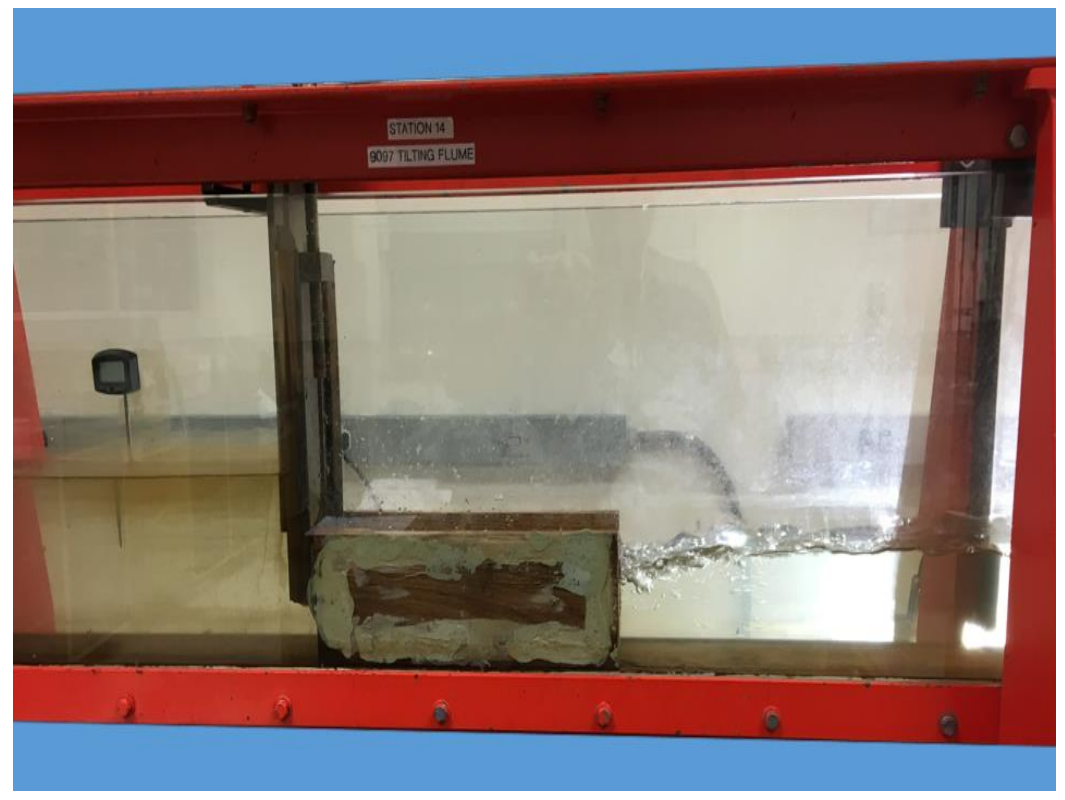

Figure 5.3.2 (a): Flow fluctuations after a gate with expansion

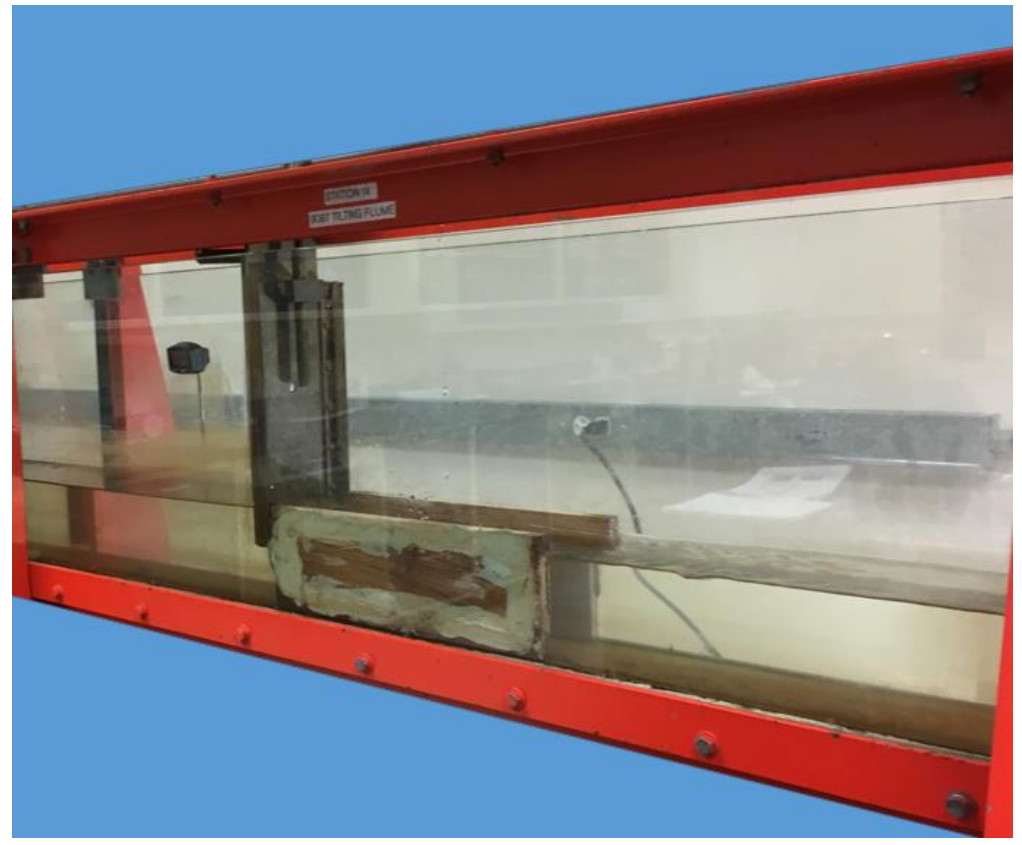

Figure 5.3.2(b): Stable flow after a gate with expansion 
Test numbers 2, 7, 8, and 10 from Table E.1 Appendix E have been selected as an example to show the details of the calculation. It is not possible to see the sediment transport in the flume which is at the FIU lab. Therefore, the bed is assumed to be alluvial silts, colloidal to find the permissible velocity (hypothetical situation). Considering Table A.1, Appendix A for stable, unlined, earthen channels, the maximum permissible velocity for fine sand, non-colloidal in clear water is $0.457 \mathrm{~m} / \mathrm{s}$. Tables 5.3.4 to 5.3.7 reported the details of the calculation to determine the acceptability of the stability. As can be seen from Table 5.3.1, the depths in the second section of tests 8 and 10 are less than the critical depth; hence, the flow is super-critical and cannot be stable. According to the results of Table 5.2.1, test numbers 8 and 10 will be excluded from the rest of the calculations. Table 5.2.2 shows that in test 7 the velocity in the second section is more than the permissible velocity; therefore, this test cannot satisfy the stability condition. Consequently, the only test which remains to check the third assumption (surface flow fluctuations) is test number 2. Table 5.3.3 shows the depth measurements in sections two and three (test number 2) downstream. These values should then be used in statistical analysis to determine if the flow is stable or not. 
Table 5.3.1 Control of the Flow Condition

\begin{tabular}{ccccc}
\hline Test Number & $\begin{array}{c}\mathbf{a} \\
(\mathbf{c m})\end{array}$ & $\begin{array}{c}\mathbf{d c} \\
(\mathbf{c m})\end{array}$ & $\begin{array}{c}\mathbf{h}_{\mathbf{1}} \mathbf{( c m )} \\
\text { Section 2 }\end{array}$ & $\begin{array}{c}\mathbf{h}_{\mathbf{2}} \mathbf{( c m )} \\
\text { Section 3 }\end{array}$ \\
\hline 2 & 5.5 & 3.42 & 7.87 & 7.90 \\
\hline 7 & 5.5 & 4.76 & 8.50 & 8.60 \\
\hline 8 & 6.5 & 5.49 & 3.00 & 8.77 \\
\hline 10 & 7.0 & 5.71 & 3.77 & 8.50 \\
\hline
\end{tabular}

Table 5.3.2 Control of the Permissible Velocity

\begin{tabular}{ccccc}
\hline Test Number & Bed Material & $\begin{array}{c}\text { Permissible } \\
\text { Velocity }(\mathbf{m} / \mathbf{s})\end{array}$ & $\begin{array}{c}\mathbf{V}_{\mathbf{1}}(\mathbf{m} / \mathbf{s}) \\
\text { Section 2 }\end{array}$ & $\begin{array}{c}\mathbf{V}_{\mathbf{2}}(\mathbf{m} / \mathbf{s}) \\
\text { Section 3 }\end{array}$ \\
\hline 2 & $\begin{array}{c}\text { Fine sand, } \\
\text { non-colloidal }\end{array}$ & 0.457 & 0.3 & 0.3 \\
\hline 7 & $\begin{array}{c}\text { Fine sand, } \\
\text { non-colloidal }\end{array}$ & 0.457 & 0.6 & 0.4 \\
\hline
\end{tabular}

Table 5.3.3 Depth Measurements

\begin{tabular}{ccc}
\hline Number & $\begin{array}{c}\mathbf{h}_{\mathbf{1}}(\mathbf{c m}) \\
\text { Section 2 }\end{array}$ & $\begin{array}{c}\mathbf{h}_{\mathbf{2}} \text { (cm) } \\
\text { Section 3 }\end{array}$ \\
\hline 1 & 7.86 & 7.91 \\
\hline 2 & 7.88 & 7.88 \\
\hline 3 & 7.87 & 7.90 \\
\hline 4 & 7.89 & 7.88 \\
\hline 5 & 7.86 & 7.92 \\
\hline 6 & 7.88 & 7.88 \\
\hline 7 & 7.90 & 7.89 \\
\hline 8 & 7.90 & 7.90 \\
\hline 9 & 7.87 & 7.87 \\
\hline 10 & 7.89 & \\
\hline & & \\
\hline & & \\
\hline & & \\
\hline & & \\
\hline & & \\
\hline
\end{tabular}


Table 5.3.4 Two-sided t-test

\begin{tabular}{|c|c|c|c|c|c|}
\hline \multirow[b]{2}{*}{ Value } & \multicolumn{5}{|c|}{ t-test } \\
\hline & $\mathbf{H}_{\mathbf{0}}$ & $\mathbf{H}_{\mathbf{a}}$ & P-Value & Result & Explanation \\
\hline \multirow[t]{2}{*}{$\begin{array}{c}\text { Section } 2 \text { versus } \\
\text { section } 3\end{array}$} & $\begin{array}{l}\text { *The average of } \\
\text { section } 2 \text { is equal to } \\
\text { the average of } \\
\text { section } 3\end{array}$ & $\begin{array}{c}\quad \mathrm{H}_{0} \\
\text { is false }\end{array}$ & 0.1792 & $\begin{array}{l}\text { Do not } \\
\text { reject } H_{0}\end{array}$ & $\begin{array}{l}\text { There is not enough evidence to } \\
\text { conclude that the average of section } 2 \text { is } \\
\text { different from the average of section } 3 \text {. } \\
\text { So, it is reasonable to assume that the } \\
\text { two averages are equal. }\end{array}$ \\
\hline & -Assume $\alpha=0.005$ & & $\begin{array}{l}\text {-Degree of } \\
\text { freedom: } \\
\text { n- } 2=18\end{array}$ & $\begin{array}{l}\text {-t value : } \\
-1.3988\end{array}$ & $\begin{array}{l}-95 \% \text { confidence interval } \\
-0.025038257 \quad 0.005038257\end{array}$ \\
\hline
\end{tabular}

*the mean of section 2 is 7.88 and the mean of section 3 is 7.89 


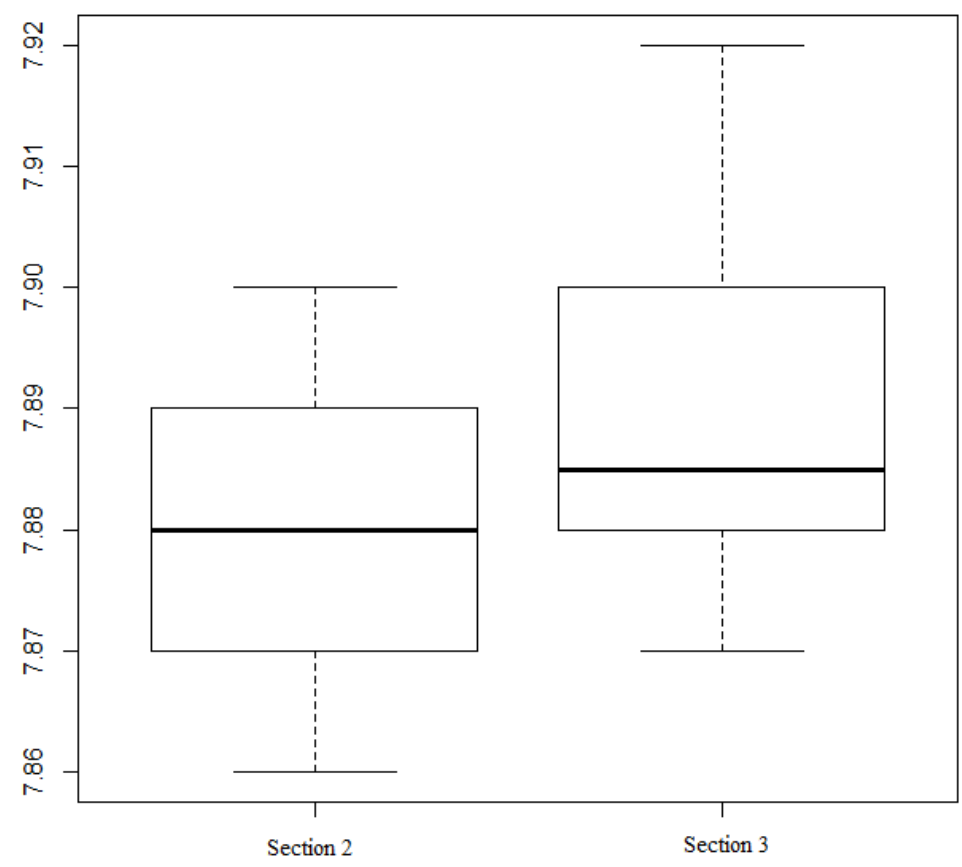

Figure 5.3.3: Boxplots - sections 2 and 3

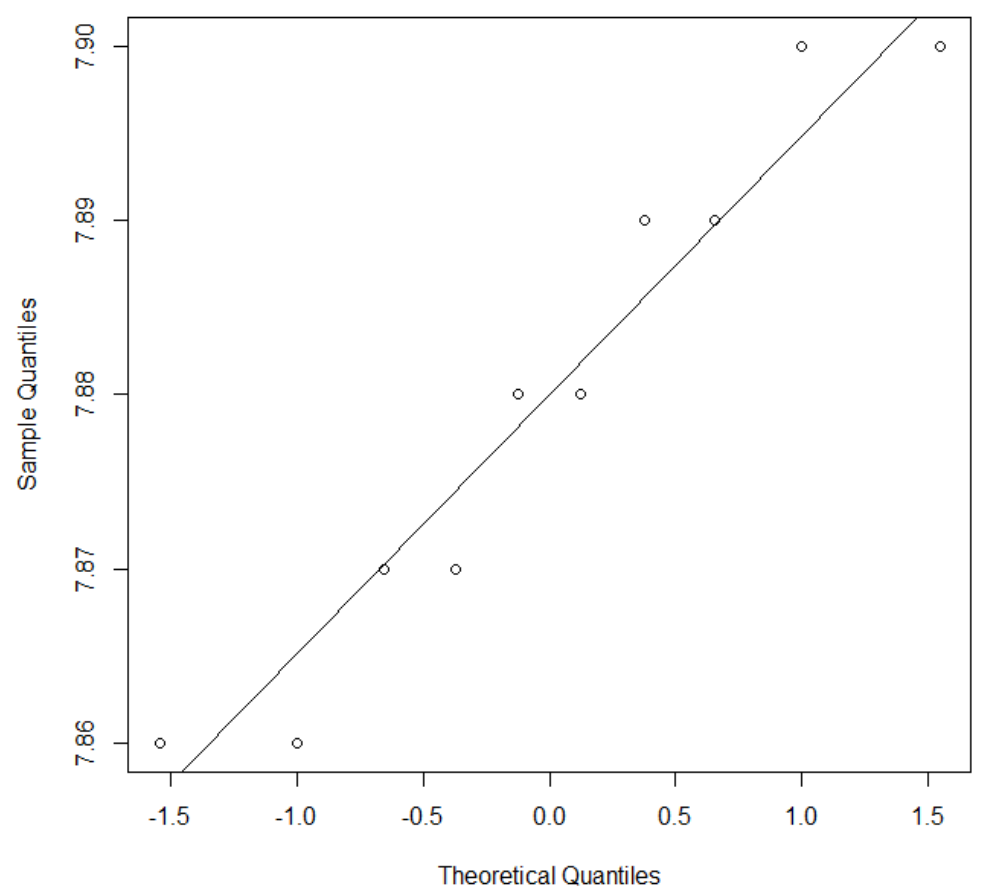

Figure 5.3.4: Normal Q-Q plot - section 2 


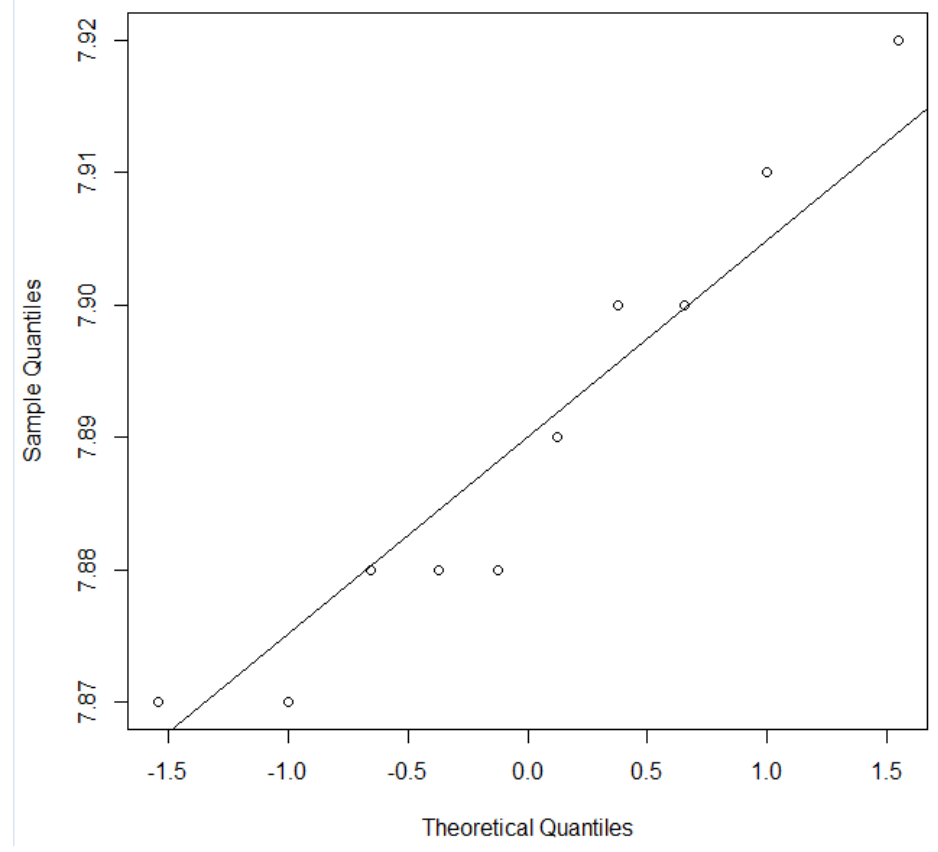

Figure 5.3.5: Normal Q-Q plot - section 3

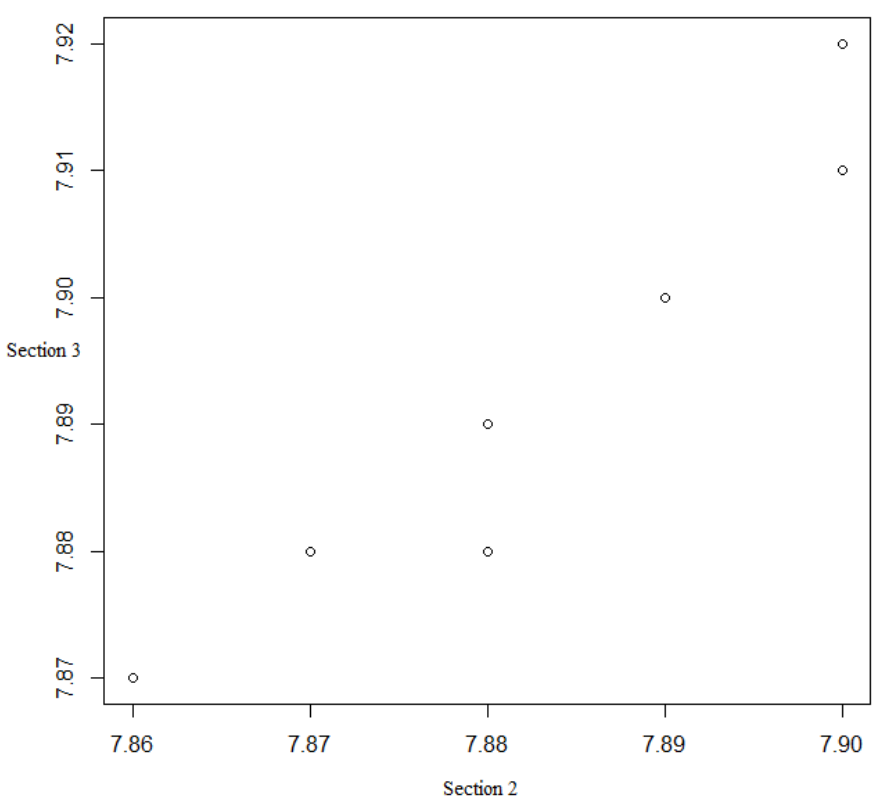

Figure 5.3.6: Q-Q plot - section 2 versus section 3 
Table 5.3.5 Check of Normality

\begin{tabular}{|c|c|c|c|c|c|}
\hline \multirow[b]{2}{*}{ Value } & \multicolumn{4}{|c|}{ Shapiro-Wilk Test } & \multirow[b]{2}{*}{ Explanation } \\
\hline & $\mathbf{H}_{\mathbf{0}}$ & $\mathbf{H}_{\mathbf{a}}$ & P-Value & Result & \\
\hline $\begin{array}{r}\mathrm{h}_{1}(\mathrm{~cm}) \\
\text { Section } 2\end{array}$ & $\begin{array}{l}\text { Data follows a } \\
\text { normal distribution }\end{array}$ & $\begin{array}{l}\mathrm{H}_{0} \\
\text { is false }\end{array}$ & 0.3411 & $\begin{array}{l}\text { Do not } \\
\text { reject } H_{0}\end{array}$ & $\begin{array}{l}\text { Fail to reject the null hypothesis. So, it } \\
\text { is reasonable to assume normality. }\end{array}$ \\
\hline $\begin{array}{r}\mathrm{h}_{2}(\mathrm{~cm}) \\
\text { Section } 3\end{array}$ & $\begin{array}{l}\text { Data follows a } \\
\text { normal distribution }\end{array}$ & $\begin{array}{c}\mathrm{H}_{0} \\
\text { is false }\end{array}$ & 0.3828 & $\begin{array}{l}\text { Do not } \\
\text { reject } H_{0}\end{array}$ & $\begin{array}{l}\text { Fail to reject the null hypothesis. So, it } \\
\text { is reasonable to assume normality. }\end{array}$ \\
\hline
\end{tabular}

Table 5.3.6 Check of the Equality of Variances

\begin{tabular}{|c|c|c|c|c|c|}
\hline \multirow[b]{2}{*}{ Value } & \multicolumn{5}{|c|}{ F Test } \\
\hline & $\mathbf{H}_{\mathbf{0}}$ & $\mathbf{H}_{\mathbf{a}}$ & P-Value & Result & Explanation \\
\hline \multirow[t]{2}{*}{$\begin{array}{c}\text { Section } 2 \text { versus } \\
\text { section } 3\end{array}$} & $\begin{array}{l}\text { The variance of } \\
\text { section } 2 \text { is equal to } \\
\text { the variance of }\end{array}$ & $\begin{array}{c}\mathrm{H}_{0} \\
\text { is false }\end{array}$ & 0.7023 & $\begin{array}{l}\text { Do not } \\
\text { reject } H_{0}\end{array}$ & $\begin{array}{l}\text { Fail to reject the null hypothesis. So, it } \\
\text { is reasonable to assume the equality of } \\
\text { variances. }\end{array}$ \\
\hline & $\bullet$ Assume $\alpha=0.005$ & & $\begin{array}{l}\text { - Degree of } \\
\text { freedom } \\
n-1=9\end{array}$ & & $\begin{array}{l}\bullet 95 \% \text { confidence interval } \\
0.1910663 .096919\end{array}$ \\
\hline
\end{tabular}


The t-test has been selected for the statistical analysis because there are just two data sets (section 2 and section 3). Table 5.3.4 shows the results of the t-test for these two sections. As can be seen from the results, the flow is completely stable.

There are two assumptions for the t-test to be applied. The first assumption is normality; it means that the data (in both data sets) should follow a normal distribution. The second assumption is the equality of variances in both data sets. Boxplots of both sections have been drawn as Figure 5.3.3. Moreover, the QQ-Plots (quantile-quantile plot) are presented in both sections (Figures 5.3.4 to 5.3.6). Furthermore, normality has been checked via the Shapiro-Wilk test (Table 5.3.5). In addition, the equality of variances has been checked by an F-test (Table 5.3.6).

All in all, four tests were selected to show the details of the calculations. In the first step, the flow was super-critical in tests 8 and 10 . Therefore, these tests were not selected for additional analysis. In the second step, the velocity was more than the permissible velocity in test number 7; therefore, this test did not meet the criteria for a stable condition. Test number 2 was the only test which was left for the third step of the analysis (surface flow fluctuations). Based on the results of the statistical analysis, the flow is completely stable in test number 2, which is compatible with the Flow Stability Number calculation; this dimensionless number is equal to one for this test number. Also, the Flow Stability Number for test number 2 is compatible with the Flow Stability Factor, at 0.9 for this test. Figure 5.3.7 shows the trend of $\mathrm{h}_{0} / \mathrm{a}$ to $\mathrm{dc} / \mathrm{h}_{0}$ in different thicknesses at the gate with an expansion structure. 


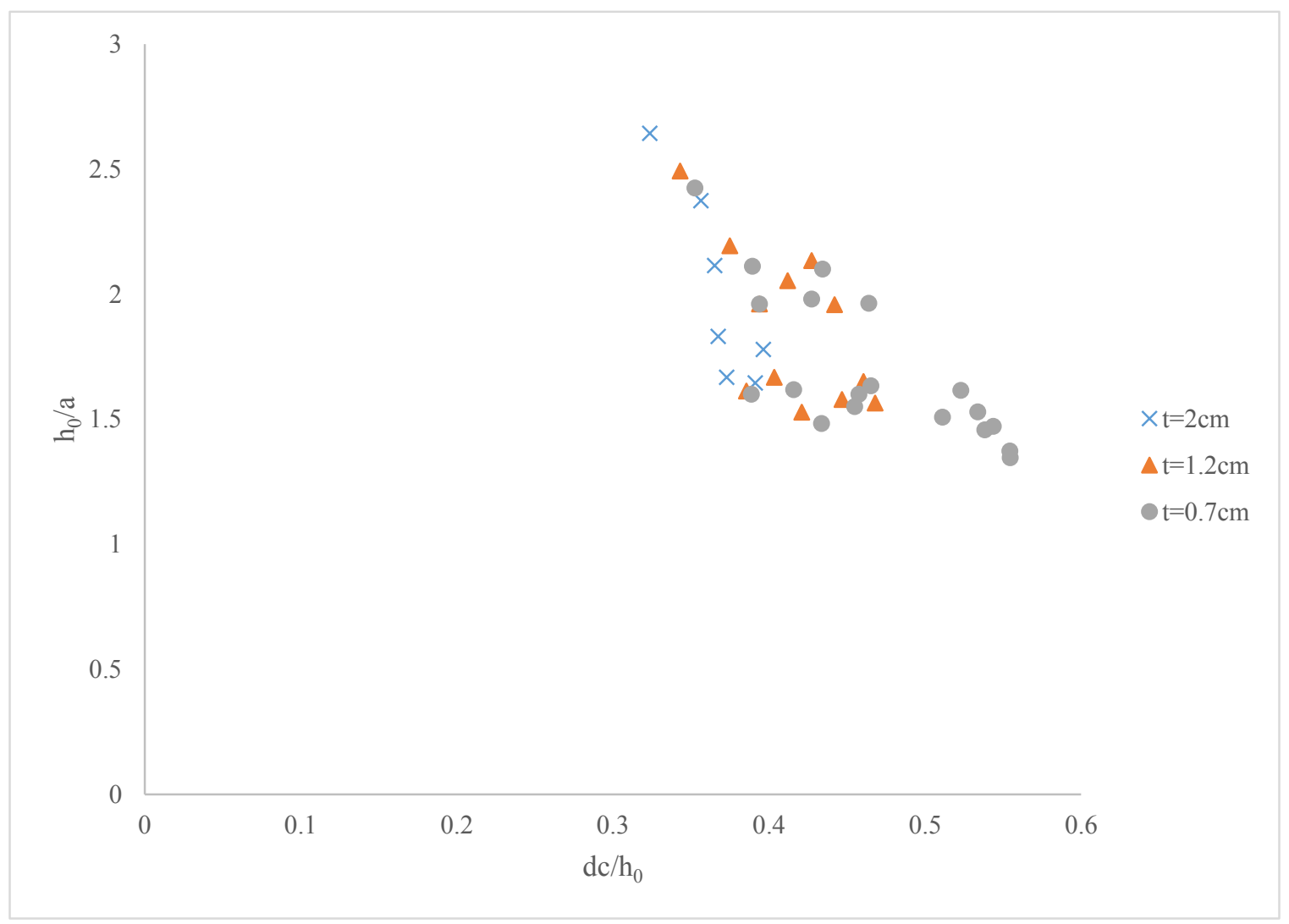

Figure 5.3.7: $\mathrm{h}_{0} / \mathrm{a}$ vs. de/ $\mathrm{h}_{0}$

Figure 5.3.7 indicates that the largest thickness ( 2 centimeters) can produce stable flow conditions only at low discharge rates and the performance of this thickness is not acceptable for mid and high discharge ranges. The second thickness (1.2 centimeters) can produce stable conditions for low and mid discharge rates. However, its performance is not acceptable at high discharge rates. Finally, the performance of the narrowest thickness ( 0.7 centimeters) is acceptable for all test discharge ranges. The results indicate that this thickness can produce a stable condition across various discharges. 
On the other hand, whenever the greatest thickness can produce a stable condition (low discharge rates), the upstream depth is higher than for the two other thicknesses (for the same discharge and gate opening); therefore, it is recommended that for low discharge rates a greater thickness be used to maintain the upstream flow at a high level. It should be noted that there is not a meaningful difference between the upstream depth results for the second and the third thicknesses.

\subsubsection{Experiments (Set Two)}

A total of three experiments (3 discharges) were selected to find the Flow Stability Number (Table 5.3.7). These experiments were performed in a flume, located at the Center for Research in Water Resources (CRWR) at the University of Texas at Austin. Flume details and measurements devices were presented in chapter 4.

Table 5.3.7 Tested Discharges

\begin{tabular}{|c|c|c|c|}
\hline \multirow[b]{2}{*}{ Numbers } & \multicolumn{3}{|c|}{ Discharges } \\
\hline & Gallons Per Minute & $\mathrm{m}^{3} / \mathrm{s}\left(\mathrm{x} 10^{3}\right)$ & $\mathrm{q}\left(\mathrm{m}^{2} / \mathrm{s}\right)$ \\
\hline 1 & 300.20 & 18.94 & 0.0344 \\
\hline 2 & 406.72 & 25.66 & 0.0466 \\
\hline 3 & 510.38 & 32.20 & 0.0585 \\
\hline
\end{tabular}

Table E.4 Appendix E reported the discharge, gate opening, critical depth, upstream depth, downstream depth in two sections, upstream and downstream velocities (two sections), and downstream energy (two sections), as well as the Flow Stability Number. Section one is located 0.4 meters upstream, section two is located 0.45 meters downstream of the gate, and finally, section three is also located one meter downstream from the gate. Depths are reported as the average of all measurements. In addition, 
Figures 5.3.8 (a) and (b) show the sediment transport and surface flow pattern in the presence of a gate with an expansion.

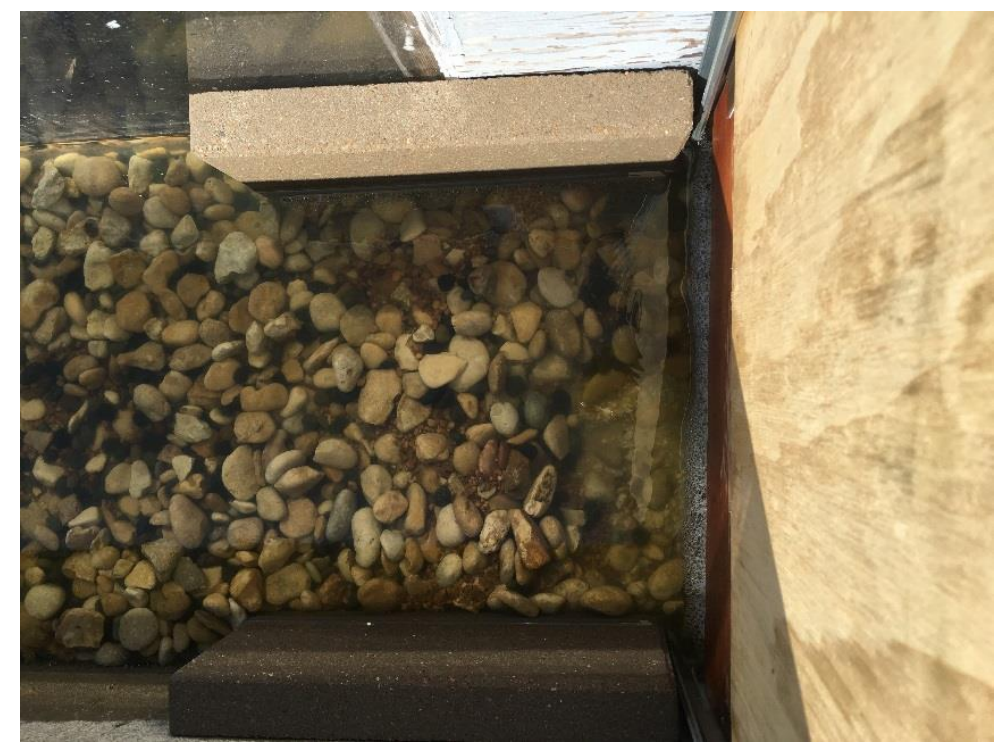

Figure 5.3.8. (a): Sediment transport in the presence of a gate with an expansion

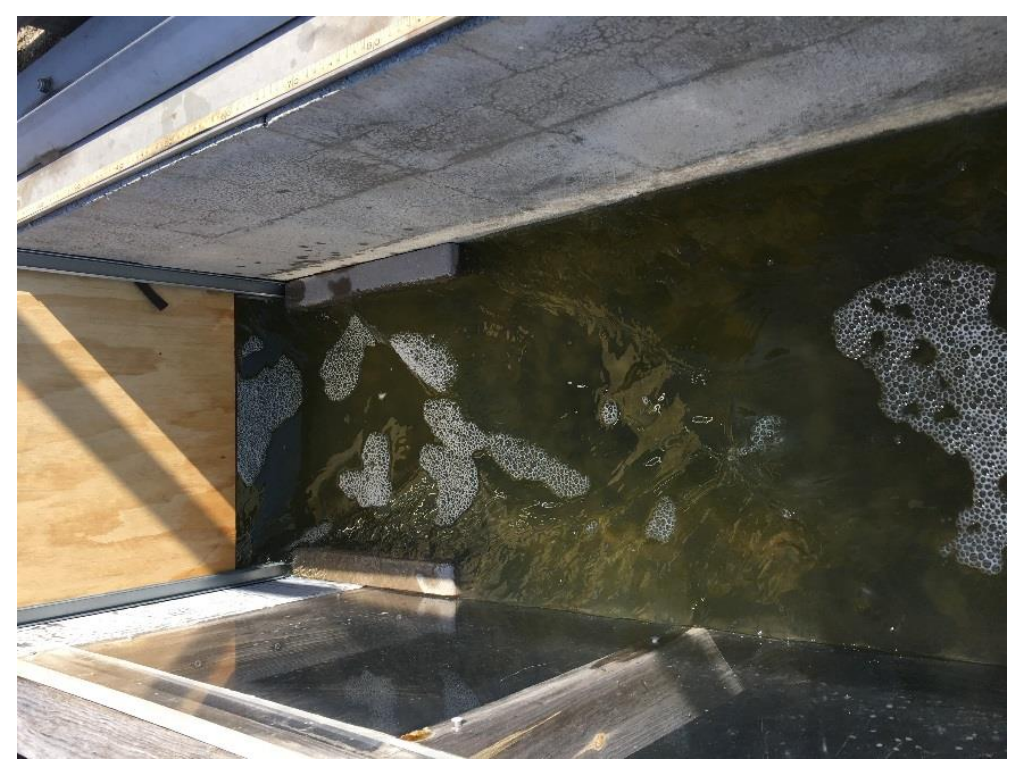

Figure 5.3.8. (b): Flow pattern in the presence of a gate with an expansion 
Test number 3 has been selected as an example to show the details of the calculation. The bed is a mixture of limestone pebbles, basalt pebbles, and brown pea gravel. Considering Table A.1, Appendix A, for stable, unlined, earthen channels, the maximum permissible velocity for coarse gravel, non-colloidal and fine gravel in clear water are 1.220 and $0.762 \mathrm{~m} / \mathrm{s}$, respectively. The minimum value is taken in this study as a safety factor. Tables 5.3.8 to 5.3.13 reported the details of the calculation to determine the acceptability of the stability. As can be seen from Table 5.3.8, the depths in both the second and the third sections are more than the critical depth; therefore, the first assumption is satisfied. Table 5.3.9 shows that the velocities in both sections are less than the permissible velocity; consequently, the test is eligible for checking the third assumption (surface flow fluctuations). Table 5.3.10 shows the depth measurements in sections two and three (test number 3) downstream. These values should then be used in the statistical analysis to determine if the flow is stable or not.

Table 5.3.8 Control of the Flow Condition

\begin{tabular}{|c|c|c|c|c|}
\hline Test Number & $\begin{array}{c}\mathrm{a} \\
(\mathrm{cm})\end{array}$ & $\begin{array}{l}\text { dc } \\
(\mathrm{cm})\end{array}$ & $\begin{array}{c}h_{1}(\mathrm{~cm}) \\
\text { Section } 2\end{array}$ & $\begin{array}{c}\mathrm{h}_{2}(\mathrm{~cm}) \\
\text { Section } 3\end{array}$ \\
\hline 3 & 14.00 & 7.04 & 12.38 & 12.38 \\
\hline
\end{tabular}

Table 5.3.9 Control of the Permissible Velocity

\begin{tabular}{ccccc}
\hline Test Number & Bed Material & $\begin{array}{c}\text { Permissible } \\
\text { Velocity }(\mathbf{m} / \mathbf{s})\end{array}$ & $\begin{array}{c}\mathbf{V}_{\mathbf{1}}(\mathbf{m} / \mathbf{s}) \\
\text { Section 2 }\end{array}$ & $\begin{array}{c}\mathbf{V}_{\mathbf{2}}(\mathbf{m} / \mathbf{s}) \\
\text { Section 3 }\end{array}$ \\
\hline 3 & Fine gravel & 0.762 & 0.50 & 0.50 \\
\hline
\end{tabular}


Table 5.3.10 Depth Measurements

\begin{tabular}{|c|c|c|}
\hline Number & $\begin{array}{c}\mathrm{h}_{1}(\mathrm{~cm}) \\
\text { Section } 2\end{array}$ & $\begin{array}{c}\mathrm{h}_{2}(\mathrm{~cm}) \\
\text { Section } 3\end{array}$ \\
\hline 1 & 12.39 & 12.38 \\
\hline 2 & 12.40 & 12.38 \\
\hline 3 & 12.39 & 12.37 \\
\hline 4 & 12.38 & 12.39 \\
\hline 5 & 12.38 & 12.39 \\
\hline 6 & 12.38 & 12.38 \\
\hline 7 & 12.39 & 12.37 \\
\hline 8 & 12.37 & 12.37 \\
\hline 9 & 12.37 & 12.40 \\
\hline 10 & 12.39 & 12.39 \\
\hline
\end{tabular}


Table 5.3.11 Two-sided t-test

\begin{tabular}{|c|c|c|c|c|c|}
\hline \multirow[b]{2}{*}{ Value } & \multicolumn{5}{|c|}{ t-test } \\
\hline & $\mathbf{H}_{0}$ & $\mathbf{H}_{\mathbf{a}}$ & P-Value & Result & Explanation \\
\hline \multirow[t]{2}{*}{$\begin{array}{c}\text { Section } 2 \text { versus } \\
\text { section } 3\end{array}$} & $\begin{array}{l}* \text { The average of } \\
\text { section } 2 \text { is equal to } \\
\text { the average of } \\
\text { section } 3\end{array}$ & $\begin{array}{l}\mathrm{H}_{0} \\
\text { is false }\end{array}$ & 0.6601 & $\begin{array}{l}\text { Do not } \\
\text { reject } H_{0}\end{array}$ & $\begin{array}{l}\text { There is not enough evidence to } \\
\text { conclude that the average of section } 2 \text { is } \\
\text { different from the average of section } 3 \text {. } \\
\text { So, it is reasonable to assume that the } \\
\text { two averages are equal. }\end{array}$ \\
\hline & $\bullet$ Assume $\alpha=0.005$ & & $\begin{array}{l}\text { Degree of } \\
\text { freedom: } \\
n-2=18\end{array}$ & $\begin{array}{l}\text {-t value : } \\
0.44721\end{array}$ & $\begin{array}{l}-95 \% \text { confidence interval } \\
-0.007398603 \quad 0.011398603\end{array}$ \\
\hline
\end{tabular}

*the mean of section 2 is 12.384 and the mean of section 3 is 12.382 


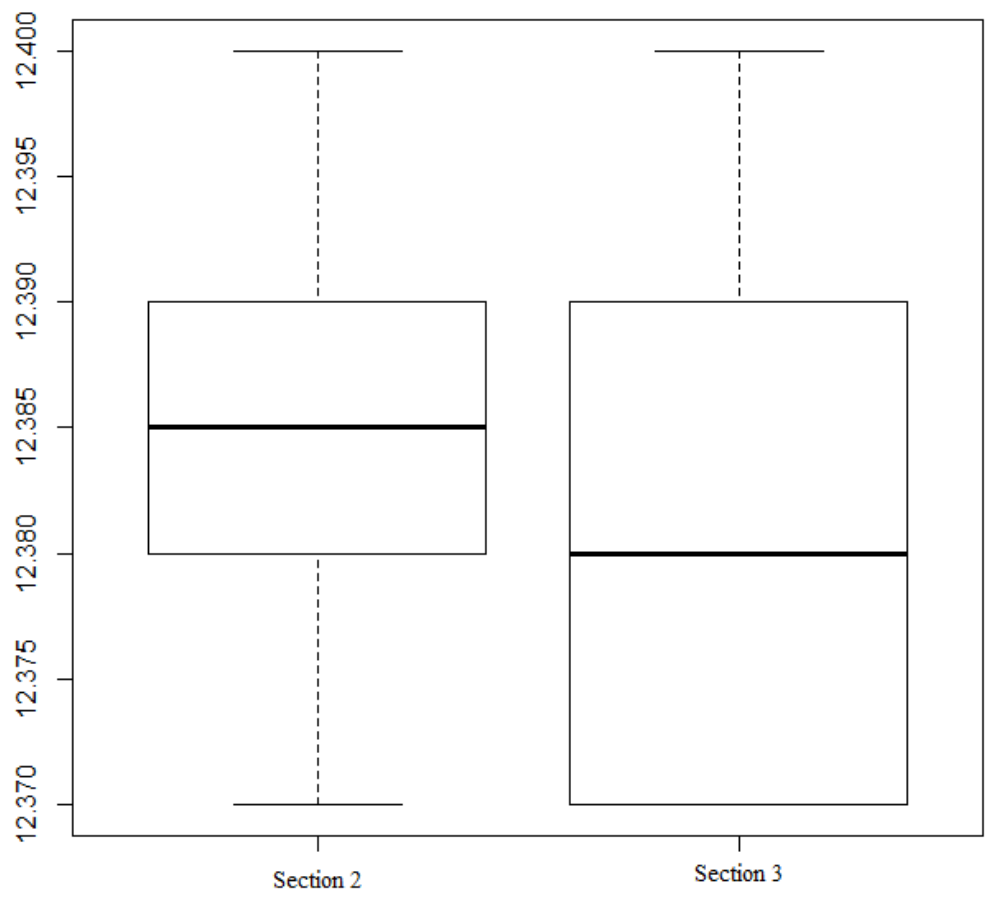

Figure 5.3.9: Boxplots - sections 2 and 3

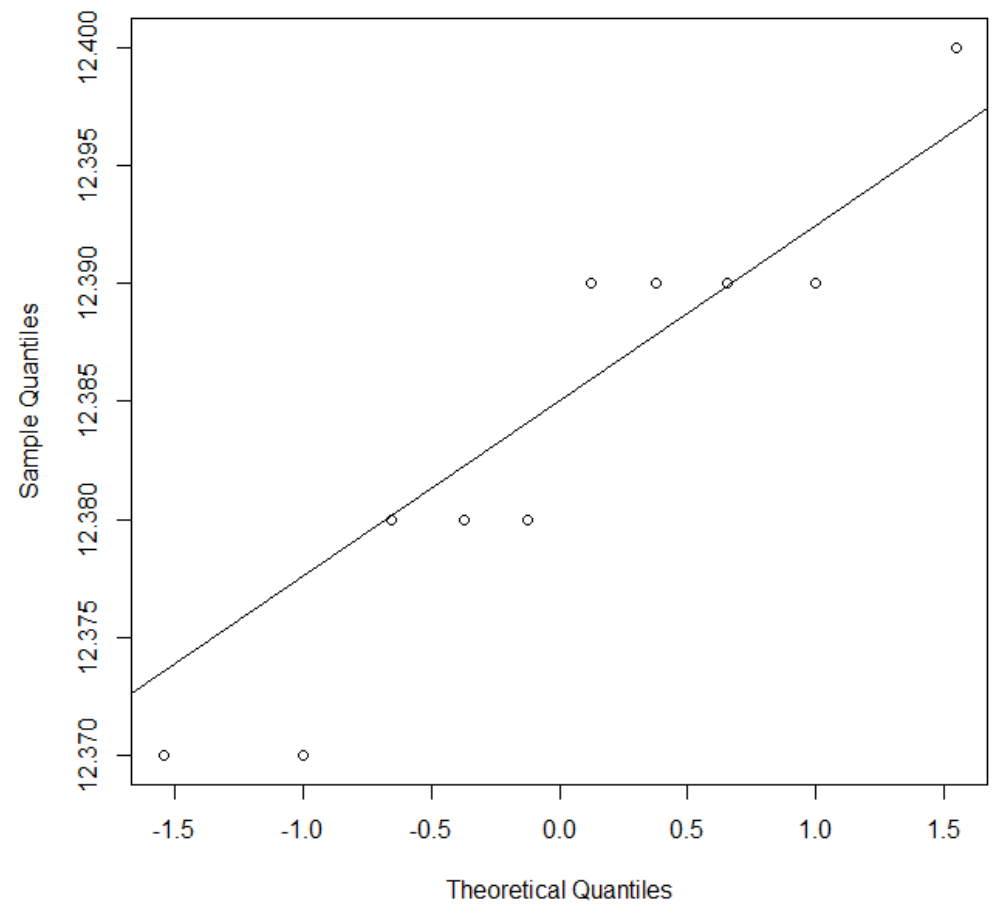

Figure 5.3.10: Normal Q-Q plot - section 2 


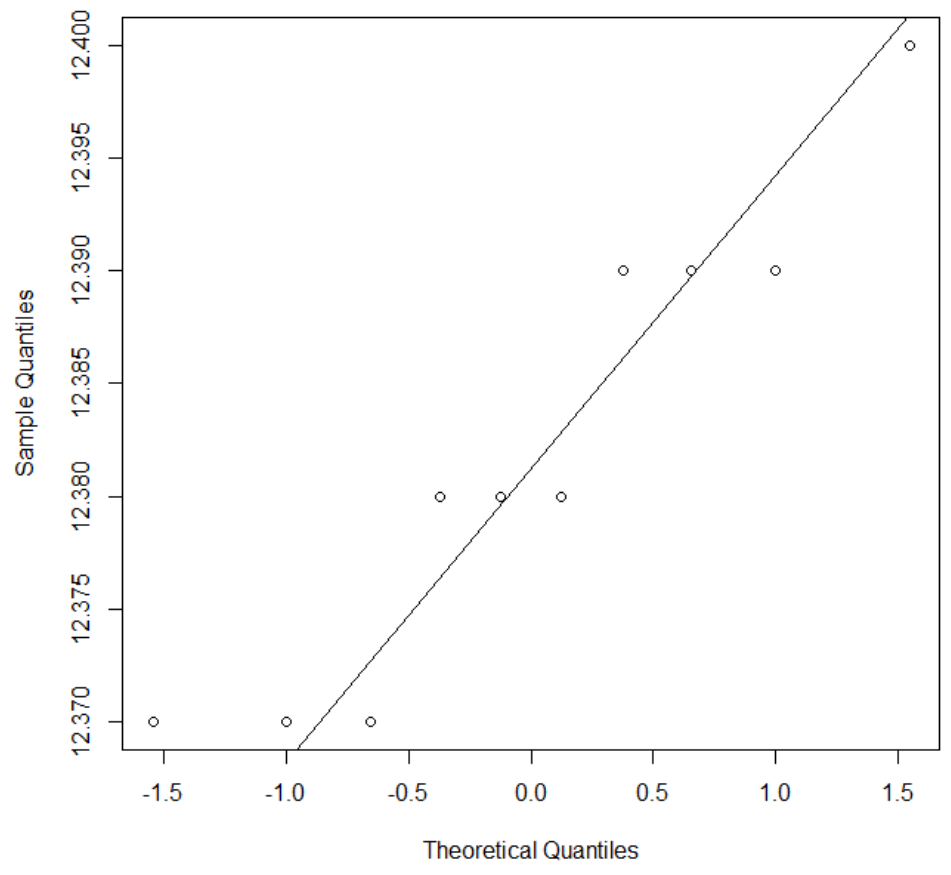

Figure 5.3.11: Normal Q-Q plot - section 3

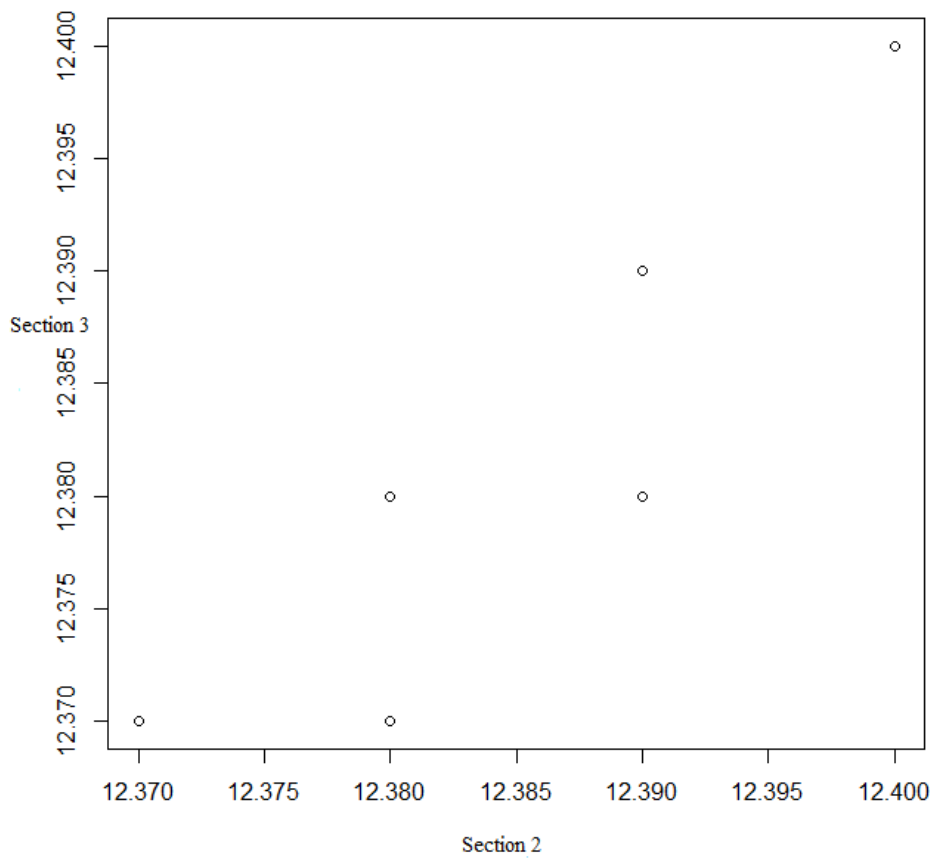

Figure 5.3.12: Q-Q plot - section 2 versus section 3 
Table 5.3.12 Check of Normality

\begin{tabular}{|c|c|c|c|c|c|}
\hline \multirow[b]{2}{*}{ Value } & \multicolumn{4}{|c|}{ Shapiro-Wilk Test } & \multirow[b]{2}{*}{ Explanation } \\
\hline & $\mathbf{H}_{\mathbf{0}}$ & $\mathbf{H}_{\mathbf{a}}$ & P-Value & Result & \\
\hline $\begin{array}{r}\mathrm{h}_{1}(\mathrm{~cm}) \\
\text { Section } 2\end{array}$ & $\begin{array}{l}\text { Data follows a } \\
\text { normal distribution }\end{array}$ & $\begin{array}{l}\mathrm{H}_{0} \\
\text { is false }\end{array}$ & 0.2449 & $\begin{array}{l}\text { Do not } \\
\text { reject } H_{0}\end{array}$ & $\begin{array}{l}\text { Fail to reject the null hypothesis. So, it } \\
\text { is reasonable to assume normality. }\end{array}$ \\
\hline $\begin{array}{r}\mathrm{h}_{2}(\mathrm{~cm}) \\
\text { Section } 3\end{array}$ & $\begin{array}{l}\text { Data follows a } \\
\text { normal distribution }\end{array}$ & $\begin{array}{c}\mathrm{H}_{0} \\
\text { is false }\end{array}$ & 0.191 & $\begin{array}{l}\text { Do not } \\
\text { reject } H_{0}\end{array}$ & $\begin{array}{l}\text { Fail to reject the null hypothesis. So, it } \\
\text { is reasonable to assume normality. }\end{array}$ \\
\hline
\end{tabular}

Table 5.3.13 Check of the Equality of Variances

\begin{tabular}{|c|c|c|c|c|c|}
\hline \multirow[b]{2}{*}{ Value } & \multicolumn{5}{|c|}{ F Test } \\
\hline & $\mathbf{H}_{\mathbf{0}}$ & $\mathbf{H}_{\mathbf{a}}$ & P-Value & Result & Explanation \\
\hline $\begin{array}{c}\text { Section } 2 \text { versus } \\
\text { section } 3\end{array}$ & $\begin{array}{l}\text { The variance of } \\
\text { section } 2 \text { is equal to } \\
\text { the variance of }\end{array}$ & $\begin{array}{l}\quad \mathrm{H}_{0} \\
\text { is false }\end{array}$ & 0.8456 & $\begin{array}{l}\text { Do not } \\
\text { reject } H_{0}\end{array}$ & $\begin{array}{l}\text { Fail to reject the null hypothesis. So, it } \\
\text { is reasonable to assume the equality of } \\
\text { variances. }\end{array}$ \\
\hline & - Assume $\alpha=0.005$ & & $\begin{array}{l}\text {-Degree of } \\
\text { freedom } \\
n-1=9\end{array}$ & & $\begin{array}{l}\bullet 95 \% \text { confidence interval } \\
0.2173376 \quad 3.5227449\end{array}$ \\
\hline
\end{tabular}


A t-test has been selected for the statistical analysis because there are just two data sets (section 2 and section 3). Table 5.3.11 shows the results of the t-test for these two sections. As can be seen from the results, the flow is completely stable.

There are two assumptions that must be satisfied for a t-test to be applied. The first assumption is normality; it means that the data (in both data sets) should follow a normal distribution. The second assumption is the equality of variances in both data sets. Boxplots of both sections have been drawn as Figure 5.3.9. Moreover, the QQPlots (quantile-quantile plot) are presented in both sections (Figures 5.3.10 to 5.3.12). Furthermore, normality was checked via the Shapiro-Wilk test (Table 5.3.12). In addition, the equality of variances was checked by an F-test (Table 5.3.13).

Based on the results of the statistical analysis, the flow is completely stable in test number 3 (in the second lab) which is compatible with the Flow Stability Number calculation; this dimensionless number is equal to one for this test number. Also, the Flow Stability Number, for test number 2 (in the first lab), is approximately compatible with the Flow Stability Factor, which was determined to be 0.9 for this test. 


\section{CHAPTER 5}

\section{RESULTS \& DISCUSSION}

\section{SECTION 4}

\section{THE FLOW STABILITY NUMBER IN A GATE WITH CONTRACTIONS}

\subsubsection{Introduction}

The Flow Stability Number was calculated for vertical sluice gates in section 2 and a gate with an expansion in section 3. In this section, a combination of gates with contractions is considered as another type of hydraulic structure. The experiments were conducted in two laboratories; the Fluid Mechanics Laboratory at Florida International University and the Center for Research in Water Resources at the University of Texas at Austin. Two laboratories were selected for this research to see the scale effect. Moreover, sediment transport was considered in the second laboratory to find the acceptable range of the Flow Stability Number.

Three thicknesses were considered in the first laboratory; 2 centimeters, 1.2 centimeters, and 0.7 centimeters to determine the effect of thickness on the Flow Stability Number.

\subsubsection{Experiments (Set One)}

A total of 16 experiments, including five discharges (in one case, six discharges) and three thicknesses, were selected from a gate with contraction results to find the Flow 
Stability Number in the first laboratory. The experiments were conducted in a narrow flume, located at the Fluid Mechanics Laboratory at the Civil and Environmental Engineering Department of Florida International University. Flume details and measurements devices were presented in chapter 4.

Six discharges were tested in this research and presented in Table 5.4.1, ranging from low to high levels. For the narrowest thickness, six tests were performed. Determining the effect of thickness on the Flow Stability Number for each discharge was the purpose of this study. The optimum gate opening happens when the flow condition is stable downstream of the hydraulic structure.

The Flow Stability Number was defined in chapter 4, based on the Fuzzy Concept in sub-critical flow, to classify the downstream flow condition. This dimensionless number is defined based on total energy. Velocity and depth were measured to calculate energy. In each test, measurements were performed in four sections; one section upstream of the hydraulic structure, one inside the structure, and two downstream of the structure.

Tables F.1 to F.3 Appendix F reported the discharge, gate opening, critical depth, upstream depth, downstream depth in two sections, upstream and downstream velocity (two sections), and downstream energy (two sections), as well as the Flow Stability Number for a gate with contractions with different thicknesses. The results of the section inside the hydraulic structure are not reported in these; therefore, section one is located upstream, section two is located immediately after the hydraulic structure, and finally, section three is also located downstream from section two at the beginning of 
the uniform flow (Figures 5.4.1). Depths are reported as the average of all measurements.

Table5.4.1 Tested Discharges

\begin{tabular}{cccc}
\hline & \multicolumn{3}{c}{ Discharges } \\
\cline { 2 - 4 } Numbers & Gallon Per Minutes & $\mathrm{m}^{3} / \mathrm{s}\left(\mathrm{x} 10^{3}\right)$ & $\mathrm{q}\left(\mathrm{m}^{2} / \mathrm{s}\right)$ \\
\hline 1 & 34.6 & 2.18 & 0.0198 \\
\hline 2 & 38.8 & 2.45 & 0.0223 \\
\hline 3 & 41.4 & 2.61 & 0.0237 \\
\hline 4 & 47.5 & 3.00 & 0.0272 \\
\hline 5 & 53.2 & 3.36 & 0.0305 \\
\hline 6 & 56.8 & 3.58 & 0.0326 \\
\hline
\end{tabular}

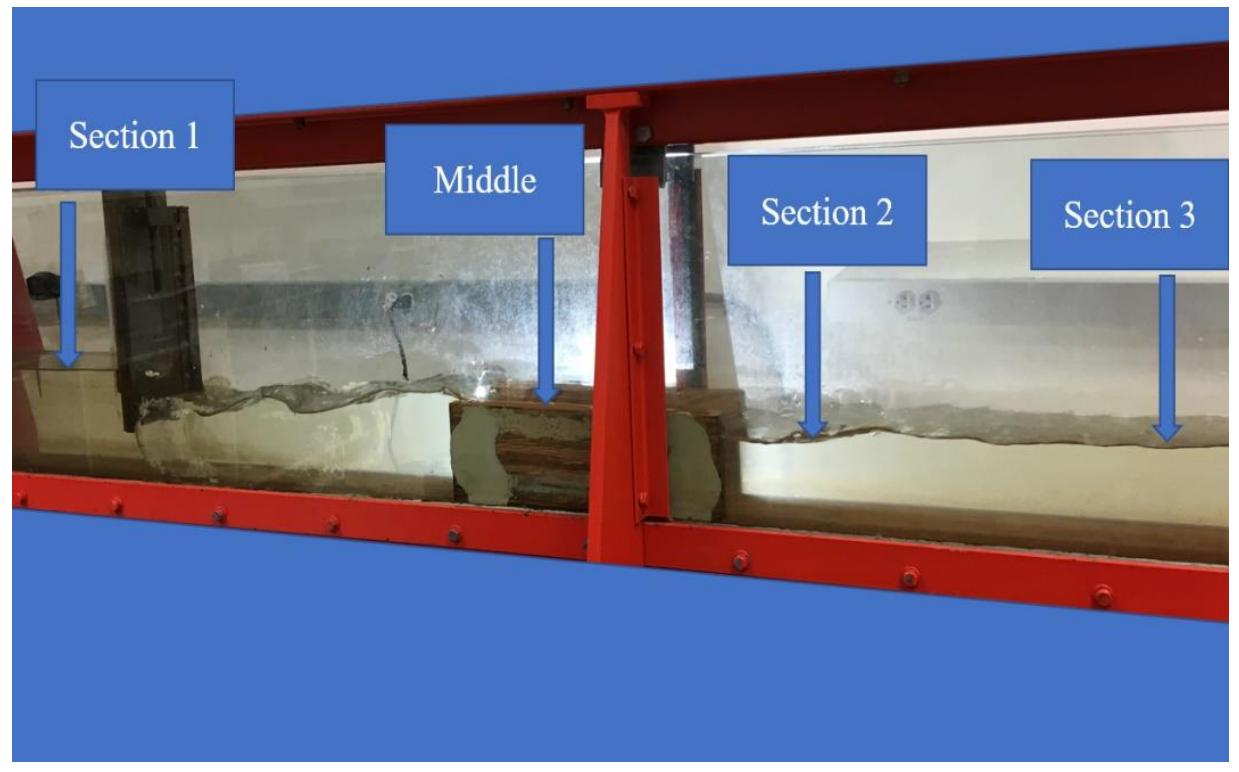

Figure 5.4.1: Sections in a gate with a contraction 
The Flow Stability Number is not defined in supercritical flows, whereas it is equal to the ratio of total energies (sections two and three) in critical and sub-critical flows (Tables F.1 to F.3 Appendix F). Figures 5.4.2 (a) and (b) show the flow fluctuations and stable flow in the presence of a gate with contractions.

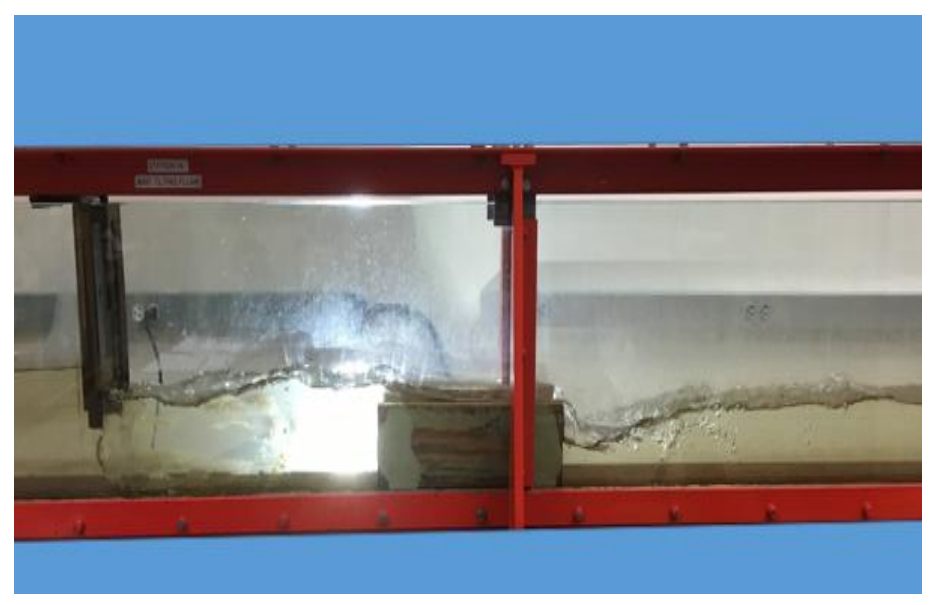

Figure 5.4.2. (a): Flow fluctuations in the presence of a gate with contractions

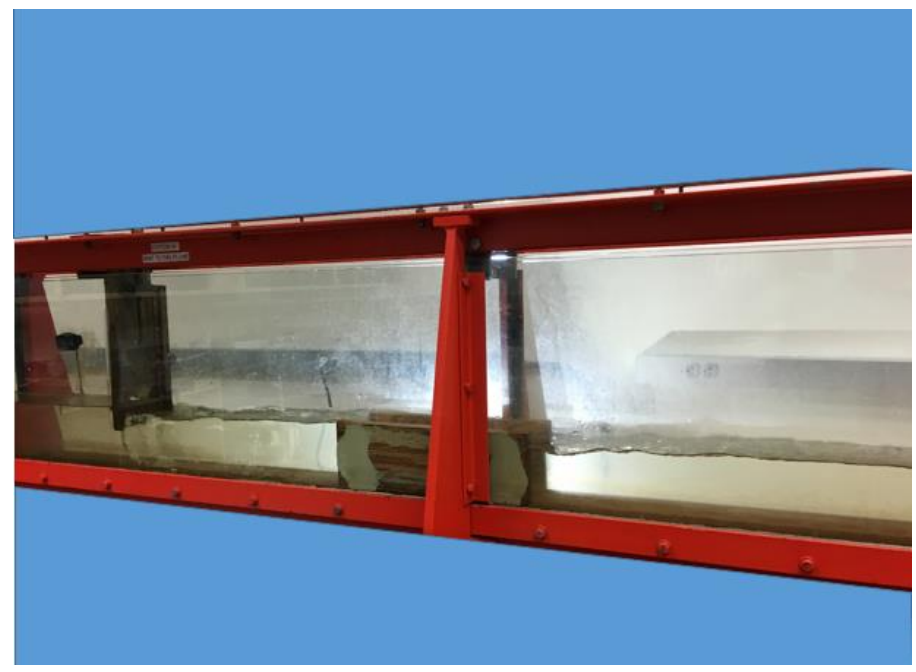

Figure 5.4.2. (b): Stable flow in the presence of a gate with contractions 
Test number four from Table F.1 and test number five from Table F.3 (Appendix F) have been selected as examples to show the details of the calculations. It is not possible to see the sediment transport in the flume at the FIU Lab. Therefore, the bed is assumed to be alluvial silts, colloidal to find the permissible velocity (hypothetical situation). Considering Table A.1, Appendix A for stable, unlined, earthen channels, the maximum permissible velocity for fine sand, non-colloidal in clear water is $0.457 \mathrm{~m} / \mathrm{s}$. Tables 5.4.2 to 5.4.7 reported the details of the calculations to determine the acceptability of the stability. As can be seen from Table 5.4.2, the depths in the second section of both tests are more than the critical depth; therefore, the flow is sub-critical and satisfies the first assumption. According to the results of Table 5.4.2, test numbers four and five will not be excluded from the rest of the calculations. Table 5.4.3 shows that in test 4 the velocity in the second section is more than the permissible velocity; therefore, this test cannot satisfy the stable condition. Consequently, the only test which remains to check the third assumption (surface flow fluctuations) is test number 5 . Table 5.4.4 shows the depth measurements in sections two and three (test number 5) downstream. These values should then be used in statistical analysis to determine if the flow is stable or not.

Table 5.4.2 Control of the Flow Condition

\begin{tabular}{ccccc}
\hline Test Number & $\begin{array}{c}\mathbf{a} \\
(\mathbf{c m})\end{array}$ & $\begin{array}{c}\mathbf{d c} \\
(\mathbf{c m})\end{array}$ & $\begin{array}{c}\mathbf{h}_{1}(\mathbf{c m}) \\
\text { Section } \mathbf{2}\end{array}$ & $\begin{array}{c}\mathbf{h}_{2}(\mathbf{c m}) \\
\text { Section 3 }\end{array}$ \\
\hline 4 & 6.0 & 4.56 & 8.50 & 8.60 \\
\hline 5 & 6.0 & 4.56 & 8.60 & 8.60 \\
\hline
\end{tabular}


Table 5.4.3 Control of the Permissible Velocity

\begin{tabular}{ccccc}
\hline Test Number & Bed Material & $\begin{array}{c}\text { Permissible } \\
\text { Velocity }(\mathbf{m} / \mathbf{s})\end{array}$ & $\begin{array}{c}\mathbf{V}_{\mathbf{1}}(\mathbf{m} / \mathbf{s}) \\
\text { Section } 2\end{array}$ & $\begin{array}{c}\mathbf{V}_{\mathbf{2}}(\mathbf{m} / \mathbf{s}) \\
\text { Section 3 }\end{array}$ \\
\hline 4 & $\begin{array}{c}\text { Fine sand, } \\
\text { non-colloidal }\end{array}$ & 0.457 & 0.5 & 0.3 \\
\hline 5 & $\begin{array}{c}\text { Fine sand, } \\
\text { non-colloidal }\end{array}$ & 0.457 & 0.4 & 0.4 \\
\hline
\end{tabular}

Table 5.4.4 Depth Measurements

\begin{tabular}{ccc}
\hline Number & $\begin{array}{c}\mathbf{h}_{\mathbf{1}}(\mathbf{c m}) \\
\text { Section 2 }\end{array}$ & $\begin{array}{c}\mathbf{h}_{2}(\mathbf{c m}) \\
\text { Section 3 }\end{array}$ \\
\hline 1 & 8.61 & 8.60 \\
\hline 2 & 8.61 & 8.60 \\
\hline 3 & 8.62 & 8.60 \\
\hline 4 & 8.61 & 8.59 \\
\hline 5 & 8.60 & 8.59 \\
\hline 6 & 8.59 & 8.60 \\
\hline 7 & 8.60 & 8.61 \\
\hline 8 & 8.59 & 8.61 \\
\hline 10 & 8.60 & 8.60 \\
\hline & 8.60 & 8.61 \\
\hline
\end{tabular}


Table 5.4.5 Two-sided t-test

\begin{tabular}{|c|c|c|c|c|c|}
\hline \multirow[b]{2}{*}{ Value } & \multicolumn{5}{|c|}{ t-test } \\
\hline & $\mathbf{H}_{0}$ & $\mathbf{H}_{\mathbf{a}}$ & P-Value & Result & Explanation \\
\hline \multirow[t]{2}{*}{$\begin{array}{l}\text { Section } 2 \text { versus } \\
\text { section } 3\end{array}$} & $\begin{array}{l}\text { *The average of } \\
\text { section } 2 \text { is equal to } \\
\text { the average of } \\
\text { section } 3\end{array}$ & $\begin{array}{l}\quad \mathrm{H}_{0} \\
\text { is false }\end{array}$ & 0.6055 & $\begin{array}{l}\text { Do not } \\
\text { reject } H_{0}\end{array}$ & $\begin{array}{l}\text { There is not enough evidence to } \\
\text { conclude that the average of section } 2 \text { is } \\
\text { different from the average of section } 3 . \\
\text { So, it is reasonable to assume that the } \\
\text { two averages are equal. }\end{array}$ \\
\hline & $\bullet$ Assume $\alpha=0.005$ & & $\begin{array}{l}\text { Degree of } \\
\text { freedom: } \\
n-2=18\end{array}$ & $\begin{array}{l}\text { et value : } \\
0.52623\end{array}$ & $\begin{array}{l}\bullet 95 \% \text { confidence interval } \\
-0.006019553 \quad 0.010019553\end{array}$ \\
\hline
\end{tabular}

*the mean of section 2 is 8.603 and the mean of section 3 is 8.601 


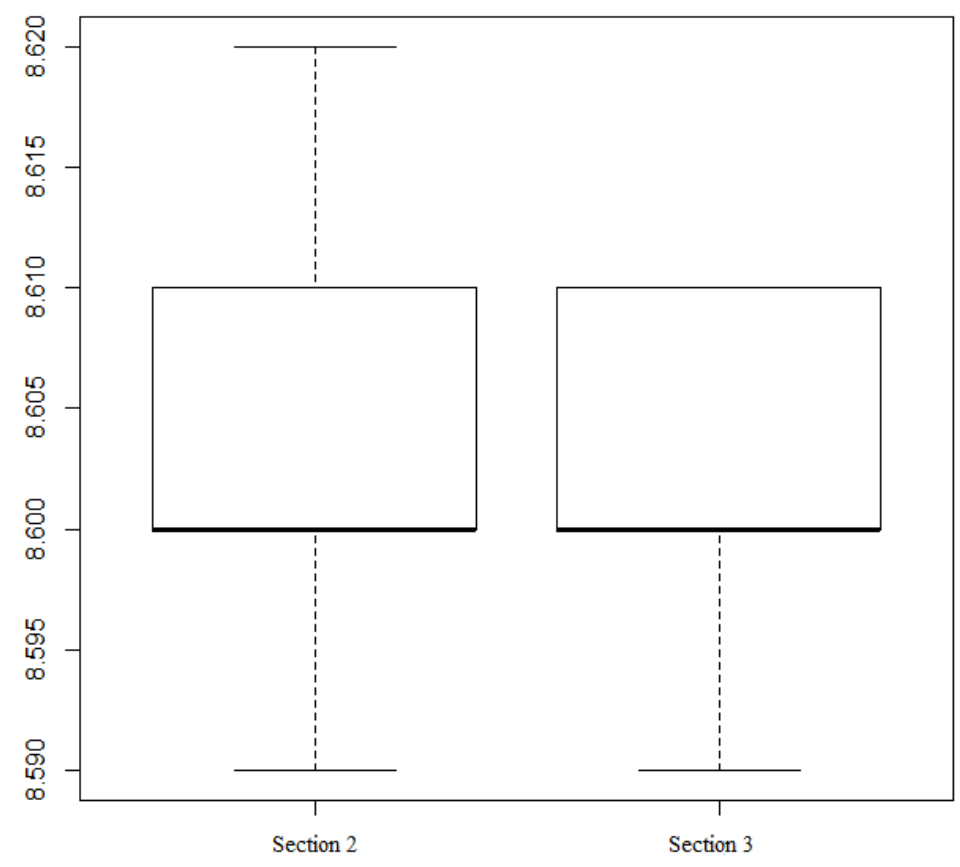

Figure 5.4.3: Boxplots - sections 2 and 3

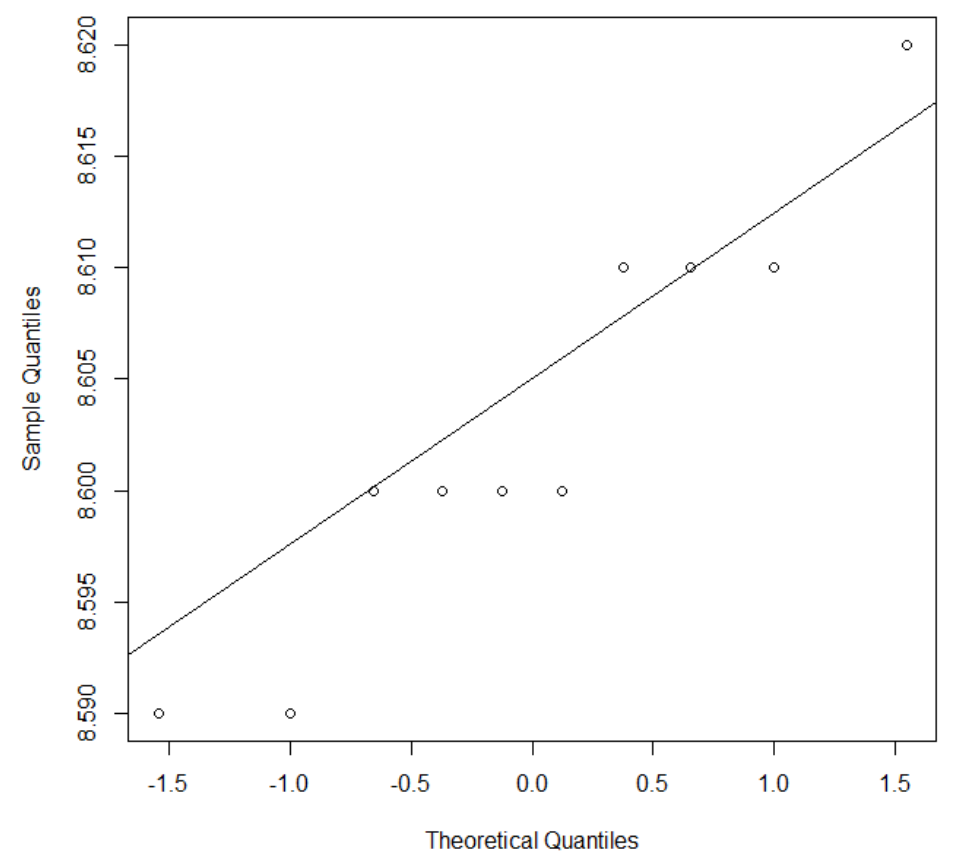

Figure 5.4.4: Normal Q-Q plot - section 2 


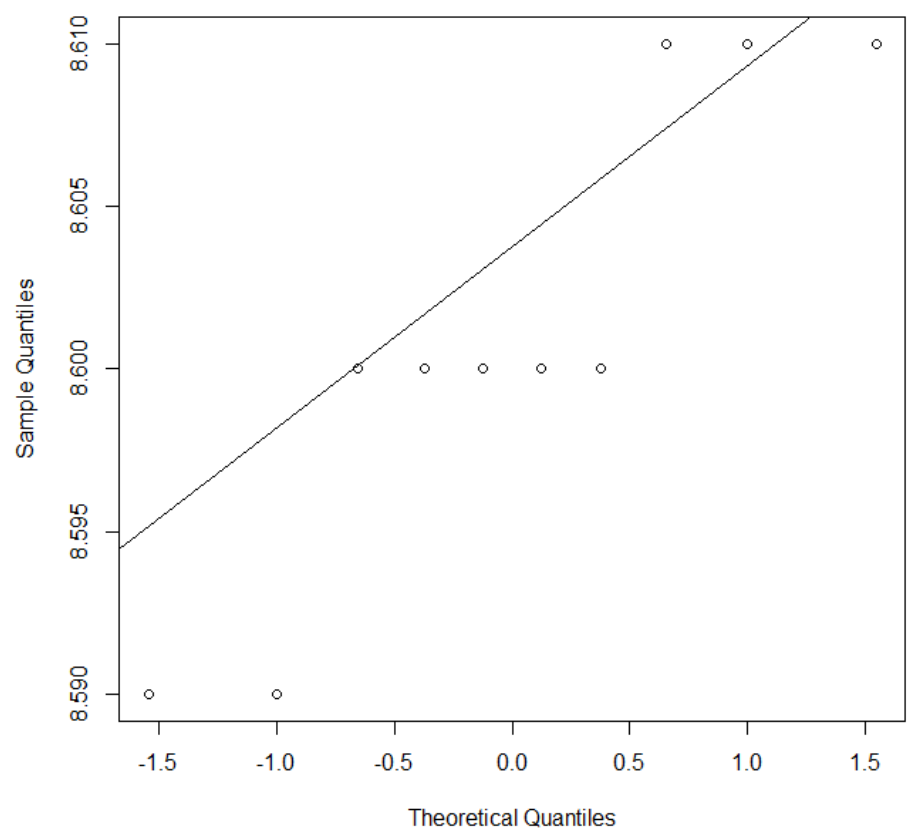

Figure 5.4.5: Normal Q-Q plot - section 3

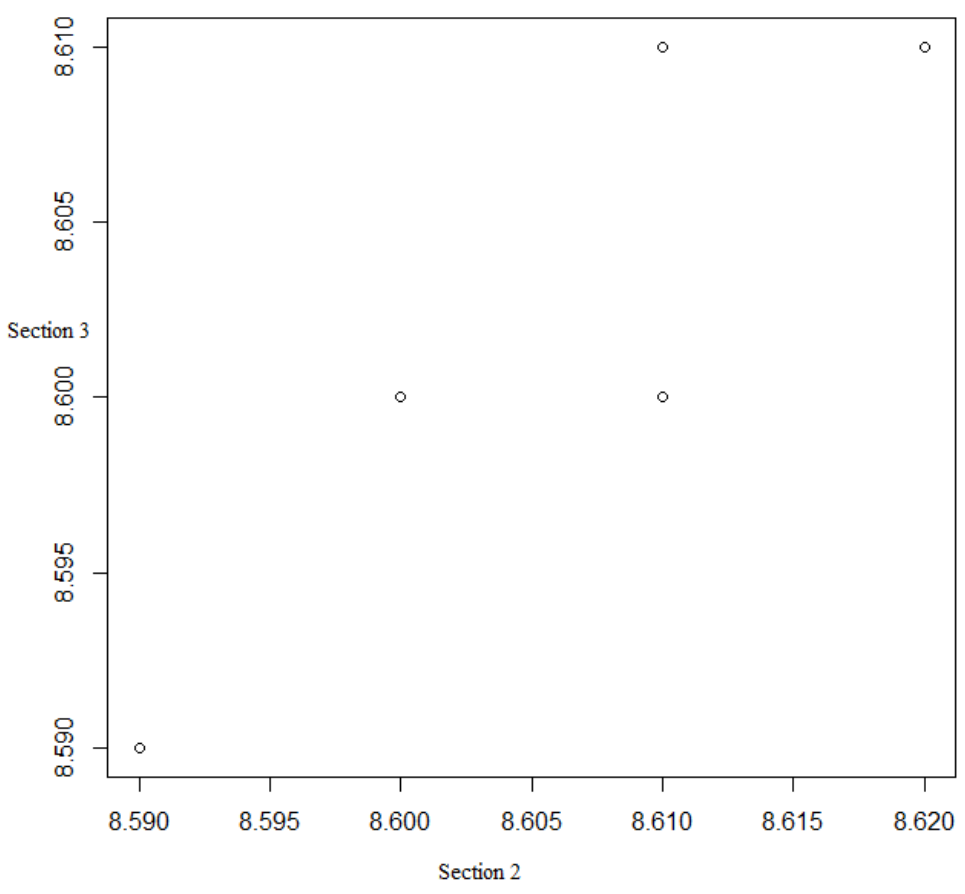

Figure 5.4.6: Q-Q plot - section 2 versus section 3 
Table 5.4.6 Check of Normality

\begin{tabular}{|c|c|c|c|c|c|}
\hline \multirow[b]{2}{*}{ Value } & \multicolumn{4}{|c|}{ Shapiro-Wilk Test } & \multirow[b]{2}{*}{ Explanation } \\
\hline & $\mathbf{H}_{\mathbf{0}}$ & $\mathbf{H}_{\mathbf{a}}$ & P-Value & Result & \\
\hline $\begin{array}{r}\mathrm{h}_{1}(\mathrm{~cm}) \\
\text { Section } 2\end{array}$ & $\begin{array}{l}\text { Data follows a } \\
\text { normal distribution }\end{array}$ & $\begin{array}{l}\mathrm{H}_{0} \\
\text { is false }\end{array}$ & 0.1488 & $\begin{array}{l}\text { Do not } \\
\text { reject } H_{0}\end{array}$ & $\begin{array}{l}\text { Fail to reject the null hypothesis. So, it } \\
\text { is reasonable to assume normality. }\end{array}$ \\
\hline $\begin{array}{r}\mathrm{h}_{2}(\mathrm{~cm}) \\
\text { Section } 3\end{array}$ & $\begin{array}{l}\text { Data follows a } \\
\text { normal distribution }\end{array}$ & $\begin{array}{c}\mathrm{H}_{0} \\
\text { is false }\end{array}$ & 0.2869 & $\begin{array}{l}\text { Do not } \\
\text { reject } H_{0}\end{array}$ & $\begin{array}{l}\text { Fail to reject the null hypothesis. So, it } \\
\text { is reasonable to assume normality. }\end{array}$ \\
\hline
\end{tabular}

Table 5.4.7 Check of the Equality of Variances

\begin{tabular}{|c|c|c|c|c|c|}
\hline \multirow[b]{2}{*}{ Value } & \multicolumn{5}{|c|}{ F Test } \\
\hline & $\mathbf{H}_{\mathbf{0}}$ & $\mathbf{H}_{\mathbf{a}}$ & P-Value & Result & Explanation \\
\hline \multirow[t]{2}{*}{$\begin{array}{c}\text { Section } 2 \text { versus } \\
\text { section } 3\end{array}$} & $\begin{array}{l}\text { The variance of } \\
\text { section } 2 \text { is equal to } \\
\text { the variance of }\end{array}$ & $\begin{array}{c}\mathrm{H}_{0} \\
\text { is false }\end{array}$ & 0.4656 & $\begin{array}{l}\text { Do not } \\
\text { reject } H_{0}\end{array}$ & $\begin{array}{l}\text { Fail to reject the null hypothesis. So, it } \\
\text { is reasonable to assume the equality of } \\
\text { variances. }\end{array}$ \\
\hline & $\bullet$ Assume $\alpha=0.005$ & & $\begin{array}{c}\text { - Degree of } \\
\text { freedom } \\
n-1=9\end{array}$ & & $\begin{array}{l}\bullet 95 \% \text { confidence interval } \\
0.410597 \quad 6.655215\end{array}$ \\
\hline
\end{tabular}


A t-test has been selected for the statistical analysis because there are just two data sets (section 2 and section 3). Table 5.4.5 shows the results of the t-test for these two sections. As can be seen from the results, the flow is completely stable.

There are two assumptions that need to be satisfied for a t-test to be applied. The first assumption is normality; it means that the data (in both data sets) should follow a normal distribution. The second assumption is the equality of variances in both data sets. Boxplots of both sections have been drawn as Figure 5.4.3. Moreover, the QQPlots (quantile-quantile plot) are presented in both sections (Figures5.4.4 to5.4.6). Moreover, normality has been checked via the Shapiro-Wilk test (Table 3.4.6). In addition, the equality of variances was checked by an F-test (Table 3.4.7).

All in all, two tests were selected to show the details of the calculations. In the first step, the flow was sub-critical in both tests, so, these tests were selected for additional analysis. In the second step, the velocity was more than the permissible velocity in test number 4; therefore, this test did not meet the criteria for a stable condition. Test number 5 was the only test which was left for the third step of the analysis (surface flow fluctuations). Based on the results of the statistical analysis, the flow is completely stable in test number 5 which is compatible with the Flow Stability Number calculation; this dimensionless number is equal to one for this test number. Also, the Flow Stability Number, for test number 5, is compatible with the Flow Stability Factor, which was found to be 0.9 for this test. Figure 5.4.7 shows the trend of $h_{0} / a$ to $d c / h_{0}$ for different thicknesses in a gate with contraction structures. 


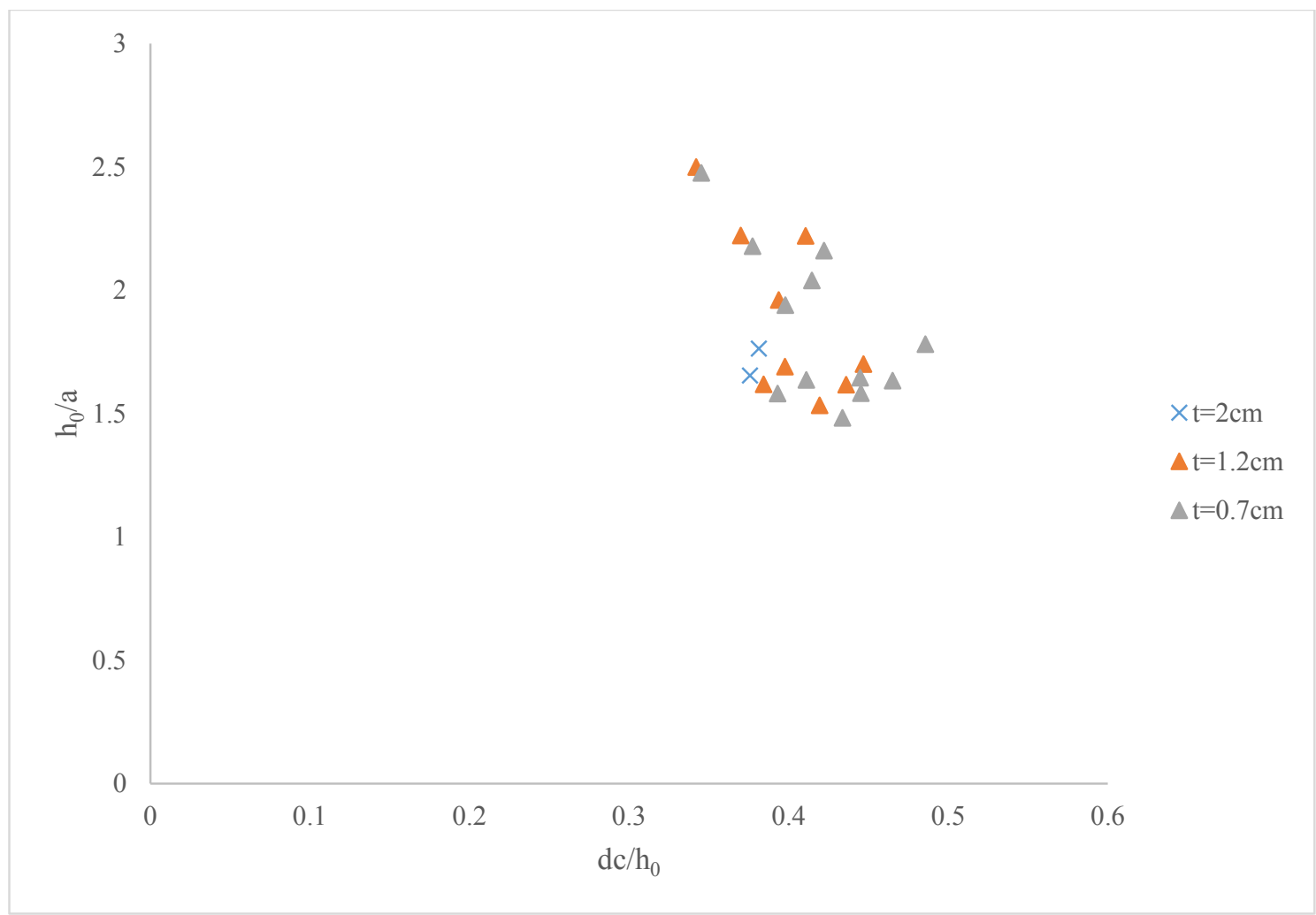

Figure 5.4.7: $\mathrm{h}_{0} / \mathrm{a}$ vs. $\mathrm{dc} / \mathrm{h}_{0}$

In Figure 5.4.7, only tests with a Flow Stability Number equal or greater than 0.96 are plotted. This Figure indicates that the greatest thickness ( 2 centimeters) can produce a stable flow condition at only very low discharge rates and the performance of this thickness is not acceptable for mid and high discharge ranges. The second thickness (1.2 centimeters) can produce a stable condition for low, mid, and high discharge rates. Finally, the performance of the narrowest thickness ( 0.7 centimeters) is acceptable for all tested discharge ranges too. The results indicate that this thickness can produce a stable condition across various discharges. It should be noted that there is not a meaningful difference between the results yielded by the second and the third thicknesses. 
Although the hydraulic performance of the two last thicknesses is acceptable to produce a stable condition downstream of a contraction, there is still a small unstable distance immediately after a gate with a contraction. This instability may produce a very weak wave in the flow.

\subsubsection{Experiments (Set Two)}

A total of three experiments ( 3 discharges) were selected to find the Flow Stability Number (Table F.4 Appendix F).These experiments were conducted in a flume, located at the Center for Research in Water Resources (CRWR) at the University of Texas at Austin. Flume details and measurements devices were presented in chapter 4.

Table 5.4.8 Tested Discharges

\begin{tabular}{cccc}
\hline & \multicolumn{3}{c}{ Discharges } \\
\cline { 2 - 4 } Numbers & Gallons Per Minute & $\mathrm{m}^{3} / \mathrm{s}\left(\mathrm{x} 10^{3}\right)$ & $\mathrm{q}\left(\mathrm{m}^{2} / \mathrm{s}\right)$ \\
\hline 1 & 300.20 & 18.94 & 0.0344 \\
\hline 2 & 406.72 & 25.66 & 0.0466 \\
\hline 3 & 510.38 & 32.20 & 0.0585 \\
\hline
\end{tabular}

Table F.4 Appendix F reported the discharge, gate opening, critical depth, upstream depth, downstream depth in two sections, upstream and downstream velocity (two sections), and downstream energy (two sections), as well as the Flow Stability Number. Section one is located 0.4 meters upstream, section two is located 0.45 meters downstream of the gate, and finally, section three is also located one meter downstream from the gate. Depths are reported as the average of all measurements. In addition, Figures 5.4.8 (a) and (b) show the sediment transport and the surface flow pattern in the presence of a gate with contractions. 


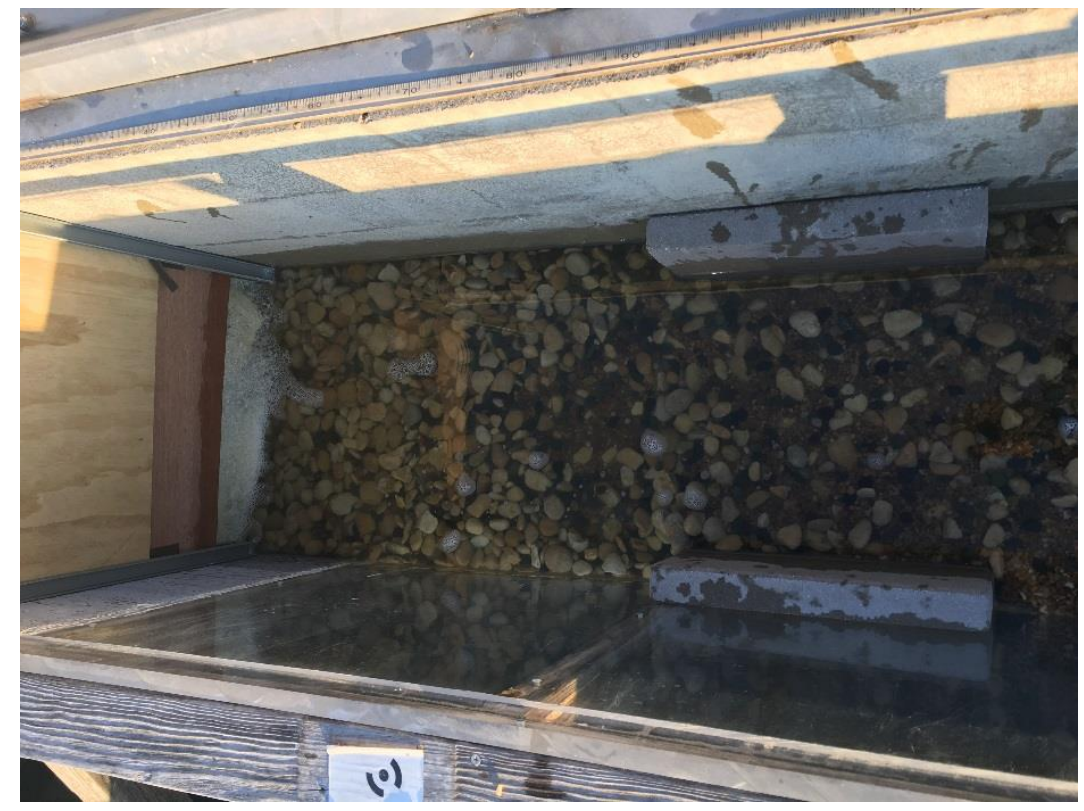

Figure 5.4.8 (a): Sediment transport in the presence of a gate with contractions

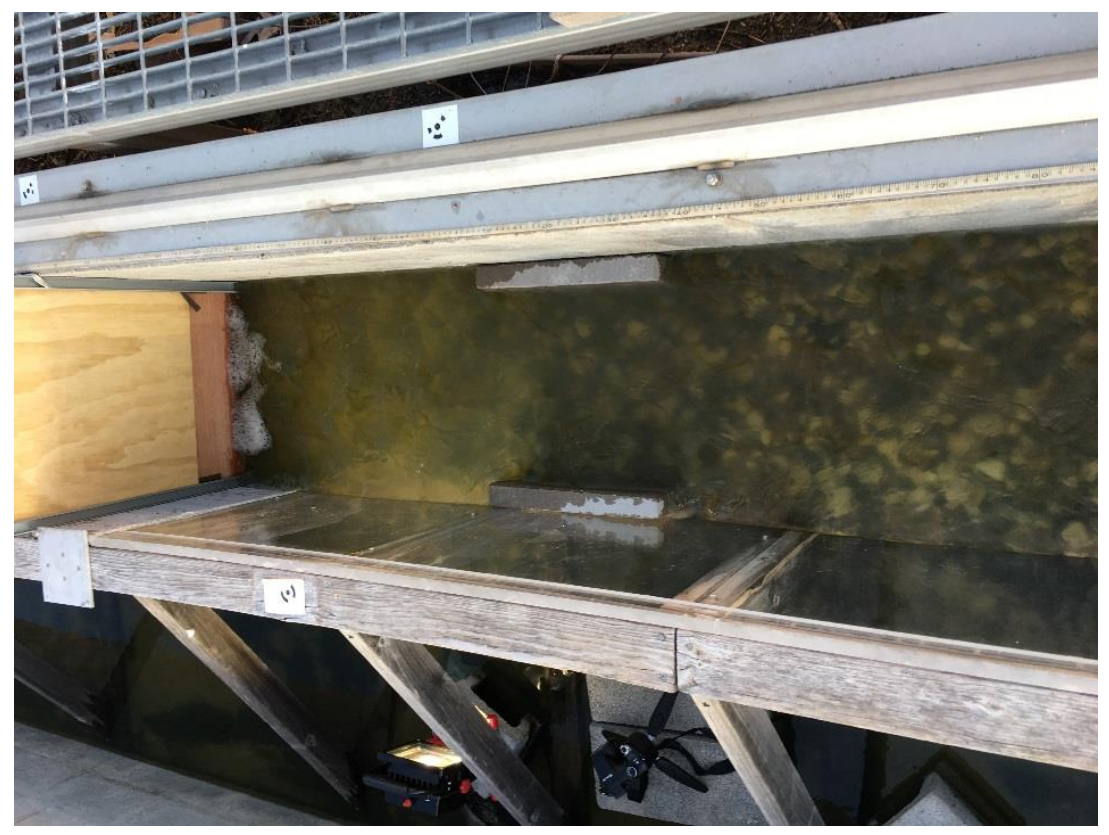

Figure 5.4.8 (b): Flow pattern in the presence of a gate with contractions 
Test number 1 was selected as an example to show the details of the calculation. The bed is a mixture of limestone pebbles, basalt pebbles, and brown pea gravel. Considering Table A.1, Appendix A, for stable, unlined, earthen channels, the maximum permissible velocity for coarse gravel, non-colloidal and fine gravel in clear water are 1.220 and $0.762 \mathrm{~m} / \mathrm{s}$, respectively. The minimum value is taken in this study as a safety factor. Tables 5.4.9 to 5.4.14 reported the details of the calculation to determine the acceptability of the stability. As can be seen from Table 5.4.9, the depths in both the second and the third sections are more than the critical depth; therefore, the first assumption is satisfied. Table 5.4.10 shows that the velocities in both sections are less than the permissible velocity; consequently, the test is eligible for checking the third assumption (surface flow fluctuations). Table 5.4.11 shows the depth measurements in sections two and three (test number 3) downstream. These values should then be used in the statistical analysis to determine if the flow is stable or not.

Table 5.4.9 Control of the Flow Condition

\begin{tabular}{|c|c|c|c|c|}
\hline Test Number & $\begin{array}{c}\mathrm{a} \\
(\mathrm{cm})\end{array}$ & $\begin{array}{c}d c \\
(\mathrm{~cm})\end{array}$ & $\begin{array}{c}h_{1}(\mathrm{~cm}) \\
\text { Section } 2\end{array}$ & $\begin{array}{c}\mathrm{h}_{2}(\mathrm{~cm}) \\
\text { Section } 3\end{array}$ \\
\hline 1 & 7.50 & 4.94 & 8.86 & 8.89 \\
\hline
\end{tabular}

Table 5.4.10 Control of the Permissible Velocity

\begin{tabular}{ccccc}
\hline Test Number & Bed Material & $\begin{array}{c}\text { Permissible } \\
\text { Velocity }(\mathbf{m} / \mathbf{s})\end{array}$ & $\begin{array}{c}\mathbf{V}_{\mathbf{1}}(\mathbf{m} / \mathbf{s}) \\
\text { Section 2 }\end{array}$ & $\begin{array}{c}\mathbf{V}_{\mathbf{2}}(\mathbf{m} / \mathbf{s}) \\
\text { Section 3 }\end{array}$ \\
\hline 1 & Fine gravel & 0.762 & 0.40 & 0.40 \\
\hline
\end{tabular}


Table 5.4.11 Depth Measurements

\begin{tabular}{|c|c|c|}
\hline Number & $\begin{array}{c}\mathrm{h}_{1}(\mathrm{~cm}) \\
\text { Section } 2\end{array}$ & $\begin{array}{c}\mathrm{h}_{2}(\mathrm{~cm}) \\
\text { Section } 3\end{array}$ \\
\hline 1 & 8.86 & 8.88 \\
\hline 2 & 8.87 & 8.87 \\
\hline 3 & 8.89 & 8.87 \\
\hline 4 & 8.87 & 8.89 \\
\hline 5 & 8.86 & 8.89 \\
\hline 6 & 8.88 & 8.90 \\
\hline 7 & 8.89 & 8.87 \\
\hline 8 & 8.88 & 8.89 \\
\hline 9 & 8.85 & 8.91 \\
\hline 10 & 8.89 & 8.87 \\
\hline
\end{tabular}


Table 5.4.12 Two-sided t-test

\begin{tabular}{|c|c|c|c|c|c|}
\hline \multirow[b]{2}{*}{ Value } & \multicolumn{4}{|c|}{ t-test } & \multirow[b]{2}{*}{ Explanation } \\
\hline & $\mathbf{H}_{\mathbf{0}}$ & $\mathbf{H}_{\mathbf{a}}$ & P-Value & Result & \\
\hline \multirow[t]{2}{*}{$\begin{array}{c}\text { Section } 2 \text { versus } \\
\text { section } 3\end{array}$} & $\begin{array}{l}{ }^{*} \text { The average of } \\
\text { section } 2 \text { is equal to } \\
\text { the average of } \\
\text { section } 3\end{array}$ & $\begin{array}{l}\mathrm{H}_{0} \\
\text { is false }\end{array}$ & 0.1353 & $\begin{array}{l}\text { Do not } \\
\text { reject } H_{0}\end{array}$ & $\begin{array}{l}\text { There is not enough evidence to } \\
\text { conclude that the average of section } 2 \text { is } \\
\text { different from the average of section } 3 . \\
\text { So, it is reasonable to assume that the } \\
\text { two averages are equal. }\end{array}$ \\
\hline & $\bullet$ Assume $\alpha=0.005$ & & $\begin{array}{l}\text { Degree of } \\
\text { freedom: } \\
\text { n- } 2=18\end{array}$ & $\begin{array}{l}\text { •t value : } \\
-1.5639\end{array}$ & $\begin{array}{l}\bullet 95 \% \text { confidence interval } \\
-0.023434224 \quad 0.003434224\end{array}$ \\
\hline
\end{tabular}

*the mean of section 2 is 8.874 and the mean of section 3 is 8.884 


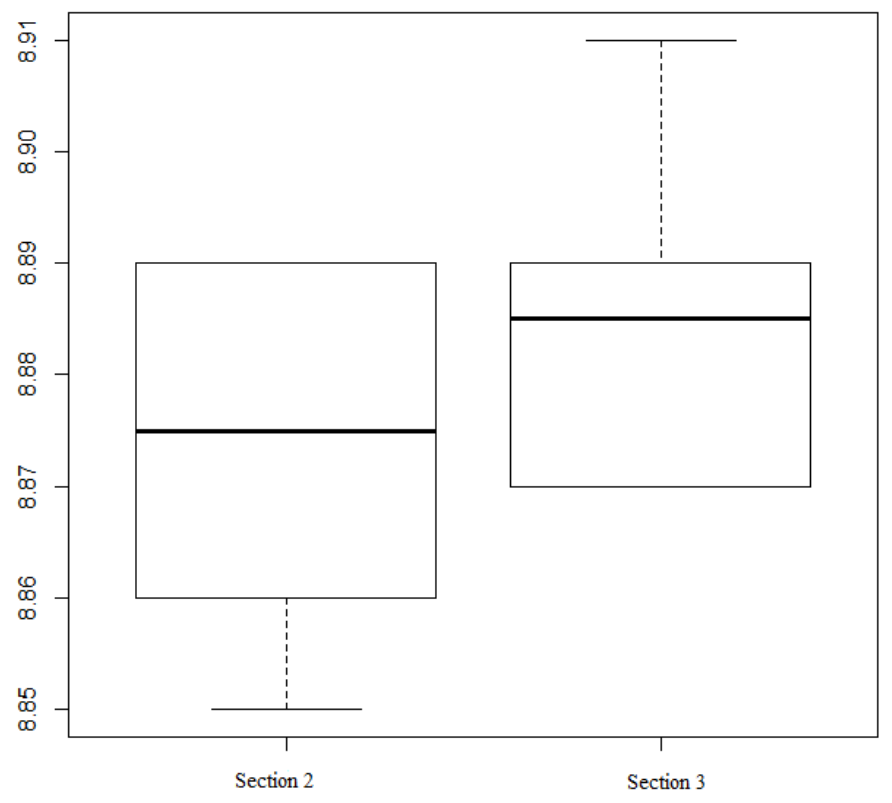

Figure 5.4.9: Boxplots - sections 2 and 3

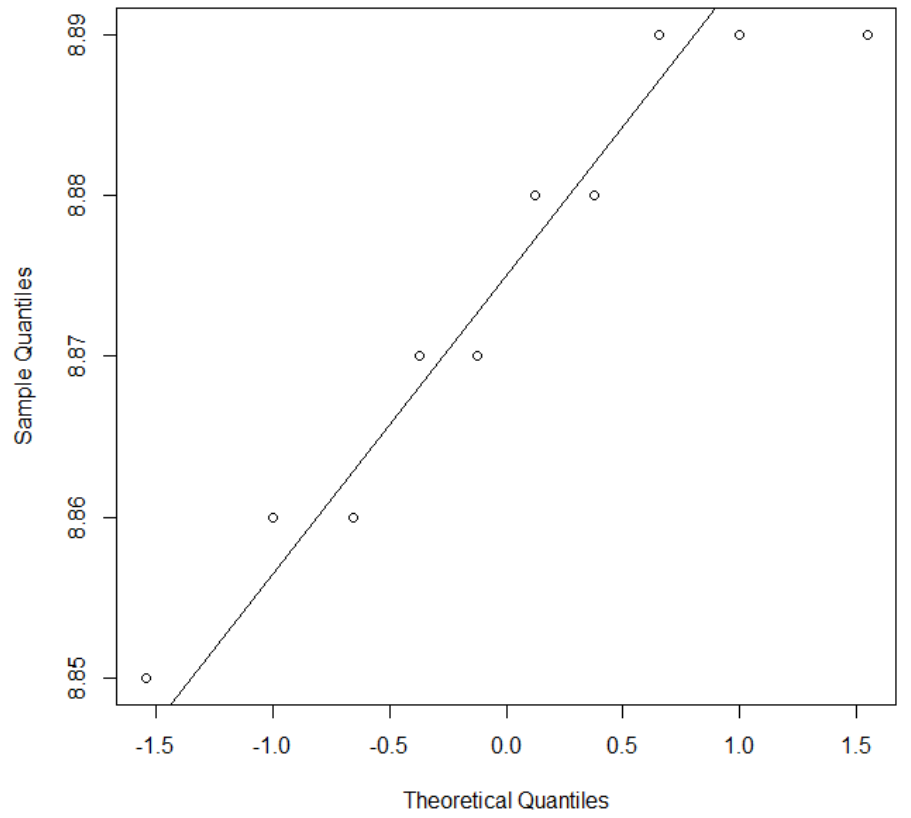

Figure 5.4.10: Normal Q-Q plot - section 2 


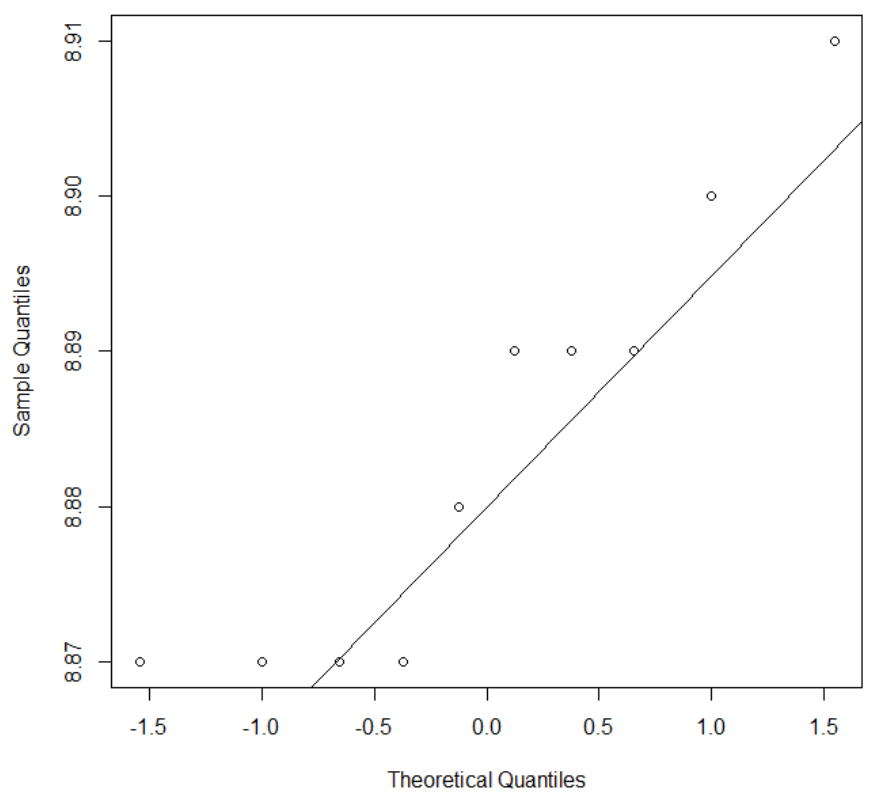

Figure 5.4.11: Normal Q-Q plot - section 3

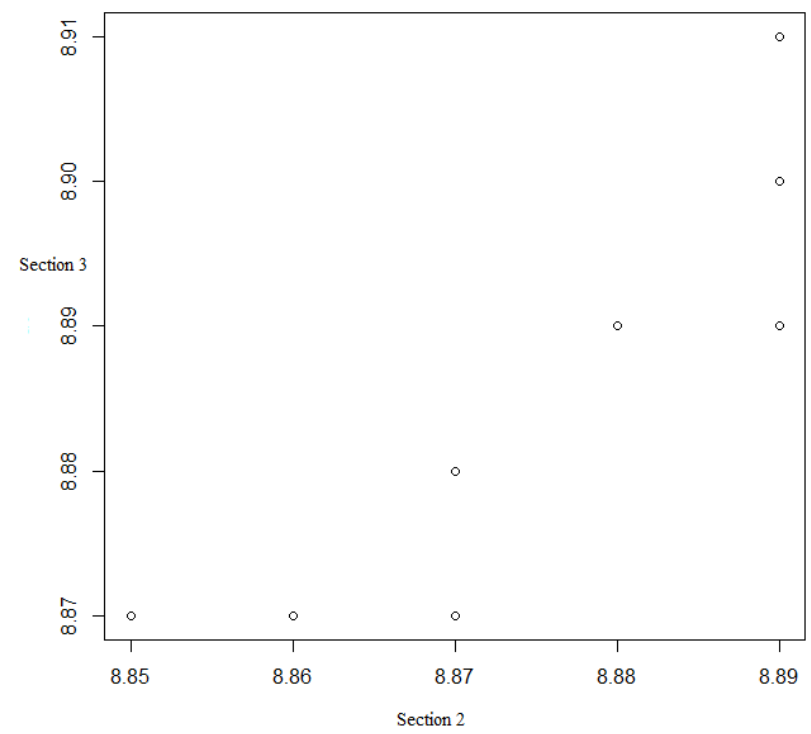

Figure 5.4.12: Q-Q plot - section 2 versus section 3 
Table 5.4.13 Check of Normality

\begin{tabular}{|c|c|c|c|c|c|}
\hline \multirow[b]{2}{*}{ Value } & \multicolumn{4}{|c|}{ Shapiro-Wilk Test } & \multirow[b]{2}{*}{ Explanation } \\
\hline & $\mathbf{H}_{\mathbf{0}}$ & $\mathbf{H}_{\mathbf{a}}$ & P-Value & Result & \\
\hline $\begin{array}{r}\mathrm{h}_{1}(\mathrm{~cm}) \\
\text { Section } 2\end{array}$ & $\begin{array}{l}\text { Data follows a } \\
\text { normal distribution }\end{array}$ & $\begin{array}{l}\mathrm{H}_{0} \\
\text { is false }\end{array}$ & 0.2683 & $\begin{array}{l}\text { Do not } \\
\text { reject } H_{0}\end{array}$ & $\begin{array}{l}\text { Fail to reject the null hypothesis. So, it } \\
\text { is reasonable to assume normality. }\end{array}$ \\
\hline $\begin{array}{r}\mathrm{h}_{2}(\mathrm{~cm}) \\
\text { Section } 3\end{array}$ & $\begin{array}{l}\text { Data follows a } \\
\text { normal distribution }\end{array}$ & $\begin{array}{c}\mathrm{H}_{0} \\
\text { is false }\end{array}$ & 0.0944 & $\begin{array}{l}\text { Do not } \\
\text { reject } H_{0}\end{array}$ & $\begin{array}{l}\text { Fail to reject the null hypothesis. So, it } \\
\text { is reasonable to assume normality. }\end{array}$ \\
\hline
\end{tabular}

Table 5.4.14 Check of the Equality of Variances

\begin{tabular}{|c|c|c|c|c|c|}
\hline \multirow[b]{2}{*}{ Value } & \multicolumn{5}{|c|}{ F Test } \\
\hline & $\mathbf{H}_{\mathbf{0}}$ & $\mathbf{H}_{\mathbf{a}}$ & P-Value & Result & Explanation \\
\hline \multirow[t]{2}{*}{$\begin{array}{c}\text { Section } 2 \text { versus } \\
\text { section } 3\end{array}$} & $\begin{array}{l}\text { The variance of } \\
\text { section } 2 \text { is equal to } \\
\text { the variance of }\end{array}$ & $\begin{array}{c}\mathrm{H}_{0} \\
\text { is false }\end{array}$ & 1 & $\begin{array}{l}\text { Do not } \\
\text { reject } H_{0}\end{array}$ & $\begin{array}{l}\text { Fail to reject the null hypothesis. So, it } \\
\text { is reasonable to assume the equality of } \\
\text { variances. }\end{array}$ \\
\hline & $\bullet$ Assume $\alpha=0.005$ & & $\begin{array}{l}\text {-Degree of } \\
\text { freedom } \\
n-1=9\end{array}$ & & $\begin{array}{l}\bullet 95 \% \text { confidence interval } \\
0.2483859 \quad 4.0259942\end{array}$ \\
\hline
\end{tabular}


A t-test has been selected for the statistical analysis because there are just two data sets (section 2 and section 3). Table 5.4.12 shows the results of the t-test for these two sections. As can be seen from the results, the flow is completely stable.

There are two assumptions that must be satisfied for a t-test to be applied. The first assumption is normality; it means that the data (in both data sets) should follow a normal distribution. The second assumption is the equality of variances in both data sets. Boxplots of both sections have been drawn as Figure 5.4.9. Moreover, the QQPlots (quantile-quantile plot) are presented in both sections (Figures 5.4.10 to 5.4.12). Furthermore, normality was checked via the Shapiro-Wilk test (Table 5.4.13). In addition, the equality of variances was checked by an F-test (Table 5.4.14).

Based on the results of the statistical analysis, the flow is completely stable in test number 1 (in the second lab), also, the Flow Stability Number is approximately compatible with the Flow Stability Factor, which was determined to be 0.9 for this test. 


\section{CHAPTER 5}

\section{RESULTS \& DISCUSSION}

\section{SECTION 5}

\section{COMPARISON OF THE RESULTS OF A GATE, A GATE WITH EXPANSION, AND A GATE WITH CONTRACTION}

\subsubsection{Introduction}

This research introduced the Flow Stability Factor as a new flow classification method, which works based on the Fuzzy Concept and can be used downstream of hydraulic structures. In addition, the Flow Stability Number - a ratio of energy in two sections - was introduced as a new dimensionless number. These sections are located downstream of the hydraulic structures. Due to the novelty of the Flow Stability Factor, as well as the Flow Stability Number, the results can not be compared with any previous studies. Therefore, in this section, the results of hydraulic structures which were used in this research were compared with each other. These hydraulic structures include a gate and a gate with expansion, as well as a gate with contraction. This section has four parts, not including the introduction. In the first part, the outcomes of the Flow Stability Factor and Flow Stability Number are compared with some experiments on a gate, a gate with expansion, and a gate with contraction. The second part shows the comparison between three hydraulic structures. In this part, the smallest thickness for a gate with expansion and a gate with contraction which are represented as the best results for these structures were compared with the results of gates in a dimensionless 
graph. The application of Game Theory to select the appropriate hydraulic structure under different conditions is presented in the third part of this section. Finally, in the fourth part of this section, the results for each hydraulic structure in the first and second laboratory were drawn in dimensionless graphs to show the scale effect in this study.

\subsubsection{Comparison of Stabilities}

In this part, the Flow Stability Factor and the Flow Stability Number were compared in a stable condition to determine if these values show good enough agreement with each other (or not). The comparison was conducted for all three hydraulic structures. Table 5.5.1 shows these two values in various discharges in gates and Figure 5.5.1 illustrates the discharges versus stability in gates.

Table 5.5.1 Stabilities in a Gate

\begin{tabular}{ccccc}
\hline Number & $\begin{array}{c}\text { Discharge } \\
\mathbf{( 1 / \mathbf { s } )}\end{array}$ & $\begin{array}{c}\text { Flow Stability } \\
\text { Factor }\end{array}$ & $\begin{array}{c}\text { Flow Stability } \\
\text { Number }\end{array}$ & $\begin{array}{c}\mathbf{a} \\
(\mathbf{c m})\end{array}$ \\
\hline 1 & 2.18 & 1.00 & 0.99 & 5.5 \\
\hline 2 & 2.45 & 1.00 & 0.98 & 5.5 \\
\hline 3 & 2.61 & 1.00 & 0.98 & 6.0 \\
\hline 4 & 3.00 & 0.90 & 0.98 & 6.0 \\
\hline 5 & 3.36 & 0.90 & 1.00 & 6.0 \\
\hline 6 & 3.58 & 0.90 & 0.99 & 6.5 \\
\hline 7 & 3.86 & 0.80 & 0.97 & 6.5 \\
\hline 8 & 4.43 & 0.90 & 0.96 & 7.0 \\
\hline 9 & 4.56 & 1.00 & 0.96 & 7.5 \\
\hline 10 & 4.70 & 0.90 & 0.97 & 7.5 \\
\hline
\end{tabular}




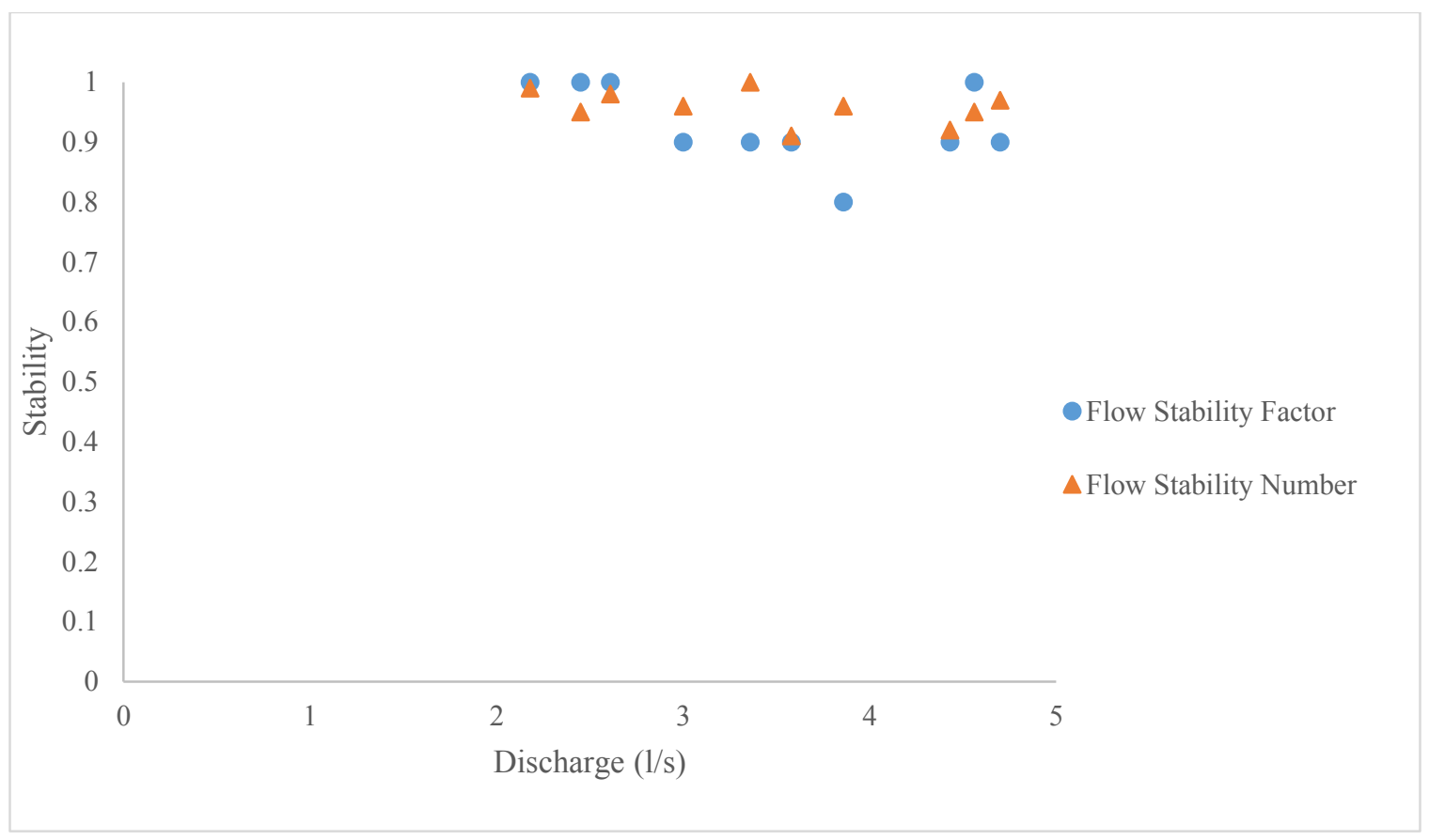

Figure 5.5.1: Stability versus discharge in a gate

The results indicate that there is a good agreement between the Flow Stability Factor and the Flow Stability Number in gates. The same comparison has been done for a gate with expansion and a gate with contraction. The smallest thickness (i.e., 0.7 centimeters) was selected for this comparison because the most stable conditions across various discharges were reported for this thickness. Table 5.5.2 and Figure 5.5.2 represented the comparison of these two values in a gate with expansion. Moreover, Table 5.5.3 and Figure 5.5.3 show the results from comparing these two values in a gate with contraction. It should be noted that in the experiments related to a gate with contraction the stable condition could not be achieved under high discharges. Due to this fact, the last four rows of Table 5.5.3 are blank. 
Table 5.5.2 Stabilities in a Gate with Expansion

\begin{tabular}{ccccc}
\hline Number & $\begin{array}{c}\text { Discharge } \\
(\mathbf{l} / \mathbf{s})\end{array}$ & $\begin{array}{c}\text { Flow Stability } \\
\text { Factor }\end{array}$ & $\begin{array}{c}\text { Flow Stability } \\
\text { Number }\end{array}$ & $\begin{array}{c}\text { a } \\
(\mathbf{c m})\end{array}$ \\
\hline 1 & 2.18 & 1.00 & 1.00 & 4.0 \\
\hline 2 & 2.45 & 1.00 & 0.99 & 6.5 \\
\hline 3 & 2.61 & 1.00 & 1.00 & 6.0 \\
\hline 4 & 3.00 & 0.90 & 0.99 & 6.0 \\
\hline 5 & 3.36 & 1.00 & 0.99 & 6.5 \\
\hline 6 & 3.58 & 0.90 & 1.00 & 6.5 \\
\hline 7 & 3.86 & 1.00 & 1.00 & 7.0 \\
\hline 8 & 4.43 & 1.00 & 0.98 & 7.5 \\
\hline 10 & 4.56 & 1.00 & 0.97 & 7.5 \\
\hline
\end{tabular}

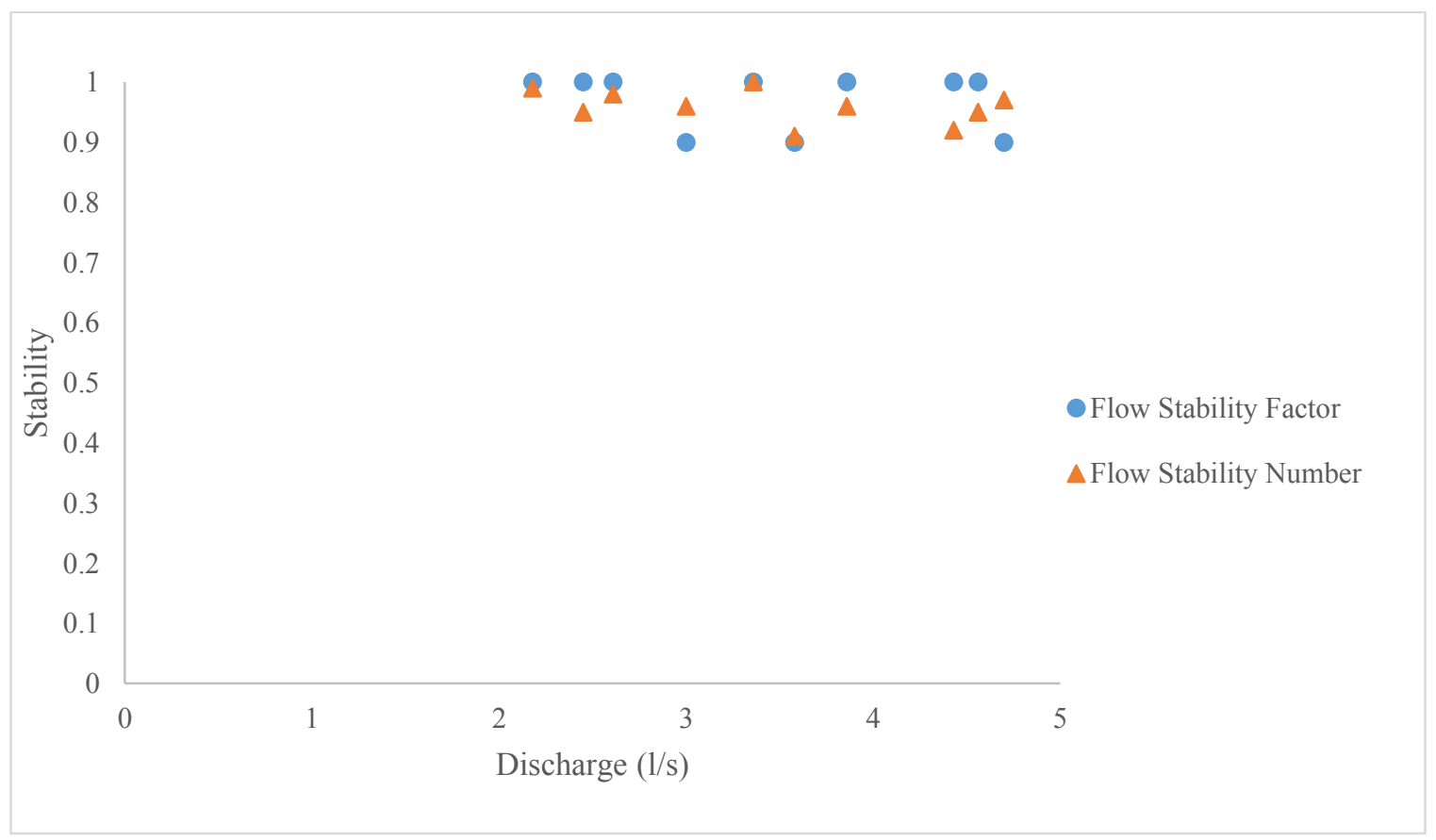

Figure 5.5.2: Stability versus discharge in a gate with expansion 
Table 5.5.3 Stabilities in a Gate with Contraction

\begin{tabular}{ccccc}
\hline Number & $\begin{array}{c}\text { Discharge } \\
(\mathbf{l} / \mathbf{s})\end{array}$ & $\begin{array}{c}\text { Flow Stability } \\
\text { Factor }\end{array}$ & $\begin{array}{c}\text { Flow Stability } \\
\text { Number }\end{array}$ & $\begin{array}{c}\text { a } \\
(\mathbf{c m})\end{array}$ \\
\hline 1 & 2.18 & 1.00 & 1.00 & 4.0 \\
\hline 2 & 2.45 & 1.00 & 0.99 & 6.5 \\
\hline 3 & 2.61 & 1.00 & 0.99 & 6.0 \\
\hline 4 & 3.00 & 0.90 & 1.00 & 6.0 \\
\hline 5 & 3.36 & 0.90 & 1.00 & 6.5 \\
\hline 6 & 3.58 & 0.90 & - & 6.5 \\
\hline 7 & 3.86 & - & - & 7.0 \\
\hline 8 & 4.43 & - & - & 7.5 \\
\hline 10 & 4.56 & - & - & 7.5 \\
\hline
\end{tabular}

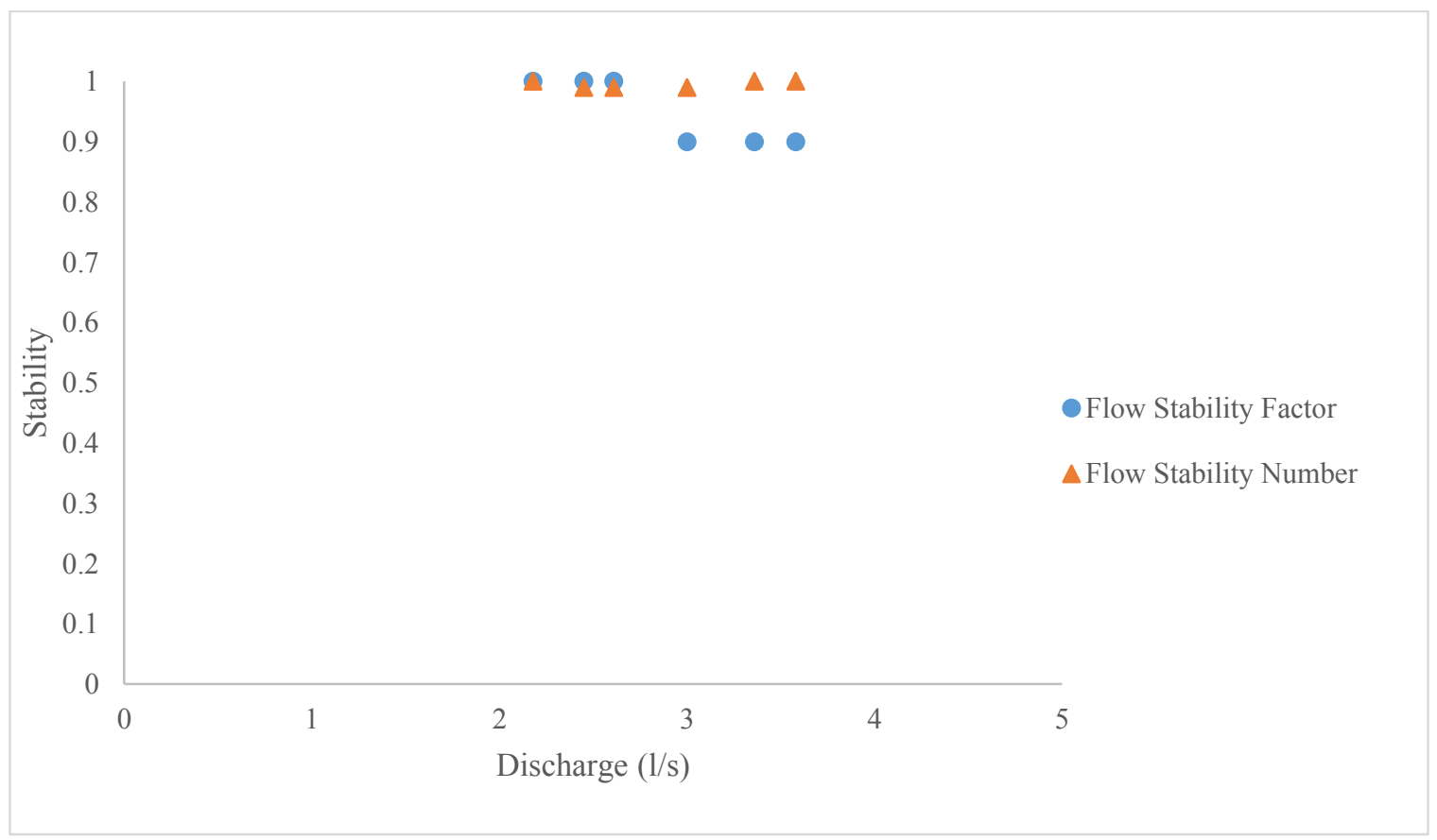

Figure 5.5.3: Stability versus discharge in a gate with contraction 
It can be inferred from the results that the Flow Stability Factor and Flow Stability Number are in good agreement with each other for all three tested hydraulic structures. The depth and velocity measures are needed to calculate the Flow Stability Number. However, the determination of the Flow Stability Factor is based on visual engineering judgment. Therefore, Flow Stability Factor, instead of the Flow Stability Number, can be determined and used in practical works with a high degree of reliability without any measurements and calculations to find the flow stability condition downstream of hydraulic structures. Furthermore, the results indicate that the hydraulic gate with a contraction structure does not have a good hydraulic performance, and it is not able to establish a stable condition under high discharges.

\subsubsection{Comparison of a Gate, a Gate with Expansion, and a Gate with Contraction}

The performance of all three tested hydraulic structures, including a gate, a gate with expansion, and a gate with contraction, were compared based on the graph using dimensionless numbers. Some researchers developed and presented different dimensionless numbers in sluice gates [5, 114, 89]. Bijankhan et al. [5] developed and used dc/a and $\mathrm{h}_{0} / \mathrm{a}$ in his research to establish a new stage-discharge relationship in radial gates. Ferro [114] also developed and used the same dimensionless numbers to establish a stage-discharge relationship for the flow under gates in both free and submerged flows. Ansar [89] mentioned that the numbers that Ferro developed and used in his work are compatible with real scale data in free flow. Ansar [89] developed a new dimensionless number for the submerged flow in gates which includes the 
tailwater. He proposed using $\left(\mathrm{h}_{1} / \mathrm{h}_{0}\right) / \mathrm{a}$ as a dimensionless number to find a stagedischarge relationship in gates which are operating in a submerged condition. Comparing the performance of hydraulic structures is the purpose of this part of the research. Based on the results of the dimensional analysis which is presented in chapter five - section one, the graph of $h_{0} / a$ versus $d c / h_{0}$ is selected to show the results and do the comparison. Although Ansar suggested using $\left(\mathrm{h}_{1} / \mathrm{h}_{0}\right) / \mathrm{a}$ in a submerged and stable condition, the flow is submerged. However, this number can not directly show the upstream water level. Therefore, other dimensionless numbers have been used in this research to show the results. Figure 5.5.4 shows the results for stable conditions in a gate, a gate with expansion, and a gate with contraction at the first laboratory. It should be noted that to show the results of a gate with expansion and a gate with contraction only the outcomes for the narrowest thickness ( 0.7 centimeters) which provided the most stable conditions under various discharges were used. Furthermore, more details are provided in Tables 5.5.4 and 5.5.5 from the first and second laboratory, respectively. 


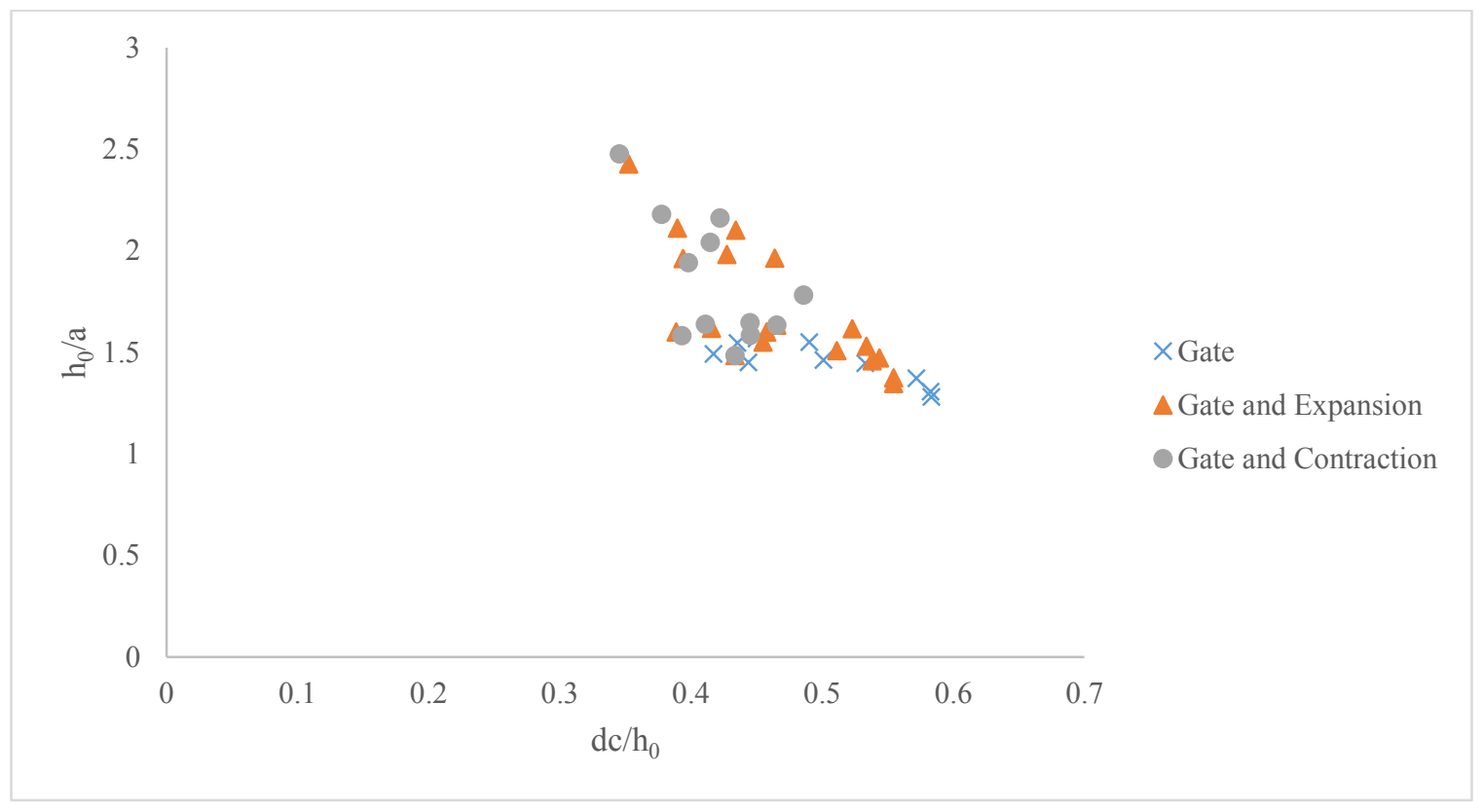

Figure 5.5.4: $\mathrm{h}_{0} / \mathrm{a}$ versus $\mathrm{dc} / \mathrm{h}_{0}$ in all three hydraulic structures 
Table 5.5.4 Results of All Three Hydraulic Structures

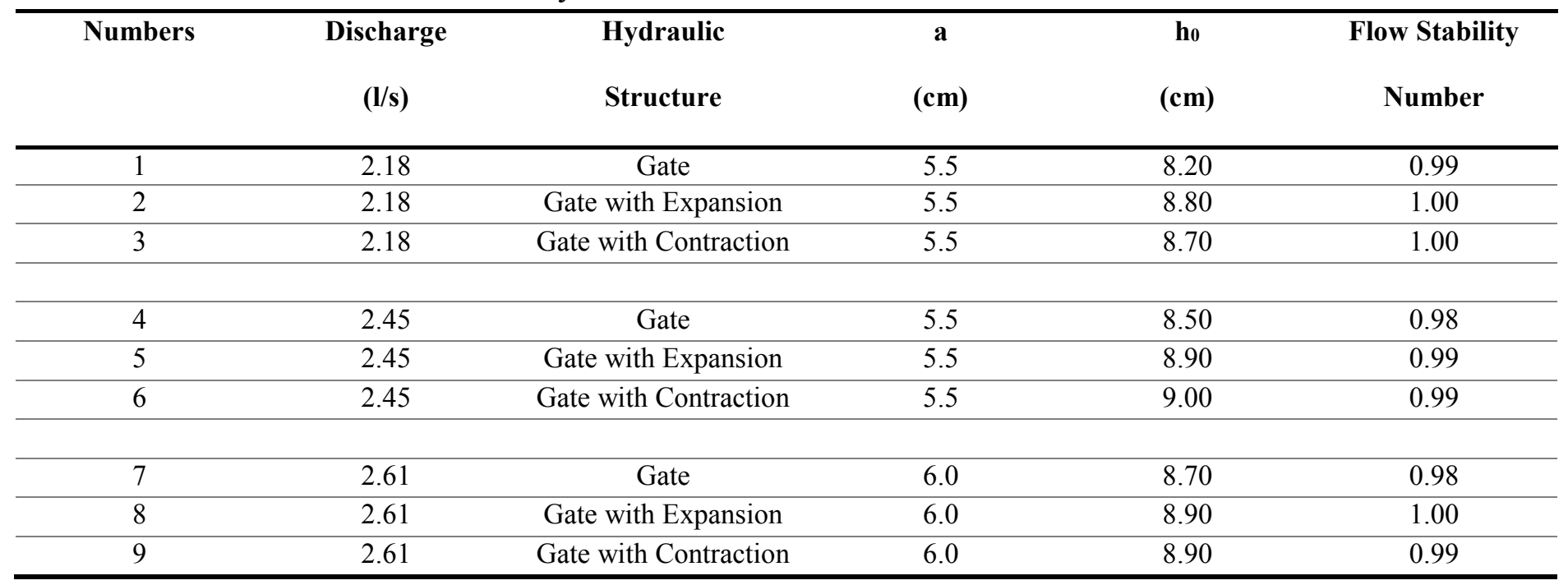


Table 5.5.4 Results of All Three Hydraulic Structures (Continued)

\begin{tabular}{|c|c|c|c|c|c|}
\hline Numbers & $\begin{array}{c}\text { Discharge } \\
(1 / \mathbf{s})\end{array}$ & $\begin{array}{l}\text { Hydraulic } \\
\text { Structure }\end{array}$ & $\begin{array}{c}a \\
(\mathrm{~cm})\end{array}$ & $\begin{array}{c}h_{0} \\
(\mathbf{c m})\end{array}$ & $\begin{array}{c}\text { Flow Stability } \\
\text { Number }\end{array}$ \\
\hline 11 & 3.00 & Gate with Expansion & 6.0 & 9.30 & 0.99 \\
\hline 12 & 3.00 & Gate with Contraction & 6.0 & 9.50 & 0.99 \\
\hline 14 & 3.36 & Gate with Expansion & 5.5 & 9.80 & 1.00 \\
\hline 15 & 3.36 & Gate with Contraction & 5.5 & 9.80 & 1.00 \\
\hline 16 & 3.58 & Gate & 6.5 & 9.50 & 0.99 \\
\hline
\end{tabular}


Table 5.5.4 Results of All Three Hydraulic Structures (Continued)

\begin{tabular}{|c|c|c|c|c|c|}
\hline Numbers & $\begin{array}{c}\text { Discharge } \\
(\mathrm{l} / \mathrm{s})\end{array}$ & $\begin{array}{l}\text { Hydraulic } \\
\text { Structure }\end{array}$ & $\begin{array}{c}\mathrm{a} \\
(\mathrm{cm})\end{array}$ & $\begin{array}{c}\mathbf{h}_{0} \\
(\mathbf{c m})\end{array}$ & $\begin{array}{c}\text { Flow Stability } \\
\text { Number }\end{array}$ \\
\hline 20 & 3.86 & Gate with Expansion & 6.5 & 9.80 & 1.00 \\
\hline 21 & 3.86 & Gate with Contraction & 6.5 & - & - \\
\hline 23 & 4.43 & Gate with Expansion & 7.0 & 10.20 & 1.00 \\
\hline 24 & 4.43 & Gate with Contraction & 7.0 & - & - \\
\hline 25 & 4.56 & Gate & 7.5 & 9.60 & 0.96 \\
\hline
\end{tabular}


Table 5.5.4 Results of All Three Hydraulic Structures (Continued)

\begin{tabular}{cccccc}
\hline Numbers & Discharge & Hydraulic & a & ho & Flow Stability \\
& $(\mathbf{l} / \mathbf{s})$ & Structure & $\mathbf{( c m )}$ & $\mathbf{( c m )}$ & Number \\
\hline 28 & 4.70 & Gate & 7.5 & 9.80 & 0.97 \\
\hline 29 & 4.70 & Gate with Expansion & 7.5 & 10.30 & - \\
\hline 30 & 4.70 & Gate with Contraction & 7.5 & - & - \\
\hline
\end{tabular}


Table 5.5.5 Results of All Three Hydraulic Structures (The Second Laboratory)

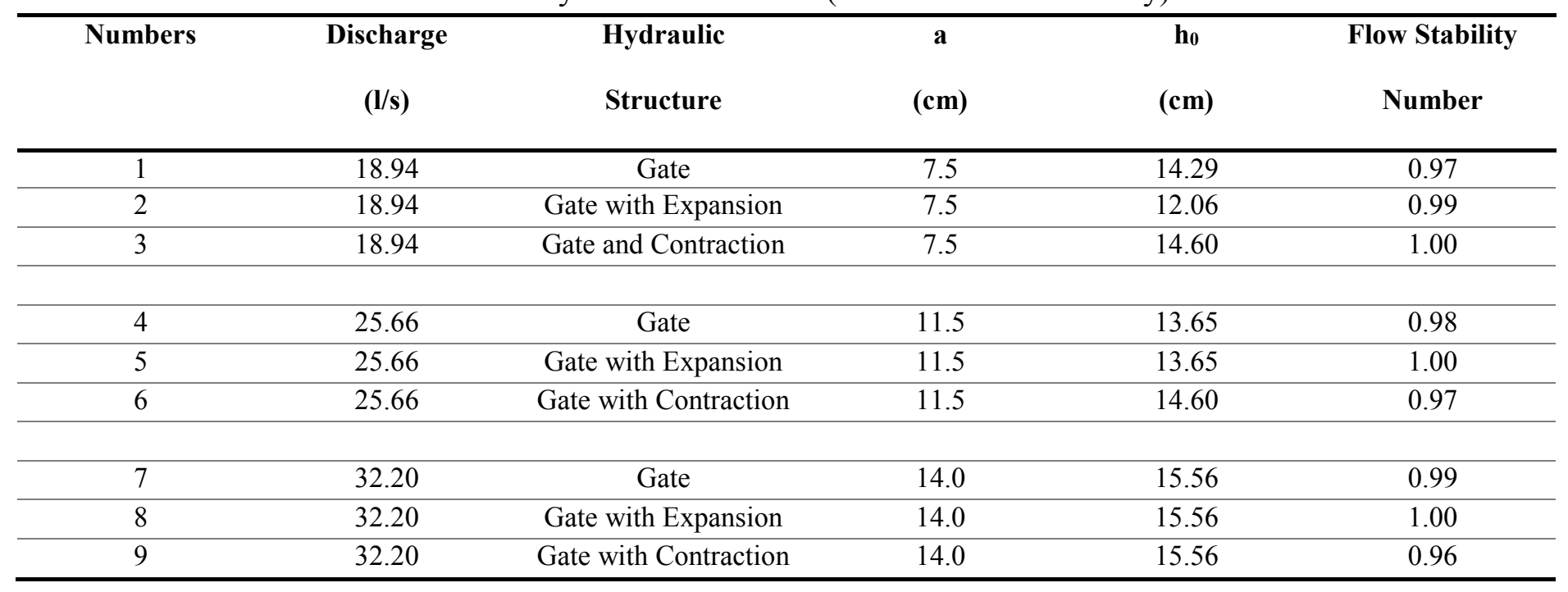


It can be inferred from Figure 5.5.4 and Tables 5.5.4 and 5.5.5 that the performance of a gate with expansion and a gate with contraction are better than the performance for a gate. With additional consideration, it can be concluded that for the same gate opening and the same discharge, a gate with contraction shows the highest upstream level and Flow Stability Number among these three hydraulic structures across a low range of discharges. However, the performance of a hydraulic gate with a contraction structure is not desirable for mid- and high-range discharges. On the other hand, a gate with expansion structures demonstrates excellent performance for low- to high-range discharges. The results indicate that a hydraulic gate with an expansion structure produces the highest upstream depth and Flow Stability Number across mid- and highrange discharges among all three hydraulic structures. Moreover, the performance of a gate with an expansion structure for low-range discharges is just slightly less than the performance of a gate with a contraction structure. Therefore, the best hydraulic structure which can be used across all discharge ranges to achieve the highest upstream level, as well as the highest Flow Stability Number, is a hydraulic gate with an expansion structure. The gate hydraulic structure can also be used across all discharge ranges. However, its performance is less than the performance of a hydraulic gate with an expansion structure.

\subsubsection{Choose an Appropriate Hydraulic Structure}

In 5.5.3, it was mentioned that among the three tested hydraulic structures two of them, including a gate and a gate with an expansion, could be used for low to high discharge ranges. Therefore, these two hydraulic structures are evaluated in this part to determine 
which one is preferable in which situation. Game Theory, initially presented by Nash [173], has been used to achieve this purpose.

Based on these results, a hydraulic gate with an expansion structure can produce a higher upstream water level, as well as a higher Flow Stability Number than a gate hydraulic structure under the same condition. As a result, a gate with an expansion hydraulic structure is better able to protect the environment than a gate. On the other hand, the construction cost of a gate hydraulic structure is lower than for a hydraulic gate with an expansion structure.

A two-person game (a hypothetical game), with the involvement of a third-party, is presented below to show what hydraulic structure should be selected when two agencies try to build a hydraulic structure on the same river (at a specific distance) with different purposes.

The assumptions in this problem are listed below:

In this problem, two agencies decide to build a hydraulic structure on the same river. The first agency is an environmental agency and the second agency is an irrigation agency. The irrigation agency wants to build a hydraulic structure to provide water for agriculture, dissipate energy, and provide drinking water at a minimum cost (some of the purposes). An environmental agency wants to build a hydraulic structure which protects the ecosystem, avoids eutrophication, and keeps aquatic life in a normal situation (some of the purposes). A design with strong environmental protection and a higher cost is preferred to a design with less environmental protection and a lower cost. Moreover, a consulting engineering company designed the hydraulic structures. The first one is a gate hydraulic structure which is closer to the objectives of the irrigation 
agency and the second is a hydraulic gate with an expansion structure which is closer to the objectives of the environmental agency. Figure 3.5.5 shows the schematic of the river and the agencies' objectives.

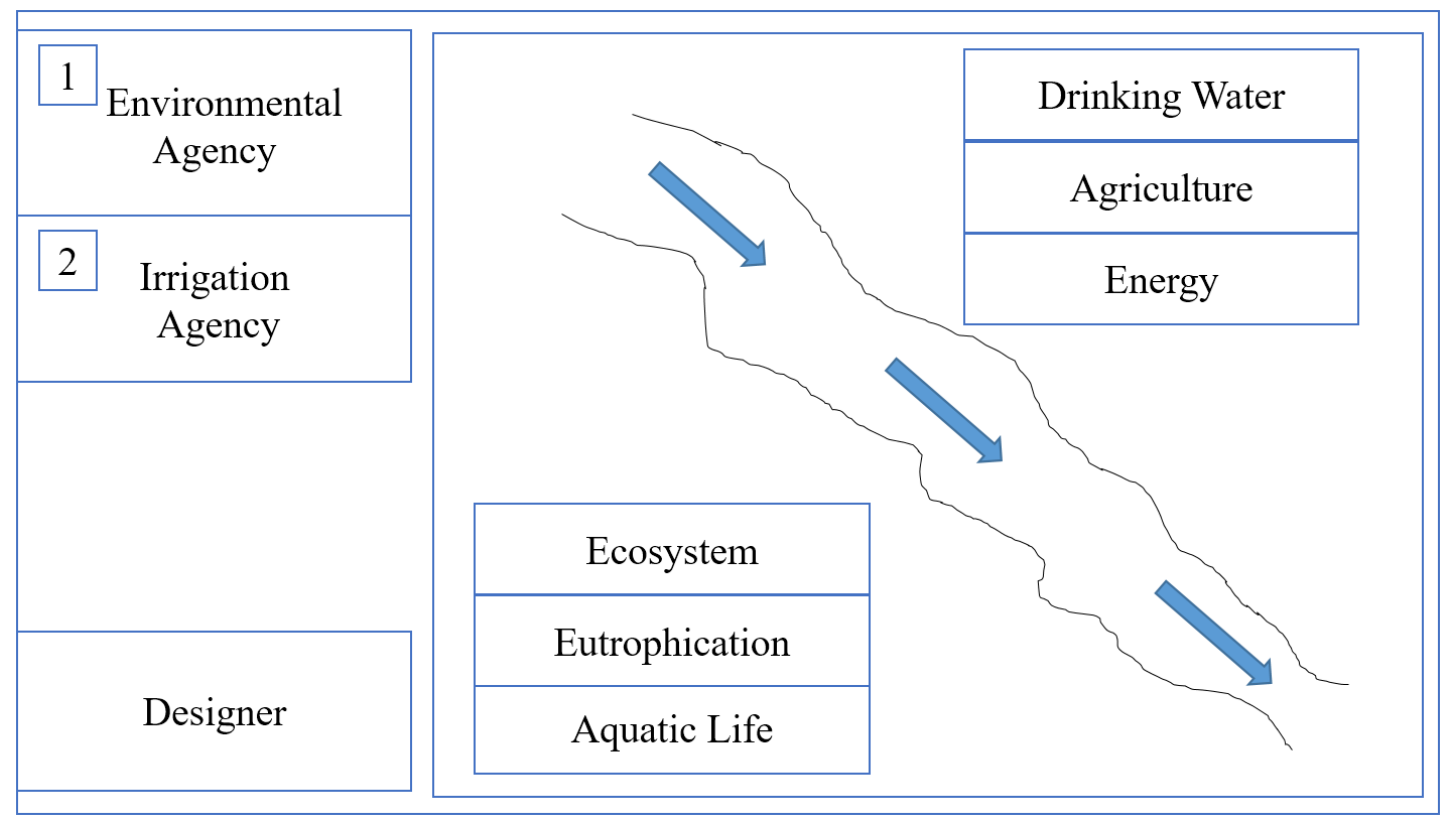

Figure 5.5.5: Schematic of the river

Each agency derives some benefits from using one of these designs. In Figure 5.5.6, the benefits for each player of the game are reported on a $0-1$ scale for an economic design, which is a gate hydraulic structure in this problem, and an environmentallyfriendly design, which is a hydraulic gate with an expansion structure in this problem. Zero means there is no benefit for the company and one shows the maximum benefit. The benefits are based on assumptions.

As can be seen in Figure 5.5.6, the benefit for the environmental agency for building an environmentally-friendly design (a gate with an expansion structure) is equal to one, 
whereas the benefit for the irrigation agency is equal to 0.4 in the same situation. A Nash Equilibrium should be investigated in this game. The Nash Equilibrium is defined as the solution concept for a non-cooperative game with two or more players, in a way that each player is assumed to be aware of the equilibrium strategies of other players. Also, none of the players has anything to gain by changing only their own strategy [174].

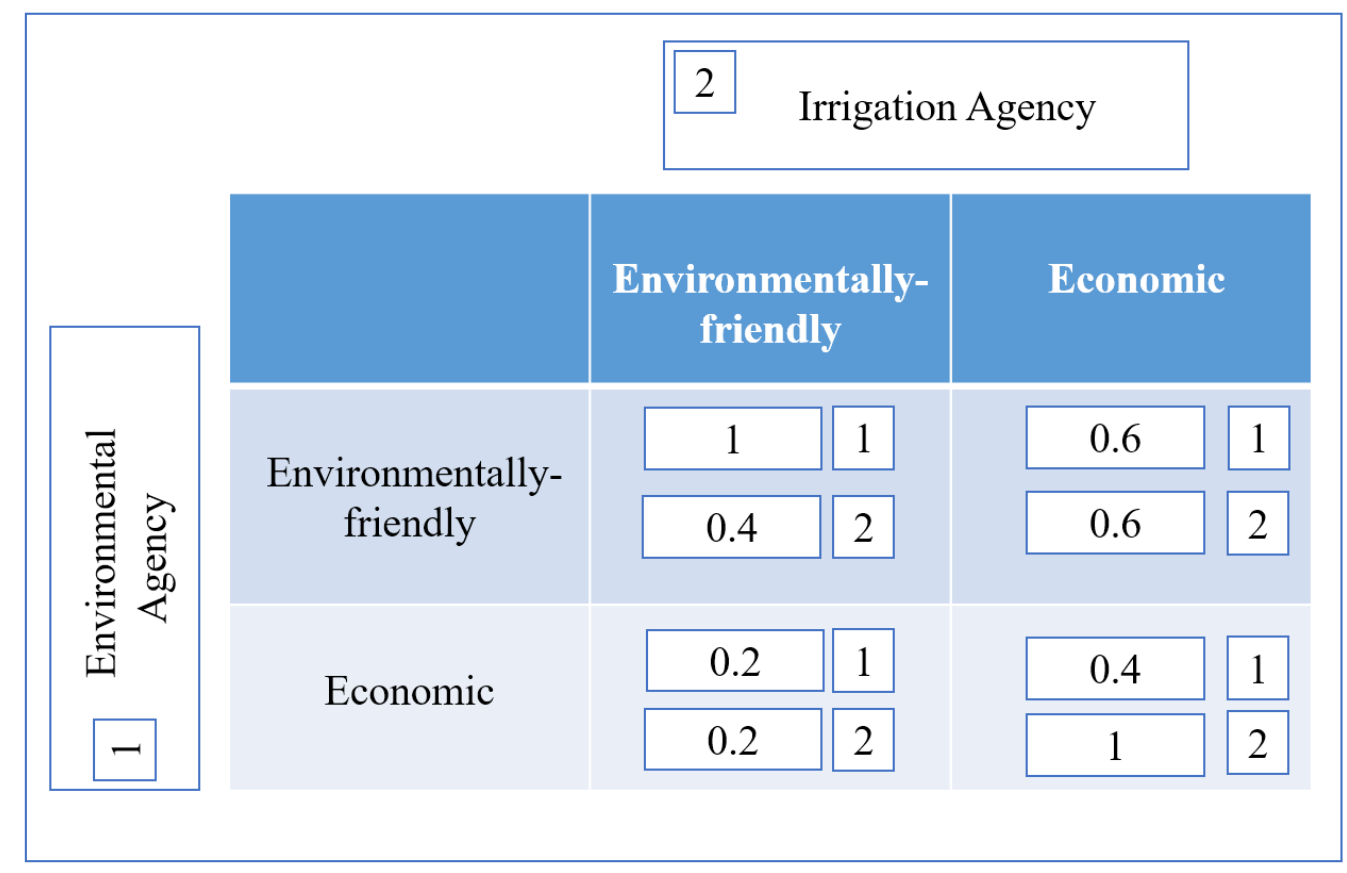

Figure 5.5.6: Benefits to each agency in different situations

Based on the definition of the Nash Equilibrium, in this game, none of the situations leads to a Nash Equilibrium. Therefore, each agency prefers to build a hydraulic structure with the highest benefit to them. In this problem, the environmental agency prefers to build an environmentally-friendly design, which is a hydraulic gate with an 
expansion structure, whereas the irrigation agency prefers to build an economic design, which is a hydraulic gate.

There is another interesting fact in this problem which is related to the existence of a third-party. Assume that the designer (the consulting engineering company) gains a benefit equal to one by selling the design to an agency. If both agencies ask the same designer (the consulting engineering company) to design a hydraulic structure for them, then the designer gains a benefit equal to two - one from the environmental agency and one from the irrigation agency. The designer is not a decision-maker in this game. However, based on the results of the game, the designer is the real winner - gaining a benefit equal to two. This is a great example that shows that the winner is not necessarily a decision-maker in the game.

\subsubsection{Scale Effect}

As previously mentioned, the experiments were conducted in two laboratories with different scales. In this part, the results of the first and second laboratory are compared to show the scale effect on the nature of the study. The graph which indicates the $h_{0} / \mathrm{a}$ versus the $\mathrm{dc} / \mathrm{h}_{0}$ was selected to compare the results from both laboratories. Figure 5.5.7 illustrated the results of both laboratories in gates. 


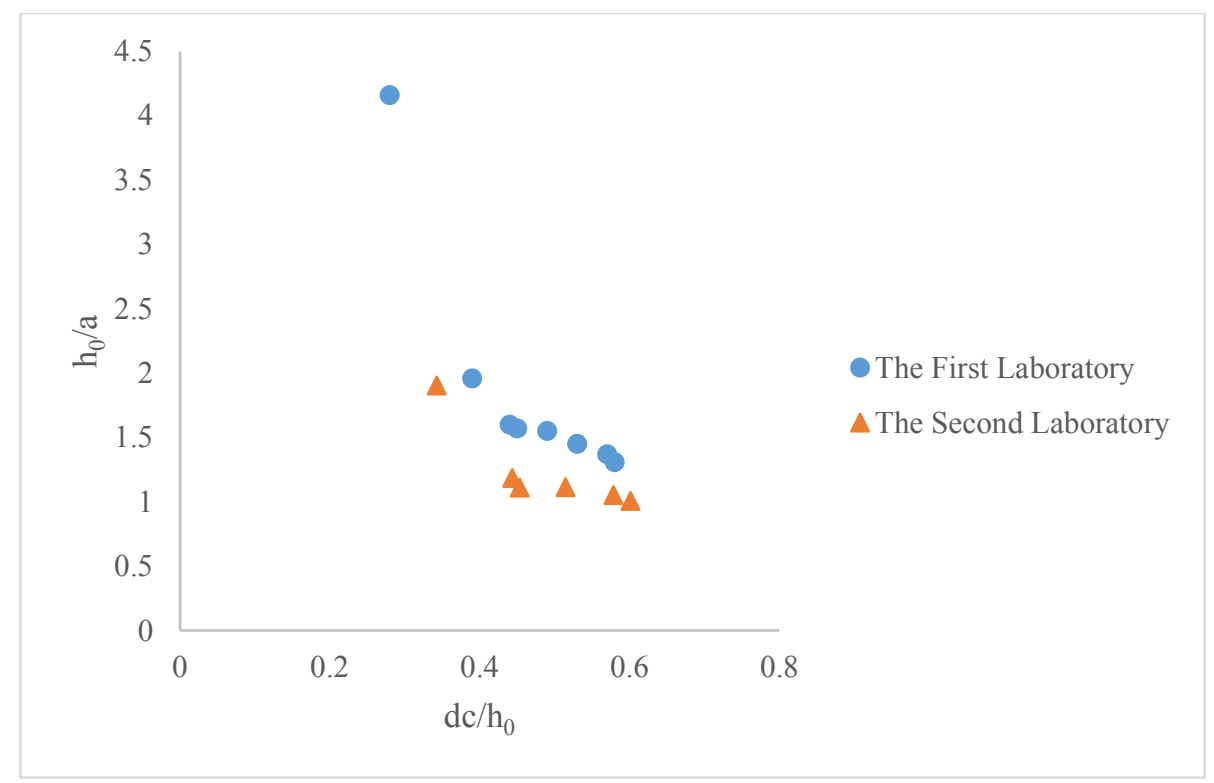

Figure 5.5.7: Scale effect in gates

As can be seen from Figure 5.5.7, the outcomes from both laboratories follow the same trend. Moreover, there is a small amount of difference between the results from the first and second laboratory. This difference may be because of experimental mistakes or due to the scale effect. It is recommended that the experiments be extended to larger scale hydraulic structures (a prototype) to investigate the reason for this difference in more detail. It should be noted that based on the previous studies, the Reynolds number could be disregarded when its value is more than $10^{4}$ [78]. In Figure 5.5.7, there is a point in the first laboratory with an $\mathrm{h}_{0} / \mathrm{a}$ of more than 4 . There are no similar experiments in the second laboratory to compare with this point. This point is far from the other points and it may have occurred due to experimental errors. However, it is recommended that this point be compared with a similar point in the second laboratory before it is deleted 
as an outlier. Figures 5.5.8 and 5.5.9 show the comparison of the results from both laboratories in a gate with expansion and a gate with contraction.

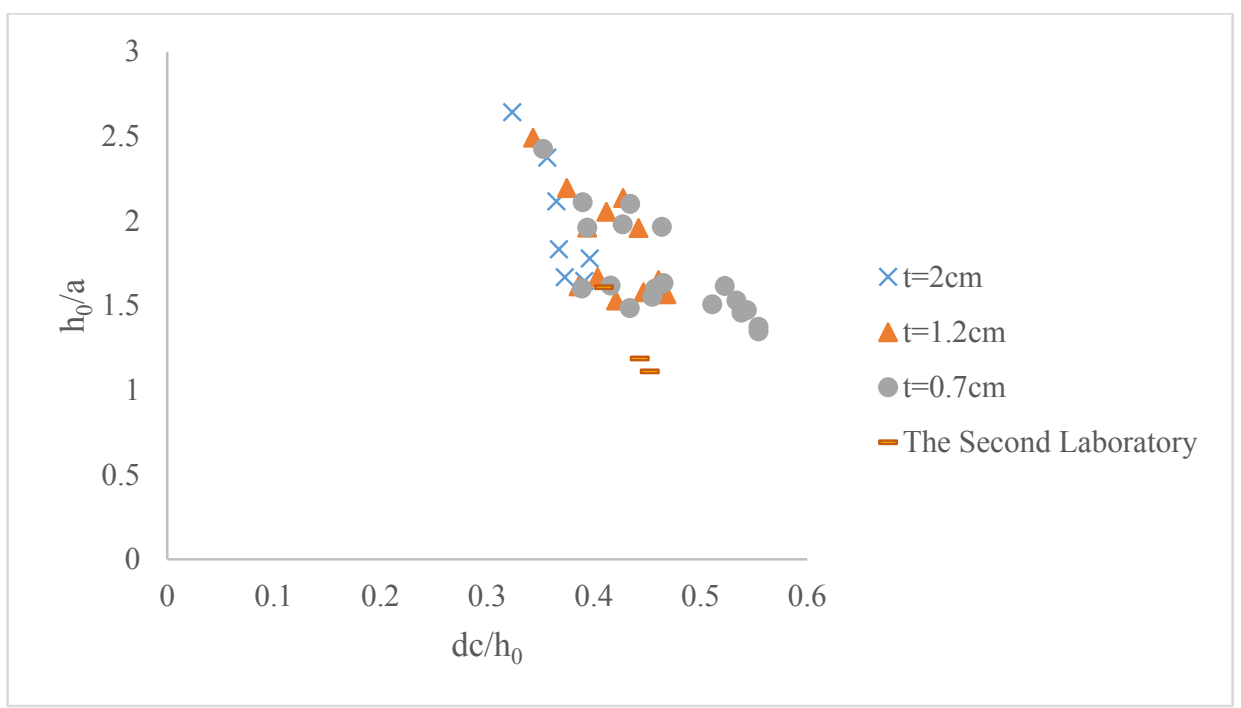

Figure 5.5.8: Scale effect in a gate with expansion

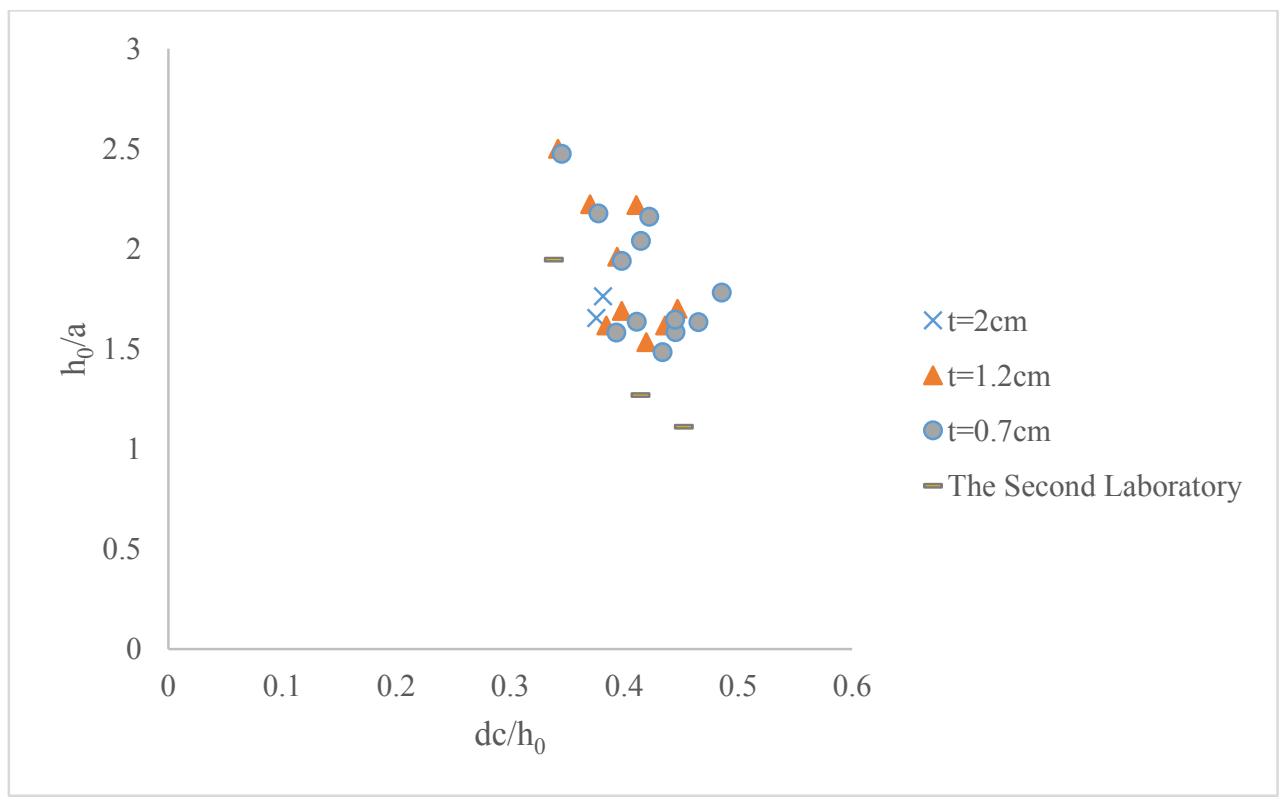

Figure 5.5.9: Scale effect in a gate with contraction 
The Reynolds number was recorded in a range of 8816 to 27000 in this research (the first laboratory). Moreover, the Froude number was recorded in a range of 0.3 to 2.77 in the first laboratory. The results of the experiments indicate that the Reynolds number is less than $10^{4}$ in all stable conditions which provides a fundamental, reasonable explanation for the scale effect observed between the various experimental set-ups. Figures 5.5.8 and 5.5.9 show that, again, the results of both laboratories follow the same trend, but with a small amount of difference. Some researchers $[5,114,89]$ selected one type of regression (like exponential) to develop a stage-discharge relationship in gates and suggested using this kind of regression with different coefficients for different scales. The coefficients should be determined separately in each structure. Due to the lack of data in this research, it is not reasonable to develop any kind of relationship based on the graphs. In Appendix G, some pictures of the real scale hydraulic structures are provided for better understanding. These structures are located in South Florida. 


\section{CHAPTER 5}

\section{RESULTS \& DISCUSSION}

\section{SECTION 6}

\section{AN IMAGE PROCESSING TECHNIQUE TO DETERMINE THE EFFICIENCY OF ENERGY DISSIPATION IN HYDRAULIC STRUCTURES}

\subsubsection{Introduction}

A number of hydraulic structures can be operated as energy dissipators (e.g., a hydraulic jump). These structures dissipate energy, thus maintaining their downstream flow in a stable, safe condition. Experimental equations are available for the types of hydraulic structures that determine their energy loss based on in-situ measurements. The efficiency of these structures is directly related to their ability to dissipate energy. In this study, an image processing technique has been assessed to determine the efficiency of some of these structures. As a first step, the study obtained and used regular, top view pictures of the structure, including upstream and downstream views; the picture(s) was then imported into MATLAB software for further processing. Next, the picture was converted to a grayscale image (to ease processing). Then, using an innovative Fuzzy-based method, which is also presented in this study, an Efficiency Index (with a 0-100 scale) was calculated. The method uses image histogram information, which is extracted by the image processing technique. The approach 
herein described offers an alternative technique that hydraulic structure managers may develop to support their operation.

\subsubsection{Digital Pictures}

Each picture is made from elements which are known as the pixel. There is some information in each pixel which represents a color. Simply put, the color in each section of the picture is represented by a pixel. The quality of the image can be determined by the intensity of the pixels; a higher quality picture needs more pixels and greater resolution [175].

Colored and black and white photos are two types of images. Colored pictures are made up of three basic colors (red, green, and blue (RGB)) in three layers with 16.7 million spectra, whereas black and white pictures are made by gray level with 256-color spectra ranging from 0 to 255 [176]. Some other types of color images, such as CMYK (cyan, magenta, yellow, and black), have more than three basic colors with 4.3 billion spectra. With image processing techniques, some information can be extracted from the image. This process is known as digitization[178].

It is easier to extract data from black and white images than from colored images, because in colored images there is one layer for each basic color (in total, three layers) and millions and billions of spectra. The huge amount of information in colored images makes analyzing these pictures very difficult.Therefore, the black and white image is preferred, because it has just 256 spectra colors. In this research, black and white images are used to extract information. The image frequency histogram is extracted for 
each picture. Then the mean and standard deviation of the image histogram were used to determine the Efficiency Index.

\subsubsection{Model Preparation}

There are some steps to complete before using the proposed method to determine the Efficiency Index:

-Prepare a top view image of the structure, including upstream and downstream views.

The image can be taken by camera or extracted from Google Earth.

- Cut three sections of the image; one upstream, one downstream, and a third one in the middle.

- Import three new images into MATLAB software.

- Convert the images to grayscale to ease processing.

- Extract the grayscale images' histogram in MATLAB.

- Change the histogram type to double format.

- Make the histogram's scale 0-1 based on the Fuzzy Concept (Figure 3.6.1).

- Extract the mean and standard deviation of the histogram.

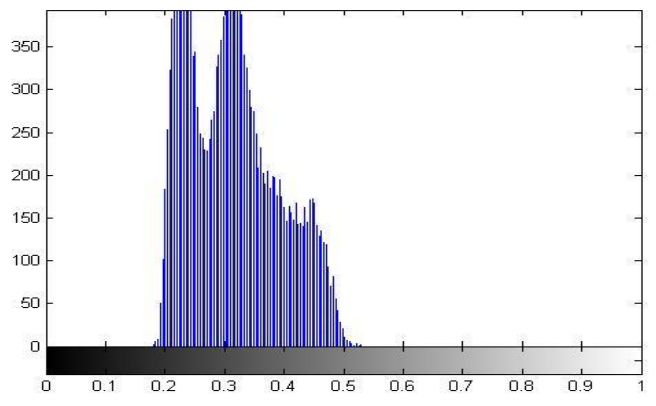

Figure 5.6.1: Image histogram on a $0-1$ scale 


\subsubsection{Efficiency Index Calculation}

After extracting the mean and the standard deviation from the image histogram, these values should then be used in the proposed method to determine the Efficiency Index. The steps below are used to calculate the Efficiency Index:

- Use the Mean and Standard Deviation (SD) obtained in the model preparation section.

- If the mean is more than 0.5 , subtract both the mean and the SD from 1 (one), otherwise do not subtract the mean and the SD from one.

- Find the average of the mean and the SD for the last step. This number is representative of the Efficiency Index.

- Compare the Efficiency Index between upstream and downstream and then estimate the efficiency of the structure.

\subsubsection{Laboratory Results}

The experiments were conducted at the Water Research Institute in Tehran, Iran to determine the Efficiency Index of a huge physical model of a stepped spillway (scale 1:30). Figures 5.6.2 (a) and (b) show the physical model from the front and top view of the model, respectively. Table 5.6.1 reported the tested discharges, the extracted mean, and the standard deviation from the image histogram, the revised mean and the standard deviation, and the Efficiency Index downstream. The way to revise the mean and the standard deviation was explained in the proposed method. It should be noted that 
discharges are reported as a prototype discharge, not for the physical model. The proposed method has been validated by the results of this physical model with an average of $96.45 \%$ agreement (Appendix H). The application of this proposed method is then shown in two case studies.

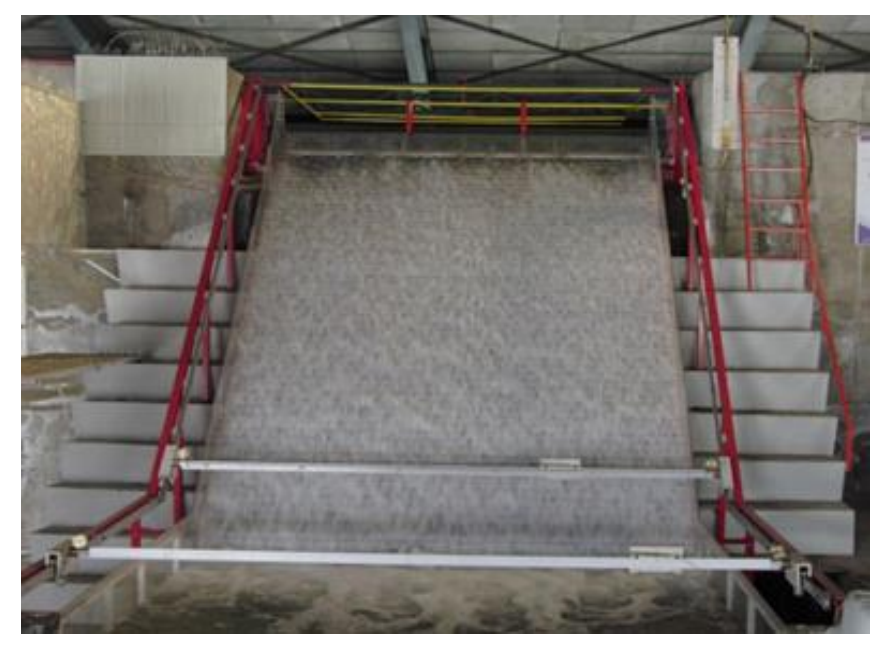

Figure 5.6.2. (a): Stepped spillway physical model, the Water Research Institute

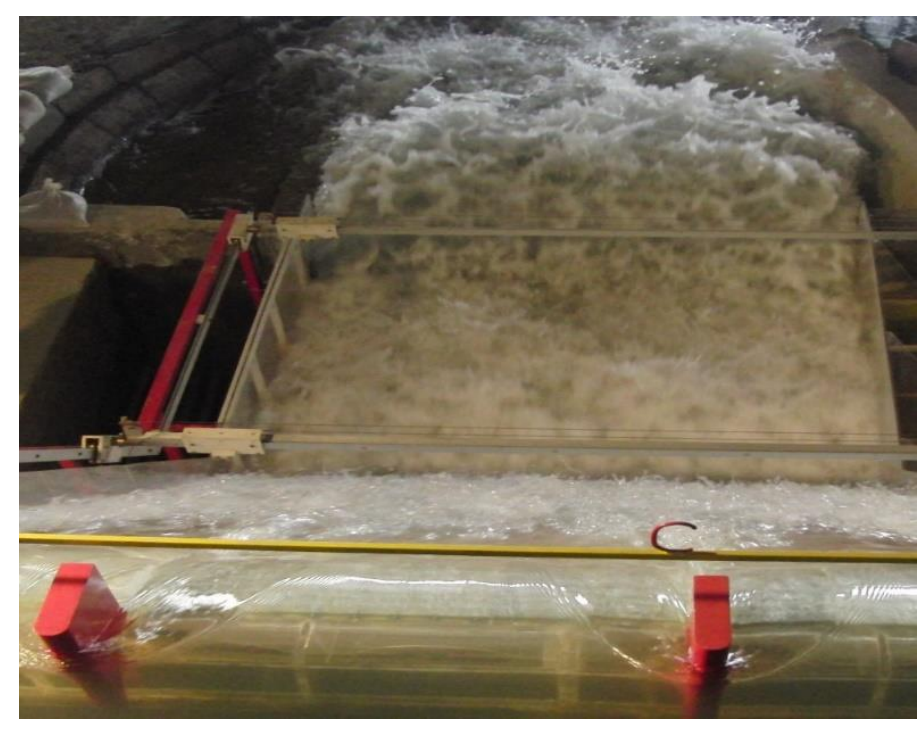

Figure 5.6.2. (b): Top view, stepped spillway, the Water Research Institute 
Table 5.6.1 Downstream Efficiency Index

\begin{tabular}{|c|c|c|c|c|c|}
\hline $\begin{array}{l}\text { Discharge } \\
\left(\mathrm{m}^{3} / \mathrm{s}\right)\end{array}$ & Mean & $\begin{array}{l}\text { Standard } \\
\text { Deviation }\end{array}$ & $\begin{array}{l}\text { Revised } \\
\text { Mean }\end{array}$ & $\begin{array}{c}\text { Revised Standard } \\
\text { Deviation }\end{array}$ & $\begin{array}{c}\text { Efficiency Index } \\
\text { Downstream }\end{array}$ \\
\hline 20 & 0.1974 & 0.0264 & 0.8026 & 0.9736 & 0.89 \\
\hline 80 & 0.2525 & 0.0294 & 0.7475 & 0.9706 & 0.86 \\
\hline 200 & 0.3129 & 0.0762 & 0.6871 & 0.9238 & 0.81 \\
\hline 800 & 0.5577 & 0.0417 & 0.5571 & 0.0417 & 0.30 \\
\hline 2100 & 0.5295 & 0.0377 & 0.5295 & 0.0377 & 0.28 \\
\hline
\end{tabular}




\subsubsection{Case Study I}

The Spillway Park in Lake Worth, Florida was selected as the first case study to show the application of the proposed method. As can be seen from Figure 5.6.3 (a), the top view of the structure is extracted from Google Earth which is free and available for use by everyone. All sections must be extracted from this image to prevent the light effect in the image processing technique. Section one is selected upstream where the flow is completely stable. Section two is selected downstream of the structure, and section three is also selected downstream where the flow is expected to be in an approximately stable condition. Figures 5.6.3 (b) to (d) depict the image histogram of these three sections, as well as the estimated Efficiency Index for each of them. Figure 5.6.3 (e) shows the downstream flow condition.

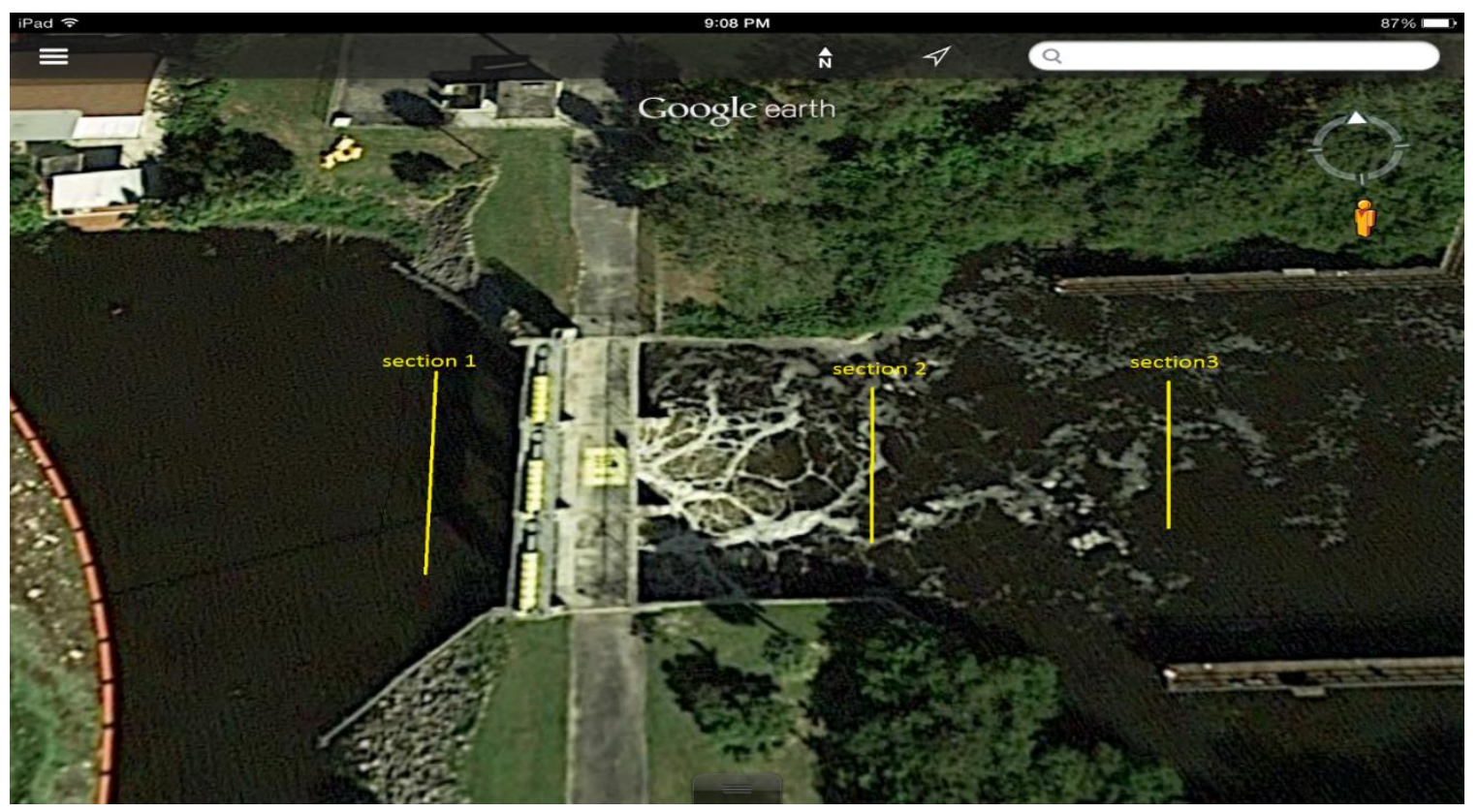

Figure 5.6.3. (a): Top view, Spillway Park - Lake Worth, FL, [Google Earth] 


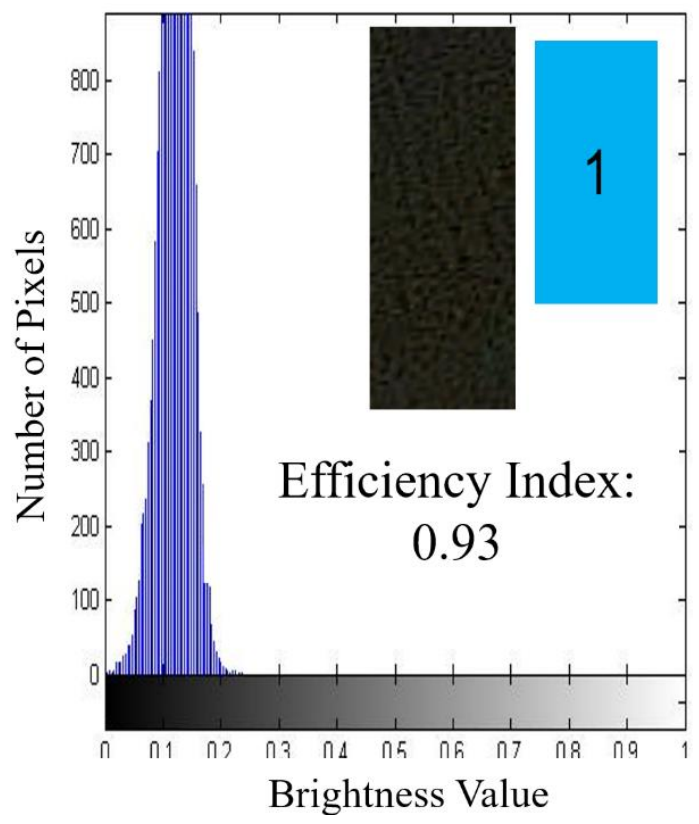

Figure 5.6.3. (b): Image histogram - section one

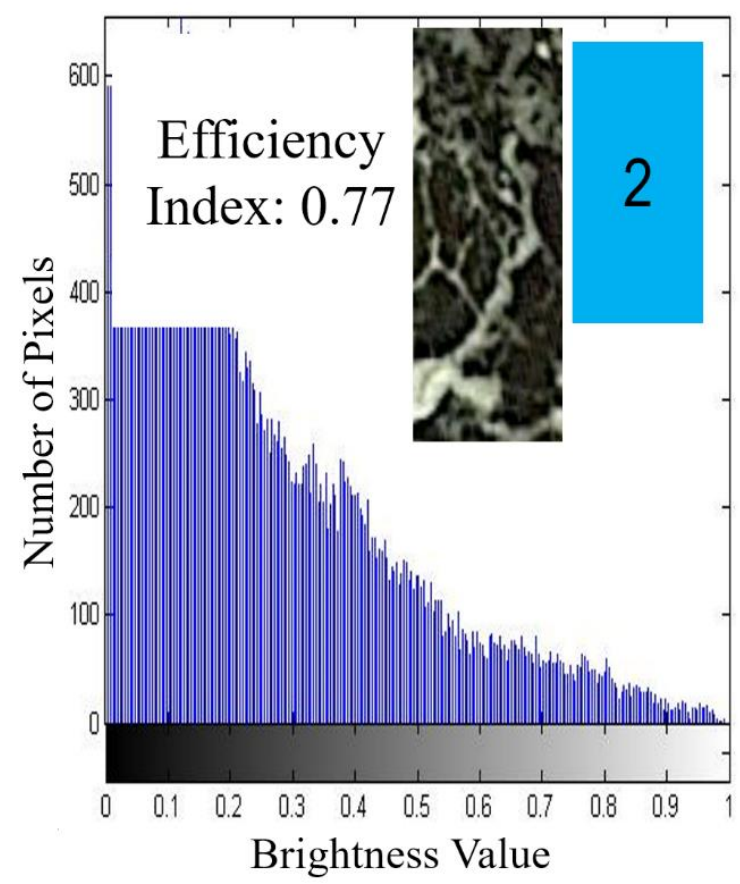

Figure 5.6.3. (c): Image histogram - section two 


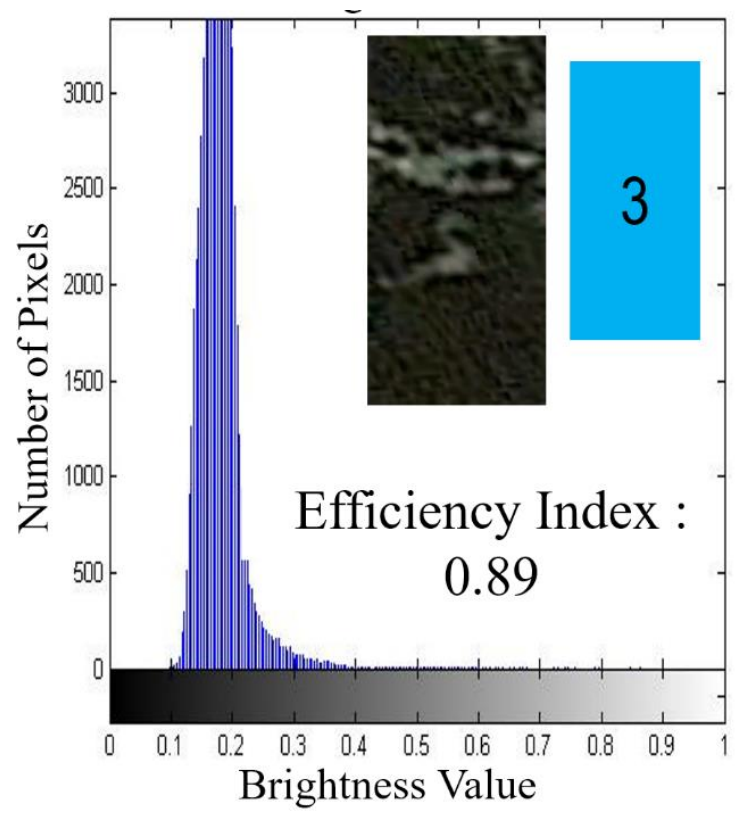

Figure 5.6.3. (d): Image histogram - section three

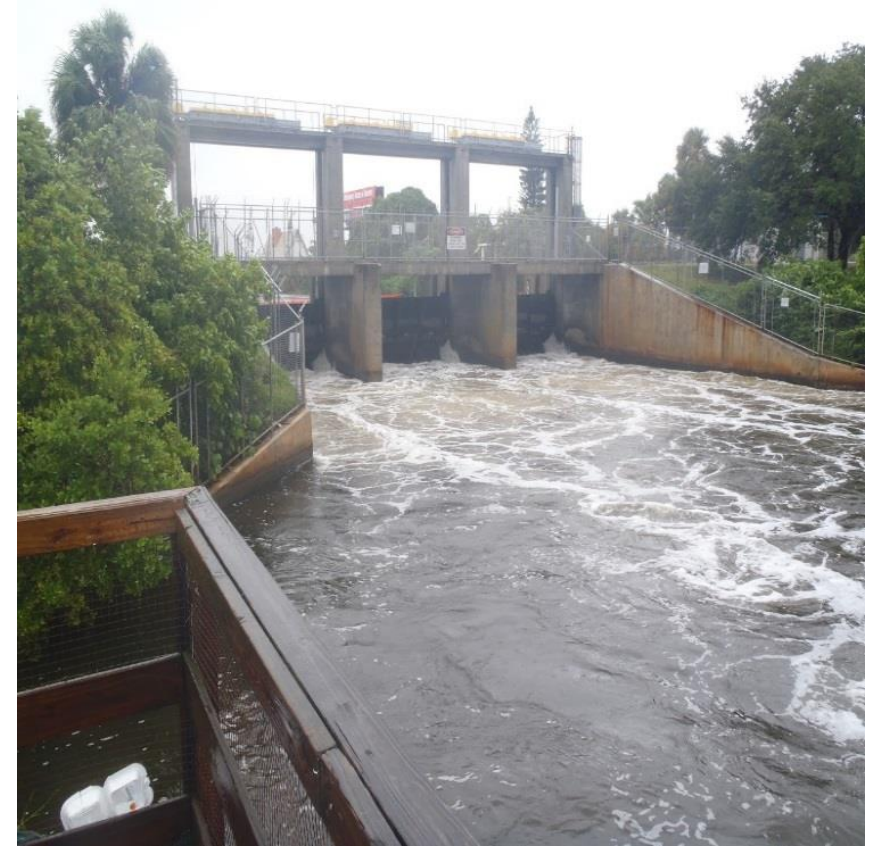

Figure 5.6.3. (e): Downstream flow condition 
The efficiency of this hydraulic structure is the difference between section one and section three. Results show that the Efficiency Index is equal to 0.93 in section one and that it is equal to 0.89 in section three. Therefore, the efficiency of this structure is $96 \%$ based on the proposed method. As is clear from the histograms, the method uses the darkness and whiteness (brightness) of the image to estimate the Efficiency Index.

In Figure 5.6.3 (b), the brightness of the image is in dark values. Dark values mean that the flow has no aeration or a small amount of aeration based on its brightness value. In Figure 5.6.3 (c), the brightness of the images distributed in both dark and white values. However, it is mostly in dark values. White values in the image histogram mean are representative of aeration in the flow which can be seen in Figure 5.6 .3 (c). Finally, in Figure 5.6.3 (d), the brightness of the image is again mostly seen in dark values; therefore, a small amount of aeration is expected. As is obvious from the method, the number of pixels is not important in this method. Brightness only is used to determine the Efficiency Index.

\subsubsection{Case Study II}

The Oroville Dam in the northern part of California was selected as the second case study to show the application of the proposed method. As can be seen from Figure 5.6.4 (a), the top view of the structure was extracted from Google Earth. All sections must be extracted from the same image to prevent the light effect in the image processing technique. Section one is selected upstream (the reservoir) where the flow is completely stable (Figure 5.6.4 (b)). Section two is selected downstream of the 
structure, and section three is also selected downstream (the river) where the flow is expected to be in an approximately stable condition (Figure 5.6 .4 (c)). The image histogram for all these sections, as well as the estimated Efficiency Index for each of them, are depicted in Figures 5.6.4 (d) to (f). In this case study, the main spillway of the Oroville Dam is carefully considered to determine the efficiency of the structure. The main spillway of this dam is located on the right side of the dam (Figure 5.6.4 (a)) and conducts flow from the reservoir to the river downstream during a flood or when the water level should be decreased in the reservoir.

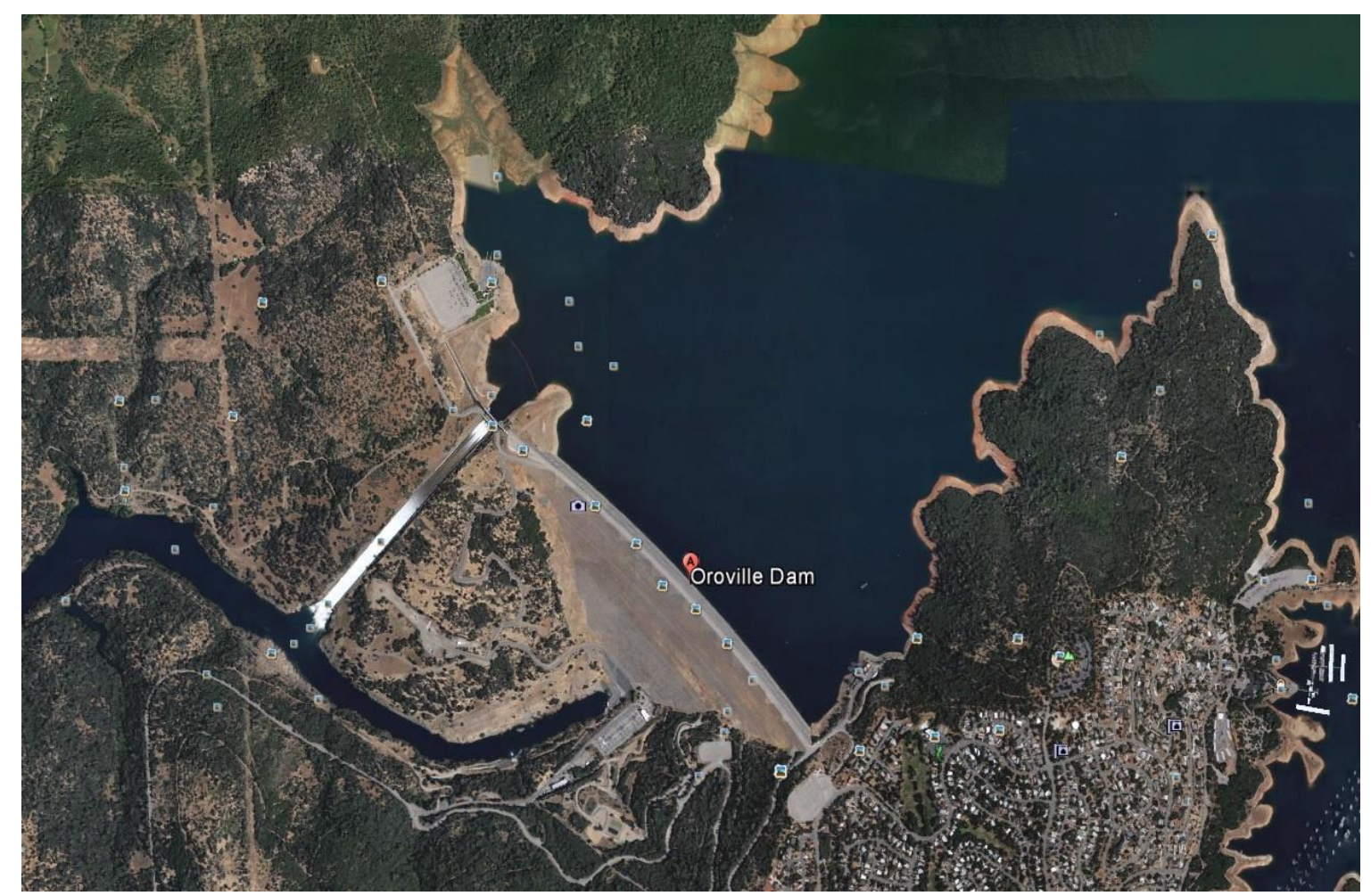

Figure 5.6.4. (a): Top view, Oroville Dam - CA, [Google Earth] 


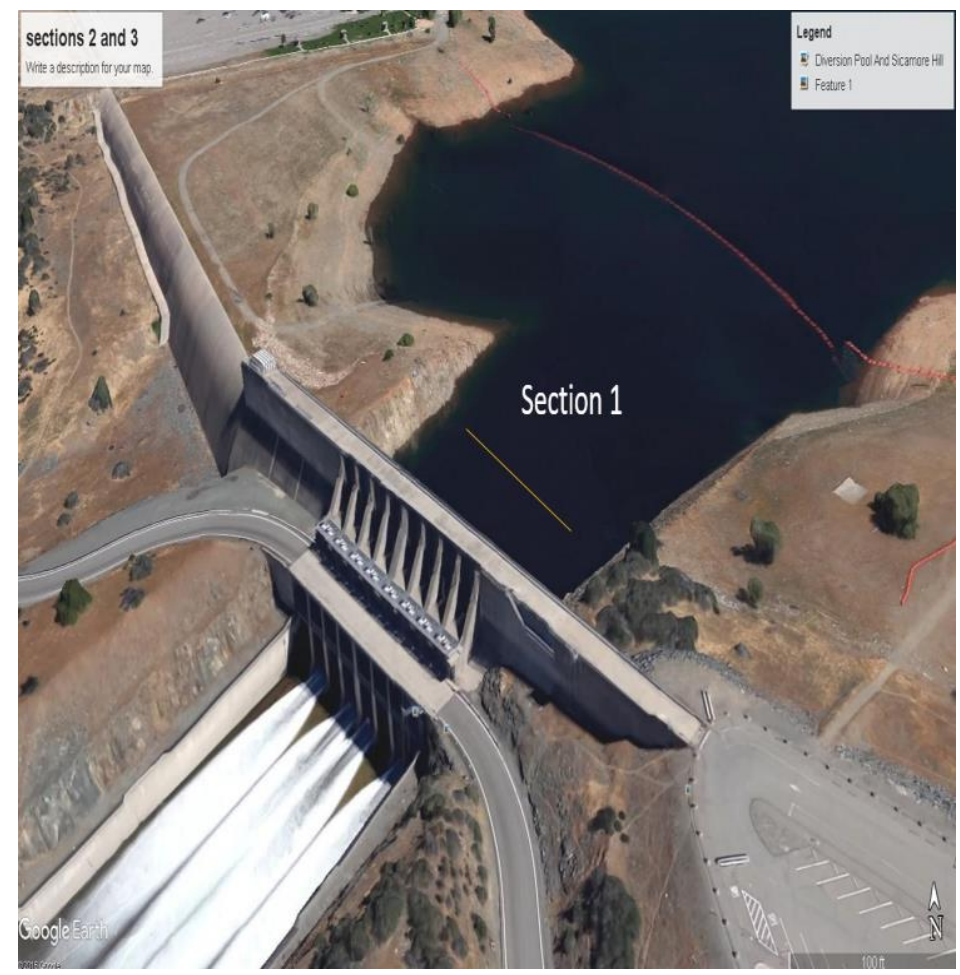

Figure 5.6.4. (b): Section one

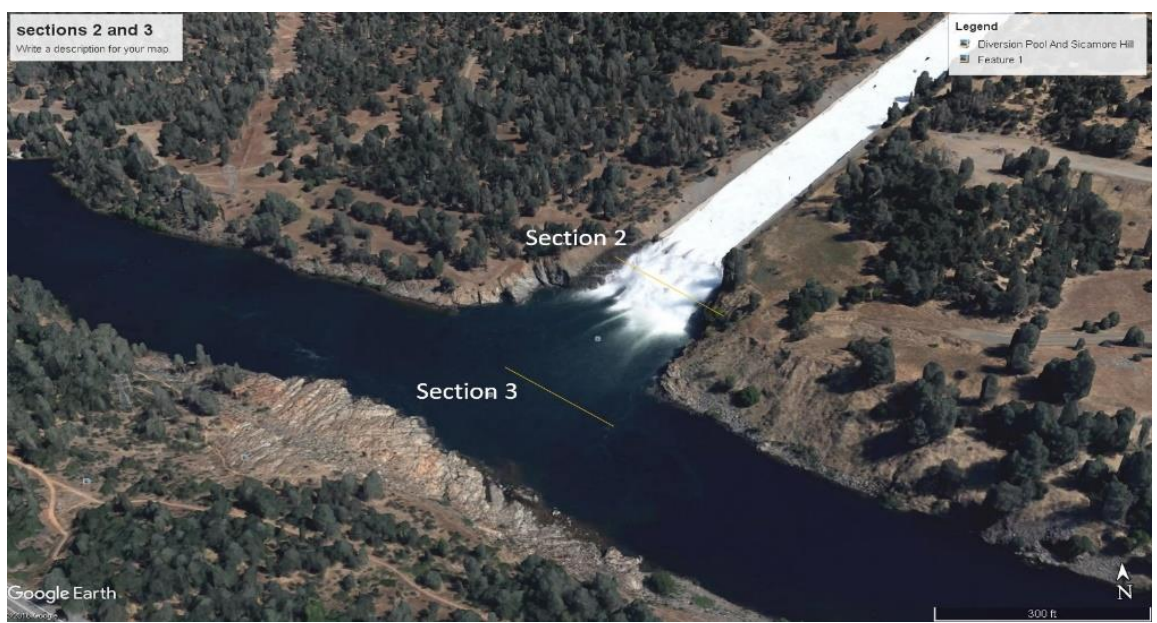

Figure 5.6.4. (c): Sections two and three 


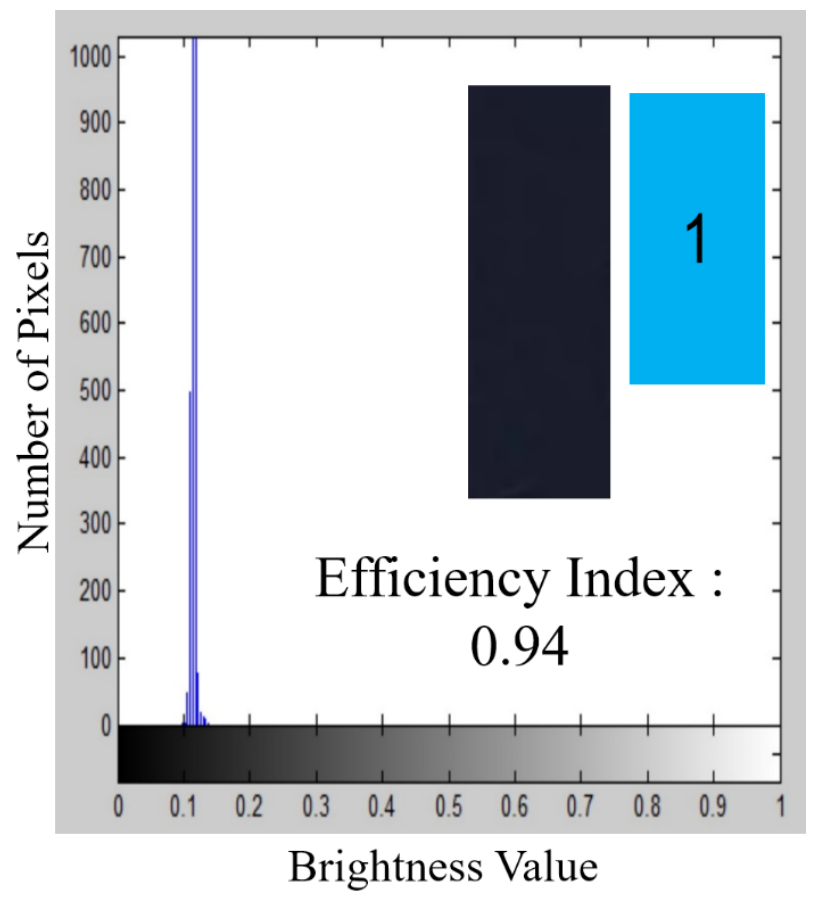

Figure 5.6.4. (d): Image histogram - section one

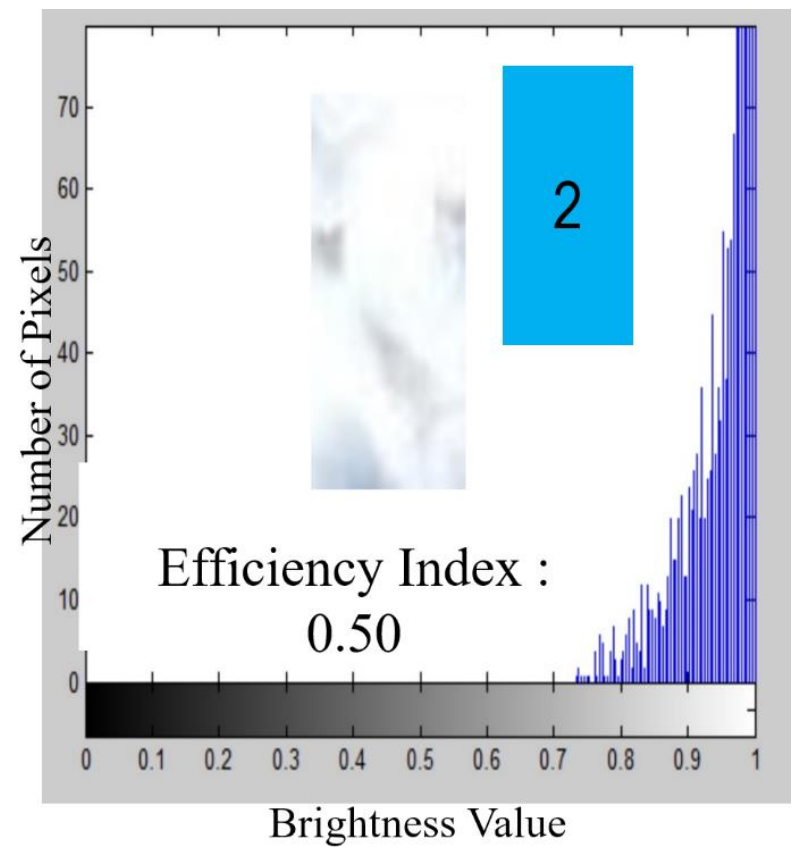

Figure 5.6.4. (e): Image histogram - section two 


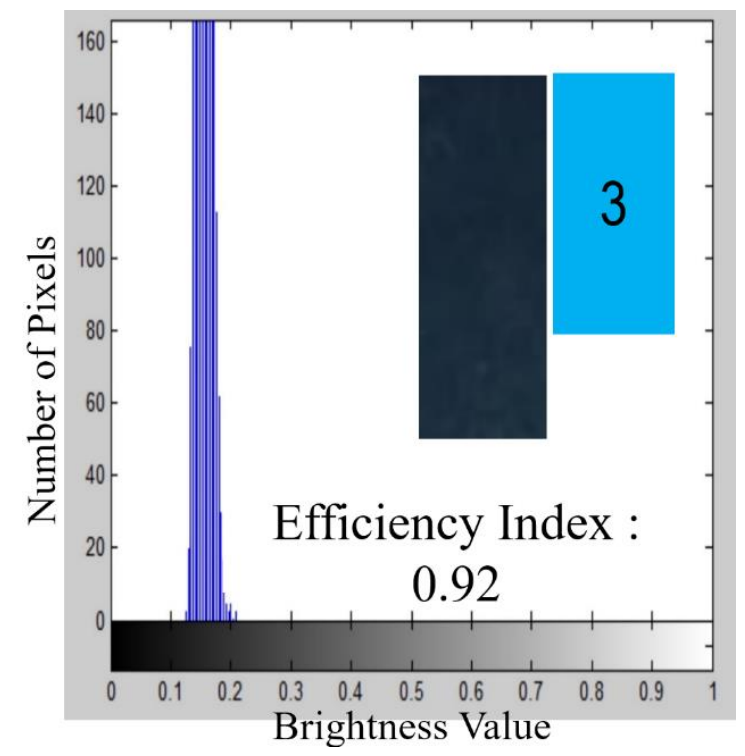

Figure 5.6.4. (f): Image histogram - section three

The efficiency of this hydraulic structure is the difference between section one and section three. Based on the results, the Efficiency Index is equal to 0.94 in section one, whereas it is equal to 0.92 in section three. Consequently, the efficiency of this structure is $97.87 \%$ based on the proposed method.

In Figure 5.6.4 (d), the brightness of the image is in the dark values. The dark values mean that the flow has no aeration or a small amount of aeration based on the brightness value. In Figure 5.6.4 (e), the brightness of the image is mostly in the white values. White values in the image histogram mean are representative of aeration in the flow. In Figure 5.6.4 (f), the brightness of the image is again mostly in the dark values; so a small amount of aeration is expected. 
Section two can be used to determine the efficiency of the chute when the stilling basin or any other type of combination is available. Moreover, the results of this section can help engineers carefully monitor the performance of the hydraulic structure and find out what is happening exactly in the middle of the structure or immediately after the structure. Based on the results of this study, the following outcomes can be highlighted:

- The proposed method effectively estimated the efficiency of the hydraulic structures in both the laboratory and the prototype.

- The proposed method, which utilizes the Image Processing Technique, is a trustworthy, quick, low-cost, and practical method for engineers to monitor hydraulic structures.

- The proposed method is simple because the pictures can be easily obtained from Google Earth. 


\section{CHAPTER 5}

\section{RESULTS \& DISCUSSION}

\section{SECTION 7}

\section{LIMITATIONS}

The concepts and methods that have been introduced and developed in this research have limitations (or constraints) that must be acknowledged. These concepts and methods include the Flow Stability Factor, the Flow Stability Number, and the image processing technique. Moreover, there are some additional factors, like the impact of the Reynolds number, which limit the results. The limitations on this research are listed in this section.

The Flow Stability Factor is a visual method and does not need any measurement, because it is based on observation. Therefore, the individual who uses this method should be an educated, trained expert in hydraulic engineering. This requirement is important to ensure the correct classification of the flow into a category. This method is based on surface flow fluctuations.

The Flow Stability Number is not defined for supercritical flow and, consequently, is only applicable to critical and subcritical flows. This method requires measuring depth and velocity. Thus, it is more elaborate and quantitative than the Flow Stability Factor. An expert using this method must be familiar with the concept of permissible velocity, the meaning and role of the energy equation, and basic statistical analysis. 
The outcomes of this research indicate that scale has an effect on the results. The scale effect has been assessed using the differences in the experimental results at the two utilized laboratories and experimental flumes. The effect may be connected with the range of the Reynolds number. Based on the literature review, results from conditions of a Reynolds number of less than $10^{4}$ cannot ensure Froude similarity, which was the case for this research. Conclusively, additional experimentation is needed to improve the understanding of the scale effect, and its implication in the transitioning laboratory and pilot conditions to real prototypes.

The Efficiency Index method also has limitations. In this method, the top view picture should capture the entire structure, fully covering the upstream and downstream areas, in one picture. Then, three sections should be selected from the captured picture. The method works based on the image processing technique and is able to estimate the Efficiency Index for each selected section based on the darkness and whiteness of the picture. If different pictures (instead of one picture) are used for different sections, the quality of the pictures (resolution) may not be the same. Hence, the method cannot be applied.

Because shadows have an effect on results, it is important to select areas without a shadow, or better yet, to use a picture without a shadow. Another limitation of this method is the availability of real time pictures. For instance, Google Earth provides "old pictures" most of the time, which does not support the online monitoring of structures. A person who uses this method should also be familiar with Matlab software, image processing, hydraulic structures, flow regime categories, and statistics. 


\section{CHAPTER 6}

\section{CONCLUSIONS AND RECOMMENDATIONS}

\subsection{KEY FINDINGS AND CONCLUSIONS}

The focus of the research is to classify the flow condition downstream of the hydraulic structures by introducing the Flow Stability Factor, as well as the Flow Stability Number. These innovative factors are presented to easily classify the flow and help to manage the hydraulic structures to maintain downstream flow in a stable condition. Three types of structures were used in this research, including a vertical sluice gate, a gate and an expansion structure, and a gate and a contraction structure. Researchers have not paid a lot of attention to flow classification and energy loss investigations, and thus, there is an information gap.

Chapter four explained the methodology, laboratory details, and the devices which were used in this study. The experiments were conducted in two laboratories. The first one was the Fluid Mechanics Laboratory at Florida International University (FIU) and the second one was the Center for Research in Water Resources (CRWR) at the University of Texas-Austin. The Flow Stability Factor and the Flow Stability Number (as a ratio of two energies) are introduced in this chapter.

Chapter five includes seven sections, presented as results and a discussion. Section one shows the application of the Flow Stability Factor based on the Fuzzy Concept to classify the flow downstream of gates. Flow classification was conducted for 14

discharges and the size of the gate opening to ensure a stable condition downstream is 
reported using dimensionless numbers. Based on this classification method, the number one is assigned to a completely stable flow and the number zero is assigned to a hydraulic jump (a completely unstable flow). Other numbers between zero and one are assigned to various hydraulic conditions between a hydraulic jump and a stable condition, like a submerged jump, a wave, and a weak wave, etc. This research developed dimensionless parameters, using the Pi-Buckingham method that shows the $\mathrm{h}_{0} / \mathrm{a}$ versus $\mathrm{dc} / \mathrm{h}_{0}$ trend, while securing a stable flow condition downstream. Two data series were used to train and validate the gate opening neural network in vertical sluice gates. Furthermore, a regression-based post-processing method was applied to the outputs of the artificial neural network to reduce the difference percentage in determining the gate opening. By considering difference percentages and average difference percentages, it can be inferred that the regression-based post-processing method results in less difference than ANN outcomes. The regression-based postprocessing method can be used with an average difference of roughly $3 \%$. Therefore, it is a reliable and accurate method even if the data set is small.

All in all, simply by measuring the depth and discharge before the gate, it is possible to find an acceptable gate opening using ANN. Section Two shows the values of the Flow Stability Number in vertical gates. This dimensionless number is a ratio of total energies in two sections downstream of a gate. The results show that there is a good agreement between the Flow Stability Number and the Flow Stability Factor.

Section three and section four represent the application of the Flow Stability Number in a gate and an expansion, as well as in a gate and a contraction hydraulic structures. Three thicknesses were used for these two structures. The results indicate that the 
narrowest thickness (i.e., 0.7 centimeters) generates the best results in these hydraulic structures. Moreover, the outcomes show that there is not a meaningful difference in the hydraulic performance between 0.7 centimeters and 1.2 centimeter thicknesses in a gate and an expansion hydraulic structure. The greatest thickness ( 2 centimeters) can be used in low rate discharges; the $1.2 \mathrm{~cm}$ thickness can be used in low- and mid-rate discharges; and finally, the narrowest thickness ( 0.7 centimeters) can be used for all discharge rates to produce a stable condition downstream of a gate and an expansion hydraulic structure.

In section five, the results of the Flow Stability Number and the Flow Stability Factor were compared. These two values demonstrate good agreement in determining the stable condition downstream of hydraulic structures. As a result, the Flow Stability Factor can be implemented in projects by hydraulic experts as a practical, quick, and reliable method to determine the stability condition. There is no need to measure any variables to determine the Flow Stability Factor; therefore, it is desirable for applications in practical work when measurements cannot be taken. Later in section five, three hydraulic structures were compared and the results indicate that a gate with an expansion structure has the best hydraulic performance among these structures across all discharge rates. Furthermore, a gate and an expansion with the smallest thickness can be used across a wide range of discharges, whereas a gate with a contraction hydraulic structure can only be used for low discharge rates. The flow immediately after a gate a contraction is somehow wavy, and this hydraulic structure is not recommended as a structure for producing a stable condition downstream. 
Game Theory was used to select an appropriate hydraulic structure based on the objectives of different agencies. A gate with an expansion structure is presented as a desirable hydraulic structure for environmental agencies, because it provides the highest degree of downstream stability for the structure. However, the construction cost of this structure is more than the cost for a gate hydraulic structure. On the other hand, the gate structure is presented as a desirable option for irrigation agencies, because the construction cost is lower than for a gate with an expansion structure. Based on the results, a Nash Equilibrium cannot be achieved in this game; therefore, each agency should build their own most desired option. Moreover, the designer is presented as a third-party who is not a decision-maker in the game, but who can benefit from it. If both agencies select the same designer for their project, then, the designer is the real winner of the game. In addition, the graphs which show the results for both laboratories, in section five, illustrate that the flow in these structures is sensitive to a scale effect and more consideration should be taken about sluice gate studies.

An image processing technique has been assessed to determine the efficiency of some of the hydraulic structures in chapter five - section six. In this method, a grayscale image should be used for processing ease. MATLAB software was used to produce a grayscale image from a colored image (the top view of the structure) and to extract an image histogram. Then, an innovative Fuzzy-based method should be applied to calculate the Efficiency Index, across a 0-100 scale. The method uses image histogram information, which is extracted by the image processing technique, and determines the Efficiency Index based on the darkness and whiteness (brightness) of the picture in question. One laboratory physical model and two case studies were selected to show 
the application of the method. The method was validated with the results of the physical method with an average $96.45 \%$ agreement. The efficiency of the structure was calculated at $96 \%$ in the Spillway Park, Lake Worth, Florida, and as $97.87 \%$ in the main spillway of the Oroville Dam, California. The outcomes show that this proposed method can be effectively used to determine the efficiency of hydraulic structures in both laboratory and real world situations. Moreover, this method can help engineers offering a practical, low-cost, trustworthy, and quick way to monitor hydraulic structures. Simplicity is another advantage of this method, because the top view pictures can be obtained from Google Earth for free and quickly.

Limitations on the methods which have been used in this research are listed in chapter five - section seven. There are some limitations to using the Flow Stability Factor, the Flow Stability Number, and the image processing technique. The Flow Stability Factor is a visual method and there is no need to measure any variable in this method. Therefore, the person who is using this method should be a hydraulic expert. The flow is classified in some categories, and there is the chance to select the flow in an incorrect category when the person using this method is not a hydraulic expert. The Flow Stability Number is not defined for supercritical flow and is only applicable in critical and subcritical flows. Also, to use this method, depths and velocities must be measured which makes it more expensive than the Flow Stability Factor. The proposed method to estimate the Efficiency Index and the overall efficiency of the structures also has some limitations. In this method, one picture should be captured for the whole structure, including both upstream and downstream. Then, three sections should be selected from the captured picture. When different pictures are used for different sections, the quality 
of the pictures (resolution) are not the same. Hence, the method cannot be applied. Moreover, a shadow affects the results of the method. Therefore, when selecting the sections, the user should try to select an area without shadows or use a picture without shadows. Another limitation of this method is the lack of access to real time pictures. Most of the time, Google Earth offers only old pictures, whereas for the online monitoring of structures the most updated pictures are needed.

\subsection{RECOMMENDATIONS FOR FUTURE WORK}

Because of the scale effect, it is recommended that experiments be conducted in largescale structures (in sections one to four) to better understand a scale effect and to find more reliable results and develop an equation which can be used to estimate the size of the gate opening. Also, it is recommended that expansion and contraction be used with different lenghths to find the effect of this factor on the hydraulic performance of these structures.

Other types of structures, like stepped spillways, ogee spillways, and flip buckets, can be combined with a gate, and then the Flow Stability Number can be estimated for different discharges and gate openings. Therefore, the secenarios which lead to downstream stable conditions can be determined.

The Efficiency Index is defined in chapter three - section six. However, the acceptable range of this index should be investigated by conducting some experiments. It is recommended that the acceptable range be found by measuring the energy and flow aeration in different hydraulic structures. 


\section{BIBLIOGRAPHY}

[1] Roth, A., \& Hager, W. H. (1999). Underflow of standard sluice gate. Experiments in fluids, 27(4), 339-350.

[2] Wu, S., \& Rajaratnam, N. (2015). Solutions to rectangular sluice gate flow problems. Journal of Irrigation and Drainage Engineering, 141(12), 06015003.

[3] Akoz, M. S., Kirkgoz, M. S., \& Oner, A. A. (2009). Experimental and numerical modeling of a sluice gate flow. Journal of Hydraulic Research, 47(2), 167-176.

[4] Altan-Sakarya, A. B., \& Kökpınar, M. A. (2013). Computation of discharge for simultaneous flow over weirs and below gates (H-weirs). Flow Measurement and Instrumentation, 29, 32-38.

[5] Bijankhan, M., Ferro, V., \& Kouchakzadeh, S. (2012). New stage-discharge relationships for radial gates. Journal of Irrigation and Drainage Engineering, 139(5), 378-387.

[6] Henderson, F. M. (1966). Open channel flow, Macmillan, New York.

[7] Shammaa, Y., Zhu, D. Z., \& Rajaratnam, N. (2005). Flow upstream of orifices and sluice gates. Journal of Hydraulic Engineering, 131(2), 127-133.

[8] Subramanya, K. (1982). Flow in open channels, National Book Trust, India.

[9] Kim, Y., Choi, G., Park, H., \& Byeon, S. (2015). Hydraulic Jump and Energy Dissipation with Sluice Gate. Water, 7(9), 5115-5133.

[10] Swamee, P. K. (1992). Sluice-gate discharge equations. Journal of Irrigation and Drainage Engineering, 118(1), 56-60.

[11] Cassan, L., \& Belaud, G. (2011). Experimental and numerical investigation of flow under sluice gates. Journal of Hydraulic Engineering, 138(4), 367-373.

[12] Shahrokhnia, M. A., \& Javan, M. (2006). Dimensionless stage-discharge relationship in radial gates. Journal of irrigation and drainage engineering, 132(2), 180-184.

[13] Yen, J. F., Lin, C. H., \& Tsai, C. T. (2001). Hydraulic characteristics and discharge control of sluice gates. Journal of the Chinese Institute of Engineers, 24(3), 301-310.

[14] Hamedi, A., \& Fuentes, H. R. (2016). New Relationship between a Vertical Gate Opening and Downstream Flow Stability: Experimental Development. In World Environmental and Water Resources Congress 2016 (pp. 47-57). 
[15] Boileau P. (1848). MeHmoire sur le jaugeage des cours d'eau a` faible ou a` moyenne section. Journal Ecole Polytechnique Paris 33.

[16] Bornemann KR. (1871). Versuche uK ber den Aus ${ }^{-}$uss unter Wasser bei SchuK tzen. Civilingenieur 17: 45-60.

[17] Bornemann KR. (1880). UG ber den Aus uss bei SchuK tzen und schuK tzenartigen MuK ndungen. Civilingenieur 26: 297-376.

[18] Haberstroh CE. (1890). Experiments on flow of water through large gates and over wide crests. Journal of Association Engineering Society 5: 1-11.

[19] von Mises, R. (1917). Berechnung von ausfluß und ueberfallzahlen, Zeitschrift des Vereine Deutscher Ingenieure, Berlin (in German).

[20] Gibson, A. (1919). Experiments on the coefficients on discharge under rectangular sluice gates. (Abridges). In Minutes of the Proceedings of the Institution of Civil Engineers (Vol. 207, No. 1919, pp. 427-434). Thomas Telford-ICE Virtual Library.

[21] Hurst HE; Watt DAF. (1925). The similarity of motion of water through sluices of the Assuan dam. Proceeding of Institution of Civil Engineering. 218: 72-180.

[22] Keutner, C. (1932). WasserabfuK hrungsvermoKgen von scharfkantigen und abgerundeten PlanschuK tzen. Bautechnik 10: 266-269; 10:303-305.

[23] Keutner, C. (1935). Die StroKmungsvorgaKnge an unterstroKmten SchuK tztafeln mit scharfen und abgerundeten Unterkanten. Wasserkraft und Wasserwirtschaft 30: 5-8; 30: $16-21$.

[24] Woycicki, K. (1935). The hydraulic jump on its role on discharge of sluice gates. Technical Rep. No. 3-2, U.S. Bureau of Reclamation, Denver, 65.

[25] Fawer, C. (1937). Calcul de la contraction causeHe par une vanne plane dans le cas d'un eHcoulement deHnoyeH. Bulletin Technique de la Suisse Romande 63: 192-198; 63: 217-219; 63: 245-252; 63: 283-287.

[26] Escande, L. (1938). Etude theHorique et expeHrimentale de l'eHcoulement par vanne de fond. Revue GeHneHrale de l'Hydraulique 4: 25-29; 4:120-128.

[27] Gentilini, B. (1941). Ef usso dalle luci soggiacenti alle paratoie piane inclinate e a settore. L'Energia Elettrica 18: 361-380.

[28] Metzler, D. E. (1948). A model study of Tainter gate operation. MS thesis, Iowa State Univ., Iowa City, Iowa. 
[29] Smetana, J. (1948). Ecoulement de l'eau au-dessous d'une vanne et forme rationelle de la surface d'appui de la vanne. La Houille Blanche 4: 126-146.

[30] Henry, H. R. (1950). Discussion of 'Diffusion of Submerged Jets. Trans. ASCE, 115, 687-694.

[31] Binnie, A. M. (1952). The flow of water under a sluice-gate. Quarterly Journal of Mechanics and Applied Mathematics, Oxford, England, 4,395-407.

[32] Marchi, E. (1953). Sui fenomeni di efflusso piano da luci a battente. Ann. Mat. Pura Appl., 35(1), 327-341 (in Italian).

[33] Benjamin, T. B. (1955). On the flow in channels when rigid obstacles are placed in the stream. Journal of Fluid Mechanics, 1, 227-248.

[34] Franke, P. G. (1956). Theoretische Betrachtungen zur Strahlkontraktion beim Ausfluss unter Schu"tzen. Bautechnik, 33(3), 73-77 (in German).

[35] Toch, A. (1955). Discharge characteristics of Tainter gates. Trans. American Society of Civil Engineers, 120, 290-300.

[36] Chow, V.T. (1959). Open channel hydraulics. McGraw-Hill Book Company, Inc; New York.

[37] King, H.W., (1963). Handbook of Hydraulics, $5^{\text {th }}$ Edition, McGraw-Hill, New York.

[38] Anwar, H. O. (1964). Discharge coefficients for control gates. WaterPower, 17(4), $152-159$.

[39] Rajaratnam, N., and Subramanya, K. (1967). Flow equation for the sluice gate. Journal Irrigation and Drainage Engineering, 93(3), 167-186.

[40] Rajaratnam, N., \& Subramanya, K. (1967). Flow immediately below submerged sluice gate. Journal of the Hydraulics Division, 93(4), 57-77.

[41] Allen, J., and Hamid, H. I. (1968). The hydraulic jump and other phenomena associated with flow under rectangular sluice-gates. Proceeding of Institution Civil Engineering, 40, 345-362.

[42] Fangmeier, D., and Strelkoff, T. S. (1968). Solution for gravity flow under sluice gates. Journal of Engineering Mechanical Division, ASCE, 94(1), 153-176.

[43] Barr, D. I. H., Huq, S. S., and Skaikh, A. H. (1969). Discussion of 'The hydraulic jump and other phenomena associated with flow under rectangular sluice-gates,' by J. Allen and H. I. Hamid. Proceeding o, Institution of Civil Engineering, 42, 529-533. 
[44] Larock, B. E. (1969). Gravity affected flows from planar sluice gates. Journal of Hydraulic Division, ASCE, 95(4), 851-864.

[45] Verma, D. V. S., \& Goel, A. (2003). Development of efficient stilling basins for pipe outlets. Journal of irrigation and drainage engineering, 129(3), 194-200.

[46] Chatterjee, S. S., Ghosh, S. N., \& Chatterjee, M. (1994). Local scour due to submerged horizontal jet. Journal of Hydraulic Engineering, 120(8), 973-992.

[47] Ojha, C. S. P., \& Subbaiah, D. (1997). Analysis of flow through lateral slot. Journal of irrigation and drainage engineering, 123(5), 402-405.

[48] Panda, S. (1981). Characteristics of side sluice flow. ME thesis, Univ. of Roorkee, Roorkee, India.

[49] Swamee, P. K., Pathak, S. K., \& Ali, M. S. (1993). Analysis of rectangular side sluice gate. Journal of irrigation and drainage engineering, 119(6), 1026-1035.

[50] Ghodsian, M. (2003). Flow through side sluice gate. Journal of irrigation and drainage engineering, 129(6), 458-463.

[51] Bijankhan, M., Darvishi, E., and Kouchakzadeh, S. (2012). Discussion of 'Energy and momentum velocity coefficients for calibrating submerged sluice gates in irrigation canals" by Oscar Castro-Orgaz, David Lozano, and Luciano Mateos. Journal of irrigation and drainage engineering, 138(9), 852-854.

[52] Bijankhan, M., and Kouchakzadeh, S. (2011). Discussion of 'Benchmark of discharge calibration methods for submerged sluice gates' by Carlos Sepúlveda, Manuel Gómez, and José Rodellar. Journal of irrigation and drainage engineering, 137(1), 56-57.

[53] Bijankhan, M., Kouchakzadeh, S., \& Bayat, E. (2011). Distinguishing condition curve for radial gates. Flow Measurement and Instrumentation, 22(6), 500-506.

[54] Safarinezhad, D. (1991). Discharge algorithms for canal radial gates. MS thesis, Shiraz Univ., Shiraz, Iran.

[55] Lin, C. H., Yen, J. F., \& Tsai, C. T. (2002). Influence of sluice gate contraction coefficient on distinguishing condition. Journal of Irrigation and Drainage Engineering, 128(4), 249-252.

[56] Eei, J., (1975). Open Channel Hydraulics, Vol. 2, (in Chinese) Tung Hwa Publishing Co., Taiwan, R.O.C. 
[57] Cho, J. N., Kim, D. H., \& Lee, S. O. (2016). Experimental Study of Shape and Pressure Characteristics of Solitary Wave generated by Sluice Gate for Various Conditions. Journal of the Korean Society of Safety, 31(2), 70-75.

[58] Kim, D. (2007). Numerical analysis of free flow past a sluice gate. KSCE Journal of Civil Engineering, 11(2), 127-132.

[59] Ohtsu, I., \& Yasuda, Y. (1994). Characteristics of supercritical flow below sluice gate. Journal of Hydraulic Engineering, 120(3), 332-346.

[60] Nago, H. (1978). Influence of gate-shapes on discharge coefficients. Trans. Japanese Society of Civil Engineering, 10, 116-119.

[61] Alhamid, A. A. (1999). Analysis and formulation of flow through combined V-notchgate-device. Journal of Hydraulic Research, 37(5), 697-705.

[62] Negm, A. M., Alhamid, A. A., \& El-Saiad, A. A. (1998). Submerged flow below sluice gate with sill. Advances in Hydroscience and Engineering, 3.

[63] Abdelaal, G.M.M., (1990). Study of the free flow conditions for silled gates Unpublished M.Sc. Thesis, Faculty of Engineering, Ain Shams University, Cairo, Egypt.

[64] Negm, A.M.; Abouelatta, N. and Abdellateef, M., (1993). Supercritical free flow characteristics under silled sluice gate. Scientific Bulletin, Faculty of Engineering, Ain Shams University, 28:4, Cairo, Egypt, pp.163-174.

[65] Negm, A.M., Abdelaal, G. M., Owais, T. M., Abdellateef, M. and Hammad, M.N., (1995) Characteristics of free hydraulic jump downstream silled sluice gates. Journal of Water and Energy International, 52:3, CBIP, India, pp.45-51.

[66] Negm, A.M., (1994). Optimum relative height of the optimal under-gate sill for supercritical submerged flow below sluice Gates. 19th Int. Conf. for Statistic, Computer Science, Scientific and Social Applications, 9-14 April, Engineering Science, Cairo, Egypt, Vol.1, pp. 39-49.

[67] Negm, A. M. and El-Saiad, A. A., (1993). Subcritical submerged flow characteristics beneath silled sluice gates. Proc. of AEIC-93, December 18-21, Faculty of Engineering, Al-Azhar University, Naser City, Cairo, Egypt, vol.4, pp. 298-309.

[68] El-Saiad, A., (1990). Study of submerged flow characteristics under silled sluice gates. Unpublished M.Sc. Thesis Ain Shams University, Cairo, Egypt. 
[69] El-Saiad, Atef A.; Abdel Hafiz, Essam; Owais, Talaat M. and Hammad, M. N., (1991). Characteristics of submerged flow under sluice gate with sill. Ain Shams University Engineering Bulletin, Vol.26, No.1, March, Cairo, Egypt, pp.109-120.

[70] El-Saiad, Atef A.; Abdel Hafiz, Essam and Hammad, M. N., (1991). Effect of sill under gate on the discharge coefficient. Journal of the Egyptian Society of Engineers, Vol.30, No.2, pp. 13-16.

[71] Abdel-Salam, M. W.; Owais, T. M., Armanious S. D. and Salem, M. N., (1990). Theoretical and experimental studies of radial gates with and without sill. Engineering Bulletin, Faculty of Engineering, Ain Shams University, Vol.25, No.3, Cairo, Egypt, Dec., pp. 18-35.

[72] Negm, A. M.; Abdellateef, M. and Owais, T. M., (1993). Effect of under-gate sill crest shapes on the flow characteristics. Proc. of AEIC-93, 18-21 Dec., Faculty of Eng., Al-Azhar University, Naser City, Cairo, Egypt, Vol.4, pp. 230-241.

[73] Salama, M., (1987). Flow below sluice gate with sill. Journal of Egyptian Society of Engineers, Vol 26, No.4, pp. 31-36.

[74] Negm AM, Al-Brahim AM, AlHamid AA. (2002). Combined free flow over weirs and below gates. Journal of Hydraulic Research ;40(3):359-65.

[75] Bove, I., Acosta, D., Gutiérreza, N., Gutiérreza, V., \& Sarasúa, L. G. (2013). Double scouring by turbulent jets downstream of a submerged sluice gate. arXiv preprint arXiv:1311.4194.

[76] Isaacs, L. T., and Allen, P. H. (1994). Contraction coefficients for radial sluice gates. Proc., 1994 Int. Conf. on Hydr. in Civ. Eng., Nat. Conf. Publ. No. 94/1, Institution of Engineers, Barton, ACT, Australia, 262-265.

[77] Isaacs, L.T., (1977). Numerical Solution for Flow under Sluice Gates. Journal of Hydraulic Division, ASCE, Vol. 103, No. 5, pp. 473-481.

[78] Montes, J. S. (1997). Irrotational flow and real fluid effects under planar sluice gates. Journal of Hydraulic Engineering, 123(3), 219-232.

[79] Webby, M.G., (1999). Discussion of 'Irrotational Flow and Real Fluid Effects under Planar Sluice Gates,' Discussion by J. S. Montes, Journal of Hydraulic Division, ASCE, Vol. 125, No. 2, pp. 210-212.

[80] Vanden-Broeck, J. M. (1997). Numerical calculations of the free-surface flow under a sluice gate. Journal of Fluid Mechanics, 330, 339-347. 
[81] Bhowmik, N. G. (1971). Hydraulic Jump Type Stilling Basins for Froude Number 2.5 to 4.5. Illinois State Water Survey.

[82] French, R. H. (1985). Open-channel hydraulics.

[83] Chung, Y. C. (1972). Solution of flow under sluice gates. Journal of Engineering Mechanical Divivision, ASCE, 98(1), 121-140.

[84] Buyalski, C. P. (1983). Discharge algorithms for canal radial gates. REC-ERC-83-9, Engineering and Research Center, U.S. Bureau of Reclamation, Denver, (http://www.usbr.gov/pmts/hydraulics_lab/pubs/REC/REC-ERC-83-09.pdf).

[85] Asavanant, J. \& Vanden-Broeck, J.-M. (1996). Nonlinear free surface flows emerging from a vessel and flows under a sluice gate. Journal of Australia Mathematic Society. B $38,63-86$.

[86] Vanden-Broeck, J.-M. (1986). Flow under a gate. Physics of Fluids. 29, 3148-3151.

[87] Hill, D. F., \& Younkin, B. D. (2009). A simple estimation of the growth rate and equilibrium size of bedforms created by a turbulent wall jet. Journal of Hydraulic Research, 47(5), 619-625.

[88] Wahl, T. (2005). Refined energy correction for calibration of submerged radial gates. Journal of Hydraulic Engineering, 131(6), 457-466.

[89] Ansar M. (2001). Discussion of Simultaneous flow over and under a gate by V Ferro. Journal of Irrigation and Drainage Engineering, ASCE; 127(5):325-6.

[90] Clemmens, A. J., Strelkoff, T. S., and Replogle, J. A. (2003). Calibration of submerged radial gates. Journal of Hydraulic Engineering, 129(9), 680-687.

[91] U.S. Bureau of Reclamation (USBR). (2001). Water measurement manual, 3rd Ed., U.S. Dept. of the Interior, Washington, DC

[92] Wahl, T. L., and Clemmens, A. J. (2005). Applying the energy-momentum method to radial gate discharge calibration. Impacts of Global Climate Change, ASCE, Reston, VA.

[93] Alminagorta, O., and Merkley, G. P. (2009). Transitional flow between orifice and nonorifice regimes at a rectangular sluice gate. Journal of Irrigation and Drainage Engineering, 135(3), 382-387.

[94] Smith, C. D. (1977). Discussion of 'Free flow immediately below sluice gates,' by Nallamuthu Rajaratnam. Jounal of Hydraulic Division, ASCE, 123(11), 1371-1373. 
[95] Rajaratnam, N., \& Macdougall, R. K. (1983). Erosion by plane wall jets with minimum tailwater. Journal of Hydraulic Engineering, 109(7), 1061-1064.

[96] Rajaratnam, N. (1981). Erosion by plane turbulent jets. Journal of hydraulic Research, 19(4), 339-358.

[97] Balachandar, R., \& Kells, J. A. (1997). Local channel in scour in uniformly graded sediments: the time-scale problem. Canadian journal of civil engineering, 24(5), 799-807.

[98] Balachandar, R., \& Kells, J. A. (1998). Instantaneous water surface and bed scour profiles using video image analysis. Canadian Journal of Civil Engineering, 25(4), 662667.

[99] Rajaratnam, N. (1977). Free flow immediately below sluice gates. Journal of the Hydraulics Division, 103(4), 345-351.

[100] Masliyah, J. H., Nandakumar, K., Hemphill, F., \& Fung, L. (1985). Body-fitted coordinates for flow under sluice gates. Journal of Hydraulic Engineering, 111(6), 922933.

[101] Rajaratnam, N., \& Humphries, J. A. (1982). Free flow upstream of vertical sluice gates. Journal of Hydraulic Research, 20(5), 427-437.

[102] Kells, J. A., Balachandar, R., \& Hagel, K. P. (2001). Effect of grain size on local channel scour below a sluice gate. Canadian Journal of Civil Engineering, 28(3), 440-451.

[103] Habibzadeh, A., Vatankhah, A. R., \& Rajaratnam, N. (2011). Role of energy loss on discharge characteristics of sluice gates. Journal of Hydraulic engineering, 137(9), 10791084.

[104] Balachandar, R., Kells, J. A., \& Thiessen, R. J. (2000). The effect of tailwater depth on the dynamics of local scour. Canadian Journal of Civil Engineering, 27(1), 138-150.

[105] Bey, A., Faruque, M. A., \& Balachandar, R. (2007). Two-dimensional scour hole problem: role of fluid structures. Journal of Hydraulic Engineering, 133(4), 414-430.

[106] Belaud, G., Cassan, L., \& Baume, J. P. (2009). Calculation of contraction coefficient under sluice gates and application to discharge measurement. Journal of Hydraulic Engineering, 135(12), 1086-1091.

[107] Cassan, L., and Belaud, G. (2010). Experimental and numerical studies of the flow structure generated by a submerged sluice gate. Proc. 1st Eur. IAHR Cong., Edinburgh, UK. 
[108] Cassan, L., and Belaud, G. (2008). Rans simulation of the flow gene-rated by sluice gates. Hydraulic structure: Proc. 2nd Int. Junior Res. and Eng. Workshop on Hydraulic Structure (IJREW'08), S. Pagliara, ed., Edizioni Plus-Pisa University Press, Pisa, Italy, 217-225.

[109] Belaud, G., and Litrico, X. (2008). Closed-form solution of the potential flow in a contracted flume. Journal of Fluid Mechanics, 599, 299-307.

[110] Fardjeli, N. (2007). Modélisation d'ouvrages de régulation pour l'aide à la gestion des canaux. MS thesis, Montpellier Supagro, France, 57 (in French).

[111] Garbrecht, G. (1977). Discussion of 'Discharge computation at river control structures,' by Dannie L. Collins. Journal of Hydraulic Division, ASCE, 104(12), 14811484.

[112] Hogg, A. J., Huppert, H. E., \& Dade, W. B. (1997). Erosion by planar turbulent wall jets. Journal of Fluid Mechanics, 338, 317-340.

[113] Budden, P. J., and Norbury, J. (1977). Sluice gate problems with gravity. Math. Proc. Cambridge Philosophical Soc., Cambridge, England, 81,157-175.

[114] Ferro, V. (2000). Simultaneous flow over and under a gate. Journal of irrigation and drainage engineering, 126(3), 190-193.

[115] Defina, A., \& Susin, F. M. (2003). Hysteretic behavior of the flow under a vertical sluice gate. Physics of Fluids, 15(9), 2541-2548.

[116] Cozzo, G. (1978). Una formula per il calcolo del coefficiente d'efflusso delle luci sotto paratoie. L'Energia Elettrica, 55(11/12), 504-513 (in Italian).

[117] Ferro, V. (1997). Applying hypothesis of self-similarity for flow-resistance law of small-diameter plastic pipes. Journal of irrigation and drainage engineering, 123(3), 175179.

[118] Ferro, V. (2001). Closure to 'Simultaneous flow over and under a gate' by Vito Ferro. Journal of Irrigation and Drainage Engineering, 127(5), 326-328.

[119] Speerli, J., Hager, W. H., Webby, M. G., \& Montes, J. S. (1999). Discussions and Closure: Irrotational Flow and Real Fluid Effects under Planar Sluice Gates. Journal of Hydraulic Engineering, 125(2), 208-213.

[120] Marcou, O., Chopard, B., El Yacoubi, S., Hamroun, B., Lefèvre, L., and Mendes, E. (2010). Lattice Boltzmann Model for the simulation of flows in open channels with application to flows in a submerged sluice gate. Journal of Irrigation and Drainage Engineering, 136(12), 809-822. 
[121] Castro-Orgaz, O., Lozano, D., and Mateos, L. (2010). Energy and momen- tum velocity coefficients for calibrating submerged sluice gates in irrigation canals. Journal of Irrigation and Drainage Engineering, 136(9), 610-616.

[122] Lozano, D., Mateos, L., Merkley, G. P., and Clemmens, A. J. (2009). Field calibration of submerged sluice gates in irrigation canals. Journal of Irrigation and Drainage Engineering, 135(6), 763-772.

[123] Sepúlveda, C., Gómez, M., and Rodellar, J. (2009). Benchmark of discharge calibration methods for submerged sluice gates. Journal of Irrigation and Drainage Engineering, 135(5), 676-682.

[124] Sepúlveda, C., Gómez, M., and Rodellar, J. (2011). Closure to 'Benchmark of discharge calibration methods for submerged sluice gates' by Carlos Sepúlveda, Manuel Gómez, and José Rodellar. Journal of Irrigation and Drainage Engineering, 137(1), 5758.

[125] Uyumaz, A. (1988). Scour downstream of vertical gate. Journal of Hydraulic Engineering, 114(7), 811-816.

[126] Altan-Sakarya B, Aydin I, Ger AM. (2004). Discussion of combined free flow over weirs and below gates by Negm AM, Al-Brahim AM, AlHamid AA. Journal of Hydraulic Research;42(5):557-60.

[127] Hoffmans, G.J.C.M.; Verheij, H.J. (1997). Scour Manual; A.A. Balkema: Rotterdam, The Netherlands; pp. 68-87.

[128] Breusers, H. N. C., \& Raudkivi, A. J. (1991). Scouring. Rotterdam: Balkema.

[129] Tel, J. (2000). Discharge relations for radial gates. MS thesis, Delft Technical Univ., The Netherlands.

[130] Chaudhry, M.H., (1993). Open Channel Flow. Prentice Hall, Englewood Cliffs, New Jersey.

[131] Ranga Raju, K.G. and Visavadia, D. S., (1979). Discharge characteristics of a sluice gate located on a raised crest. Proc. IMEKO in Industry Tokyo, Japan, Nov., pp.39-43.

[132] Ranga Raju, K.G., (1981). Flow through open channels. Tata McGraw Hill Publishing Company Limited, pp.246-247.

[133] Johnston, A. J. (1990). Scourhole developments in shallow tailwater. Journal of Hydraulic Research, 28(3), 341-354. 
[134] Mohamed, M. S., \& McCorquodale, J. A. (1992). Short-term local scour. Journal of Hydraulic Research, 30(5), 685-699.

[135] Noutsopoulos, G. K., and Fanariotis, S. (1978). Discussion of 'Free flow immediately below sluice gates,' by Nallamuthu Rajaratnam. Journal of Hydraulic Division, ASCE, 124(3), 451-454.

[136] Noshi, H. M. (1999, August). Energy dissipation near the bed downstream end sill. In Proceedings of the 28th IAHR Congress, Graz, Austria (Vol. 2227, p. 1-8).

[137] Hecker, G.E. (1984). Scale effects in modelling vortices. In: Proc. Symp. on Scale Effects in Modelling Hydraulic Structures, Technische Akademie Esslingen, ed. H. Kobus 6: $1-9$.

[138] Muskatirovic, D., \& Batinic, B. (1977). The influence of abrupt change of channel geometry on hydraulic regime characteristics. In Proceedings of the 17th IAHR Congress (pp. 397-404).

[139] Leng, X., \& Chanson, H. (2014). Turbulent Advances of Breaking Bores: Experimental Observations (No. Hydraulic Model Report CH96/14, pp. 1-40). The University of Queensland School of Civil Engineering.

[140] Han, T. Y., and Chow, W. L. (1981). The study of sluice gate and sharp crested weir through hodograph transformations. Journal of Applied Mechanics, 48, 229-238.

[141] Forbes, L. K. \& Schwartz, L. W. (1982). Free-surface flow over a semicircular obstruction. Journal of Fluid Mechanics, 114, 299-314.

[142] Jain, S. C. (2001). Open-channel flow, Wiley, New York.

[143] Horváth, K., van Overloop, P. J., Galvis, E., Gómez, M., \& Rodellar, J. (2014). Multivariable model predictive control of water levels on a laboratory canal. In Advances in hydroinformatics (pp. 77-92). Springer Singapore.

[144] Chadwick, A. J., and Morfett, J. C. (1986). Hydraulics in civil engineering, Allen \& Unwin, London.

[145] Barenblatt, G. I. (1987). Dimensional analysis. CRC Press.

[146] Barenblatt, G. I., \& Cole, J. D. (1981). Similarity, self-similarity and intermediate asymptotics. Journal of Applied Mechanics, 48, 213.

[147] Fortier, S., \& Scobey, F. C. (1923). Permissible canal velocities. In Proceedings of the American Society of Civil Engineers (Vol. 51, No. 7, pp. 1398-1414). ASCE 
[148] McGill, R., Tukey, J. W., \& Larsen, W. A. (1978). Variations of box plots. The American Statistician, 32(1), 12-16.

[149] Chernoff, H., \& Savage, I. R. (1958). Asymptotic normality and efficiency of certain nonparametric test statistics. The Annals of Mathematical Statistics, 972-994.

[150] Shapiro, S. S., \& Wilk, M. B. (1965). An analysis of variance test for normality (complete samples). Biometrika, 52(3-4), 591-611.

[151] Wilk, M. B., \& Gnanadesikan, R. (1968). Probability plotting methods for the analysis for the analysis of data. Biometrika, 55(1), 1-17.

[152] Levene, H. (1960). Robust tests for equality of variances. Contributions to probability and statistics, 1, 278-292.

[153] Zadeh, L. A. (1975). Fuzzy logic and approximate reasoning. Synthese, 30(3), 40

[154] Guven, A., \& Gunal, M. (2008). Genetic programming approach for prediction of local scour downstream of hydraulic structures. Journal of Irrigation and Drainage Engineering, 134(2), 241-249.

[155] Güven, A., Günal, M., \& Cevik, A. (2006). Prediction of pressure fluctuations on sloping stilling basins. Canadian Journal of Civil Engineering, 33(11), 1379-1388.

[156] Najafzadeh, M., \& Lim, S. Y. (2015). Application of improved neuro-fuzzy GMDH to predict scour depth at sluice gates. Earth Science Informatics, 8(1), 187-196.

[157] Zhang, W. (2010). Computational ecology: artificial neural networks and their applications. World Scientific.

[158] Leondes, C. T. (1998). Neural network systems techniques and applications. Elsevier.

[159] McCulloch, W. S., \& Pitts, W. (1943). A logical calculus of the ideas immanent in nervous activity. The bulletin of mathematical biophysics, 5(4), 115-133.

[160] Hebb, D. O. (1949). The first stage of perception: Growth of the assembly. The Organization of Behavior, 60-78.

[161] Minsky, M. (1954). Neural nets and the brain-model problem. Unpublished doctoral dissertation, Princeton University, NJ.

[162] Rosenblatt, F. (1958). The perceptron: A probabilistic model for information storage and organization in the brain. Psychological review, 65(6), 386.

[163] Minsky, M., \& Papert, S. (1969). Perceptrons. 
[164] Hopfield, J. J. (1982). Neural networks and physical systems with emergent collective computational abilities. Proceedings of the national academy of sciences, 79(8), 2554-2558.

[165] Edwards, P. J., \& Murray, A. F. (1996). Analogue imprecision in MLP training (Vol. 4). World Scientific.

[166] Baldi, P., \& Hornik, K. (1989). Neural networks and principal component analysis: Learning from examples without local minima. Neural networks, 2(1), 53-58.

[167] Dong, D., \& McAvoy, T. J. (1996). Nonlinear principal component analysis—based on principal curves and neural networks. Computers \& Chemical Engineering, 20(1), 6578.

[168] Karhunen, J., \& Joutsensalo, J. (1995). Generalizations of principal component analysis, optimization problems, and neural networks. Neural Networks, 8(4), 549-562.

[169] Oja, E. (1992). Principal components, minor components, and linear neural networks. Neural networks, 5(6), 927-935.

[170] Hamedi, A., \& Fuentes, H. R. (2015). Comparative Effectiveness and Reliability of NEXRAD Data to Predict Outlet Hydrographs Using the GSSHA and HEC-HMS Hydrologic Models. In World Environmental and Water Resources Congress. pp. 14441453.

[171] Nash, J. E., \& Sutcliffe, J. V. (1970). River flow forecasting through conceptual models part I—A discussion of principles. Journal of hydrology, 10(3), 282-290.

[172] Beach, C. M., \& MacKinnon, J. G. (1978). A maximum likelihood procedure for regression with autocorrelated errors. Econometrica: Journal of the Econometric Society, $51-58$.

[173] Nash, J. (1953). Two-person cooperative games. Econometrica: Journal of the Econometric Society, 128-140.

[174] Osborne, M. J., \& Rubinstein, A. (1994). A course in game theory. MIT press.

[175] J. Sachs, J. (1996). Digital Image Basics, Digital Light \& Color.

[176] Castleman, K.R. (1996). Digital Imaging Processing, Prentice Hall.

[177] Jähne, B. (2005). Digital Image Processing, Springer. 


\section{APPENDIX A}

\section{PERMISSIBLE VELOCITY}

The table which was used to find the permisible velocity in an ulined, earthen channel is presented in this section. This table represents Fortier and Scobey's limiting velocities in straight channels [147] after ageing in clear water, as well as in water transporting colloidal silts. The data in this table was used to determine permissible velocities in this research. 
Table A.1 Permissible Velocities in Unlined, Earthen Channels

Clear Water

Water Transporting

\section{Colloidal Silts}

\begin{tabular}{|c|c|c|c|}
\hline Material & $\begin{array}{c}\text { Roughness } \\
\text { Coefficient, n }\end{array}$ & $\begin{array}{c}\text { Velocity } \\
(\mathrm{m} / \mathrm{s})\end{array}$ & Velocity $(\mathrm{m} / \mathrm{s})$ \\
\hline Sandy loam, noncolloidal & 0.020 & 0.53 & 0.76 \\
\hline Silt loam, noncolloidal & 0.020 & 0.61 & 0.92 \\
\hline Alluvial silts, noncolloidal & 0.020 & 0.61 & 1.07 \\
\hline Volcanic ash & 0.020 & 0.76 & 1.07 \\
\hline Stiff clay, very colloidal & 0.025 & 1.14 & 1.53 \\
\hline Alluvial silts, colloidal & 0.025 & 1.14 & 1.53 \\
\hline Shales and hardpans & 0.025 & 1.83 & 1.83 \\
\hline Fine gravel & 0.020 & 0.76 & 1.53 \\
\hline Graded loam to cobbles when noncolloidal & 0.030 & 1.14 & 1.53 \\
\hline Coarse gravel, noncolloidal & 0.025 & 1.22 & 1.83 \\
\hline Cobbles and shingles & 0.035 & 1.53 & 1.68 \\
\hline
\end{tabular}




\section{APPENDIX B}

\section{GRAIN SIZE DISTRIBUTION}

The grain size distribution (GSD) of the mixture which was used in this research is presented in this section. The flume bed is covered with a mixture of sand and gravel, including brown pea gravel circled, white limestone (coarsest), and dark basalt gravel (intermediate size). 
Table B.1 Grain Size Distribution

\begin{tabular}{|c|c|c|c|c|c|}
\hline Sieve Size & Limestone & Basalt & Brown Pea & Bulk & Passing Rate \\
\hline$(\mathbf{m m})$ & Pebbles (g) & Pebbles (g) & Gravel (g) & (g) & $(\%)$ \\
\hline 40.00 & 1680.07 & & & 46113.19 & 100.00 \\
\hline 31.50 & 9047.46 & & & 44433.12 & 96.36 \\
\hline 22.40 & 7544.9 & 101.66 & & 35385.66 & 76.74 \\
\hline 16.00 & 1620.48 & 5490.48 & & 27739.10 & 60.15 \\
\hline 11.20 & & 717.33 & 371.21 & 20628.14 & 44.73 \\
\hline 8.00 & & & 1858.25 & 19539.60 & 42.37 \\
\hline 6.30 & & & 8735.58 & 17681.35 & 38.34 \\
\hline 4.00 & & & 5816.97 & 8945.77 & 19.40 \\
\hline 2.80 & & & 2075.56 & 3128.80 & 6.79 \\
\hline 2.00 & & & 1053.24 & 1053.24 & 2.28 \\
\hline 1.00 & & & 0.00 & 0.00 & 0.00 \\
\hline
\end{tabular}




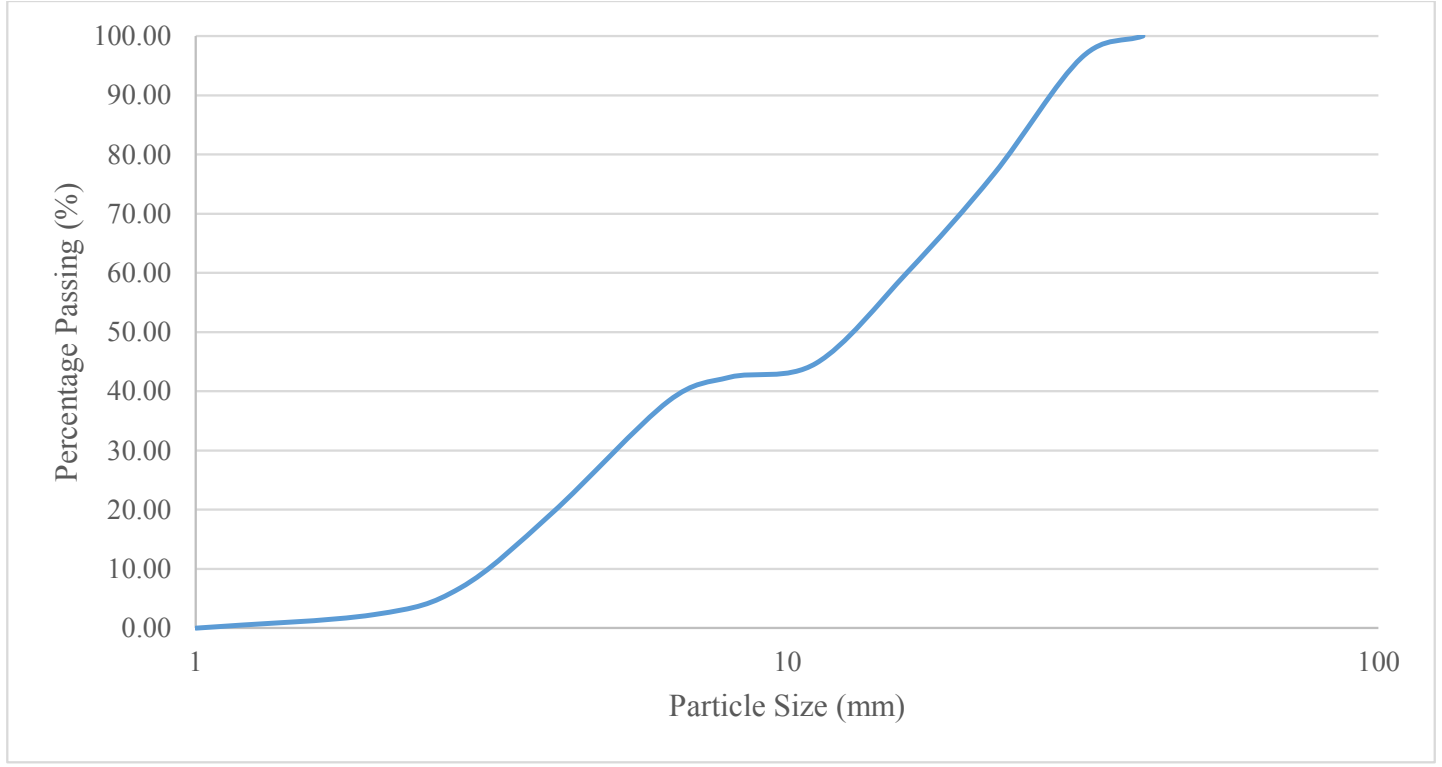

Figure B.1: Grain Size Distribution Curve 


\section{APPENDIX C}

\section{EXPERIMENTAL MEASUREMENTS}

Experimental measurements in vertical sluice gates are presented in Table C. 1 and C.2 for the main discharges and validation measurements. Gate opening, upstream depth, downstream depth, downstream flow condition, the Flow Stability Factor, and the ho/a ratio are reported in these tables. The data in these tables have been used in chapter three, sections one and two, to show the experimental results and to also determine the Flow Stability Number. 
Table C.1 Experimental Measurements (Main Data)

\begin{tabular}{|c|c|c|c|c|c|c|}
\hline$\underset{\left(\mathbf{m}^{2} / \mathbf{s}\right)}{\mathbf{q}}$ & $\begin{array}{r}a \\
(\mathrm{~cm})\end{array}$ & $\begin{array}{l}\mathbf{h}_{0} \\
(\mathbf{c m})\end{array}$ & $\begin{array}{c}\mathbf{h}_{1} \\
(\mathbf{c m})\end{array}$ & $\begin{array}{l}\text { Downstream } \\
\text { Condition }\end{array}$ & Stability & $\mathbf{h}_{0} / \mathbf{a}$ \\
\hline \multirow{4}{*}{0.0057} & 1.0 & 5.9 & 5.9 & Stable & 1.0 & 5.90 \\
\hline & 1.5 & 5.5 & 5.5 & Stable & 1.0 & 3.67 \\
\hline & 2.0 & 5.5 & 5.5 & Stable & 1.0 & 2.75 \\
\hline & 3.0 & 5.5 & 5.5 & Stable & 1.0 & 1.83 \\
\hline \multirow[t]{3}{*}{0.0086} & 1.5 & 12.4 & 7.6 & Stable & 1.0 & 8.27 \\
\hline & 2.0 & 10.0 & 7.6 & Stable & 1.0 & 5.00 \\
\hline & 2.5 & 8.9 & 7.6 & Weak Waves & 1.0 & 3.56 \\
\hline \multirow[t]{4}{*}{0.0159} & 1.0 & 21.4 & 8.0 & Submerged H.J & 0.2 & 21.40 \\
\hline & 1.5 & 16.6 & 7.9 & Wave & 0.7 & 11.07 \\
\hline & 2.0 & 12.6 & 7.5 & Wave & 0.7 & 6.30 \\
\hline & 2.5 & 10.4 & 7.4 & Weak Wave & 0.8 & 4.16 \\
\hline \multirow[t]{9}{*}{0.0198} & 2.0 & 17.1 & 8.4 & H.J & 0.0 & 8.55 \\
\hline & 2.5 & 13.2 & 8.1 & Submerged H.J & 0.2 & 5.28 \\
\hline & 3.0 & 10.8 & 8.1 & Weak submerge H.J & 0.4 & 3.60 \\
\hline & 3.5 & 9.9 & 8.1 & Very weak submerge H.J & 0.5 & 2.83 \\
\hline & 4.0 & 9.3 & 8.1 & Wave & 0.7 & 2.33 \\
\hline & 4.5 & 8.8 & 8.1 & Weak Wave & 0.8 & 1.96 \\
\hline & 5.0 & 8.4 & 8.1 & Very weak wave & 0.9 & 1.68 \\
\hline & 5.5 & 8.2 & 7.9 & Stable & 1.0 & 1.49 \\
\hline & 6.0 & 8.2 & 8.0 & Stable & 1.0 & 1.37 \\
\hline \multirow[t]{10}{*}{0.0237} & 1.5 & 23.5 & 8.7 & H.J & 0.0 & 15.67 \\
\hline & 2.0 & 16.6 & 8.7 & H.J & 0.0 & 8.30 \\
\hline & 2.5 & 14.4 & 8.7 & H.J & 0.0 & 5.76 \\
\hline & 3.0 & 12.3 & 8.7 & Submerged H.J & 0.2 & 4.10 \\
\hline & 3.5 & 11.3 & 8.7 & Submerged H.J & 0.2 & 3.23 \\
\hline & 4.0 & 10.3 & 8.7 & Weak submerge H.J & 0.4 & 2.58 \\
\hline & 4.5 & 9.9 & 8.5 & Wave & 0.7 & 2.20 \\
\hline & 5.0 & 8.9 & 8.2 & Wave & 0.7 & 1.78 \\
\hline & 5.5 & 8.8 & 8.2 & Weak Wave & 0.8 & 1.60 \\
\hline & 6.0 & 8.7 & 8.1 & Stable & 1.0 & 1.45 \\
\hline \multirow[t]{9}{*}{0.0270} & 2.0 & 21.9 & 8.0 & H.J & 0.0 & 10.95 \\
\hline & 2.5 & 18.6 & 8.2 & H.J & 0.0 & 7.44 \\
\hline & 3.0 & 13.7 & 8.7 & H.J & 0.0 & 4.57 \\
\hline & 3.5 & 12.2 & 8.7 & H.J & 0.0 & 3.49 \\
\hline & 4.0 & 11.0 & 8.7 & Submerged H.J & 0.2 & 2.75 \\
\hline & 4.5 & 10.4 & 8.7 & Strong Wave & 0.6 & 2.31 \\
\hline & 5.0 & 9.9 & 8.8 & Weak wave & 0.8 & 1.98 \\
\hline & 5.5 & 9.4 & 8.8 & Weak wave & 0.8 & 1.71 \\
\hline & 6.0 & 9.4 & 8.8 & Very weak wave & 0.9 & 1.57 \\
\hline
\end{tabular}


Table C.1 Experimental Measurements (Main Data) (Continued)

\begin{tabular}{|c|c|c|c|c|c|c|}
\hline$\underset{\left(\mathbf{m}^{2} / \mathbf{s}\right)}{\mathbf{q}}$ & $\begin{array}{c}\mathrm{a} \\
(\mathrm{cm})\end{array}$ & $\begin{array}{l}\mathbf{h}_{0} \\
\text { (cm) }\end{array}$ & $\begin{array}{c}h_{1} \\
\text { (cm) }\end{array}$ & $\begin{array}{l}\text { Downstream } \\
\text { Condition }\end{array}$ & Stability & $\mathbf{h}_{0} / \mathbf{a}$ \\
\hline \multirow[t]{7}{*}{0.0305} & 3.0 & 15.3 & 8.5 & H.J & 0.0 & 5.10 \\
\hline & 3.5 & 13.7 & 8.7 & H.J & 0.0 & 3.91 \\
\hline & 4.0 & 11.5 & 8.7 & H.J & 0.0 & 2.88 \\
\hline & 4.5 & 10.6 & 8.7 & Submerged H.J & 0.2 & 2.36 \\
\hline & 5.0 & 10.0 & 8.7 & Strong Wave & 0.6 & 2.00 \\
\hline & 5.5 & 9.5 & 8.7 & Weak wave & 0.8 & 1.73 \\
\hline & 6.0 & 9.3 & 8.7 & Very weak wave & 0.9 & 1.55 \\
\hline \multirow[t]{7}{*}{0.0350} & 3.5 & 15.2 & 8.8 & H.J & 0.0 & 4.34 \\
\hline & 4.0 & 11.9 & 8.8 & H.J & 0.0 & 2.98 \\
\hline & 4.5 & 11.9 & 8.9 & H.J & 0.0 & 2.64 \\
\hline & 5.0 & 10.8 & 8.9 & H.J & 0.0 & 2.16 \\
\hline & 5.5 & 10.4 & 8.9 & Submerged H.J & 0.2 & 1.89 \\
\hline & 6.0 & 9.9 & 8.9 & Wave & 0.7 & 1.65 \\
\hline & 6.5 & 9.4 & 8.9 & Weak wave & 0.8 & 1.45 \\
\hline \multirow[t]{3}{*}{0.0400} & 6.0 & 10.8 & 8.8 & Wave & 0.7 & 1.80 \\
\hline & 6.5 & 10.6 & 9.3 & Weak wave & 0.8 & 1.63 \\
\hline & 7.0 & 9.6 & 9.3 & Very weak wave & 0.9 & 1.37 \\
\hline \multirow[t]{3}{*}{0.0427} & 6.5 & 10.5 & 9.4 & Wave & 0.7 & 1.62 \\
\hline & 7.0 & 9.9 & 9.1 & Weak wave & 0.8 & 1.41 \\
\hline & 7.5 & 9.8 & 9.0 & Very weak wave & 0.9 & 1.31 \\
\hline
\end{tabular}


Table C.2 Experimental Measurements (Validation Data)

\begin{tabular}{ccccccc}
\hline $\begin{array}{c}\mathbf{q} \\
\left(\mathbf{m}^{2} / \mathbf{s}\right)\end{array}$ & $\begin{array}{c}\mathbf{a} \\
(\mathbf{c m})\end{array}$ & $\begin{array}{c}\mathbf{h}_{\mathbf{c}} \\
(\mathbf{c m})\end{array}$ & $\begin{array}{c}\mathbf{h}_{\mathbf{1}} \\
(\mathbf{c m})\end{array}$ & $\begin{array}{c}\text { Downstream } \\
\text { Condition }\end{array}$ & Stability & ho/a \\
\hline 0.0171 & 2.5 & 11.2 & 7.8 & Wave & 0.7 & 4.48 \\
\hline & 3.0 & 10.0 & 7.9 & Weak wave & 0.8 & 3.33 \\
\hline & 3.5 & 9.0 & 7.9 & Very weak wave & 0.9 & 2.57 \\
\hline & 4.0 & 8.6 & 7.9 & Stable & 1.0 & 2.15 \\
\hline 0.0223 & 4.0 & 9.7 & 8.4 & Wave & 0.7 & 2.43 \\
\hline & 4.5 & 8.8 & 8.2 & Weak wave & 0.8 & 1.96 \\
\hline & 5.0 & 8.7 & 8.1 & Very weak wave & 0.9 & 1.74 \\
\hline 0.0326 & 5.5 & 8.5 & 8.1 & Stable & 1.0 & 1.55 \\
\hline & 5.5 & 9.8 & 8.7 & Strong wave & 0.6 & 1.78 \\
\hline & 6.0 & 9.7 & 8.7 & Weak wave & 0.8 & 1.62 \\
\hline 0.0415 & 6.5 & 9.5 & 8.7 & Very weak wave & 0.9 & 1.46 \\
\hline & 7.0 & 9.3 & 9.2 & Weak wave & 0.8 & 1.58 \\
\hline & 7.5 & 9.6 & 9.0 & Very weak wave & 0.9 & 1.40 \\
\hline & & & & Stable & 1.0 & 1.28 \\
\hline
\end{tabular}




\section{APPENDIX D}

\section{EXPERIMENTAL MEASUREMENTS}

Experimental measurements for the vertical sluice gates for the first and second laboratories are presented in Tables D.1 and D.2, respectively. Discharge, critical depth, gate opening, upstream depth, downstream depth (section 2), downstream depth (section 3), upstream velocity, downstream velocity and energy (section 2), downstream velocity and energy (section 3), and the Flow Stability Number are reported in this table. The data in these tables have been used in chapter five, section two, for statistical analysis and to determine the flow stability. 
Table D.1 Measurements in the First Laboratory

\begin{tabular}{|c|c|c|c|c|c|c|c|c|c|c|c|c|}
\hline Numbers & $\begin{array}{l}\text { Discharge } \\
\left(\mathrm{m}^{3} / \mathrm{s}\left(\mathbf{x 1 0 ^ { 3 }}\right)\right)\end{array}$ & $\begin{array}{c}\text { dc } \\
(\mathrm{cm})\end{array}$ & $\begin{array}{c}\mathrm{a} \\
(\mathrm{cm})\end{array}$ & $h_{0}(\mathrm{~cm})$ & $\begin{array}{c}h_{1} \\
(\mathbf{c m})\end{array}$ & $\begin{array}{c}\mathbf{h}_{2} \\
(\mathrm{~cm})\end{array}$ & $\begin{array}{c}V_{0} \\
(\mathrm{~m} / \mathrm{s})\end{array}$ & $\begin{array}{c}\mathrm{V}_{1} \\
(\mathrm{~m} / \mathrm{s})\end{array}$ & $\begin{array}{c}V_{2} \\
(\mathrm{~m} / \mathrm{s})\end{array}$ & $\begin{array}{l}\mathbf{E}_{1} \\
(\mathrm{~m})\end{array}$ & $\begin{array}{l}\mathbf{E}_{2} \\
(\mathrm{~m})\end{array}$ & $\begin{array}{c}\text { Flow } \\
\text { Stability } \\
\text { Number }\end{array}$ \\
\hline 1 & 2.18 & 3.42 & 5.5 & 8.20 & 7.83 & 7.93 & 0.2 & 0.2 & 0.2 & 0.081 & 0.081 & 0.99 \\
\hline 2 & 2.45 & 3.70 & 5.5 & 8.50 & 7.63 & 7.66 & 0.3 & 0.3 & 0.2 & 0.080 & 0.079 & 0.98 \\
\hline 3 & 2.61 & 3.86 & 6.0 & 8.70 & 7.90 & 8.10 & 0.3 & 0.3 & 0.2 & 0.085 & 0.083 & 0.98 \\
\hline 4 & 3.00 & 4.23 & 6.0 & 9.40 & 8.73 & 8.80 & 0.3 & 0.3 & 0.3 & 0.093 & 0.092 & 0.98 \\
\hline 5 & 3.36 & 4.56 & 6.0 & 9.30 & 8.71 & 8.70 & 0.3 & 0.3 & 0.3 & 0.093 & 0.093 & 1.00 \\
\hline
\end{tabular}


Table D.1 Measurements in the First Laboratory (Continued)

\begin{tabular}{|c|c|c|c|c|c|c|c|c|c|c|c|c|}
\hline Numbers & $\begin{array}{l}\text { Discharge } \\
\left(\mathrm{m}^{3} / \mathrm{s}\left(\times 10^{3}\right)\right)\end{array}$ & $\begin{array}{c}\text { dc } \\
(\mathrm{cm})\end{array}$ & $\begin{array}{c}a \\
(\mathrm{~cm})\end{array}$ & $h_{0}(\mathrm{~cm})$ & $\begin{array}{c}h_{1} \\
(\mathbf{c m})\end{array}$ & $\begin{array}{c}\mathbf{h}_{2} \\
(\mathrm{~cm})\end{array}$ & $\begin{array}{c}V_{0} \\
(\mathrm{~m} / \mathrm{s})\end{array}$ & $\begin{array}{c}V_{1} \\
(\mathrm{~m} / \mathrm{s})\end{array}$ & $\begin{array}{c}V_{2} \\
(\mathrm{~m} / \mathrm{s})\end{array}$ & $\begin{array}{l}E_{1} \\
(m)\end{array}$ & $\begin{array}{l}\mathrm{E}_{2} \\
\text { (m) }\end{array}$ & $\begin{array}{c}\text { Flow } \\
\text { Stability } \\
\text { Number }\end{array}$ \\
\hline 6 & 3.58 & 4.76 & 6.5 & 9.50 & 8.60 & 8.70 & 0.3 & 0.4 & 0.3 & 0.095 & 0.094 & 0.99 \\
\hline 8 & 4.43 & 5.49 & 7.0 & 9.60 & 8.86 & 9.10 & 0.4 & 0.5 & 0.4 & 0.099 & 0.097 & 0.96 \\
\hline 9 & 4.56 & 5.60 & 7.5 & 9.60 & 8.91 & 9.00 & 0.4 & 0.5 & 0.4 & 0.102 & 0.098 & 0.96 \\
\hline 10 & 4.70 & 5.71 & 7.5 & 9.80 & 8.93 & 9.00 & 0.4 & 0.5 & 0.4 & 0.102 & 0.099 & 0.97 \\
\hline
\end{tabular}


Table D.2 Measurements in the Second Laboratory

\begin{tabular}{|c|c|c|c|c|c|c|c|c|c|c|c|c|}
\hline Numbers & 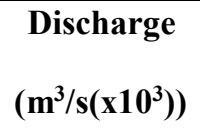 & $\begin{array}{c}\text { dc } \\
(\mathrm{cm})\end{array}$ & $\begin{array}{c}\mathrm{a} \\
(\mathrm{cm})\end{array}$ & $\begin{array}{c}\mathbf{h}_{0} \\
(\mathrm{~cm})\end{array}$ & $\begin{array}{c}\mathbf{h}_{1} \\
(\mathrm{~cm})\end{array}$ & $\begin{array}{c}\mathbf{h}_{2} \\
(\mathbf{c m})\end{array}$ & $\begin{array}{c}V_{0} \\
(\mathrm{~m} / \mathrm{s})\end{array}$ & $\begin{array}{c}\mathrm{V}_{1} \\
(\mathrm{~m} / \mathrm{s})\end{array}$ & $\begin{array}{c}V_{2} \\
(\mathrm{~m} / \mathrm{s})\end{array}$ & $\begin{array}{l}\mathrm{E}_{1} \\
(\mathrm{~m})\end{array}$ & $\begin{array}{l}\mathbf{E}_{2} \\
(\mathbf{m})\end{array}$ & $\begin{array}{c}\text { Flow Stability } \\
\text { Number }\end{array}$ \\
\hline 1 & 18.94 & 4.90 & 7.5 & 14.29 & 8.89 & 9.21 & 0.25 & 0.39 & 0.20 & 0.096 & 0.094 & 0.97 \\
\hline 2 & 25.66 & 6.05 & 11.5 & 13.65 & 10.48 & 10.79 & 0.34 & 0.44 & 0.30 & 0.115 & 0.112 & 0.98 \\
\hline 3 & 32.20 & 7.06 & 14.0 & 15.56 & 13.02 & 13.17 & 0.38 & 0.45 & 0.40 & 0.140 & 0.139 & 0.99 \\
\hline 4 & 52.39 & 9.74 & 16.0 & 16.83 & 14.29 & 14.43 & 0.57 & 0.67 & 0.64 & 0.165 & 0.165 & 0.99 \\
\hline 5 & 69.57 & 11.77 & 18.0 & 22.86 & 19.05 & 19.73 & 0.55 & 0.66 & 0.48 & 0.213 & 0.209 & 0.98 \\
\hline 6 & 89.66 & 13.94 & 23.0 & 23.18 & 21.91 & 21.91 & 0.70 & 0.74 & 0.74 & 0.247 & 0.247 & 1.00 \\
\hline
\end{tabular}




\section{APPENDIX E \\ EXPERIMENTAL MEASUREMENTS}

Experimental measurements in a gate with an expansion hydraulic system at the first and second laboratories are presented in Tables E.1 to E.3 and E.4, respectively. Discharge, critical depth, gate opening, upstream depth, downstream depth (section 2), downstream depth (section 3), upstream velocity, downstream velocity and energy (section 2), downstream velocity and energy (section 3), and the Flow Stability Number are reported in this table. The data in these tables have been used in chapter five, section three, for statistical analysis and to determine the flow stability. 
Table E.1 Measurements, Thickness Two Centimeters

\begin{tabular}{|c|c|c|c|c|c|c|c|c|c|c|c|c|}
\hline Numbers & $\begin{array}{l}\text { Discharge } \\
\left(\mathrm{m}^{3} / \mathrm{s}\left(\times 10^{3}\right)\right)\end{array}$ & $\begin{array}{c}\text { dc } \\
(\mathrm{cm})\end{array}$ & $\begin{array}{c}\mathbf{a} \\
(\mathrm{cm})\end{array}$ & $\begin{array}{c}h_{0} \\
(\mathbf{c m})\end{array}$ & $\begin{array}{c}\mathbf{h}_{1} \\
(\mathbf{c m})\end{array}$ & $\begin{array}{c}\mathbf{h}_{2} \\
(\mathrm{~cm})\end{array}$ & $\begin{array}{c}V_{0} \\
(\mathrm{~m} / \mathrm{s})\end{array}$ & $\begin{array}{c}\mathrm{V}_{1} \\
(\mathrm{~m} / \mathrm{s})\end{array}$ & $\begin{array}{c}V_{2} \\
(\mathrm{~m} / \mathrm{s})\end{array}$ & $\begin{array}{l}\mathbf{E}_{1} \\
(\mathrm{~m})\end{array}$ & $\begin{array}{l}\mathbf{E}_{2} \\
(\mathrm{~m})\end{array}$ & $\begin{array}{c}\text { Flow } \\
\text { Stability } \\
\text { Number }\end{array}$ \\
\hline 1 & 2.18 & 3.42 & 5.5 & 9.17 & 7.87 & 7.90 & 0.2 & 0.3 & 0.3 & 0.082 & 0.082 & 1.00 \\
\hline 3 & 2.61 & 3.86 & 6.0 & 9.87 & 7.87 & 7.85 & 0.2 & 0.3 & 0.3 & 0.083 & 0.083 & 1.00 \\
\hline 4 & 3.00 & 4.23 & 6.0 & 10.67 & 7.96 & 8.00 & 0.3 & 0.3 & 0.3 & 0.085 & 0.084 & 0.98 \\
\hline 5 & 3.36 & 4.56 & 6.0 & 11.57 & 7.77 & 8.08 & 0.3 & 0.5 & 0.4 & 0.090 & 0.089 & 0.98 \\
\hline
\end{tabular}


Table E.1 Measurements, Thickness Two Centimeters (Continued)

\begin{tabular}{|c|c|c|c|c|c|c|c|c|c|c|c|c|}
\hline Numbers & $\begin{array}{l}\text { Discharge } \\
\left(\mathrm{m}^{3} / \mathrm{s}\left(\times 10^{3}\right)\right)\end{array}$ & $\begin{array}{c}\text { de } \\
(\mathrm{cm})\end{array}$ & $\begin{array}{c}\mathbf{a} \\
(\mathbf{c m})\end{array}$ & $\begin{array}{c}h_{0} \\
(\mathbf{c m})\end{array}$ & $\begin{array}{c}\mathbf{h}_{1} \\
(\mathbf{c m})\end{array}$ & $\begin{array}{c}\mathbf{h}_{2} \\
(\mathbf{c m})\end{array}$ & $\begin{array}{c}V_{0} \\
(\mathrm{~m} / \mathrm{s})\end{array}$ & $\begin{array}{c}\mathrm{V}_{1} \\
(\mathrm{~m} / \mathrm{s})\end{array}$ & $\begin{array}{c}V_{2} \\
(\mathrm{~m} / \mathrm{s})\end{array}$ & $\begin{array}{l}\mathbf{E}_{1} \\
(\mathrm{~m})\end{array}$ & $\begin{array}{l}\mathbf{E}_{2} \\
(\mathrm{~m})\end{array}$ & $\begin{array}{c}\text { Flow } \\
\text { Stability } \\
\text { Number }\end{array}$ \\
\hline 6 & 3.58 & 4.76 & 6.5 & 12.00 & 8.45 & 8.57 & 0.3 & 0.5 & 0.4 & 0.097 & 0.094 & 0.96 \\
\hline 7 & 3.86 & 5.01 & 6.5 & 13.07 & 8.50 & 8.60 & 0.3 & 0.6 & 0.4 & 0.103 & 0.094 & 0.91 \\
\hline 8 & 4.43 & 5.49 & 7.0 & 14.57 & 3.00 & 8.77 & 0.3 & 1.3 & 0.5 & 0.122 & 0.098 & - \\
\hline 9 & 4.56 & 5.60 & 7.5 & 13.87 & 3.87 & 8.47 & 0.3 & 1.1 & 0.5 & 0.097 & 0.097 & - \\
\hline 10 & 4.70 & 5.71 & 7.5 & 14.80 & 3.77 & 8.50 & 0.3 & 1.1 & 0.5 & 0.103 & 0.098 & - \\
\hline
\end{tabular}


Table E.2 Measurements, Thickness 1.2 Centimeters

\begin{tabular}{|c|c|c|c|c|c|c|c|c|c|c|c|c|}
\hline Numbers & $\begin{array}{l}\text { Discharge } \\
\left(\mathrm{m}^{3} / \mathrm{s}\left(\mathbf{x} 10^{3}\right)\right)\end{array}$ & $\begin{array}{c}\text { dc } \\
(\mathrm{cm})\end{array}$ & $\begin{array}{c}\mathrm{a} \\
(\mathrm{cm})\end{array}$ & $\begin{array}{c}\mathbf{h}_{0} \\
(\mathbf{c m})\end{array}$ & $\begin{array}{c}\mathrm{h}_{1} \\
(\mathrm{~cm})\end{array}$ & $\begin{array}{c}\mathbf{h}_{2} \\
(\mathbf{c m})\end{array}$ & $\begin{array}{c}V_{0} \\
(\mathrm{~m} / \mathrm{s})\end{array}$ & $\begin{array}{c}V_{1} \\
(\mathrm{~m} / \mathrm{s})\end{array}$ & $\begin{array}{c}V_{2} \\
(\mathrm{~m} / \mathrm{s})\end{array}$ & $\begin{array}{l}\mathbf{E}_{1} \\
(\mathrm{~m})\end{array}$ & $\begin{array}{l}\mathbf{E}_{2} \\
\text { (m) }\end{array}$ & $\begin{array}{c}\text { Flow } \\
\text { Stability } \\
\text { Number }\end{array}$ \\
\hline 1 & 2.18 & 3.42 & 5.5 & 8.87 & 7.87 & 7.90 & 0.2 & 0.3 & 0.3 & 0.082 & 0.082 & 1.00 \\
\hline 3 & 2.61 & 3.86 & 6.0 & 9.17 & 7.99 & 8.03 & 0.3 & 0.3 & 0.3 & 0.086 & 0.085 & 0.99 \\
\hline 4 & 3.00 & 4.23 & 6.0 & 9.47 & 8.23 & 8.28 & 0.3 & 0.3 & 0.3 & 0.088 & 0.088 & 1.00 \\
\hline 5 & 3.36 & 4.56 & 6.0 & 9.90 & 8.07 & 8.57 & 0.3 & 0.5 & 0.3 & 0.093 & 0.090 & 0.97 \\
\hline
\end{tabular}


Table E.2 Measurements, Thickness 1.2 Centimeters (Continued)

\begin{tabular}{|c|c|c|c|c|c|c|c|c|c|c|c|c|}
\hline Numbers & $\begin{array}{l}\text { Discharge } \\
\left(\mathrm{m}^{3} / \mathrm{s}\left(\mathbf{x 1 0 ^ { 3 }}\right)\right)\end{array}$ & $\begin{array}{c}\text { de } \\
(\mathrm{cm})\end{array}$ & $\begin{array}{c}\mathrm{a} \\
(\mathrm{cm})\end{array}$ & $\begin{array}{c}\mathbf{h}_{0} \\
(\mathrm{~cm})\end{array}$ & $\begin{array}{c}\mathbf{h}_{1} \\
(\mathrm{~cm})\end{array}$ & $\begin{array}{c}\mathbf{h}_{2} \\
(\mathbf{c m})\end{array}$ & $\begin{array}{c}\mathrm{V}_{0} \\
(\mathrm{~m} / \mathrm{s})\end{array}$ & $\begin{array}{c}V_{1} \\
(\mathrm{~m} / \mathrm{s})\end{array}$ & $\begin{array}{c}V_{2} \\
(\mathrm{~m} / \mathrm{s})\end{array}$ & $\begin{array}{l}\mathbf{E}_{1} \\
(\mathrm{~m})\end{array}$ & $\begin{array}{l}\mathbf{E}_{2} \\
\text { (m) }\end{array}$ & $\begin{array}{c}\text { Flow } \\
\text { Stability } \\
\text { Number }\end{array}$ \\
\hline 6 & 3.58 & 4.76 & 6.5 & 10.17 & 8.37 & 8.77 & 0.3 & 0.6 & 0.4 & 0.102 & 0.096 & 0.94 \\
\hline 7 & 3.86 & 5.01 & 6.5 & 10.03 & 8.47 & 8.87 & 0.3 & 0.6 & 0.4 & 0.103 & 0.096 & 0.94 \\
\hline 8 & 4.43 & 5.49 & 7.0 & 10.90 & 8.37 & 8.77 & 0.4 & 0.7 & 0.5 & 0.109 & 0.100 & 0.92 \\
\hline 9 & 4.56 & 5.60 & 7.5 & 11.33 & 8.47 & 8.77 & 0.4 & 0.7 & 0.5 & 0.109 & 0.100 & 0.91 \\
\hline 10 & 4.70 & 5.71 & 7.5 & 11.10 & 8.65 & 8.99 & 0.4 & 0.7 & 0.5 & 0.111 & 0.102 & 0.92 \\
\hline
\end{tabular}


Table E.3 Measurements, Thickness 0.7 Centimeters

\begin{tabular}{|c|c|c|c|c|c|c|c|c|c|c|c|c|}
\hline Numbers & $\begin{array}{l}\text { Discharge } \\
\left(\mathrm{m}^{3} / \mathrm{s}\left(\times 10^{3}\right)\right)\end{array}$ & $\begin{array}{c}\text { de } \\
(\mathrm{cm})\end{array}$ & $\begin{array}{c}\mathrm{a} \\
(\mathrm{cm})\end{array}$ & $\begin{array}{c}\mathbf{h}_{0} \\
(\mathbf{c m})\end{array}$ & $\begin{array}{c}\mathbf{h}_{1} \\
(\mathbf{c m})\end{array}$ & $\begin{array}{c}\mathbf{h}_{2} \\
(\mathrm{~cm})\end{array}$ & $\begin{array}{c}V_{0} \\
(\mathrm{~m} / \mathrm{s})\end{array}$ & $\begin{array}{c}\mathrm{V}_{1} \\
(\mathrm{~m} / \mathrm{s})\end{array}$ & $\begin{array}{c}V_{2} \\
(\mathrm{~m} / \mathrm{s})\end{array}$ & $\begin{array}{l}\mathbf{E}_{1} \\
(\mathbf{m})\end{array}$ & $\begin{array}{l}\mathbf{E}_{2} \\
\text { (m) }\end{array}$ & $\begin{array}{c}\text { Flow } \\
\text { Stability } \\
\text { Number }\end{array}$ \\
\hline 1 & 2.18 & 3.42 & 5.5 & 8.80 & 8.03 & 8.07 & 0.2 & 0.2 & 0.2 & 0.084 & 0.084 & 1.00 \\
\hline 3 & 2.61 & 3.86 & 6.0 & 8.90 & 8.20 & 8.20 & 0.3 & 0.3 & 0.3 & 0.086 & 0.086 & 1.00 \\
\hline 4 & 3.00 & 4.23 & 6.0 & 9.30 & 8.43 & 8.50 & 0.3 & 0.3 & 0.3 & 0.090 & 0.089 & 0.99 \\
\hline 5 & 3.36 & 4.56 & 6.0 & 9.80 & 8.70 & 8.70 & 0.3 & 0.4 & 0.4 & 0.093 & 0.093 & 1.00 \\
\hline
\end{tabular}


Table E.3 Measurements, Thickness 0.7 Centimeters (Continued)

\begin{tabular}{|c|c|c|c|c|c|c|c|c|c|c|c|c|}
\hline Numbers & $\begin{array}{l}\text { Discharge } \\
\left(\mathrm{m}^{3} / \mathrm{s}\left(\times 10^{3}\right)\right)\end{array}$ & $\begin{array}{c}\text { de } \\
(\mathrm{cm})\end{array}$ & $\begin{array}{c}\mathrm{a} \\
(\mathrm{cm})\end{array}$ & $\begin{array}{c}\mathbf{h}_{0} \\
(\mathbf{c m})\end{array}$ & $\begin{array}{c}\mathbf{h}_{1} \\
(\mathrm{~cm})\end{array}$ & $\begin{array}{c}\mathbf{h}_{2} \\
(\mathbf{c m})\end{array}$ & $\begin{array}{c}\mathrm{V}_{0} \\
(\mathrm{~m} / \mathrm{s})\end{array}$ & $\begin{array}{c}V_{1} \\
(\mathrm{~m} / \mathrm{s})\end{array}$ & $\begin{array}{c}V_{2} \\
(\mathrm{~m} / \mathrm{s})\end{array}$ & $\begin{array}{l}\mathbf{E}_{1} \\
(\mathrm{~m})\end{array}$ & $\begin{array}{l}\mathbf{E}_{2} \\
\text { (m) }\end{array}$ & $\begin{array}{c}\text { Flow } \\
\text { Stability } \\
\text { Number }\end{array}$ \\
\hline 6 & 3.58 & 4.76 & 6.5 & 10.40 & 8.67 & 8.70 & 0.3 & 0.4 & 0.4 & 0.095 & 0.094 & 0.99 \\
\hline 7 & 3.86 & 5.01 & 6.5 & 9.80 & 8.70 & 8.70 & 0.4 & 0.4 & 0.4 & 0.095 & 0.095 & 1.00 \\
\hline 8 & 4.43 & 5.49 & 7.0 & 10.20 & 8.90 & 8.90 & 0.4 & 0.5 & 0.5 & 0.099 & 0.099 & 1.00 \\
\hline 9 & 4.56 & 5.60 & 7.5 & 10.10 & 8.99 & 9.01 & 0.4 & 0.5 & 0.5 & 0.104 & 0.102 & 0.98 \\
\hline 10 & 4.70 & 5.71 & 7.5 & 10.30 & 8.74 & 8.80 & 0.4 & 0.5 & 0.5 & 0.102 & 0.099 & 0.97 \\
\hline
\end{tabular}


Table E.4 Measurements in the Second Laboratory

\begin{tabular}{|c|c|c|c|c|c|c|c|c|c|c|c|c|}
\hline Numbers & $\begin{array}{l}\text { Discharge } \\
\left(\mathbf{m}^{3} / \mathbf{s}\left(\times 10^{3}\right)\right)\end{array}$ & $\begin{array}{l}\text { de } \\
\text { (cm) }\end{array}$ & $\begin{array}{c}\mathrm{a} \\
(\mathrm{cm})\end{array}$ & $\begin{array}{c}\mathbf{h}_{0} \\
(\mathrm{~cm})\end{array}$ & $\begin{array}{c}\mathrm{h}_{1} \\
(\mathrm{~cm})\end{array}$ & $\begin{array}{c}\mathbf{h}_{2} \\
(\mathrm{~cm})\end{array}$ & $\begin{array}{c}\mathbf{V}_{0} \\
(\mathbf{m} / \mathbf{s})\end{array}$ & $\begin{array}{c}V_{1} \\
(m / s)\end{array}$ & $\begin{array}{c}\mathrm{V}_{2} \\
(\mathrm{~m} / \mathrm{s})\end{array}$ & $\begin{array}{l}E_{1} \\
(m)\end{array}$ & $\begin{array}{l}E_{2} \\
(m)\end{array}$ & $\begin{array}{c}\text { Flow Stability } \\
\text { Number }\end{array}$ \\
\hline 1 & 18.94 & 4.94 & 7.5 & 12.06 & 8.85 & 8.89 & 0.30 & 0.40 & 0.40 & 0.097 & 0.096 & 0.99 \\
\hline 2 & 25.66 & 6.05 & 11.5 & 13.65 & 10.79 & 10.79 & 0.30 & 0.40 & 0.40 & 0.117 & 0.117 & 1.00 \\
\hline 3 & 32.20 & 7.04 & 14.0 & 15.56 & 12.38 & 12.38 & 0.40 & 0.50 & 0.50 & 0.135 & 0.135 & 1.00 \\
\hline
\end{tabular}




\section{APPENDIX F \\ EXPERIMENTAL MEASUREMENTS}

Experimental measurements in a gate with a contraction hydraulic system at the first and second laboratories are presented in Tables F.1 to F.3 and F.4, respectively. Discharge, critical depth, gate opening, upstream depth, downstream depth (section 2), downstream depth (section 3), upstream velocity, downstream velocity and energy (section 2), downstream velocity and energy (section 3), and the Flow Stability Number are reported in this table. The data in these tables have been used in chapter five, section four, for statistical analysis and to determine the flow stability. 
Table F.1 Measurements, Thickness Two Centimeters

\begin{tabular}{|c|c|c|c|c|c|c|c|c|c|c|c|c|}
\hline Numbers & $\begin{array}{l}\text { Discharge } \\
\left(\mathrm{m}^{3} / \mathrm{s}\left(\mathrm{x10}^{3}\right)\right)\end{array}$ & $\begin{array}{c}\text { dc } \\
(\mathrm{cm})\end{array}$ & $\begin{array}{c}\mathbf{a} \\
(\mathrm{cm})\end{array}$ & $h_{0}(\mathrm{~cm})$ & $\begin{array}{c}\mathbf{h}_{1} \\
(\mathbf{c m})\end{array}$ & $\begin{array}{c}\mathbf{h}_{2} \\
(\mathbf{c m})\end{array}$ & $\begin{array}{c}\mathrm{V}_{0} \\
(\mathrm{~m} / \mathrm{s})\end{array}$ & $\begin{array}{c}\mathrm{V}_{1} \\
(\mathrm{~m} / \mathrm{s})\end{array}$ & $\begin{array}{c}V_{2} \\
(\mathrm{~m} / \mathrm{s})\end{array}$ & $\begin{array}{l}\mathbf{E}_{1} \\
\text { (m) }\end{array}$ & $\begin{array}{l}\mathbf{E}_{2} \\
(\mathrm{~m})\end{array}$ & $\begin{array}{c}\text { Flow } \\
\text { Stability } \\
\text { Number }\end{array}$ \\
\hline 1 & 2.18 & 3.42 & 5.5 & 9.10 & 7.94 & 8.02 & 0.2 & 0.3 & 0.2 & 0.085 & 0.082 & 0.96 \\
\hline 2 & 2.45 & 3.70 & 5.5 & 9.70 & 7.95 & 8.02 & 0.2 & 0.3 & 0.2 & 0.085 & 0.082 & 0.96 \\
\hline 3 & 2.61 & 3.86 & 6.0 & 9.80 & 8.03 & 8.10 & 0.2 & 0.4 & 0.3 & 0.089 & 0.085 & 0.95 \\
\hline 4 & 3.00 & 4.23 & 6.0 & 10.80 & 8.50 & 8.60 & 0.3 & 0.5 & 0.3 & 0.097 & 0.090 & 0.92 \\
\hline 5 & 3.36 & 4.56 & 6.0 & 11.60 & 8.74 & 8.80 & 0.3 & 0.6 & 0.4 & 0.108 & 0.096 & 0.89 \\
\hline
\end{tabular}


Table F.2 Measurements, Thickness 1.2 Centimeters

\begin{tabular}{|c|c|c|c|c|c|c|c|c|c|c|c|c|}
\hline Numbers & $\begin{array}{l}\text { Discharge } \\
\left(\mathrm{m}^{3} / \mathrm{s}\left(\mathbf{x 1 0 ^ { 3 }}\right)\right)\end{array}$ & $\begin{array}{c}\text { dc } \\
(\mathrm{cm})\end{array}$ & $\begin{array}{c}\mathrm{a} \\
(\mathrm{cm})\end{array}$ & $h_{0}(\mathrm{~cm})$ & $\begin{array}{c}\mathbf{h}_{1} \\
(\mathbf{c m})\end{array}$ & $\begin{array}{c}h_{2} \\
(\mathbf{c m})\end{array}$ & $\begin{array}{c}\mathrm{V}_{0} \\
(\mathrm{~m} / \mathrm{s})\end{array}$ & $\begin{array}{c}\mathrm{V}_{1} \\
(\mathrm{~m} / \mathrm{s})\end{array}$ & $\begin{array}{c}\mathrm{V}_{2} \\
(\mathrm{~m} / \mathrm{s})\end{array}$ & $\begin{array}{l}\mathbf{E}_{1} \\
(\mathbf{m})\end{array}$ & $\begin{array}{l}\mathbf{E}_{2} \\
(\mathrm{~m})\end{array}$ & $\begin{array}{c}\text { Flow } \\
\text { Stability } \\
\text { Number }\end{array}$ \\
\hline 1 & 2.18 & 3.42 & 5.5 & 8.90 & 7.90 & 8.00 & 0.2 & 0.3 & 0.2 & 0.084 & 0.083 & 0.99 \\
\hline 2 & 2.45 & 3.70 & 5.5 & 9.30 & 8.31 & 8.40 & 0.2 & 0.3 & 0.2 & 0.089 & 0.086 & 0.97 \\
\hline 3 & 2.61 & 3.86 & 6.0 & 9.20 & 8.51 & 8.76 & 0.3 & 0.4 & 0.2 & 0.093 & 0.090 & 0.96 \\
\hline 4 & 3.00 & 4.23 & 6.0 & 9.70 & 8.91 & 9.00 & 0.3 & 0.4 & 0.3 & 0.098 & 0.095 & 0.96 \\
\hline 5 & 3.36 & 4.56 & 6.0 & 10.20 & 8.99 & 9.11 & 0.3 & 0.5 & 0.4 & 0.102 & 0.099 & 0.97 \\
\hline
\end{tabular}


Table F.3 Measurements, Thickness 0.7 Centimeters

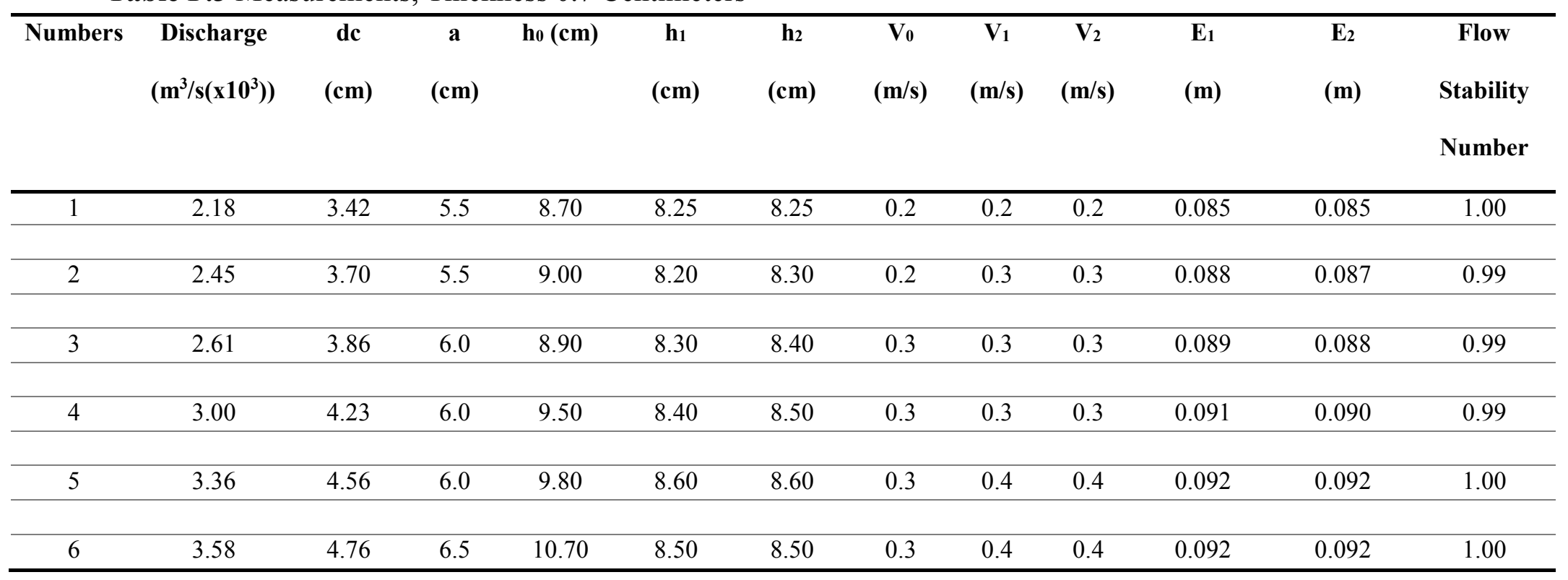


Table F.4 Measurements in the Second Laboratory

\begin{tabular}{|c|c|c|c|c|c|c|c|c|c|c|c|c|}
\hline Numbers & 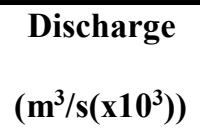 & $\begin{array}{c}\text { dc } \\
(\mathrm{cm})\end{array}$ & $\begin{array}{c}\mathbf{a} \\
(\mathbf{c m})\end{array}$ & $\begin{array}{c}\mathbf{h}_{0} \\
(\mathrm{~cm})\end{array}$ & $\begin{array}{c}\mathbf{h}_{1} \\
(\mathbf{c m})\end{array}$ & $\begin{array}{c}\mathbf{h}_{2} \\
(\mathrm{~cm})\end{array}$ & $\begin{array}{c}V_{0} \\
(\mathrm{~m} / \mathrm{s})\end{array}$ & $\begin{array}{c}\mathrm{V}_{1} \\
(\mathrm{~m} / \mathrm{s})\end{array}$ & $\begin{array}{c}V_{2} \\
(\mathrm{~m} / \mathrm{s})\end{array}$ & $\begin{array}{l}\mathbf{E}_{1} \\
(\mathrm{~m})\end{array}$ & $\begin{array}{l}\mathbf{E}_{2} \\
(\mathrm{~m})\end{array}$ & $\begin{array}{c}\text { Flow Stability } \\
\text { Number }\end{array}$ \\
\hline 1 & 18.94 & 4.94 & 7.5 & 14.60 & 8.86 & 8.89 & 0.20 & 0.40 & 0.40 & 0.096 & 0.096 & 1.00 \\
\hline 2 & 25.66 & 6.05 & 11.5 & 14.60 & 10.21 & 10.47 & 0.30 & 0.50 & 0.40 & 0.116 & 0.113 & 0.97 \\
\hline 3 & 32.20 & 7.04 & 14.0 & 15.56 & 13.19 & 13.38 & 0.40 & 0.50 & 0.40 & 0.146 & 0.141 & 0.96 \\
\hline
\end{tabular}




\section{APPENDIX G}

\section{PROTOTYPE IMAGES}

Pictures of the real-scale hydraulic structures (prototype) are provided in this section. The structures are located in South Florida, Miami-Dade County. 


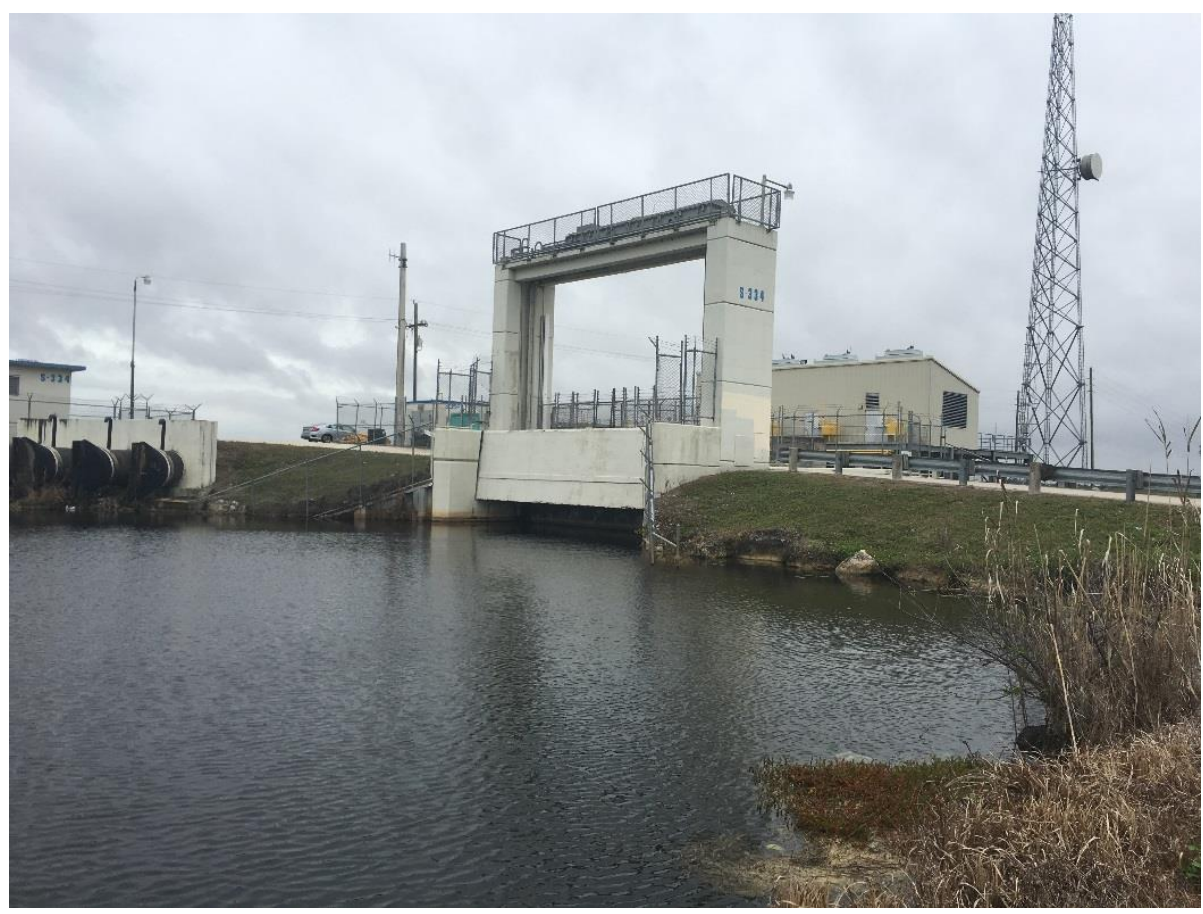

Figure G.1: Gate hydraulic structure (S334)

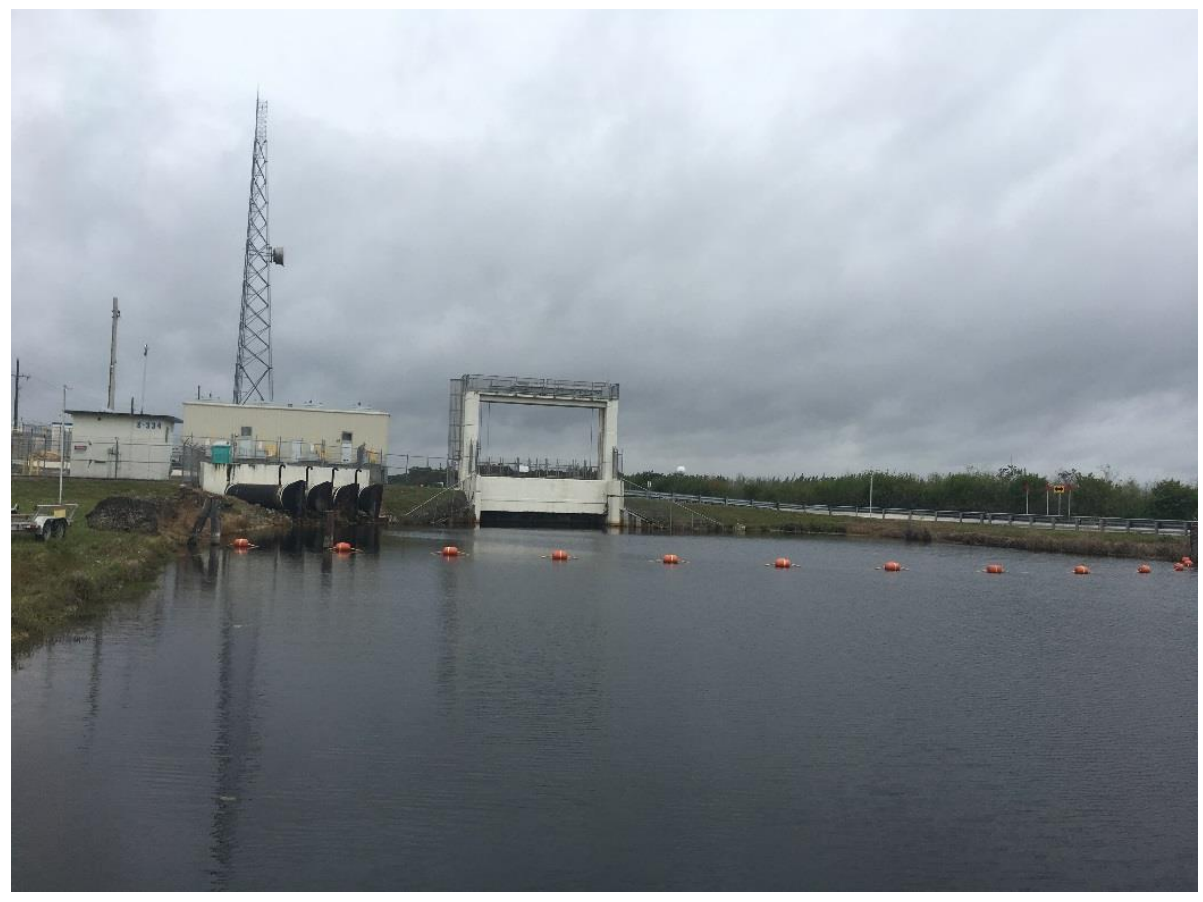

Figure G.2: Downstream of the hydraulic structure (S334) 


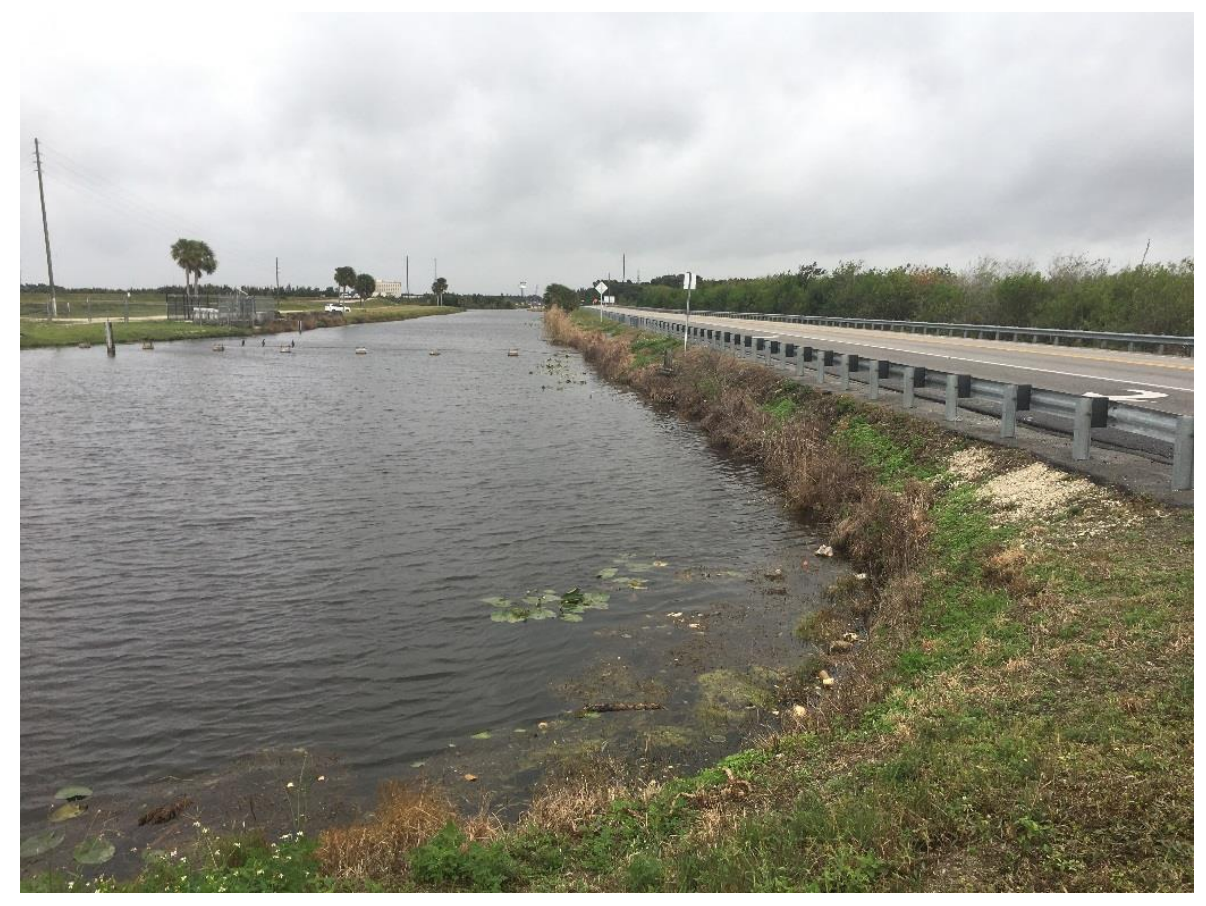

Figure G.3: Upstream of the hydraulic structure (S334)

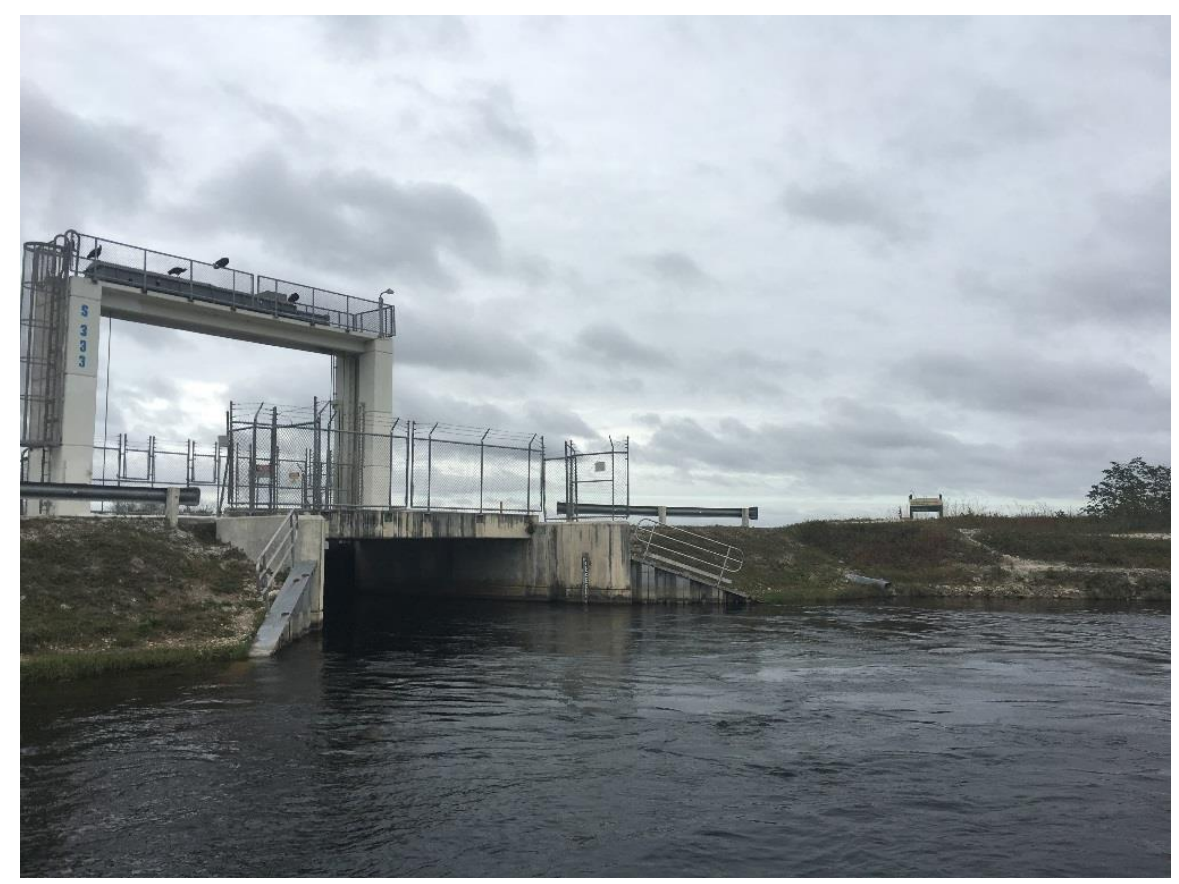

Figure G.4: Flow condition immediately after a gate (S334) 


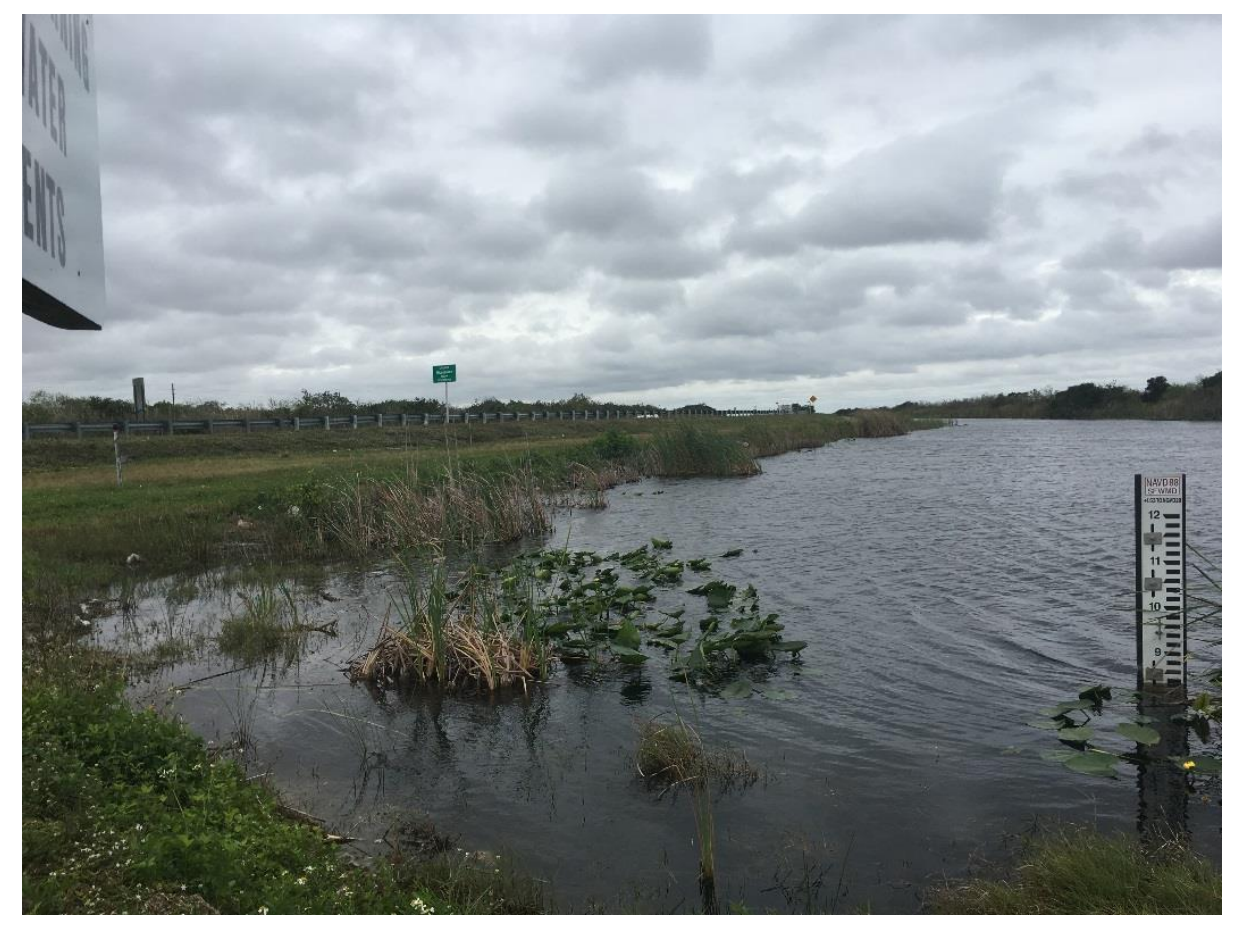

Figure G.5: Depth measurement

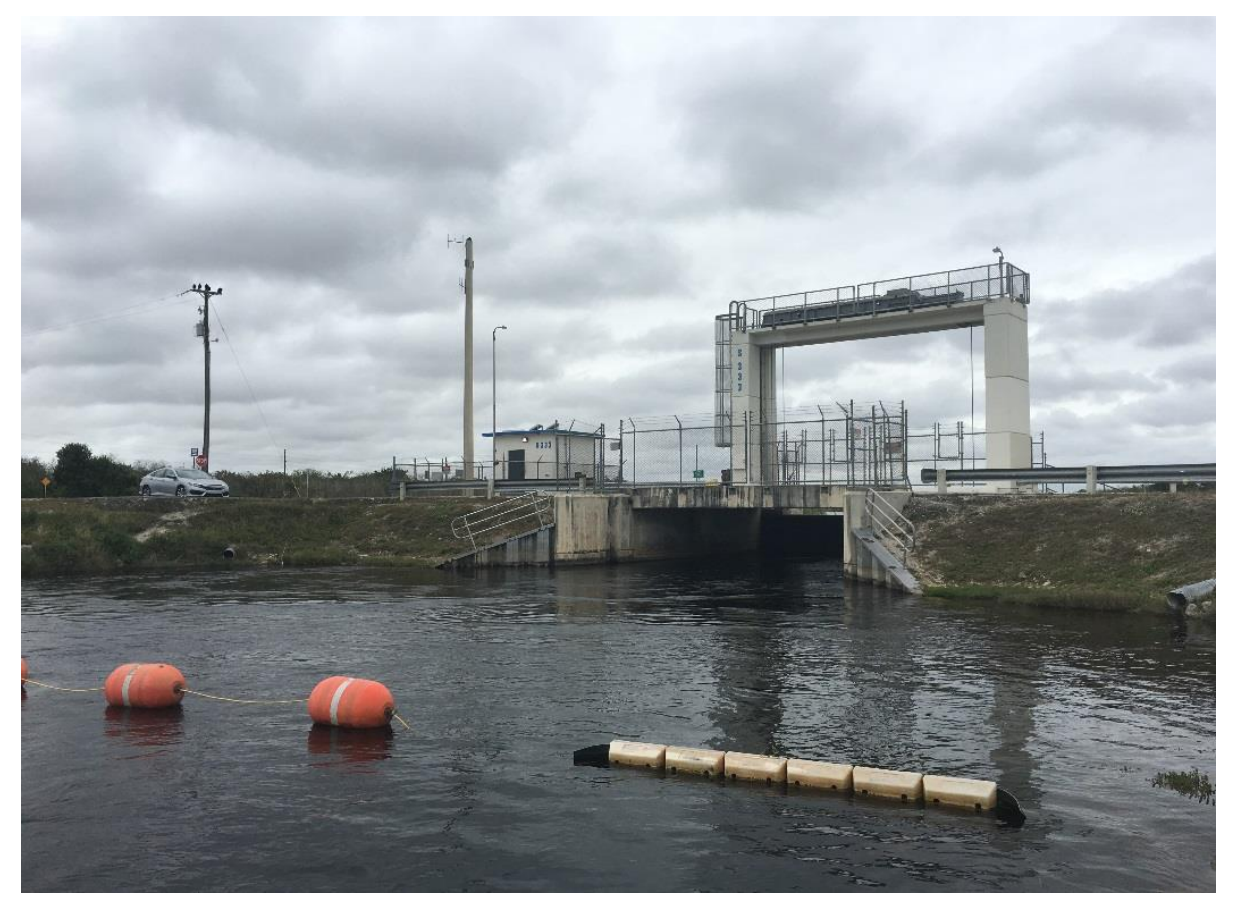

Figure G.6: Upstream of the hydraulic structure (S333) 


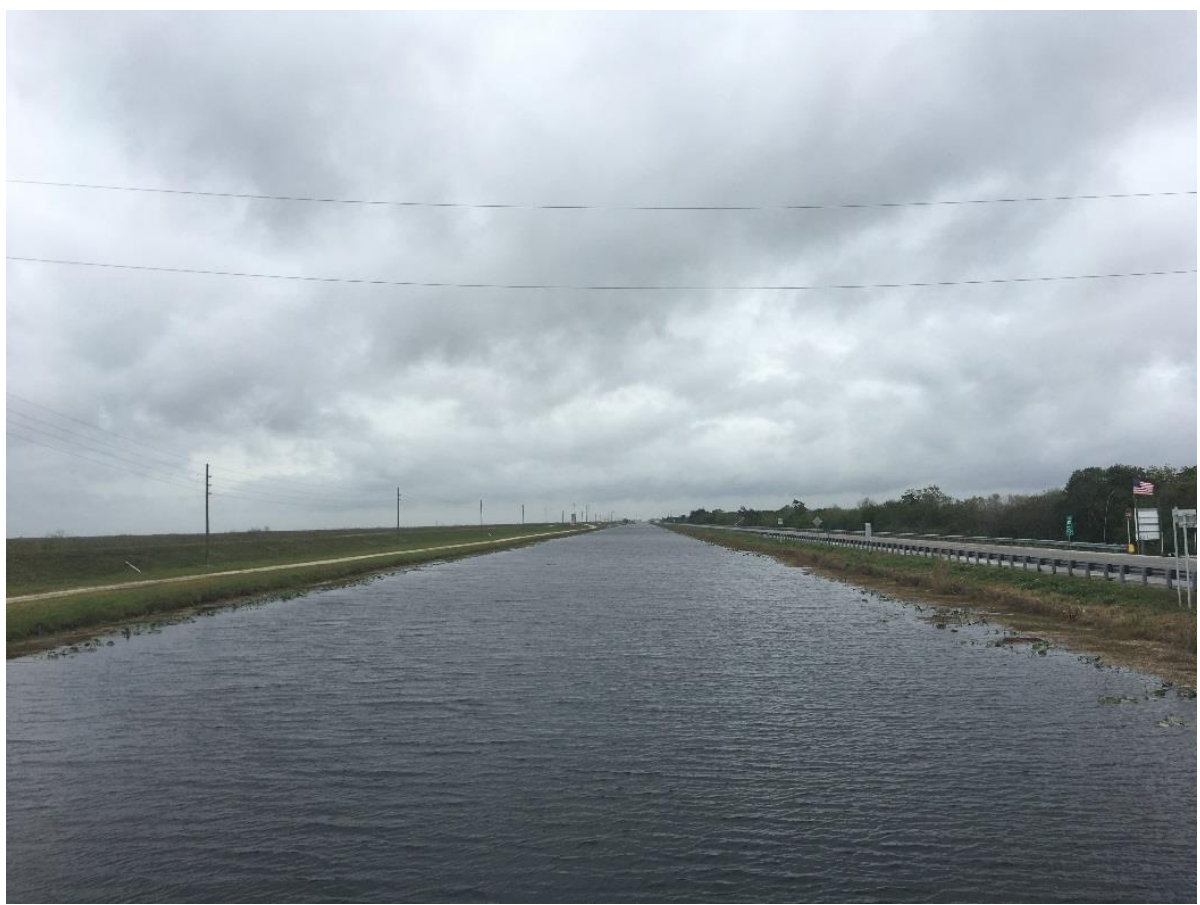

Figure G.7: Flow in the canal

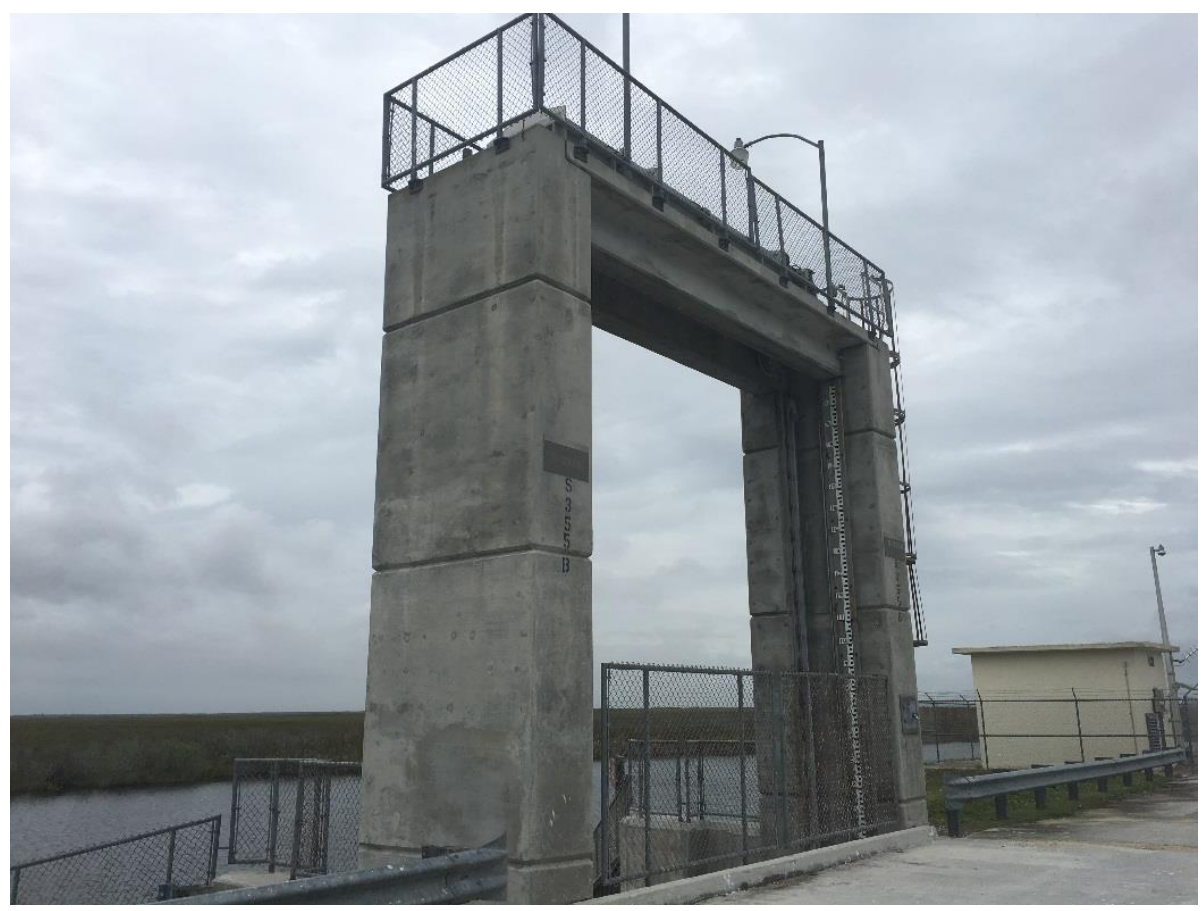

Figure G.8: The gate hydraulic structure (S355B) 


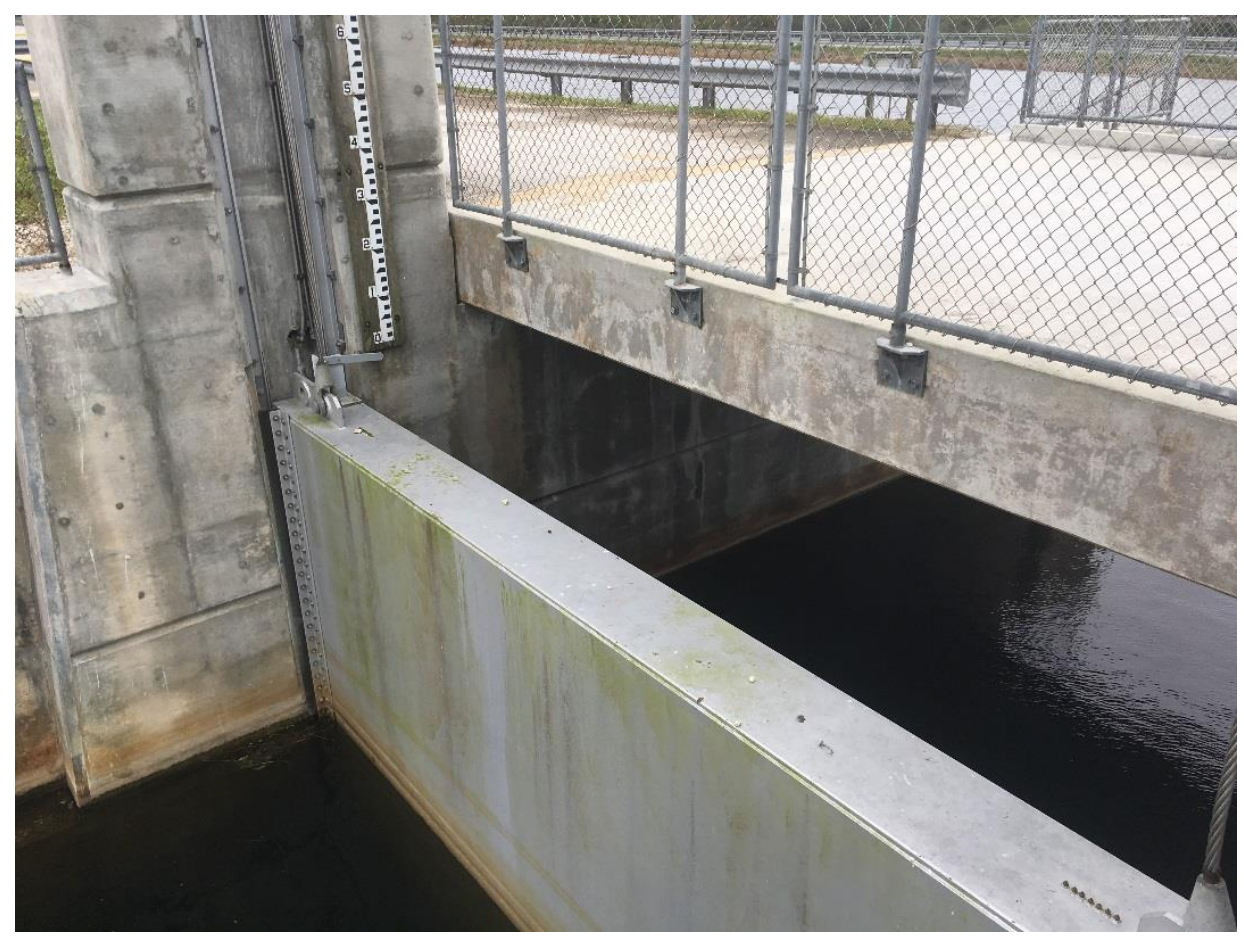

Figure G.9: Details of the gate hydraulic structure (S355B)

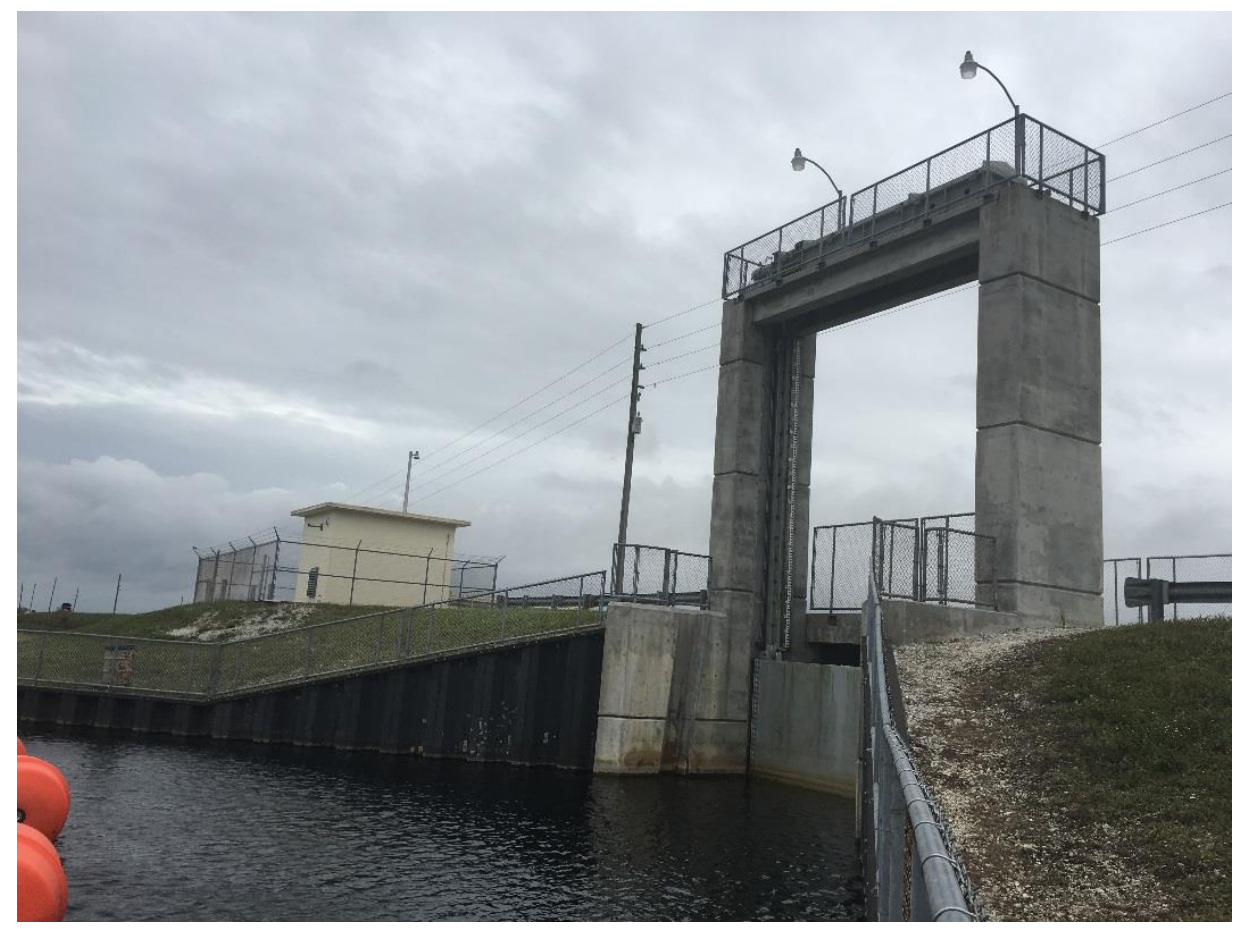

Figure G.10: Upstream of the gate hydraulic structure (S355B) 


\section{APPENDIX H}

\section{VALIDATION}

The proposed method to determine the Efficiency Index that is documented in section 6 of chapter 5 was validated with the results of the large physical model in the laboratory. The validation data is reported in this section. The overall efficiency of the structure is the difference between the total energies in the reservoir and the end of the stilling basin in percentage terms. 
Table H.1 Validation Results

\begin{tabular}{cccc}
\hline $\begin{array}{c}\text { Discharge } \\
\left(\mathbf{m}^{\mathbf{3}} / \mathbf{s}\right)\end{array}$ & $\begin{array}{c}\text { Overall Efficiency } \\
\text { (Experimental Results) }\end{array}$ & Overall Efficiency & Efficiency Index \\
& & & Basin \\
\hline 20 & $99 \%$ & $98.7 \%$ & 0.89 \\
\hline 80 & $91 \%$ & $90.2 \%$ & 0.86 \\
\hline 200 & $84.6 \%$ & $81.7 \%$ & 0.81 \\
\hline 800 & $37.3 \%$ & $34.2 \%$ & 0.30 \\
\hline 2100 & $33.1 \%$ & $31.5 \%$ & 0.28 \\
\hline
\end{tabular}


VITA

\section{AMIRMASOUD HAMEDI}

Born, Tehran, Iran

2002-2007

B.Sc., Civil Engineering

Azad University South Branch of Tehran

Tehran, Iran

2008-2010

M.Sc., Civil Engineering (Water Resources)

Azad University Central Branch of Tehran

Tehran, Iran

2014-2016

Research and Teaching Assistant

Florida International University

Miami, Florida

$2014-2017$

$\mathrm{PhD}$, Civil Engineering

Florida International University

Miami, Florida

\section{PUBLICATIONS AND PRESENTATIONS*}

Baqersad, M., Hamedi, A., Mohammadafzali, M., Ali, H., (2017). Asphalt Mixture Segregation Detection: Digital Image Processing Approach. Advances in Material Science and Engineering. (doi.org/10.1155/2017/9493408)

*Hamedi, A., Fuentes, H.R., (2016) New Relationship between a Vertical Gate Opening and Downstream Flow Stability: Experimental Development. World Environmental and Water Resources Congress, pp. 47-57. 
Hamedi, A., Ketabdar, M., (2016). Energy Loss Estimation and Flow Simulation in the Skimming Flow Regime of Stepped Spillways with Inclined Steps and End Sill: A Numerical Model. International Journal of Science and Engineering Applications. 5(7), 399-407.

Hamedi, A., Haji Gholizadeh, M., Mansoori, A., (2016). Flow Simulation and Energy Loss Estimation in the Nappe Flow Regime of Stepped Spillways with Inclined Steps and End Sill: A Numerical Approach. Civil Engineering Journal. 2(9), 426-437.

Hamedi, A., Ketabdar, M., Hamedi, A., Fesharaki, M., Mansoori, A., (2016). Nappe Flow Regime Energy Loss in Stepped Chutes Equipped with Reverse Inclined Steps: Experimental Development. Florida Civil Engineering Journal. Volume 2, 28-37. ASCEFlorida Section.

Ketabdar, M., Hamedi, A., (2016). Intake Angle Optimization in 90-degree Converged Bends in Presence of Floating Wooden Debris: Experimental Development. Florida Civil Engineering Journal. Volume 2, 22-27. ASCE-Florida Section.

Fesharaki, M., Hamedi, A., (2016). Effects of High-Speed Rail Substructure on Groundborne Vibrations. Florida Civil Engineering Journal. Volume 2, 38-47. ASCE-Florida Section.

Haji Gholizadeh, M., Hamedi, A., Niazi, A., \& Eazi, M. (2016). Optimal Design of WaterSupply Pipe Systems Using Economic and Technical Analysis. In World Environmental and Water Resources Congress. pp. 284-293.

*Hamedi, A., \& Fuentes, H. R. (2015). Comparative Effectiveness and Reliability of NEXRAD Data to Predict Outlet Hydrographs Using the GSSHA and HEC-HMS Hydrologic Models. In World Environmental and Water Resources Congress. pp. 14441453.

Hamedi, A., Mansoori, A., Shamsai, A., Amirahmadian, S., (2014). The Effect of End Sill and Stepped Slope on Stepped Spillway Energy Dissipation. Journal of Water Sciences Research. 6(1), 1-15.

Hamedi, A., Malekmohammadi, I., Mansoori, A., \& Roshanaei, H. (2012). Energy Dissipation in Stepped Spillway Equipped with Inclined Steps Together with End Sill. In Computational Intelligence and Communication Networks (CICN), Fourth International Conference. pp. 638-642. IEEE.

Hamedi, A., Mansoori, A., Malekmohamadi, I., \& Roshanaei, H. (2011). Estimating Energy Dissipation in Stepped Spillways with Reverse Inclined Steps and End Sill. In World Environmental and Water Resources Congress: Bearing Knowledge for Sustainability (pp. 2528-2537). 